\title{
INTER-RELAÇÕES ECONÔMICAS DOS ESTADOS NA BACIA DO RIO SÃO FRANCISCO: UMA ANÁLISE DE INSUMO - PRODUTO
}

\author{
SUELY DE FÁTIMA RAMOS SILVEIRA \\ Economista
}

Orientador: Prof. Dr. JOAQUIM JOSÉ MARTINS GUILHOTO

Tese apresentada à Escola Superior de Agricultura "Luiz de Queiroz", Universidade de São Paulo, para obtenção do título de Doutor em Ciências, Área de Concentração: Economia Aplicada

P I R A C I C A B A

Estado de São Paulo - Brasil

Fevereiro - 2000 


\title{
Dados Internacionais de Catalogação na Publicação (CIP) DIVISÃO DE BIBLIOTECA E DOCUMENTAÇĀO - Campus "Luiz de Queiroz"/USP
}

\author{
Silveira, Suely de Fátima Ramos \\ Inter-relaçōes econômicas dos estados na bacia do Rio Săo Francisco: uma análise de \\ insumo-produto / Suely de Fátima Ramos Silveira. - - Piracicaba, 2000. \\ $245 \mathrm{p}$. \\ Tese (doutorado) - Escola Superior de Agricultura Luiz de Queiroz, 2000. \\ Bibliografia.
}

1. Análise econômica 2. Desenvolvimento económico 3. Economia regional 4. Insumo-produto 5. Recurso hidrico 6. Relação intersetorial 7. Rio São Francisco (Bacia) I. Título

CDD 330.981

Germitida a copia total ou parcial deste documento, desde que citada a fonte $-O$ autor? 
À minha mãe, Maria Pureza, pelo amor incondicional, pela dedicação e pelo estímulo constante dos meus ideais.

Ao meu pai, Antônio Ramos (in memorian), pelo exemplo de vida, sempre presente na minha mente e no meu coração.

Ao meu esposo, Max, è̀ minha filha, Ana Carolina, por compartilharem dos meus sonhos, pelo incentivo, $o$ apoio e as suas alegres presenças.

Às minhas irmãs, Kátia e Daisy, pelo apoio às minhas idéias e pelo carinho que sempre me dedicaram.

À minha cunhada, Marly, pelas demonstrações de afeto e amizade. 


\section{AGRADECIMENTOS}

À CAPES, à ESALQ e à UFV, pelo apoio institucional e financeiro em todas as etapas deste curso.

Ao Prof. Dr. Joaquim José Martins Guilhoto, pelos ensinamentos transmitidos, inteligente orientação, incentivos constantes, pela paciência, dedicação e, sobretudo, pela amizade demonstrada, que foram imprescindíveis para a realização desta pesquisa e para o meu aprimoramento pessoal e profissional.

Aos professores Dr. Joaquim Bento de Souza Ferreira Filho e Dr. Ricardo Shirota, pelas valiosas contribuições e sugestões apresentadas durante o desenvolvimento da pesquisa.

A todos os professores do Departamento de Economia, Administração e Sociologia Rural e, em especial, àqueles dos quais tive a oportunidade de ser aluna, pelos ensinamentos transmitidos. Também aos seus funcionários, pela atenção e respeito com que sempre me trataram. Em especial, agradeço à Maielli, à Helena, à Cristiane, à Mácia, à Elenice, à Maria Helena e ao Sr. Pedro.

Às bibliotecárias, Luciane e Ligiana, pelo auxílio precioso na localização de obras da biblioteca e em outras instituições e pela consideração com que sempre me trataram, um agradecimento especial.

Às instituições e às pessoas que colaboraram com esta pesquisa, cedendo informações, em especial, ao Dr. Expedito José Ferreira, da CODEVASF; à Dra Maria de Fátima Paiva, da SRH; ao Dr. Valter Zschaber Júnior, da COPASA; ao Dr. José Theodomiro, da CEEIVASF; ao Dr. Augusto César Soares dos Santos, da RURALMINAS; ao Dr. Evaldo Lebre de Lima, da Secretaria da Fazenda do Estado de Minas Gerais; ao Prof. Dr. Ivo Vasconcelos Pedrosa; da UFPE e ao Prof. Dr. Antônio Alves Soares, do DEA/UFV.

À Prof ${ }^{\mathrm{a}}$ Graciema Pires Therezo, pela competente e criteriosa revisão de alguns capítulos desta pesquisa. Ao Dr. Leonardo Lott Rodrigues, pela paciente e dedicada revisão do Summary e à Prof Fernanda Barcelar.

Aos professores Dr. Fernando Curi Peres e Dr. José Antônio Frizzone, pelo apoio, a confiança e o privilégio de suas amizades. 
À Rossana Lott Rodrigues, que me presenteou com sua amizade fraterna. Minha companheira nos estudos e nas experiências diárias. A quem devo muito e com quem muito aprendi, meu carinho e agradecimentos especiais.

Ao companheiro de estudos, Antônio Carlos Moretto, pela convivência amena, pela dedicação, pelo estímulo, pelas discussões e sugestões e pelas demonstrações de amizade sincera.

Aos companheiros de estudos, Mário Antônio Margarido e Lílian Cristina Anefalos, pelo carinho, pelo incentivo, pela colaboração e a alegria de poder tê-los como amigos.

Ao Eng. Fernando Antônio Celso, que com competência e desvelo, prestou assistência técnica aos meus computadores durante todo o período da realização curso de doutorado, socorrendo-me, especialmente no final da redação deste trabalho, quando tudo parecia perdido.

À dedicada amiga, Lêda Rita D'Antonino Faroni que, mesmo distante, soube se fazer presente.

Ao Prof. Juarez de Sousa e Silva, pela amizade e pelas oportunidades de desenvolvimento profissional.

Aos professores da Área de Irrigação, do Departamento de Engenharia Agrícola da UFV, pela oportunidade para realização deste curso.

Ao amigo Ricardo Silveira Martins e à sua esposa, Cleide, pela acolhida inicial em Piracicaba.

À Margarida e à Perpétua, da AIT/UFV, pela atenção e prestimosidade com que sempre atenderam às minhas solicitações durante a realização deste curso.

Aos estudantes dos cursos de doutorado e mestrado com os quais convivi e dos quais aprendi a gostar.

Aos meus familiares em geral, pelo carinho e incentivo em todas as fases dessa jornada.

Aos meus amigos, em especial às pessoas maravilhosas que conheci em Piracicaba, que me incentivaram e sempre torceram pelo meu sucesso.

E, finalmente, a todas as demais pessoas e instituições que contribuíram para realização deste trabalho. 


\section{SUMÁRIO}

Página

LISTA DE FIGURAS .................................................................. viii

LISTA DE TABELAS ......................................................................... $\mathrm{x}$

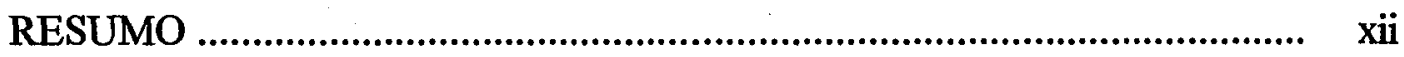

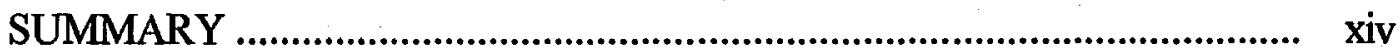

1 INTRODUÇÃO..................................................................... 1

1.1 Inter-relações entre os estados da bacia do São Francisco: o problema e sua importância ........................................................ 3

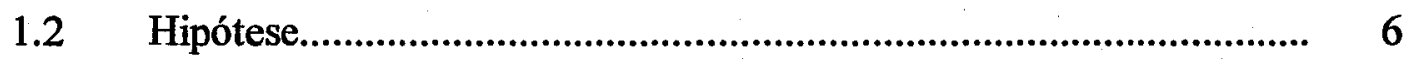

1.3 Objetivos ........................................................................... 7

2 A BACIA DO RIO SÃO FRANCISCO ..................................... 9

2.1 Caracterização da bacia do Rio São Francisco..................................... 9

2.2 A economia regional .............................................................. 14

2.2.1 A economia da região da bacia do São Francisco............................... 20

2.2.2 A agricultura irrigada na região......................................................... 28

$2.3 \quad$ Usos múltiplos da água............................................................ 36

3 TEORIA BÁSICA E AS ANÁLISES REGIONAL E INTERREGIONAL DO INSUMO-PRODUTO.......................................... 44

3.1 A teoria básica do modelo de insumo-produto..................................... 44

3.1.1 O sistema de Leontief: o modelo aberto.......................................... 46

3.1.2 Uma ilustração do sistema de insumo-produto................................. 50

3.2 Modelos de insumo-produto: uma análise regional e interregional....................................................................................... 53

3.3 Os modelos de análises inter-regionais............................................... 60

3.3.1 O modelo "ideal" de Isard............................................................... 64

3.3.2 O modelo Chenery-Moses ou modelo modificado de Isard ................ 66

3.3.3 O modelo do coeficiente linha...................................................... 69

3.3.4 O modelo de Leontief-Strout ou modelo gravitacional de fluxo de comércio inter-regional......................................................... 
3.3.5 O modelo intranacional............................................................ 73

3.4 Os modelos de insumo-produto e o recurso água.............................. 74

3.5 A seleção de um modelo inter-regional .......................................... 80

4 AS LIGAÇÕES INTERINDUSTRIAIS E OS SETORES-CHAVE NA ECONOMIA REGIONAL ............................................ 83

4.1 A abordagem de Rasmussen/Hirschman..................................... 85

4.2 Matriz de Intensidade.............................................................. 86

$4.3 \quad$ O enfoque do Campo de Influência ................................................ 88

4.4 O modelo GHS: os índices puros de ligações.................................. 90

4.5 Interações sinergéticas dentro de uma hierarquia de pares de subsistemas econômicos ............................................................ 95

4.5.1 Multiplicadores regionais internos .............................................. 96

4.5.2 Bloco de matrizes inversas de Leontief e classificação do bloco de matrizes dos multiplicadores externos à esquerda e à direita

4.5.3 Decomposição hierárquica aditiva dos blocos inversos de Leontief ... 103

4.5.4 $\mathrm{O}$ caso de $n$ regiões ............................................................... 104

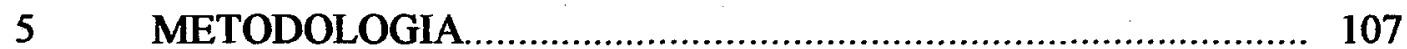

5.1 Construção das matrizes regionais ............................................ 108

$5.2 \quad$ O modelo inter-regional proposto................................................ 113

5.3 A matriz de coeficientes de uso e a matriz de "conteúdo de água"..... 118

6 ANÁlISE DA ESTRUTURA PRODUTIVA: OS SETORESCHAVE DA ECONOMIA BRASILEIRA E DAS ECONOMIAS DO SISTEMA INTER-REGIONAL ........................................ 123

6.1 Índices de ligações de Rasmussen/Hirschman ................................. 123

6.2 Matrizes de Intensidade - Aplicação ao sistema inter-regional do São Francisco.

6.3 Campo de Influência ............................................................... 139

6.4 Índices Puros de Ligações .......................................................... 143

6.4.1 Índices Puros de Ligações para o Brasil .......................................... 143

6.4.2 Índices Puros de Ligações para o sistema inter-regional do São Francisco 
6.5 Comparação dos resultados dos índices Rasmussen/Hirschman e os dos índices Puros de Ligações.

7 INFLUÊNCIA DAS DEMANDAS FINAIS DOBRE A PRODUÇÃO: UMA APLICAÇÃO DO MODELO GHS ............... 160

7.1 Demanda final e produção induzida no sistema inter-regional do São Francisco

7.2 Produção setorial induzida pelas demandas finais do sistema interregional do São Francisco

7.3 Interações entre as regiões econômicas da bacia do São Francisco e o Resto do Brasil: Impactos da demanda final sobre a produção

7.4 Desagregações setoriais das produções induzidas: impactos da próprios da demanda final

7.5 Desagregações setoriais das produções induzidas: impactos da demanda final de outras regiões

7.6 Interações sinergéticas entre as regiões do sistema inter-regional ...... 177

8 Usos da água na bacia do rio São Francisco ................................. 186

8.1 Consumo de água por setor no sistema inter-regional ................... 187

8.2 Matriz inter-regional de consumo de água ................................. 189

8.3 Dependência inter-regional e multiplicadores do consumo de água .... 192

9 Conclusão .................................................................... 202

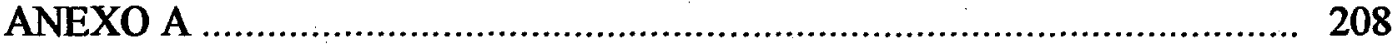

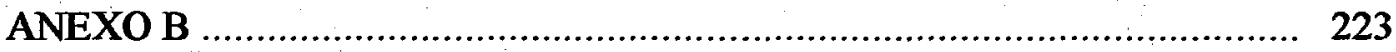

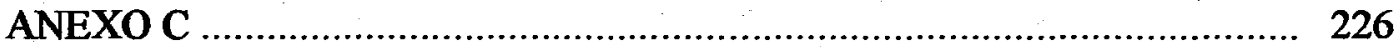

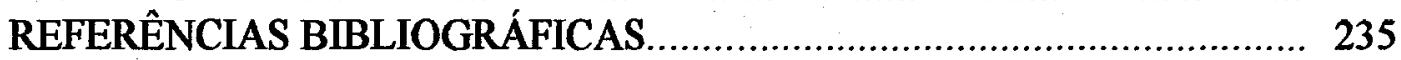




\section{LISTA DE FIGURAS}

Página

2.1 Bacia hidrográfica do rio São Francisco

4.1 Representação esquemática das formas possíveis da matriz $A_{1}-0$ caso de 2 regiões

4.2 Representação esquemática das formas possíveis da matriz $A_{l}-0$ caso de 4 regiões

5.1 Consumo de anual de água por categoria de usuário e por categoria de usuário por unidades atendidas, abastecidas pela COPASA, a partir de água captada na região de abrangência da bacia do São Francisco, no estado de Minas Gerais.

6.1 Ligações para trás e para a frente de Rasmussen - Hirschman para o Brasil

6.2 Ligações para trás e para a frente de Rasmussen - Hirschman para o estado de Minas Gerais

6.3 Ligações para trás e para a frente de Rasmussen - Hirschman para o estado da Bahia

6.4 Ligações para trás e para a frente de Rasmussen - Hirschman para o estado de Pernambuco

6.5 Síntese do padrão médio das ligações de Rasmussen - Hirschman para o sistema inter-regional

6.6 Minas Gerais: Topografia das estruturas cruzadas para campos de intensidade de primeira ordem

6.7 Bahia: Topografia das estruturas cruzadas usando a hierarquia de Minas Gerais

6.8 Pernambuco: Topografia das estruturas cruzadas usando a hierarquia de Minas Gerais

6.9 Coeficientes setoriais com maior campo de influência para o Brasil....

6.10 Coeficientes com maior campo de influência para o sistema interregional do São Francisco

6.11 Índices puros para ligações para trás, para frente e total, Brasil, 1995

6.12 Índice puro de ligações para trás do sistema inter-regional do São 
6.13 Índice puro de ligações para frente para o sistema inter-regional do São Francisco

7.1 Produção setorial induzida que depende da demanda final doméstica 164

7.2 Participação da produção total, induzida pela demanda final e a das outras regiões

7.3 Participação da produção total, por região, induzida pela própria demanda final

7.4 Participação da demanda final das outras regiões na indução da produção setorial de Minas Gerais

7.5 Participação da demanda final das outras regiões na indução da produção setorial da Bahia

7.6 Participação da demanda final das outras regiões na indução da produção setorial de Pernambuco

7.7 Participação da demanda final das outras regiões na indução da produção setorial do Resto do Brasil

7.8 Contribuição (\%) de cada bloco de matriz para a parte total de $\left(x_{l}-f\right)$ em $x$ na região de Minas Gerais, 1995

7.9 Contribuição (\%) de cada bloco de matriz para a parte total de $\left(x_{l}-f\right)$ em $x$ na região da Bahia, 1995

7.10 Contribuição (\%) de cada bloco de matriz para a parte total de $\left(x_{I}-f\right)$ em $x$ na região de Pernambuco, 1995

7.11 Contribuição (\%) de cada bloco de matriz para a parte total de $\left(x_{I}-f\right)$ em $x$ na região do Resto do Brasil, 1995 


\section{LISTA DE TABELAS}

Página

2.1 Área e população nos estados do Vale do São Francisco

2.2 PIB nominal regional e dos estados da Bacia do São Francisco - per capita - $1985-1994$

2.3 Taxas médias do crescimento do PIB e contribuição percentual dos PIBs de estados selecionados para o crescimento do PIB nordestino para o período compreendido entre 1970-1992

2.4 Estimativas dos Produtos Brutos por sub-região do Nordeste do Brasil, 1970, 1975, 1980, 1985, 1988 e 1992

2.5 Produto Interno Bruto por sub-regiões do Nordeste do Brasil

2.6 Área plantada, produção total e valor bruto da produção dos perímetros irrigados da CODEVASF - 1995-1997

2.7 Vazões médias observadas ao longo do rio São Francisco (durante os últimos 20 anos)

3.1 Modelo de insumo-produto aberto estático simplificado

4.1 Multiplicadores regionais internos e suas propriedades

4.2 Ordenação das interações sinergéticas entre os subsistemas econômicos

5.1 Quadro: Relações de insumo - produto usadas para regionalização da matriz nacional

5.1 Tabela de insumo-produto inter-regional para os estados da Bacia do São Francisco e o Resto do Brasil

5.2 Matriz de insumo-produto - inter-regional - Região da bacia do São Francisco e Resto do Brasil, 1995

6.1 Índices de ligações de Rasmussen - Hirschman para o Brasil, 1995 ... 125

6.2 Índices de ligações de Rasmussen - Hirschman para o sistema interregional do São Francisco

6.3 Índices puros para ligações para trás, para frente e total, Brasil 1995. 145

6.4 Índices puros do sistema inter-regional do São Francisco, 1995 ....... 149

6.5 Comparação dos resultados dos índices de Rasmussen/Hirschman e os índices puros do sistema inter-regional e do Brasil 
6.6 Setores-chave consolidados - índices de ligações de Rasmussen/Hirschman (R/H) e os indices puros totais (PTL), Brasil e sistema inter-regional do São Francisco

7.1 Produção total induzida pela demanda final no sistema inter-regional do São Francisco, 1995

7.2 Produção das regiões do sistema inter-regional do São Francisco segundo indução da própria demanda e pelas demandas finais das outras regiões

7.3 Produção das regiões do sistema inter-regional segundo indução da própria demanda e pelas demandas finais das outras regiões

7.4 Contribuição (\%) das combinações $1,2,3,4$ e 5 dos blocos de matrizes para a produção em cada região da bacia do São Francisco e o Resto do Brasil, 1995

7.5 Contribuição (\%) de cada bloco de matriz para a parte total de $\left(x_{1}-f\right)$ em $x$ para as regiões do São Francisco e Resto do Brasil, 1995

8.1 Consumo de água por setor da economia no sistema inter-regional do São Francisco

8.2 Consumo de água por setor da Indústria de Transformação no sistema inter-regional do São Francisco

8.3 Consumo setorial de água, por unidade de produto, no sistema interregional do São Francisco

8.4 Multiplicadores inter-regionais do consumo de água- Minas Gerais..

8.5 Multiplicadores inter-regionais do consumo de água- Bahia 195

8.6 Multiplicadores inter-regionais do consumo de água- Pernambuco .. 


\title{
INTER-RELAÇÕES ECONÔMICAS DOS ESTADOS NA BACIA DO RIO SÃO FRANCISCO: UMA ANÁLISE DE INSUMO - PRODUTO
}

\author{
Autora: SUELY DE FÁTIMA RAMOS SILVEIRA \\ Orientador: Prof. Dr. JOAQUIM JOSÉ MARTINS GUILHOTO
}

RESUMO

Esta pesquisa procurou analisar as relações interindustriais, a capacidade de indução das demandas finais ao crescimento e as relações de comércio das economias dos estados na bacia hidrográfica do rio São Francisco. Também associou à tradicional matriz de insumos do sistema econômico, uma matriz considerando o recurso água $\mathrm{e}$, a partir desta, estimou os coeficientes de uso da água e calculou os multiplicadores. Para atender a esses propósitos, foi construído um modelo inter-regional de insumo-produto para a região da bacia do São Francisco, para o ano de 1995, considerando-se as economias dos estados de Minas Gerais, Bahia e Pernambuco.

Por meio dos instrumentais analíticos da teoria de insumo-produto, foi possivel estimar os índices de ligações de Rasmussen (1956) e Hirschman (1958), o campo de influência, os índices puros e a obtenção das matrizes de intensidade, que possibilitaram a caracterização de importantes aspectos da estrutura produtiva inter-regional. $O$ modelo GHS permitiu identificar e avaliar a importância de cada região na produção induzida pelas demandas finais regionais e setoriais. Foram analisadas as interações sinergéticas entre as regiões do sistema, com base na metodologia desenvolvida por Sonis, Hewings e Miyazawa (1997) e expandida para o caso de $n$ regiões por Guilhoto (1999). 
O modelo permitiu constatar que as estruturas das economias das regiões Minas Gerais, Bahia e Pernambuco apresentaram diferenças significativas. Minas Gerais apresenta uma estrutura industrial mais interligada, com predominância do setor Siderurgia e Metalurgia. A Bahia, na qual se destaca a Indústria Química, exibe uma estrutura industrial menos interligada que a de Minas Gerais,. A economia da região de Pernambuco, na qual se sobressaem os setores do grupo dos Serviços, é a que apresenta a estrutura menos interligada do sistema inter-regional do São Francisco.

As relações de comércio entre essas três economias são fracas. As maiores interações ocorrem com a economia de Minas Gerais, no entanto, as mais importantes aparecem entre as três regiões da bacia do São Francisco e o Resto do Brasil.

Ao se avaliar os usos da água, segundo as inter-relações setoriais das economias do sistema inter-regional (considerando-se Minas Gerais, Bahia e Pernambuco), verificou-se, por meio da estimativa dos multiplicadores, que os volumes consumidos no sistema são muito maiores do que os estimados quando se considera um setor da economia isoladamente. Essas relações proporcionam uma visualização das interações dos usos do recurso água, na economia inter-regional, e das proporções em que esse insumo deve ser ofertado caso ocorra uma expansão da atividade econômica na região. 


\title{
ECONOMIC INTERRELATIONS AMONG THE STATES OF THE SÃO FRANCISCO RIVER BASIN, BRAZIL: AN INPUT-OUTPUT ANALYSIS
}

\author{
Author: SUELY DE FÁTIMA RAMOS SILVEIRA \\ Adviser: Prof. Dr. JOAQUIM JOSÉ MARTINS GUILHOTO
}

SUMMARY

Through the use of input-output techniques this study makes an analysis of the economic interrelations among the states the São Francisco River Basin. Going a step further, it is also constructed an input-output system that takes into account the use of the water resources from the basin. The base year of the analysis is 1995 and the states taken into consideration are: Minas Gerais, Bahia and Pernambuco.

The main analytical tools used in this work refers to the linkage indices of Rasmussen (1956) and Hirschman (1958), the field of influence, the pure linkages indices and the intensity matrix (all described in the text). They made possible to study the interregional productive structure. The identification and evaluation of the importance of each state in the induced production by the regional and sectoral final demands is done through the use of the GHS approach. The synergetic interactions among the regions were analyzed based on the methodology originally developed by Sonis, Hewings and Miyazawa (1997) for 2 regions and expanded to the $n$ regions case by Guilhoto (1999). 
The results show that the economic structures of Minas Gerais, Bahia and Pernambuco have significant differences. Minas Gerais shows to have the more complex productive structure, and in special the sector of Metal Products plays a special role in the economy. Bahia shows an economic structure with fewer links than Minas Gerais, with a predominance of the Chemicals sector. Of the three states economies, Pernambuco shows to be the less developed one with the predominance of the Service sector.

The trade relations among the three economies shows to be weak, with the three states having a greater economic relation with the Rest of Brazil than among themselves.

Using the water use input-output system it was possible to study how the water is used by the sectors and how the interrelation among the states and the sectors do affect the use of the water from the São Francisco River Basin. These relations provide a visualization of the interactions of the uses of the resource water in interregional economy and of the measure this input should be offered in case of growth of economic activity in the regions. 


\section{INTRODUÇÃO}

A desigualdade regional, tanto no que diz respeito à produção, às oportunidades de investimento, ao consumo quanto à distribuição de renda, tem sido uma característica da economia brasileira.

Segundo Baer (1996), desde os tempos coloniais, cada um dos ciclos de exportação de produtos primários beneficiou uma ou outra região brasileira. Enquanto a economia estava voltada basicamente para a exportação, a distribuição regional da renda era determinada pelo tipo de produtos primários comercializados. Entretanto, "quando a principal fonte de crescimento foi internalizada, as taxas de crescimento e desenvolvimento regional desiguais tenderam a se perpetuar ou, às vezes, até a aumentar". Essas características são tratadas pela economia do desenvolvimento econômico como desequilíbrios regionais.

Várias correntes teóricas têm buscado explicar o fenômeno. Embora não haja um modelo amplamente aceito para o desenvolvimento econômico regional, há um consenso geral de que as desigualdades regionais são um fenômeno universal.

Das teorias e modelos tradicionais que influenciaram o estudo da economia regional destacam-se as idéias de Weber, 1929, Lösch, 1954, Ohlin ,1933 e 1967 e Isard, 1956, que, sob o arcabouço teórico neoclássico, desenvolveram modelos da teoria da localização. Esses autores consideraram diferenças nas fontes de crescimento regional, destacando economias de escala internas e externas. As raízes da teoria do Crescimento Polarizado estão nos trabalhos de Perroux, 1950 e 1955, Myrdal, 1957 e Hirschman, 1958. Esta abordagem tenta explicar por que as atividades econômicas tendem a se 
desenvolver em volta de um subgrupo, de uma região ou de um país, enquanto o atraso impera em outra parte qualquer ${ }^{1}$ (Hirschman, 1961).

Novas abordagens das teorias de desenvolvimento regional vêm recebendo destaque na literatura. Segundo Amaral Filho (1999) destacam-se as contribuições das novas teorias de crescimento (endógeno) feitas por autores como Arthur, 1994, Krugman, 1991, 1995, 1996 que se empenharam no sentido de refazer a teoria da localização, partindo, "de um lado, da força das idéias de Myrdal e Hirschman e, de outro, da fragilidade formal das mesmas, causada por uma falta de modelização". Nessa abordagem, os autores consideram os custos de transportes, o conceito dos rendimentos crescentes, utilizando-se de "instrumentos matemáticos complexos para formalizar seus modelos" (p.1284). Uma abordagem com enfoque semelhante, conforme salientado pelo referido autor, foi apresentada anteriormente por Kaldor, em 1970, quando este buscou relacionar o conceito de rendimentos crescentes com o de causação circular. Ainda, segundo Amaral Filho (1999), no trabalho de Krugman, enfatiza-se a incorporação das idéias marshallianas de "economias externas", enquanto no de Kaldor privilegia-se o tamanho do mercado e a divisão do trabalho como fonte de crescimento da produtividade. Outros trabalhos de "economistas evolucionistas-institucionalistas regionais", como Schmitz, Becattini, Brusco, Aydalot são referenciados pelo citado autor; que conclui que "por vias metodológicas diferentes todos tentam endogeneizar as fontes de crescimento e de desenvolvimento" (p.1296).

Dos estudos que tratam da questão regional, a aplicação empírica do modelo de insumo-produto permite identificar e mensurar as interdependências entre os setores produtivos das diferentes regiões. Buscando a compreensão dos problemas regionais, novos métodos de análise foram incorporados ao arcabouço da teoria de insumo-produto ao longo dos últimos 40 anos, desde a publicação do livro de Walter Isard, Methods of regional analisys: an introduction to regional science, em 1960, com destaque para a análise inter-regional.

\footnotetext{
${ }^{1}$ Uma revisão detalhada pode ser vista, por exemplo, em Cavalcanti (1990).
} 
Desde os anos 1950, uma técnica que tem sido explorada e desenvolvida intensivamente na área da ciência regional é a da análise regional e inter-regional de insumo-produto. A evolução dos métodos computacionais permitiu explorar novos métodos de análise, como os modelos aplicados de equilibrio geral, por exemplo, possibilitando uma maior compreensão de um sistema econômico regional, quer dentro de uma nação, quer num contexto mais global, de blocos de países, ou ainda, de uma comunidade global, até seu extremo oposto, uma pequena região, compreendendo um conjunto de comunidades urbanas (Isard et al., 1998).

No caso da presente pesquisa, o instrumental básico de análise é o de insumoproduto, desenvolvido por Leontief, em 1936 e 1941. Dentre suas aplicações para análise econômica, essa metodologia tem-se revelado bastante útil para análises inter-regionais, pois, pelas propriedades sistêmicas que apresenta (como dependência e independência, hierarquia e circulação entre os setores da economia), constitui base empírica para identificar as ligações intersetoriais mais importantes para o desenvolvimento econômico das regiões de um país ou regiões constituídas por blocos internacionais.

\subsection{Inter-relações entre os estados da bacia do São Francisco: o problema e sua importância}

A despeito da permanência do crescimento desigual e desequilibrado, especialmente em termos intra-regionais (Diniz, 1999), a economia brasileira passou por intensas mudanças no período 1980 a 1990.

A aceleração do processo de abertura comercial, iniciado nos anos 1980 , concorreu para intensificação das mudanças estruturais na economia, com a reestruturação produtiva e a mudança do papel do Estado no processo de desenvolvimento econômico do país.

Parece existir, na literatura, um consenso sobre o novo papel do estado nas questões relativas ao desenvolvimento nacional, regional e local. Altera-se a natureza da intervenção governamental que, agora, assume um caráter mais qualitativo. "Ao invés do 
tradicional enfoque de prover subsídios indiscriminados para indústrias ou empresas, os governos, em todo mundo, estão reconhecendo que a melhor política regional é a de criar um ambiente mais favorável nas regiões, para que estas possam enfrentar os desafios da competitividade e dos constantes avanços na esfera tecnológica"(Galvão, 1999, p.1326).

Em que pese o novo papel recentemente atribuído ao Estado na economia brasileira, a questão regional vem sendo tratada pelos governos federal e estaduais, tendo sido implantados no país diversos planos e programas. A influência da CEPAL (Comissão de Estudos para América Latina) prevaleceu nas questões relativas aos problemas dos desequilíbrios regionais brasileiros (Cano, 1998, p.18). Entretanto, conforme ressaltado por Haddad (1989, p.33), durante toda a década de oitenta, a prática do planejamento de médio a longo prazo foi abandonada no Brasil, sendo substituída por uma sequêencia de políticas de curto prazo, que "resultaram numa dinâmica perversa para os objetivos do nosso processo de desenvolvimento econômico e social".

Ao estudar a questão regional brasileira, destacando a concentração industrial, Cano (1998) chama a atenção para as várias fases do processo de industrialização da economia. Ao estabelecer uma periodização, identificou características importantes do processo de industrialização brasileiro. Guimarães Neto (1996. p.480), referindo-se à análise desenvolvida por Cano, afirma que "eram ressaltadas, entre outras, questões associadas ao caráter complementar e competitivo das demais regiões relativamente a São Paulo e, neste contexto, os momentos inibidores, de estímulo ou destruidores. $O$ autor chamava a atenção, entre vários momentos da formação do mercado interno brasileiro e da articulação entre as várias e desiguais regiões para o fato de que 0 dinamismo da economia, embora compartilhado geralmente por todas regiões, se dava de modo desigual, através de taxas diferentes de crescimento".

No contexto do "desequilíbrio econômico inter-regional brasileiro", freqüentemente, a região da bacia hidrográfica do rio São Francisco é referenciada como eixo de desenvolvimento regional. Historicamente, as questões relativas às secas no semiárido da região Nordeste vêm sendo consideradas nos planos de desenvolvimento implementados pelo governo federal. Vale ressaltar que desde o início dos anos 1960 , as 
políticas de desenvolvimento regional contribuíram para ampliação da infra-estrutura da região. Conforme ressaltado por Locatteli \& Silva (1996), a partir da criação da SUDENE, os planos e programas governamentais para a região nordeste enfatizaram ao desenvolvimento industrial. Entretanto, a agricultura não foi esquecida nesses programas, vários foram os planos que visavam a implantação de sistemas de irrigação, com objetivo de melhoria da produtividade e expansão da produção agrícola regional.

No caso da bacia do São Francisco, os primeiros estudos tinham o objetivo de avaliar o potencial hidrelétrico da região. Em seguida, por iniciativa do governo federal, a utilização das águas do São Francisco para irrigação apareceu vinculada ao abastecimento do semi-árido e ao planos de desenvolvimento regionais, visando amenizar os problemas decorrentes das secas periódicas. Em conseqüência dessas políticas, vários projetos de irrigação, públicos e privados, foram implementados na região (CODEVASF, 1998b).

Todas essas medidas levaram a intensificação dos usos das águas na bacia do São Francisco. Atualmente, já existem disputas para os usos das águas para irrigação, para geração de energia elétrica, para consumo humano e industrial. Segundo a CODEVASF (1998b) a discussão sobre a utilização das águas do São Francisco não é nova, entretanto, o tema é relativo ao conflito entre o uso para irrigação e o uso para geração de energia. $\mathrm{Na}$ atualidade, com o projeto de transposição das águas, surge uma nova fonte de conflito, qual seja, abastecer, gerar energia e irrigar também fora da área da bacia hidrográfica.

A Política Nacional de Recursos Hídricos, conforme a Lei 9.433, de 8 de janeiro de 1997, prevê, entre seus aspectos básicos: a adoção da bacia hidrográfica como unidade de planejamento, usos múltiplos dos recursos hídricos, gestão descentralizada e a necessidade de reconhecimento de que a água é um bem finito e vulnerável, de que tem valor econômico (Setti, 1998).

Para se estabelecer uma política de desenvolvimento regional compatível com esses princípios, qualquer atividade que venha a ser incentivada na área compreendida pela bacia hidrográfica deverá ensejar uma realocação, de modo a resultar no uso eficaz 
do recurso água. Políticas setoriais orientadas para o desenvolvimento regional necessitam de estudos que identifiquem a amplitude dos efeitos de encadeamento entre as economias dos estados da região abrangida.

Nesse contexto, acredita-se ser importante a identificação de um padrão regional de interação entre os estados que compõem a região do São Francisco.

No caso da bacia, estão envolvidas as economias de cinco estados. Nesta pesquisa, a área identificada como região do São Francisco corresponde aos estados de Minas Gerais, Bahia e Pernambuco. A seleção desses estados deveu-se ao fato de serem importantes economias da região, além de, no caso dos dois primeiros, a maior área da bacia do São Francisco estar localizada nos seus territórios.

Para que melhor se entendam as desigualdades regionais e os possíveis efeitos do uso da água sobre as atividades na região da bacia, a mensuração dos efeitos de encadeamento entre os setores das economias dos estados compreendidos na região apresenta-se como importante indicador para os programas de desenvolvimento, que devem considerar a amplitude das inter-relações econômicas.

\subsection{Hipótese}

No processo de industrialização da economia brasileira, os setores produtivos vinculados à região da bacia do São Francisco, devido à pouca articulação entre suas indústrias, apresentam maior interdependência comercial fora da região. Assim, suas inter-relações não são suficientes para promover o desenvolvimento regional. Uma vez confirmada essa hipótese, os programas destinados à promoção do desenvolvimento regional deverão ser orientados para identificação das complementaridades regionais e o incentivo dessas inter-relações. 


\subsection{Objetivos}

O principal objetivo desta pesquisa é construir, a partir de dados empíricos, um modelo inter-regional para a região da bacia hidrográfica do São Francisco, visando à compreensão das inter-relações setoriais e espaciais entre os estados da região. Para tal finalidade, especificamente, pretende-se:

a) identificar e avaliar a importância relativa das relações interindustriais, os setores chave, a capacidade de indução das demandas finais ao crescimento da economia regional;

b) identificar as interações sinergéticas entre as estruturas produtivas dos estados que compõem a região, possibilitando examinar as relações de comércio entre eles;

c) considerando o aspecto multidisciplinar da gestão dos recursos hídricos e a partir de uma visão das relações econômicas inter-regionais, obtida pela consecução dos objetivos (a) e (b), examinar as inter-relações entre os estados e o uso do insumo água, por meio de uma matriz inter-regional de uso da água.

Com esses objetivos, esta pesquisa apresenta inicialmente (Capítulo 2), as principais características da região na qual está inserida a bacia do São Francisco e descreve, sucintamente, as economias dos estados que a constituem, além de discorrer sobre o papel da irrigação e dos usos múltiplos da água na região.

No Capítulo 3 apresenta-se a teoria básica do modelo de insumo-produto; em seguida são descritos alguns dos principais modelos inter-regionais, suas aplicações para estudar o recurso água.

No Capítulo 4 discorre-se sobre os métodos de identificação da interdependência setorial da economia regional. São apresentados: a abordagem de Rasmussen/Hirschman para identificação dos setores-chave da economia; a da matriz de intensidade; o enfoque do campo de influência e o modelo GHS (índices puros de ligações). 
No Capítulo 5 encontram-se as informações básicas dos dados utilizados, bem como os procedimentos metodológicos adotados na construção das matrizes do modelo inter-regional e dos coeficientes de água.

Nos capítulos 6, 7 e 8 encontram-se os resultados empíricos obtidos e, finalmente, no Capítulo 9 apresentam-se as conclusões. 


\section{A BACLA DO RIO SÃO FRANCISCO}

A compreensão das relações inter-setoriais na bacia do São Francisco, inicialmente, exige o conhecimento das principais características da região na qual está inserida.

O presente capítulo tem o propósito de apresentar as principais características da região, descrever sucintamente as economias dos estados que a constituem, além de discorrer sobre o papel da irrigação na economia regional e os usos múltiplos das águas.

A área de estudo abrangerá os estados de Minas Gerais, Bahia e Pernambuco, que, a rigor, correspondem às regiões do Alto, Médio e Submédio São Francisco, no entanto, nesta pesquisa, serão considerados como bacia do rio São Francisco.

\subsection{Caracterização da bacia do rio São Francisco}

O Brasil, segundo a Fundação Instituto Brasileiro de Geografia e Estatística IBGE (1996), possui a maior dotação de água doce do mundo, correspondente a 8\% das reservas mundiais, com vasta e densa rede hidrográfica. Dentre as grandes bacias hidrográficas no país, destacam-se a do rio Amazonas, a do Nordeste, a do rio São Francisco, a do Leste, a do Prata e a do Sudeste.

A bacia do rio São Francisco abrange uma área de $640 \mathrm{mil} \mathrm{km}{ }^{2}$ (Figura 2.1), sendo 36,8\% no estado de Minas Gerais, 0,7\% no estado de Goiás e Distrito Federal e os restantes 62,5\% na Região Nordeste, especificamente nos estados da Bahia, Sergipe, Alagoas e Pernambuco. Com extensão de $2700 \mathrm{~km}$ entre a nascente, na Serra da Canastra, município de São Roque de Minas, estado de Minas Gerais e a foz, no Oceano 
atlântico, entre os estados de Sergipe e Alagoas, o rio São Francisco corta uma região onde vivem, aproximadamente, 15,1 milhões de pessoas (CODEVASF, 1998b).

O rio São Francisco abriga as usinas hidrelétricas de Três Marias (MG), Sobradinho (BA), Paulo Afonso (BA), Moxotó (AL), Xingó (AL) e Itaparica (PE), e apresenta um potencial gerador de energia elétrica da ordem de $26.354,66 \mathrm{MW}$.

$\mathrm{O}$ vale do rio é dividido em quatro regiões fisiográficas: Alto, Médio, Submédio e Baixo São Francisco. Cada uma dessas regiões possui características de relevo, clima e vegetação bem definidas.

A região do Alto São Francisco está no estado de Minas Gerais e compreende a nascente do rio, na Serra da Canastra até a cidade de Pirapora, abrangendo também as sub-bacias dos rios das Velhas, Pará, Indaiá, Abaeté e Jequitaí. O clima é o tropical úmido, a vegetação é constituída por florestas e cerrados e a topografia é ligeiramente acidentada, com altitudes variando de 450 a $1600 \mathrm{~m}$. Essa região caracteriza-se pela ocorrência de muitas chuvas no verão, entre os meses de novembro a abril, com precipitação entre 1500 a $1000 \mathrm{~mm}$ anuais. A temperatura média anual é de $23^{\circ} \mathrm{C}$ e a evaporação é de $2300 \mathrm{~mm}$ anuais. As principais cidades são as que compõem a Região Metropolitana de Belo Horizonte e a cidade de Patos de Minas.

A região do Médio São Francisco inicia-se no estado de Minas Gerais, a partir de Pirapora, e estende-se até o estado da Bahia, cidade de Remanso. As sub-bacias, nessa região, são as dos rios Pilão Arcado, Jacaré, Paracatu, Urucuia, Cariranha, Corrente, Grande, Verde Grande e Paramirim. O clima é o tropical semi-árido; a vegetação é de cerrados e caatingas, apresentando algumas pequenas matas; a altitude varia de 500 a $2000 \mathrm{~m}$. O período de chuvas ocorre entre os meses de novembro e abril, com precipitação média anual de $1400 \mathrm{a} 600 \mathrm{~mm}$. A temperatura média anual é de $24^{\circ} \mathrm{C}$ e a evaporação é de $2900 \mathrm{~mm}$ anuais. As principais cidades, no estado de Minas Gerais, são Montes Claros e Januária. No estado da Bahia, destacam-se Barreiras, Guanambi, Irecê e Bom Jesus da Lapa. Em Goiás, sobressaem-se Formosa e Brasilia, esta no Distrito Federal. 
Abrangendo áreas dos estados da Bahia e Pernambuco (passando pela cidade de Cabrobó), a região do Submédio São Francisco inicia-se na cidade de Remanso e vai até a cidade de Paulo Afonso (BA). Nela estão compreendidas as sub-bacias dos rios Pajeú, Tourão, Vargem e Moxotó, sendo este o último afluente do São Francisco da margem esquerda. O clima predominante é o semi-árido e a vegetação característica é a caatinga. A altitude varia de 200 a $800 \mathrm{~m}$. Na região de Juazeiro/Petrolina, a precipitação média anual chega a $350 \mathrm{~mm}$, sendo que a precipitação máxima, de $800 \mathrm{~mm}$, ocorre nas serras da divisa com o Ceará. A temperatura média anual é de $27^{\circ} \mathrm{C}$ e a evaporação é de 3000 $\mathrm{mm}$ anuais. As principais cidades no estado da Bahia são Juazeiro e Paulo Afonso. Em Pernambuco destacam-se Petrolina, Ouricuri e Serra Talhada.

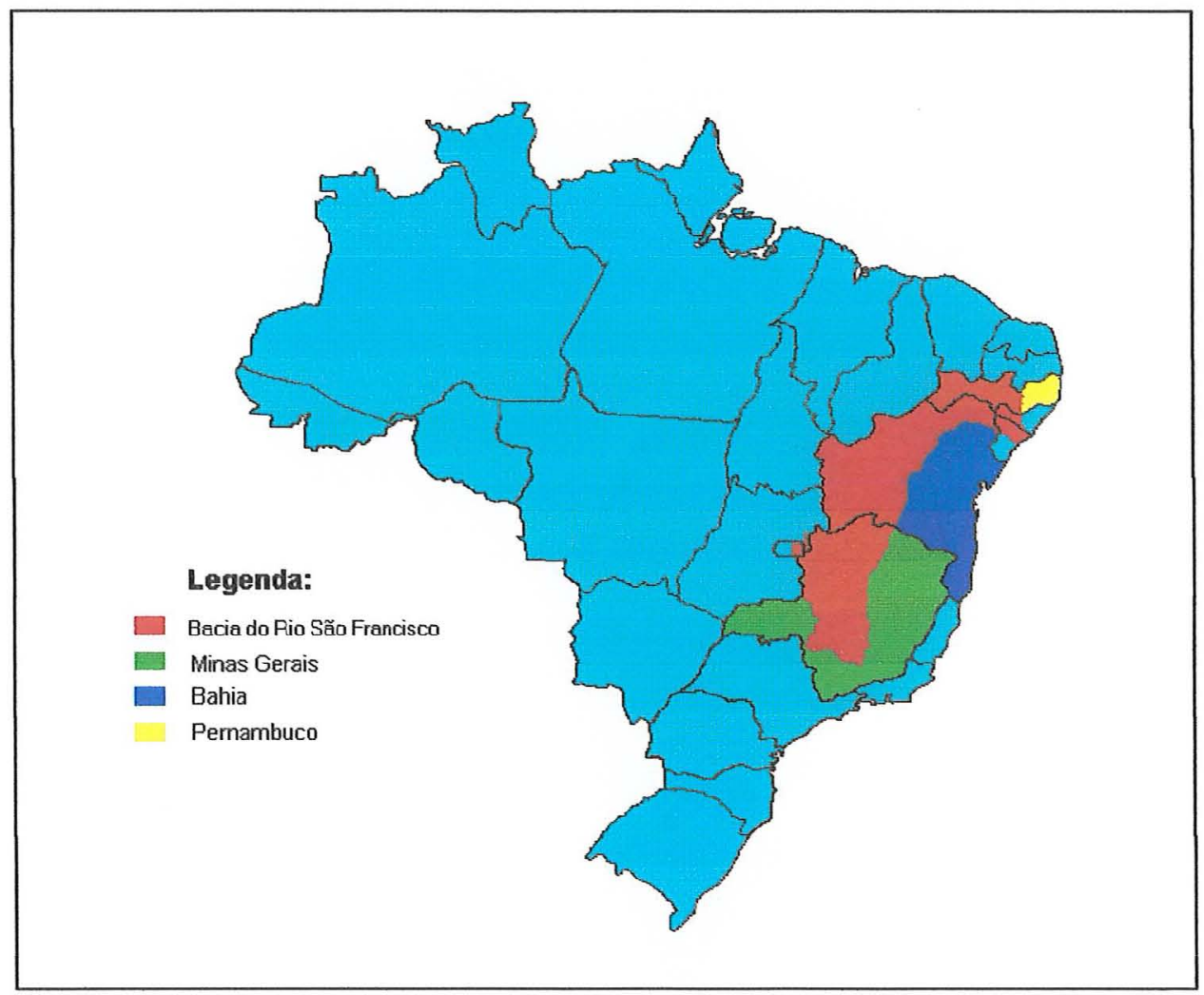

Fonte: http://www.nma.embrapa.br/ ana/xico/bacia/locbr.htlm. (Reelaborado pela autora), 1999.

Figura 2.1 - Bacia hidrográfica do rio São Francisco. 
A partir da cidade de Paulo Afonso até a foz do rio, entre os estados de Sergipe e Alagoas, estende-se a região do Baixo São Francisco. As sub-bacias dos rios Ipanema e Capivara estão compreendidas nessa região. O clima é o tropical semi-úmido. A vegetação varia entre a caatinga, no trecho mais alto, e mata, na região costeira. A altitude varia de $200 \mathrm{~m}$ até o nível do mar. As chuvas ocorrem no inverno, de março a setembro, embora, na faixa mais próxima ao oceano, ocorram durante o ano todo. A precipitação média anual varia de $1300 \mathrm{a} 800 \mathrm{~mm}$. A temperatura média anual é de $25^{\circ} \mathrm{C}$ e a evaporação é de $2300 \mathrm{~mm}$ anuais. As principais cidades são Jeremoabo na Bahia, Pesqueira e Bom Conselho em Pernambuco, Propriá e Nossa senhora da Glória em Sergipe e Arapiraca e Penedo em Alagoas.

Em toda a extensão do Vale do São Francisco, há uma grande variedade de solos que vão desde os que apresentam boa aptidão agrícola aos de baixa fertilidade. Devido à baixa declividade - a maioria das áreas do Vale apresentam declividade menor que $6 \%$, o que reduz os riscos de erosão - a região apresenta condições muito favoráveis à irrigação, embora na área de clima semi-árido o risco de salinização dos solos seja alto.

As vazões médias do rio são as seguintes: média anual máxima de $5.244 \mathrm{~m}^{3} / \mathrm{s}$; média anual de $2.980 \mathrm{~m}^{3} / \mathrm{s}$, que corresponde a uma descarga média anual de 94 bilhões de $\mathrm{m}^{3}$; média anual mínima de $1.768 \mathrm{~m}^{3} / \mathrm{s}$; máxima mensal de $13.743 \mathrm{~m}^{3} / \mathrm{s}$ (ocorre em março) e mínima mensal de $644 \mathrm{~m}^{3} / \mathrm{s}$ (ocorre em outubro). Quanto às vazões dos afluentes, os rios da margem esquerda apresentam maior estabilidade que os afluentes da margem direita, comparando-se as vazões médias mensais durante os meses de cheias e de estiagem.

O rio Grande, cuja vazão é de $262 \mathrm{~m}^{3} / \mathrm{s}$, é o último grande afluente perene do São Francisco, desembocando nele a $1.178 \mathrm{~km}$ de sua foz no Atlântico. A partir desse ponto, os demais afluentes, situados no Polígono das Secas, são intermitentes (CODEVASF, 1998b).

$\mathrm{Na}$ área correspondente aos estados que abrangem o Vale do São Francisco estão 503 municípios e, destes, apenas 92 possuem áreas além dos limites da bacia hidrográfica. 
Dos aproximadamente 15,1 milhões de habitantes dessa região, 3,9 milhões estão na região metropolitana de Belo Horizonte ${ }^{2}$ e representam $25,7 \%$ da população da bacia, numa área de $6.254,6 \mathrm{~km}^{2}$. Na região do Polígono das Secas ${ }^{3}$ estão 5,7 milhões de habitantes, $37,5 \%$ do total. São 251 municípios, o que eqüivale a $50 \%$ dos municípios do Vale, numa área de $343.784,1 \mathrm{~km}^{2}$. O Semi-Árido abriga 5,06 milhões de habitantes, $33,4 \%$ do total da população em 226 municípios, ocupando uma área de $320.745,3 \mathrm{~km}^{2}$.

Observando-se a Tabela 2.1, pode-se verificar que os estados da Bahia e Minas Gerais possuem as maiores áreas no Vale, seguidos pelo estado de Pernambuco. Quanto à população, Minas Gerais e Bahia ocupam, respectivamente, a primeira e segunda posições. O Distrito Federal ocupa a terceira posição com relação ao número de habitantes no Vale, seguido pelo estado de Pernambuco, que detém a quarta posição. Dos municípios ${ }^{4}$ inseridos no Vale do São Francisco, 240 são do estado de Minas Gerais, 114 da Bahia, 3 de Goiás, 69 de Pernambuco, 27 de Sergipe, 49 de Alagoas, mais o Distrito Federal.

Diante do exposto, observa-se que a principal fonte de água doce nessa região é a da bacia do São Francisco. A disponibilidade hídrica da bacia é usada para atender as demandas de irrigação, piscicultura, geração de energia, pecuária, abastecimento urbano, etc.

\footnotetext{
${ }^{2}$ Fazem parte da região metropolitana de Belo Horizonte os seguintes municípios: Belo Horizonte, Betim, Brumadinho, Caeté, Confins, Contagem, Esmeraldas, Florestal, Ibirité, Igarapé, Juatuba, Lagoa Santa, Mário Campos, Mateus Leme, Nova Lima, Pedro Leopoldo, Raposos, Ribeirão das Neves, Rio Acima, Rio Manso, Sabará, Santa Luzia, São Joaquim de Bicas, São José da Lapa, Sarzedo e Vespaziano.

${ }^{3}$ Poligono das Secas: De acordo com a CODEVASF “É um território reconhecido pela legislação como sujeito a períodos críticos de prolongadas estiagens. Trata-se de uma divisão regional efetuada em termos político-administrativo e não corresponde à zona semi-árida, pois apresenta diferentes zonas geográficas com distintos indices de aridez, indo desde áreas com características estritamente de seca, com paisagem típica de semi-deserto a áreas com balanço hídrico positivo. Situa-se majoritariamente na região Nordeste, porém estende-se até o norte de Minas Gerais. O Semi-Árido corresponde a uma das seis grandes zonas climáticas do Brasil. Caracteriza-se basicamente pelo regime de chuvas definido pela escassez, irregularidade e concentração num curto período de três meses. Tem a caatinga como vegetação predominante e apresenta temperaturas elevadas." Para maiores detalhes ver CODEVASF (1998b).
}

${ }^{4}$ Os dados utilizados pela CODEVASF para computar o número de municípios por estado têm, como referência, o Censo de 1991 (IBGE), Malha Municipal do Brasil 1997 e SUDENE. 
Tabela 2.1 - Área e população dos Estados no Vale do São Francisco.

\begin{tabular}{|c|c|c|c|c|c|}
\hline \multirow[b]{2}{*}{ Estados } & \multicolumn{2}{|c|}{$\begin{array}{c}\text { Áreas dos Estados } \\
\left(\mathrm{Km}^{2}\right)\end{array}$} & \multicolumn{3}{|c|}{$\begin{array}{l}\text { População dos Municípios no Vale } \\
\text { (hab.) - } 1991\end{array}$} \\
\hline & Total & Área no Vale ${ }^{(1)}$ & Total & Urbana & Rural \\
\hline Minas C & $588.383,6$ & $235.471,3$ & 6.931 .099 & 5.667 .175 & 1.263 .924 \\
\hline Bahia & $567.295,3$ & $307.940,8$ & 2.500 .422 & 1.056 .487 & 1.443 .935 \\
\hline Distrito F & $5.822,1$ & $1.335,6$ & 1.601 .094 & 1.515 .889 & 85.205 \\
\hline Goiás & $341.289,5$ & 8 & 94.383 & 94 & 22.889 \\
\hline Pernambu & $98.937,8$ & 69. & 1.58 & 117 & 851.737 \\
\hline Sergipe & 22.0 & 7. & 27 & 022 & 148.426 \\
\hline Alagoas & $27.933,1$ & $14.338,2$ & 966.312 & 431.793 & 534.519 \\
\hline Total & $1.651 .711,7$ & $639.219,4$ & 13.956 .612 & $\mathbf{9 . 6 0 5 . 9 7 7}$ & 4.350 .635 \\
\hline
\end{tabular}

Fonte: CODEVASF (1998b).

Notas: (1) Não inclui a área externa dos municípios parcialmente inseridos no Vale

(2) Inclui o total da população dos municípios parcialmente inseridos no Vale

As atividades desenvolvidas nessa região, bem como as ações voltadas para o desenvolvimento regional devem contemplar o uso racional da água de forma a não prejudicar as vazões do rio São Francisco. Segundo a CODEVASF (1996a, p.24), "nos períodos de estiagem longa, torna-se necessário aumentar a vazão regularizada do rio São Francisco, em Sobradinho, atualmente de $2.060 \mathrm{~m}^{3} / \mathrm{s}$, já quase totalmente comprometida com a geração de energia e com a irrigação no Vale do Rio São Francisco".

A partir dessas características, pode-se perceber a importância da gestão dos recursos hídricos da bacia do São Francisco, dada sua amplitude e implicações econômicas, sociais e ambientais.

\subsection{A economia regional}

Considerando a importância do rio São Francisco para a região Nordeste e as desigualdades econômicas entre as regiões brasileiras, cabe, neste estudo, uma ligeira discussão sobre a economia regional. Adicionalmente, com o objetivo de se apresentar um quadro da economia dos estados da bacia do São Francisco faz-se, de forma sucinta, uma 
descrição das economias dos estados da Bahia, Pernambuco, Alagoas, Sergipe e Minas Gerais.

A maior parcela de área compreendida pela bacia do São Francisco está na região Nordeste e, nesta, a maior extensão localiza-se no estado da Bahia. Somando-se as áreas dos quatro estados nordestinos chega-se a $8,6 \%$ do território brasileiro. Entretanto, é no estado de Minas Gerais, que ocupa $6,9 \%$ do território do país, que concentram $70 \%$ dos rios perenes da bacia (CODEVASF, 1998b; Diniz, 1995).

Em análise da dinâmica regional da economia brasileira, Diniz (1995) menciona a elevação da participação da região Nordeste na produção industrial do país, no período compreendido entre 1970 e 1990, destacando o desempenho do estado da Bahia, que passou de uma participação na produção industrial brasileira de $1,5 \%$ para $4 \%$ no período, crescimento esse impulsionado por incentivos fiscais e pela construção do Pólo Petroquímico de Camaçari.

Lavinas et al. (1997) mostram que, a despeito das políticas governamentais que visavam à integração das regiões periféricas - Norte, Nordeste e Centro-Oeste - ao Centro-Sul e dos resultados favoráveis obtidos no período entre 1970 e 1985, a partir dos anos 90 , verificou-se o recrudescimento do comportamento divergente, com o aumento da dispersão das rendas dos estados brasileiros.

Na Tabela 2.2, são apresentados os valores do PIB nominal per capita das grandes regiões brasileiras e os dos estados da bacia do São Francisco. Pode-se observar que dos estados da bacia, o estado de Minas Gerais foi o que apresentou, durante o período 19851994, o maior valor PIB per capita, embora o mesmo esteja abaixo do PIB per capita do país e da Região Sudeste, durante todo o período de referência. Dos estados da Região Nordeste que integram a região da bacia, Sergipe, Bahia e Pernambuco são os que apresentam o melhor desempenho no período, com valores acima do PIB per capita do Nordeste, que se manteve com valores abaixo da metade dos valores do país.

Gomes \& Vergolino (1995), ao estudarem a evolução dos produtos internos brutos reais do Nordeste e do Brasil, no período de 1960 a 1993, constataram uma evolução dos PIBs reais nordestino e brasileiro praticamente na mesma velocidade até 
1981, ano a partir do qual o crescimento do PIB nordestino se acelera até se igualar à taxa de crescimento do PIB do país em 1986. Entretanto, constataram esses autores que, a partir de 1987, enquanto a taxa de crescimento do PIB brasileiro se manteve estagnada, a do PIB nordestino passou a declinar.

Tabela 2.2 - PIB nominal regional e dos estados da Bacia do São Francisco - per capita $1985-1994$.

\begin{tabular}{|c|c|c|c|c|c|c|c|c|c|c|}
\hline & 1985 & 1986 & 1987 & 1988 & 1989 & 1990 & 1991 & 1992 & 1993 & 1994 \\
\hline Brasil & $3.376,62$ & $3.523,85$ & $3.650,01$ & $3.483,67$ & $3.146,07$ & $4.146,07$ & $3.330,70$ & $3.253,21$ & $3.310,19$ & $\overline{3.380,14}$ \\
\hline Região Norte & $2.368,34$ & $2.515,74$ & $2.635,90$ & $2.554,65$ & $2.672,82$ & $2.340,68$ & $2.381,79$ & $2.173,58$ & $2.259,06$ & $2.299,94$ \\
\hline Região Nordeste & $1.616,09$ & $1.718,67$ & $1.771,58$ & $1.693,15$ & $1.732,65$ & $1.522,73$ & $1.628,65$ & $1.564,10$ & 1640,44 & $1.635,13$ \\
\hline Região Sudeste & $4.628,77$ & $4.802,75$ & $5.010,74$ & $4.798,18$ & $4.822,40$ & $4.302,34$ & $4.601,47$ & $4.463,43$ & $4.398,29$ & $4.490,83$ \\
\hline Região Sul & $3.778,68$ & $3.899,84$ & $3.921,95$ & $3.608,52$ & $3.603,91$ & $3.295,67$ & $3.374,68$ & $3.589,93$ & $3.834,71$ & $3.983,42$ \\
\hline Região Centro-Oeste & $2.931,88$ & $3.203,99$ & $3.401,90$ & $3.442,66$ & $3.505,85$ & $3.259,82$ & $3.454,15$ & $3.196,22$ & $3.525,71$ & $3.650,90$ \\
\hline Pernambuco & $1.682,16$ & $1.741,86$ & $1.872,82$ & $1.799,00$ & $1.935,02$ & $1.643,20$ & $1.883,55$ & $1.767,55$ & $1.814,15$ & $1.765,59$ \\
\hline Alagoas & $1.479,90$ & $1.399,00$ & $1.592,84$ & $1.398,90$ & $1.509,80$ & $1.569,80$ & $1.532,05$ & $1.493,71$ & $1.485,35$ & $1.511,40$ \\
\hline Sergipe & $2.386,39$ & $2.787,31$ & $2.940,61$ & $2.583,26$ & $2.705,67$ & $2.520,16$ & $2.458,96$ & $2.412,41$ & $2.238,46$ & $2.156,33$ \\
\hline Bahia & $2.237,45$ & $2.322,28$ & $2.272,64$ & $2.208,43$ & $2.200,30$ & $1.871,33$ & $1.943,64$ & $1.916,32$ & 2.056 .82 & $2.025,52$ \\
\hline Minas Gerais & $3.012,92$ & $3.092,35$ & $3.154,65$ & $3.039,44$ & $3.086,02$ & $2.732,57$ & $2.936,62$ & $2.945,20$ & $3.063,58$ & $3.120,61$ \\
\hline
\end{tabular}

Fonte: Adaptada de Lavinas et al. (1997).

Nota: Os valores estão expressos em Reais de 1995 , deflacionados pelo deflator implicito do PIB.

É interessante destacar o comportamento das economias estaduais no período 1970-92, notadamente dos estados da Bahia, Pernambuco, Alagoas e Sergipe.

Conforme se pode observar na Tabela 2.3, no período aludido, o PIB da região nordeste cresceu a uma taxa anual de 5,3\%. Os estados compreendidos na bacia do São Francisco, Alagoas e Sergipe apresentaram as maiores taxas médias anuais de crescimento do PIB com, respectivamente, 6,8 e 6,5\%, enquanto Bahia e Pernambuco apresentaram as taxas de 5,4 e 4,9\%. Apesar de exibirem as menores taxas médias de crescimento do PIB, Bahia e Pernambuco contribuíram, no mesmo período, com um percentual de $33,8 \%$ e $25,4 \%$, respectivamente, para o crescimento do PIB regional.

Diniz (1995) ressalta a ocorrência de um processo de reversão da polarização e desconcentração industrial no período 1970-1990 - até então a indústria estava concentrada em São Paulo e polarizada em sua região metropolitana - para várias regiões 
do país. No que denomina primeira fase (década de 70), o processo de reversão de polarização ${ }^{5}$ deveu-se à interiorização da indústria no estado de São Paulo bem como nos demais estados brasileiros. É importante ressaltar, no período em questão, o papel dos investimentos industriais realizados pelas empresas controladas pelo governo federal, principalmente no que se refere ao cumprimento das metas do II PND. A região Nordeste passou de uma participação de 5,7\%, na produção industrial brasileira, em 1970, para 8,4\%, em 1990, destacando-se a elevação da participação do estado da Bahia, de 1,5 para $4,0 \%$ e o declínio de Pernambuco de 2,2 para 1,8\%. Os demais estados da região tiveram suas participações elevadas, passando, em conjunto, de 2,2 para 2,8\%. Deve-se destacar, também, a participação do estado de Minas Gerais, que passa de uma participação de $6,5 \%$, em 1970, para 8,8\% em 1990, na produção industrial do país.

Tabela 2.3 - Taxas médias de crescimento do PIB e contribuição percentual dos PIBs de estados selecionados para o crescimento do PIB nordestino para o período compreendido entre 1970 - 1992.

\begin{tabular}{lc|cc}
\hline \multirow{2}{*}{ Estados } & $\begin{array}{c}\text { Taxa Média Anual de } \\
\text { Crescimento }\end{array}$ & $\begin{array}{c}\text { Contribuição Percentual dos Produtos } \\
\text { Internos Brutos Estaduais para o Crescimento } \\
\text { do PIB Nordestino (1970/1992) }\end{array}$ \\
\cline { 3 - 4 } & & $\begin{array}{c}\text { Participação (\%) no } \\
\text { PIB do NE (1970) }\end{array}$ & $\begin{array}{c}\text { Contribuição } \\
\text { Normalizada }{ }^{1} \text { (\%) }\end{array}$ \\
\hline Bahia & 5,4 & 33,8 & 31,4 \\
Sergipe & 6,5 & 4,1 & 4,6 \\
Alagoas & 6,8 & 5,3 & 6,3 \\
Pernambuco & 4,9 & 25,4 & 21,5 \\
Nordeste & 5,3 & & \\
\hline
\end{tabular}

Fonte: Adaptada de Gomes \& Vergolino (1995).

Nota 1 : A contribuição percentual do estado para o crescimento total do PIB foi calculada, multiplicando-se a taxa de crescimento média anual do produto total pela participação do estado no PIB (início do periodo) e normalizando para 100 a soma das contribuições estimadas.

Entretanto, tem-se verificado, nos últimos anos, uma tendência à reconcentração industrial nas áreas mais desenvolvidas do país, que estaria ocorrendo em função: a) das mudanças tecnológicas e da reestruturação produtiva; b) das mudanças ideológicas e

\footnotetext{
${ }^{5}$ De acordo com Lima (1998, p.47-66) esse processo de despolarização deu-se em função da perda de posição de São Paulo, principalmente de sua Região Metropolitana, e do Rio de Janeiro para as outras macrorregióes do país.
} 
políticas do papel do Estado; c) do processo de abertura externa da economia, especialmente das relações decorrentes da criação do Mercosul (Diniz, 1995, p.13-14).

No que tange à distribuição regional da agropecuária, nos anos 1970, as regiões Sul e Centro-Oeste aumentaram significativamente a produção, especialmente a de grãos. Num período mais recente, notadamente a partir dos anos 1980, o aproveitamento da região dos cerrados de Minas Gerais e da Bahia, com significativa elevação da produção de soja, passou a contribuir para que essas duas áreas participassem da mesma dinâmica da produção da região Centro-Oeste que, a partir da segunda metade da década de 1970, anos de expansão da fronteira agrícola, juntamente com alguns estados da região Norte, tornou-se uma das áreas de continuidade e avanço da moderna agricultura brasileira (Diniz, 1995, p.17).

Azzoni \& Ferreira (1997), ao retornarem à discussão do tema desigualdades regionais, analisaram o comportamento locacional do setor industrial. Consideraram o fato de este exibir menores vínculos territoriais, quando comparado a outros ramos de atividades, como a agricultura, a agroindústria, atividades de extração e beneficiamento de minérios, bem como atividades relacionadas ao comércio e aos serviços.

Esses autores avaliaram os indicadores de produtividade, salários e excedente da indústria, subdividindo a Indústria de Transformação das regiões Nordeste e Sul e dos estados de São Paulo, Rio de Janeiro e Minas Gerais, no período $1970-1995^{6}$ em três grandes grupos: Bens de Consumo Não Durável, Bens Intermediários, Bens de Consumo Durável e de Capital.

Verificaram que a região Nordeste apresentou os indicadores de produtividade mais baixos em 1970, ano a partir do qual se elevaram até 1985, quando voltaram a cair, mantendo-se em um patamar em torno de 30\% abaixo da média nacional até 1993 . Ressalte-se que, segundo o estudo, a indústria nordestina de bens intermediários manteve uma performance muito próxima da média nacional, ultrapassando-a em vários anos no referido período. Os salários na região mantiveram-se no nível mais baixo de 1970, 1975 e

\footnotetext{
${ }^{6}$ No escopo do presente trabalho serão apresentados apenas os indicadores relativos à região Nordeste e ao estado de Minas Gerais por estarem diretamente relacionados com sua área de estudo. Para maior aprofundamento ver Azzoni, Carlos Roberto e Ferreira, Dirceu Alves (1997, p.55-85).
} 
1980 , ultrapassando os indicadores da região Sul e de Minas Gerais em 1985-86, voltando a cair em seguida até o final do período. Os indicadores de excedente do Nordeste, nos anos 1970 e 1975, mantiveram-se abaixo dos apresentados pelas outras regiões consideradas, apresentando, entretanto, um índice acima do da região Sul e bastante próximo dos demais estados em 1985. No período de 1986-1995 o Nordeste apresentou o menor indicador de lucratividade nacional.

O estado de Minas Gerais apresentou indicadores de produtividade, nos anos 1970, 1975 e 1980, abaixo dos de São Paulo e Rio de Janeiro. Em 1985, esse indicador já superava o do estado do Rio de Janeiro e, a partir de 1986, sua performance melhorou e o estado de Minas passou a apresentar indicadores melhores até mesmo que os de São Paulo. Quanto aos indicadores de salários, o estado de Minas Gerais, durante todo o período analisado, apresentou indicadores inferiores aos dos estados de São Paulo e Rio de Janeiro. Os indicadores de excedente exibidos pelo estado apresentaram elevada ascensão, partindo de níveis próximos à média em 1970 e elevando-se a partir de 1975 até o final do período; conforme ressaltam os autores, "esses resultados são determinados fundamentalmente pela performance desse estado nos setores produtores de bens intermediários"(Azzoni \& Ferreira, p.79).

Esse trabalho demonstra o aumento da concentração industrial na área tradicional no período 1985-95 - São Paulo, seguido por uma grande elevação da participação de Minas Gerais e pela perda da participação relativa das demais regiões consideradas, o que se refletirá nos aspectos de atração de novos investimentos. "Em termos do futuro das desigualdades regionais do país, os resultados destas análises são preocupantes"( Azzoni \& Ferreira, p.81).

Tendo como pano de fundo as questões sobre a economia regional apresentadas até aqui, seria interessante um maior detalhamento das economias dos estados compreendidos na área da bacia do São Francisco, que será apresentado na próxima seção. 


\subsubsection{A economia da região da bacia do São Francisco}

Reconhece-se nos estudos sobre economia regional, de forma consensual, a importância dos investimentos diretos do governo federal para o dinamismo econômico da região Nordeste, durante os anos 1970 , bem como das políticas de incentivos fiscais e financeiros.

Devido à iniciativa do Estado, surgiram e desenvolveram-se importantes complexos produtivos na região, que se aglomeraram nas sub-regiões de acordo com suas especificidades, em função dos recursos naturais disponiveis e dos movimentos políticoregionais, podendo-se destacar: a) Complexo Petroquímico de Camaçari/BA; b) Complexo Cloroquímico de Sergipe; c) Complexo Petroquímico e de Minerais NãoMetálicos de Alagoas; d) Complexo Sucro-Alcooleiro do Litoral Oriental/PE e AL; e) Complexo Agroindustrial do Perímetro Irrigado do Médio São Francisco/PE e BA; f) Complexo Industrial-Portuário de Suape/PE, g) Complexo Químico-Metalúrgico do Rio Grande do Norte; h) Complexo Têxtil e de Confecções do Ceará; e i) Complexo MineralMetalúrgico no Maranhão. Esses investimentos consubstanciaram a reversão do quadro produtivo da Indústria de Transformação nordestina que, predominantemente, de Bens de Consumo Não-Duráveis, nos anos 1970, tornou-se de Bens Intermediários nos anos 1980 (Melo \& Duarte, 1997).

No contexto das economias estaduais, é importante ressaltar a influência decisiva desses complexos industriais. Para o estado da Bahia, o Complexo Petroquímico de Camaçari trouxe novo dinamismo, passando a indústria química deste estado, de $45 \%$ da indústria química do Nordeste, em 1959, para $73 \%$ em 1984. Situado na Região Metropolitana de Salvador, compreende, atualmente, 53 indústrias em operação, $12 \mathrm{em}$ implantação e sete com projetos aprovados (Alves et al., 1997; Galindo, 1997).

Outra importante área industrial do estado é a do Centro Industrial de Aratu, localizado nos municípios de Candeias e de Simões Filho, Região Metropolitana de Salvador, que resultou de iniciativa do governo estadual, nos anos de 1960, visando atrair investimentos industriais. 
O Complexo Petroquímico de Camaçari e o Centro Industrial de Aratu deram ao estado da Bahia condições de abrigar o principal centro manufatureiro da Região Nordeste. Uma política de incentivos, que propiciou a implantação de toda uma infraestrutura básica, combinada com a disponibilidade de recursos naturais, além da privilegiada localização geográfica do estado - mais próxima aos mercados do Centro-Sul - trouxe vantagens locacionais ou fatores de atração industrial.

Segundo Silveira (1992), a diversificação do perfil da indústria do estado da Bahia entre 1950-1970 é responsável pela maior integração da economia estadual com a do Centro-Sul do país, destacando-se como importante produtora de matérias-primas e bens intermediários.

Resultantes de um Programa de Distritos Industriais (DI) do Interior, que visava evitar a concentração industrial na Região Metropolitana de Salvador, foram implantados outros DI's no Estado, destacando-se os de Ilhéus, Vitória da Conquista (Imborés), Jequié, Juazeiro (DI do São Francisco), Porto Seguro (Itabela) e Alagoinhas (Sauípe). Entretanto, conforme observa Silveira (1992), o programa de criação dos DI's no interior do estado não obteve os resultados esperados, uma vez que somente em algumas localidades, onde já havia uma atividade econômica forte, houve algum ganho significativo.

De acordo com Alves et al. (1997), o estado da Bahia apresenta um setor industrial diversificado, com as indústrias dos setores químico, mecânico, borracha $\mathrm{e}$ metalúrgica (do denominado grupo dinâmico) e as dos setores fumo e madeira (do grupo tradicional). Apresenta as maiores participações relativas no valor da transformação industrial (VTI) e pessoal ocupado, no período 1959-1980.

No estado de Pernambuco, o Complexo Industrial-Portuário de SUAPE, localizado nos municípios do Cabo e de Ipojuca, possui oito empresas instaladas na zona portuária e quatro na zona industrial, havendo mais quatro empresas em fase de implantação e previsão de instalação de mais dez. O DI do Cabo tem dezoito empresas em operação, enquanto o DI Comendador Arthur Lundgren, situado nos municípios de Paulista e de Abreu e Lima, possui vinte e seis empresas em operação, predominando as 
indústrias dos setores químico, metal-mecânico, vestuário, calçados e artefatos de tecidos. O DI do Curado localiza-se entre Recife e Jaboatão. Possui quatorze empresas em operação, predominando as indústrias dos setores químico, minerais não-metálicos e material elétrico. No DI Sócio-Integrado de Henrique Dias, existem, atualmente, dezoito empresas em operação, pertencentes aos setores químico, metal-mecânico, vestuário, calçados e artefatos de tecido. Ressalte-se, também, o Conjunto Industrial Multifabril do Jaboatão, no qual estão instaladas quinze empresas, e o DI Senador José Ermírio de Moraes, com onze empresas dos setores metal-mecânico, metalúrgico e produtos alimentares. Todos esses DI's pertencem à Região Metropolitana de Recife (Galindo, 1997).

No estado de Alagoas destaca-se o DI Governador Luiz Cavalcanti, situado a 13 km de Maceió, onde se encontram quarenta e oito indústrias em operação.

Deve-se ressaltar a importância do Pólo Cloroquímico, iniciado na década de 1970, com base na exploração do sal-gema, para a modificação do perfil da economia do estado, até então estruturada basicamente na agroindústria canavieira.

As indústrias de transformação e extrativa mineral do estado apresentaram participação declinante no VTI regional, passando de $6,52 \%$, em 1970 , para $4,51 \%$, em 1980. Nos anos de 1982 e 1984, a indústria de transformação apresentou melhor desempenho, passando a contribuir respectivamente, com $7,18 \%$ e $6,21 \%$, no VTI do Nordeste. Destacaram-se as participações das indústrias dos setores minerais nãometálicos, material de transporte, borracha (do grupo dinâmico) e fumo e produtos alimentares (do grupo tradicional). Ressalte-se, também, a evolução da participação da indústria química do estado no VTI e pessoal ocupado no total regional (Alves et al, 1997).

No estado de Sergipe, o Pólo Cloroquímico abrange nove municípios ${ }^{7}$ e insere-se numa área polarizada pela cidade de Aracaju, contando com disponibilidade de toda uma infra-estrutura de transportes o que facilita as movimentações de insumos e produtos. $O$

\footnotetext{
7 Aracaju, Barra dos Coqueiros, Nossa Senhora do Socorro, Laranjeiras, Santo Amaro das Brotas, Maruim, Rosário do Catete, General Maynard e Pirambu.
} 
estado é o único produtor de fertilizantes potássicos no país e, segundo Alves et al. (1997, p.239), serviu para implantação do Complexo Industrial Taquari-Vassouras, cujo subproduto - o cloreto de sódio - dará origem ao Complexo Cloroquímico de Sergipe.

A agroindústria da cana-de-açúcar tem papel de destaque nas economias dos estados nordestinos, especialmente os de Pernambuco e de Alagoas, apresentando uma constante tendência de crescimento.

A cultura da cana-de-açúcar expandiu-se para além da tradicional Zona da Mata do estado de Pernambuco incentivada pela implantação do PROÁlCOOL, nos anos 1970. Nesse período, o estado de São Paulo, incentivado pelo mesmo programa, também ampliou sua área de cultivo que, combinada com tecnologia moderna (uso de técnicas de cultivo mais modernas e variedades mais produtivas, por exemplo), aptidão de solos, condições climáticas favoráveis e outros aspectos gerenciais, superou a posição daquele estado como maior produtor nacional.

No período seguinte, com a retração do PROÁLCOOL, o estado de Alagoas passou a ocupar a segunda posição no ranking nacional. $O$ setor sucro-alcooleiro expandiu-se naquele estado que, no período 1975/85, chegou quase a duplicar sua produção de açúcar e multiplicou 25 vezes a produção de álcool, ao passo que Pernambuco expandiu a produção desses produtos em 1,7 e 7 vezes respectivamente. Os bons resultados alcançados por Alagoas devem-se à capacidade do capital sucroalcooleiro de expandir seu ritmo de acumulação e níveis de produção enquanto os grupos pernambucanos encontram-se presos ao tradicionalismo e à baixa eficiência (Lima, 1987).

O mesmo autor enfatiza que os maiores rendimentos de Alagoas em relação aos de Pernambuco devem-se aos fatores naturais favoráveis e ao padrão de gerenciamento mais dinâmico.

No estado da Bahia, a área dos cerrados corresponde à do Extremo Oeste Baiano cujas terras, propícias para o desenvolvimento agrícola, correspondem a 3.100 mil hectares. De acordo com Melo \& Duarte (1997) o desenvolvimento da agricultura, voltada para a produção de culturas de exportação, na região dos cerrados, deveu-se ao deslocamento do capital das regiões mais ricas do país para as novas fronteiras agrícolas. 
A produção agrícola dos cerrados baianos tem-se concentrado nas culturas do arroz e da soja, cultura esta que, em 1986, correspondia a $99 \%$ da área ocupada pela agricultura moderna, respondendo por $\mathbf{9 0 \%}$ da produção total de grãos. Essa região configura-se como um "pólo de produção emergente no espaço econômico regional, como manchas descontínuas, cuja articulação principal se opera na perspectiva de integração ao circuito do moderno capitalismo brasileiro" (Melo \& Duarte, p.54).

Apesar do seu potencial produtivo, os cerrados baianos apresentam-se como uma área carente de infra-estrutura em termos de transportes, abastecimento de energia elétrica, infra-estrutura de armazenagem e outras, caracterizando-se como uma região periférica dos cerrados brasileiros (Galindo, 1997).

$O$ estado de Minas Gerais foi o precursor nesse processo de incorporação dos cerrados (regiões Noroeste, Triângulo e Alto São Francisco) beneficiando-se das políticas de governo para modernização da agricultura brasileira e de crédito subsidiado, sendo a cultura da soja a que mais se expandiu nos anos 1970. Na década seguinte, outras culturas como as de cana, milho, arroz e feijão também se expandiram naquela área (BDMG, 1989a).

Dentre os programas voltados para a promoção da agricultura, na área dos cerrados mineiros, dois se destacam: o Programa de Assentamento Dirigido do Alto Paranaíba (PADAP), proposto em 1972-73, cujo principal objetivo era a introdução das atividades agropecuária e agroindustrial com características de exploração moderna e sob um enfoque empresarial; e o Programa de Desenvolvimento dos Cerrados (PRODECER), criado oficialmente em 1979, que visava incorporar 50 mil hectares sob a forma de exploração intensiva em capital. Seria proposta, mais tarde, pelo governo federal, a ampliação desse programa para a incorporação de uma área de 150 mil ha de cerrados que, além do estado de Minas, deveria incluir áreas dos estados da Bahia, Goiás, Mato Grosso e Mato Grosso do Sul (BDMG, 1989a).

O crescimento da agropecuária no estado de Minas Gerais foi também estimulado pelo Plano Nacional de Renovação e Revigoramento dos Cafezais, no início da década de 
1970, que favoreceu a expansão da cafeicultura em todo o estado, especialmente, na sua região sul.

Nos anos 1960, o estado de Minas Gerais era predominantemente fornecedor de matérias-primas. A partir dos anos 1970, nele desenvolveu-se e consolidou-se a produção de bens intermediários com maior grau de elaboração industrial, aumentando significativamente a exportação desses produtos, que em 1979 representavam $38,5 \%$ da pauta de exportações (BDMG, 1989b, p.14).

No período de 1970-77, a partir de grandes investimentos realizados no estado, sua indústria passou a contar com novos ramos de Bens de Capital, Bens de Consumo Duráveis e diversificação da produção de Bens Intermediários. As taxas de investimento, obtidas por meio da relação formação bruta de capital fixo (FBKF) / PIB, passaram de $21 \%$ em 1970 para $31,2 \%$ em 1980 . No início da década de 1980, as taxas de crescimento econômico do país começam a dar sinais de arrefecimento e, já durante a primeira metade da referida década, as taxas de investimento em Minas Gerais começam a declinar; em 1985 a relação FBKF/PIB do estado passou a ser da ordem de $18,1 \%$. Ao longo de todo período de 1985-1994 o estado manteve praticamente inalterada sua participação relativa no PIB brasileiro, que foi de $9,79 \%$, no primeiro ano do aludido período, e de $\mathbf{9 , 8 1 \%}$ no último (BDMG, 1989a; Lavinas et al., 1997; Fernandes, 1997).

Ao longo da década de 1970, a política de incentivos fiscais de ICMS adotada pelo estado resultou na expansão de todos os setores, destacando-se o de Bens de Consumo Intermediário, que recebeu $83,5 \%$ dos investimentos industriais do estado, notadamente os dirigidos às indústrias metalúrgicas $(72,7 \%$ do total do investimento industrial), havendo também, embora em menor escala, um maior aporte de recursos para os setores de Bens de Consumo Duráveis e de Capital (9,3\%). Todo esse processo resultou em alterações significativas na estrutura produtiva do estado no período 1970-80, tais como: a) grande elevação da participação no valor agregado bruto da indústria de transformação de Minas Gerais dos ramos de Bens de Consumo Duráveis e de Capital, destacando-se os setores da indústria mecânica, de material de transporte e, de material elétrico e de comunicação; b) queda da participação do ramo de Bens Intermediários; e c) 
manteve-se a estabilidade de Bens de Consumo Não-Duráveis (BDMG, 1989a; Fernandes, 1997).

Fernandes (1997) destaca que, embora a indústria mineira se apresentasse, em 1980, bastante diversificada, tendo incorporado vários gêneros produtores de bens com significativos avanços tecnológicos, o estado manteve sua característica de produtor de Bens Intermediários, com ênfase para os setores de metalurgia e de minerais nãometálicos. Mesmo apresentando uma elevação da participação relativa do ramo de Bens de Consumo Duráveis e de Capital no produto interno bruto industrial, passando de 11,89\% em 1989 para 21,35\% em 1996, a hegemonia do ramo de Bens Intermediários no estado de Minas Gerais é marcante. Sua participação no PIB industrial do estado foi de 44,94\% em 1996.

Integrada à dinâmica da indústria nacional, a economia mineira tornou-se, a partir dos anos 1980, bastante articulada com os mercados externos, passando de $8,2 \%$ do total das exportações brasileiras, em 1973, para 12,1\% em 1996. Lavinas et al. (1997) ressaltaram o desempenho da economia mineira no período 1985-1995, destacando a posição do estado como primeiro exportador do país de produtos básicos em 1995 (22\%).

Uma característica importante do aspecto locacional da indústria do estado de Minas é sua concentração na região Metropolitana de Belo Horizonte e municípios vizinhos e, também, nos municípios de porte médio, situados na macrorregião de planejamento denominada Metalúrgica e Campo das Vertentes. Segundo BDMG (1989a), a indústria extrativa mineral apresenta-se concentrada nessa região, haja vista as indústrias do Quadrilátero Ferrífero, área com grande potencial produtivo, e as do pólo industrial do Vale do Aço. Não obstante esse fato, o estado apresenta outras áreas promissoras para o crescimento industrial como a região Sul de Minas que, devido à proximidade com o estado de São Paulo, juntamente com a região do Triângulo e Alto Paranaíba, têm experimentado um processo de expansão diversificada; e a região Noroeste, com destaque para a concentração industrial ocorrida no município de Montes Claros que, estando 
incluído na Área Mineira da SUDENE, conta com incentivos fiscais para industrialização (Diniz, 1995; BDMG, 1989a).

Conforme o BDMG (1989b, p.89) “a concentração espacial das indústrias gera um conjunto de externalidades que se constituem nas economias de aglomeração, fator preponderante na decisão locacional por parte dos empresários" e, embora a economia mineira apresente concentração industrial em algumas regiões, ainda não apresenta sinais de exaustão que levem às deseconomias de aglomeração; pelo contrário, o estado pode servir-se dessa característica e aproveitar suas potencialidades como forma estratégica para o crescimento de sua economia.

Locatelli \& Silva (1991, p.26), ao analisarem a economia do estado, visando à identificação dos complexos industriais existentes na economia mineira, concluíram que “em função da escassez atual de recursos, das limitações de alguns fatores locacionais e das vantagens comparativas, a estratégia recomendável para a economia mineira, na fase atual, é incentivar a consolidação dos complexos industriais existentes, notadamente, o metal-mecânico e segmentos dos complexos agroindustriais e do têxtil".

Pode-se constatar, pelo exposto, que, dos estados considerados nesta pesquisa, é no estado de Minas Gerais que se concentra a principal área de atividade industrial da região de abrangência da bacia do rio São Francisco. A Região Metropolitana de Belo Horizonte (RMBH) destaca-se das demais por ser onde se concentra o mais diversificado e dinâmico parque industrial da bacia, merecendo destaque, fora da RMBH, o município de Montes Claros.

A atividade agro-industrial na região da bacia tem sua maior expressão nos municípios de Petrolina e Juazeiro, conforme já se mencionou anteriormente. No restante da área, a atividade industrial é pouco expressiva, merecendo destaque as indústrias de produtos alimentares, de minerais não-metálicos, têxteis e a metalúrgica.

A atividade agropecuária predomina nas demais áreas da região da bacia. A atividade agrícola é extremamente vulnerável às secas, assim, visando à promoção do desenvolvimento regional, a agricultura irrigada foi uma das atividades priorizadas nos planos governamentais. 


\subsubsection{A agricultura irrigada na região}

Uma vez apresentada uma visão geral das economias dos estados da bacia, nesta subseção será discutido o papel da agricultura irrigada no contexto da economia regional.

A agricultura irrigada proporciona aumento da produtividade quando comparada com a agricultura tradicional, de sequeiro. É uma atividade intensiva em capital e integrada a outros setores do complexo agroindustrial, utilizando intensivamente insumos (adubos, defensivos), máquinas agrícolas e infra-estrutura de irrigação. E, mais uma vez, quando comparada com as culturas de sequeiro, é mais intensiva no emprego da mão-deobra que, nela, recebe uma remuneração maior. Assim, um importante papel sócioeconômico é reservado para a agricultura irrigada no Nordeste, a qual, integrada às atividades da agroindústria, tem a tarefa de alavancar o crescimento econômico nas áreas em que é implantada.

Segundo a CODEVASF (1998b), a renda obtida na região semi-árida pelas culturas tradicionais de sequeiro está na faixa de US\$260/ha/ano, enquanto nas áreas irrigadas, a renda obtida pela atividade agrícola situa-se na faixa de US\$ 2.500 a US\$ $3.000 / \mathrm{ha} / \mathrm{ano}$, podendo chegar até a US\$5.000/ha/ano nos projetos públicos de irrigação voltados para a produção de produtos com maior elasticidade-renda.

Considerando essa peculiaridade, será feita uma breve apresentação do desempenho da agricultura irrigada no Nordeste e em Minas Gerais, sem pretensão de se esgotar o assunto, com ênfase para a região da bacia do rio São Francisco.

A irrigação na região Nordeste e no norte de Minas Gerais surge vinculada à questão do problema da seca no Semi-Árido e aos planos de desenvolvimento engendrados, em sua grande maioria, por iniciativa do Governo Federal.

Desde o final do século XIX, vêm sendo realizados estudos sobre as potencialidades de navegação, irrigação e geração de energia do rio São Francisco. Vários órgãos governamentais foram criados, como o Instituto Federal de obras Contra as Secas (IFOCS), em 1906, substituído em 1949 pelo Departamento Nacional de Obras Contra as 
Secas (DNOCS). Também foram criados o Banco do Nordeste do Brasil (BNB), em 1952; a Superintendência do Desenvolvimento do Nordeste (SUDENE), em 1959, a Comissão do Vale do São Francisco (CVSF), em 1948, substituída pela SUVALE, em 1969, sendo esta substituída pela CODEVASF, em 1974. Essas instituições, criadas inicialmente sob o enfoque governamental de se encontrar uma solução para o problema da seca, passam, nos primeiros anos da década de 1960, a fazer parte dos instrumentos do Governo Federal em busca de uma perspectiva de planejamento regional para redução das disparidades sócio-econômicas entre as regiões brasileiras.

É importante ressaltar, entre as estratégias de desenvolvimento adotadas pelo Governo Federal, o Plano Plurianual de Irrigação (PPI), publicado pelo Grupo Executivo de Irrigação para o Desenvolvimento Agrícola (GEIDA) em 1971; a edição da Lei de Irrigação (Lei $\mathrm{n}^{\mathrm{0}}$ 6.662, de 25 de junho de 1979), regulamentada pelo Decreto $\mathrm{n}^{\circ}$ 89.496, de 29 de março de 1984 e os programas criados sob o amparo desses dispositivos legais, como o Programa Nacional para o Aproveitamento Racional das Várzeas Irrigáveis (PROVÁRZEAS NACIONAL), criado em junho de 1981; o Programa de Financiamento de Equipamentos de Irrigação (PROFIR), instituído em fevereiro de 1982; o Programa Nacional de Irrigação (PRONI), criado pelo Decreto $\mathrm{n}^{\circ} 92.395$, de 12 de fevereiro de 1986, voltado para o apoio às ações de irrigação nas regiões Sul, Sudeste, Centro-Oeste e Norte; e o Programa de Irrigação do Nordeste, criado pelo mesmo decreto (CODEVASF, 1998b; Assirati, 1994; Avellar, 1976).

Todos esses planos e programas faziam parte de um conjunto mais amplo de medidas do Governo Federal, visando ao desenvolvimento nacional. No caso da região em tela, os programas de irrigação visavam, por meio da elevação da produção e da produtividade agrícola, contribuir para a geração de empregos (diretos e indiretos), resultando em desenvolvimento sócio-econômico da região, por meio do aumento da renda. Entretanto, segundo a CODEVASF (1998b), não há, no país, uma política de irrigação estável em virtude do apoio governamental ser segmentado e descontínuo. Assim, apesar do inegável crescimento da irrigação no país e dos benefícios sócioeconômicos obtidos em algumas regiões irrigadas na bacia do São Francisco, as 
transformações são pontuais e localizadas, persistindo nas demais áreas, principalmente as da agricultura de sequeiro, questões como baixos índices de educação, saúde, saneamento básico, baixa produtividade e renda.

Gomes \& Vergolino (1995), após terem desenvolvido um estudo sob uma visão macroeconômica do Nordeste, subdividiram-no em quatro sub-regiões: a) Regiões Metropolitanas - considerando os três maiores aglomerados urbanos nordestinos: Fortaleza, Recife e Salvador; b) região Semi-Árida - que abrange a região do agreste e grande parte do sertão; c) Zona da Mata - área que abrange parte dos estados de Pernambuco, Alagoas, Rio Grande do Norte, Bahia e Sergipe e a totalidade do estado do Maranhão; e d) Área de Irrigação - constituída pelas microrregiões do Sertão de São Francisco, em Pernambuco, das Corredeiras do Rio São Francisco, na Bahia, e do Açu, no Rio Grande do Norte.

Segundo os autores, nessas três principais Regiões Metropolitanas concentram-se os grandes complexos industriais do Nordeste, devido, principalmente, às economias de aglomeração resultantes das políticas de incentivos fiscais. $O$ desenvolvimento das atividades industriais contribuiu para a urbanização, favorecendo o desenvolvimento dos setores do comércio e da prestação de serviços.

Já a Zona da Mata é a mais antiga área de exploração econômica, com destaque para o complexo sucro-alcooleiro dos estados de Pernambuco e Alagoas e, mais recentemente, o desenvolvimento do turismo, bem como a agroindústria cacaueira, a exploração da madeira e o turismo no estado da Bahia. Concentram-se, também, nessa área - nas microrregiões do Recôncavo - as indústrias do setor de fumo, significativas na composição do produto bruto estadual baiano. Por suas características e área de abrangência, a "Zona da Mata do Nordeste concentra uma base agrícola extremamente forte, uma atividade manufatureira bastante significativa e uma indústria do turismo em franco processo de desenvolvimento" (Gomes \& Vergolino, 1995, p.79).

$\mathrm{Na}$ região Semi-Árida, predominam a agricultura de subsistência, de baixa produtividade, e a pecuária extensiva. As três microrregiões incluídas na área de Irrigação ou Pólos de Irrigação são as que apresentam uma agricultura moderna, empregando 
técnicas de alta produtividade, voltadas para produtos agrícolas com alta elasticidaderenda.

Como os autores demonstraram, as sub-regiões compostas pelas Regiões Metropolitanas e os Pólos de Irrigação, apresentaram, no período 1970-1992, um acentuado crescimento (Tabela 2.4).

Também é interessante observar a participação relativa dessas quatro sub-regiões no produto do Nordeste durante o período mencionado. As Regiões Metropolitanas, Irrigação e Zona da Mata ampliaram suas respectivas participações no produto regional durante todo o período, enquanto a Semi-Árida teve sua participação dramaticamente reduzida. Atendo-se apenas à região diretamente relacionada à presente pesquisa, verificase que os Pólos de Irrigação apresentaram um grande dinamismo, passando de uma participação no produto do Nordeste de $0,97 \%$, em 1970, para $1,80 \%$, em 1992 . Se se considerar o reduzido espaço geográfico desses pólos em relação à área total da Região Nordeste ${ }^{8}$, pode-se avaliar o potencial produtivo deles (Tabela 2.5). É importante ressaltar que tal dinamismo decorre do emprego de técnicas modernas de produção bem como das práticas de comercialização, tendo em vista que o principal mercado que os produtores vislumbram para os seus produtos é extra-regional.

Tabela 2.4 - Estimativas dos Produtos Brutos por Sub-Região do Nordeste do Brasil, $1970,1975,1980,1985,1988$ e 1992

(Valores em milhões de dólares de 1992)

\begin{tabular}{lrrrrrr}
\hline & \multicolumn{7}{c}{ Anos } \\
\cline { 2 - 7 } \multicolumn{1}{c}{ Sub-Região } & 1970 & 1975 & 1980 & 1985 & 1988 & 1992 \\
\hline Regiões Metropolitanas & 5.165 & 9.606 & 16.286 & 23.288 & 29.065 & 32.081 \\
Zona da Mata & 5.774 & 9.270 & 12.120 & 15.863 & 14.044 & 19.824 \\
Semi-Árido & 8.457 & 12.629 & 16.263 & 15.958 & 20.193 & 9.350 \\
Irrigação & 191 & 370 & 556 & 845 & 886 & 1.122 \\
Total (Nordeste) & 19.587 & 31.876 & 45.225 & 55.954 & 64.188 & 62.379 \\
\hline
\end{tabular}

Fonte: Gomes \& Vergolino (1995).

${ }^{8}$ A maior expansão da agricultura irrigada na Região Nordeste ocorreu no Submédio São Francisco. Segundo o DNAEE (1983) as áreas potencialmente irrigáveis da Bacia Hidrográfica do São Francisco correspondem a 2.300 mil hectares. Conforme CODEVASF (1996a), estudos indicam 800.000 ha como área possível de ser irrigada na bacia do rio São Francisco, sem acarretar maiores problemas com relação à geração de energia elétrica pelo sistema CHESF. A CODEVASF dispõe de projetos de irrigação que, entre aqueles em fase de estudos, em implementação e em operação, totalizam 387.170 ha. 
Tabela 2.5 - Produto Interno Bruto por Sub-Regiões do Nordeste do Brasil, 1970 - 1992 (participação relativa)

\begin{tabular}{lrrrrrr}
\hline & \multicolumn{7}{c}{ Anos } \\
\cline { 2 - 7 } \multicolumn{1}{c}{ Sub-Região } & 1970 & 1975 & 1980 & 1985 & 1988 & 1992 \\
\hline Regiões Metropolitanas & 26,37 & 30,14 & 36,01 & 41,62 & 45,28 & 51,43 \\
Zona da Mata & 29,48 & 29,08 & 26,80 & 28,35 & 21,88 & 31,78 \\
Semi-Árido & 43,18 & 39,62 & 35,96 & 28,52 & 31,46 & 14,99 \\
Irrigação & 0,97 & 1,16 & 1,23 & 1,51 & 1,38 & 1,80 \\
Total (Nordeste) & 100,00 & 100,00 & 100,00 & 100,00 & 100,00 & 100,00 \\
\hline
\end{tabular}

Fonte: Gomes \& Vergolino (1995).

Vergolino \& Vergolino (1997) analisaram o papel desempenhado pelo Estado no desenvolvimento da região do Submédio São Francisco, especialmente na área do pólo Petrolina/Juazeiro, e discutiram as características do modelo de irrigação dessa região vis $\grave{a}$ vis aos demais modelos implantados em outras regiões do Semi-Árido do Nordeste. Identificaram, como características singulares dos projetos de irrigação no Submédio, sua escala e o perfil mercadológico das culturas implantadas. Nesses projetos "a escala ou tamanho proporcionou efeitos para frente e para trás de grande significação, e que reverberaram de maneira positiva sobre os segmentos de serviços e manufatureiro da região por eles polarizada"(p.451).

Segundo esses autores, uma das principais características desses projetos de irrigação é a opção por "um conjunto de produtos voltados para o mercado extraregional, com uma demanda garantida e com potencial de crescimento altamente promissor (...) ficando razoavelmente claro que a renda local será comandada, por um longo período de tempo, pelo multiplicador das exportações, sem que haja possibilidade de que fatores tipicamente endógenos possam regular a trajetória de crescimento local" (Vergolino \& Vergolino, 1997, p.452).

O pólo Petrolina/Juazeiro apresenta uma produção diversificada, com ênfase para culturas que apresentam alta produtividade como é o caso da uva (35 t/ha), da manga (16 t/ha), da laranja (70 t/ha), do abacaxi (34 t/ha) e do maracujá (68 t/ha), entre outras. Em 1996, a área plantada com frutas no pólo correspondia a, aproximadamente, $72 \%$ da área total, com uma produção de 1.128 mil toneladas (CODEVASF, 1998b). 
A agricultura irrigada, quando praticada sob um modelo de modernização da tecnologia de produção, possibilita a geração de um excedente agrícola de proporções tais que gera demandas suplementares por bens de consumo, bens intermediários e bens de capital que, por seu turno, propiciam a expansão do emprego em outros setores da economia.

O trabalho de Vergolino \& Vergolino (1997, p.454) permite verificar que, nos complexos irrigados do Submédio São Francisco, a prática da moderna agricultura irrigada foi alavancadora de setores como os do comércio, da prestação de serviços, do turismo e de outras atividades dentro do próprio setor agrícola, com grande potencial gerador de emprego, tendo sido a participação do Estado o principal instrumento desse processo. Adicionalmente, afirmam os autores que "o modelo de crescimento baseado no setor agrícola é perfeitamente factível para a região do semi-árido nordestino desde que exista uma oferta abundante de recursos hídricos". Essa afirmação é polêmica e muitos pesquisadores consideram que, mesmo havendo uma oferta suficiente de recursos hídricos, outras condicionantes, como escassez de capital, de mão-de-obra especializada e outros fatores ainda se apresentariam como entraves para o crescimento da região.

Sousa \& Souza $(1989$, p. 435) realizaram uma avaliação quantitativa dos impactos sobre o emprego e a renda decorrentes da expansão da área cultivada com lavouras irrigadas, considerando onze modelos de produção para diferentes regiões do país, concluindo que o maior impacto na geração de empregos diretos ocorre na Região Nordeste, enquanto na região Centro-Sul a absorção de mão-de-obra direta é bem menos significativa. Quanto aos empregos indiretos, concluíram que "a agricultura irrigada, por estar sempre associada a um conjunto de técnicas modernas, é mais integrada com o resto da economia e, portanto, gera mais empregos indiretos", o que se verificou em todas as regiões estudadas. No tocante à geração de renda, constataram que a renda indireta é superior à renda direta em todos os modelos de produção; a renda obtida nos modelos em que se produz hortifrutigrangeiros é superior à obtida nos modelos com produção de 
grãos; e a relação renda indireta/renda direta é mais elevada para os modelos com produção de grãos'.

Os projetos de irrigação nos estados da bacia do São Francisco têm contribuído para dinamizar as economias regionais e para a gerar empregos. Nos projetos públicos, a infra-estrutura implantada e a indução dos irrigantes à prática de uma agricultura tecnificada, têm a finalidade de atrair o capital privado para ampliação da área irrigada. $O$ incentivo à atividade agroindustrial tem, como objetivo, torná-la "um complemento estratégico da dinamização da atividade agrícola" . Além de Petrolina e Juazeiro, destacam-se outros centros urbanos que apresentam potencial para a atração de investimentos privados como Montes Claros (MG), Unaí (MG) e Barreiras (BA).

Os perímetros irrigados pela CODEVASF ocupavam, até dezembro de 1997, uma área total de 91.184 ha. Conforme a Tabela 2.6, a área efetivamente plantada decresceu no período 1995-97. Entretanto, pode-se observar que, no mesmo período, houve ganhos de produtividade, haja vista os acréscimos na produção que passou de um total de 1.224.396,78 t, em 1995, para 1.458.627,43 t em 1997. Quanto ao valor bruto da produção, observa-se ligeiro decréscimo no período, passando de 173.553,23 mil dólares, em 1995, para 166.625,14 mil dólares, em 1997.

Segundo a CODEVASF (1998a), nos perímetros irrigados do Baixo São Francisco, predomina o cultivo do arroz; nos do Submédio, dos canaviais e nos do Médio São Francisco, a maior área cultivada é ocupada pela banana. Há uma tendência, nos perímetros, do aumento da fruticultura, reduzindo-se as áreas cultivadas com o feijão e o milho que, anteriormente, predominavam nas áreas irrigadas.

Os produtos da agricultura irrigada são usados como insumos para a produção de indústrias locais e extra-regionais, com encadeamentos na economia que, aliados aos efeitos sobre o emprego e a renda, poderiam servir como forma de atrair o capital privado e propiciar a expansão da economia regional.

\footnotetext{
9 Para maior detalhamento ver Sousa, Maria da Conceição Sampaio de; Oliveira, Augusto César de e Souza, Hermínio Ramos de (1989).
} 
Sob esse ponto de vista, surgem três questões: a da alocação do recurso escasso água - entre os diversos setores produtivos; a dos objetivos de intensificação das atividades agropecuárias, especialmente da agricultura irrigada, e a do atendimento das demandas interindustriais advindas do crescimento econômico.

Tabela 2.6 - Área Plantada, Produção Total e Valor Bruto da Produção dos Perímetros Irrigados da CODEVASF - 1995 - 1997

\begin{tabular}{lrrr}
\hline & \multicolumn{3}{c}{ Periodo } \\
\cline { 2 - 4 } & \multicolumn{1}{c}{1995} & \multicolumn{1}{c}{1996} & \multicolumn{1}{c}{1997} \\
\hline 1 Área Plantada (ha) & $\mathbf{6 8 . 9 1 8 , 9 8}$ & $\mathbf{6 4 . 5 8 7 , 1 0}$ & $\mathbf{6 3 . 6 8 2 , 3 6}$ \\
1.1 Unidade Familiar & $43.206,35$ & $39.654,81$ & $37.718,76$ \\
Culturas Temporárias & $30.341,84$ & $22.463,26$ & $20.793,85$ \\
Culturas Permanentes & $12.864,51$ & $17.191,55$ & $16.924,91$ \\
1.2 Empresa & $25.712,63$ & $24.932,29$ & $25.963,60$ \\
Culturas Temporárias & $4.299,85$ & $3.199,71$ & $3.714,05$ \\
Culturas Permanentes & $21.412,78$ & $21.732,58$ & $22.249,55$ \\
2 Produção Agrícola (t) & $1.224 .396,78$ & $1.395 .406,80$ & $1.458 .627,43$ \\
2.1 Unidade Familiar & $345.230,97$ & $271.788,03$ & $299.099,85$ \\
Culturas Temporárias & $284.938,42$ & $173.771,70$ & $120.302,91$ \\
Culturas Permanentes & $60.292,55$ & $\mathbf{9 8 . 0 1 6 , 3 3}$ & $178.796,61$ \\
2.2 Empresa & $\mathbf{8 7 9 . 1 6 5 , 8 1}$ & $1.123 .618,77$ & $1.159 .527,58$ \\
Culturas Temporárias & $59.957,92$ & $27.301,35$ & $53.178,88$ \\
Culturas Permanentes & $\mathbf{8 1 9 . 2 0 7 , 8 9}$ & $1.096 .317,42$ & $1.106 .348,70$ \\
3. Valor Bruto da Produção (US\$ 1.000) & $173.553,23$ & $172.063,05$ & $166.625,14$ \\
3.1 Unidade Familiar & $86.899,75$ & $\mathbf{8 8 . 1 1 9 , 0 2}$ & $\mathbf{7 8 . 7 6 4 , 4 4}$ \\
Culturas Temporárias & $51.882,43$ & $39.041,64$ & $19.247,95$ \\
Culturas Permanentes & $35.017,32$ & $49.077,38$ & $59.516,49$ \\
3.2 Empresa & $86.653,48$ & $\mathbf{8 3 . 9 4 4 , 0 3}$ & $\mathbf{8 7 . 8 6 0 , 7 0}$ \\
Culturas Temporárias & $12.231,33$ & $7.186,44$ & $\mathbf{6 . 0 5 9 , 2 6}$ \\
Culturas Permanentes & $74.422,15$ & $\mathbf{7 6 . 7 5 7 , 5 9}$ & $\mathbf{8 1 . 8 0 1 , 4 4}$ \\
\hline
\end{tabular}

Fonte: CODEVASF/ Superintendências Regionais (1996b; 1998a).

Nota: (1) Dólar médio de 1996, conforme FGV: US\$1.00 = R\$1,0051

Dólar médio de 1997, conforme FGV: US\$1.00 = R \$1,078.

Qualquer política de desenvolvimento regional requer uma cuidadosa análise dessas inter-relações antes de se chegar a conclusões e se estabelecer diretrizes para solucionar os problemas regionais. 


\subsection{Usos múltiplos da água}

A água e o ar são elementos vitais. A água é recurso natural dos mais utilizados nas atividades humanas. À medida que a civilização vai se desenvolvendo, a água é utilizada com mais intensidade.

Embora renovável ${ }^{10}$ por meio do ciclo hidrológico ${ }^{11}$ e relativamente abundante, a distribuição espacial e temporal da água torna-a limitada, podendo não atender às demandas dos diferentes usos requeridos.

Normalmente, após seu uso, a água é devolvida ao meio-ambiente com qualidade inferior à de sua captação. Os principais agentes determinantes dessa degradação são as matérias orgânicas, organismos patogênicos e elementos químicos (Sperling, 1997). Assim, como insumo, a água sofre contaminações, freqüentemente, em níveis superiores à sua capacidade natural de absorção e renovação, sendo, dessa forma, um dos recursos naturais mais facilmente sujeitos à poluição.

As bacias fluviais são sistemas complexos e a maioria das atividades humanas tem efeitos que se refletem sobre o ciclo hidrológico, sobre as comunidades e ecossistemas das mesmas. Quase todas as atividades que utilizam água e solo afetam a qualidade e o volume da água, desde as nascentes até a foz do rio.

Cada um dos possíveis usos do recurso água demanda um padrão de qualidade diferenciado. Determinados usos exigem um padrão de qualidade elevado, com rigoroso controle, outros não apresentam grandes restrições nesse sentido. A alteração qualitativa do recurso leva à diminuição de sua utilidade para os diversos fins, podendo, até mesmo, restringir o crescimento ou contribuir para o declínio das atividades que dependem dele.

De acordo com Setti $(1998$, p.7), as quantidades e a natureza dos elementos que constituem as águas variam em função das características do solo de onde se originam,

\footnotetext{
10 "A água é considerada um recurso renovável devido à sua capacidade de se recompor em quantidade, principalmente pelas chuvas e por sua capacidade de absorver poluentes". No entanto, essa classificação é limitada pelo tipo de uso, que irá repercutir sobre sua disponibilidade em virtude da quantidade existente e pela qualidade que apresentar. (Setti, 1998, p.5).

${ }^{11}$ Ciclo hidrológico: evaporação $\Rightarrow$ precipitação $\Rightarrow$ escoamento $\Rightarrow$ evaporação.
} 
das condições climáticas e do nível de poluição ao qual estão submetidas, considerando, especialmente, os despejos industriais e municipais.

As alterações na qualidade da água ocorrem em razão das inter-relações dos componentes do meio ambiente, influenciando os recursos hídricos devido aos múltiplos usos que são dados a ela.

Os recursos hídricos têm capacidade de se autodepurarem, ou seja, de diluir e assimilar esgotos e resíduos por meio de processos físicos, químicos e biológicos. Entretanto, essa capacidade é limitada pela quantidade e qualidade que esses recursos apresentavam antes de receber a carga poluidora (carga de esgotos e resíduos, por exemplo).

A água tem múltiplos usos e muitos deles exigem que ela seja retirada da sua fonte natural. Em alguns casos, depois de utilizada, a água é devolvida à fonte, entretanto com seu nível qualitativo alterado em relação ao inicial.

Os usos da água podem ser consuntivos, aqueles que retiram a água de sua fonte natural, reduzindo sua disponibilidade sob os aspectos temporal e espacial, ou não consuntivos, os usos em que a água é devolvida à sua fonte natural, praticamente em volume equivalente ao total retirado, com alguma modificação (ou não) no seu padrão qualitativo e no padrão de disponibilidade temporal (Lanna \& Rocha, 1988). Em qualquer atividade, quanto mais água for utilizada, mais consuntivo pode se tornar o seu uso. A redução da sua disponibilidade pode ocorrer devido à evapotranspiração ${ }^{12}$ durante o uso ou porque a água é incorporada ao produto durante o processo de produção.

De acordo com os padrões de disponibilidade temporal e de qualidade da água, seus usos podem se tornar cada vez mais competitivos entre si, resultando na escassez do recurso e limitações para seu consumo.

Ao se considerar os aspectos qualitativo e quantitativo dos recursos hídricos, há que se observar que, numa situação de abundância de água, ela pode ser tratada como um bem livre, sem valor econômico. Entretanto, com o aumento da demanda pelo recurso,

\footnotetext{
${ }^{12}$ A evaporação da água da superficie do solo e a transpiração, quando associadas, recebem a denominação genérica de evapotranspiração (ET) (Carvalho, 1998, p.13).
} 
que passa, então, a ser escasso, podem ocorrer conflitos entre os usos e os usuários. Dessa forma, os recursos hídricos "precisam ser geridos como um bem econômico, aos quais deve ser atribuído seu justo valor" (Setti, 1998, p.8).

As emissões de outorgas de uso de água ${ }^{13}$, quando as alterações do padrão de disponibilidade desse recurso levam à escassez, necessitam de uma maior coordenação política, que propicie seu uso de forma racional.

O crescimento demográfico, a expansão urbana e a intensificação das atividades industriais e agrícolas exercem influência sobre a disponibilidade da água e sobre o seu nível qualitativo. À medida em que aumenta o consumo da água, ela vai se tornando, cada vez mais, um bem com valor econômico. O status econômico da água tem sido reforçado em todas as partes do mundo por meio de leis que regulamentam seu uso, visando à manutenção de sua qualidade e sua disponibilidade.

Então, a água é um bem econômico? Se se considerar que a água serve para múltiplos fins (uso domésticos como bebida, preparação de alimentos, banho, limpeza, entre outros, uso industrial e agropecuário como para irrigação, dessedentação de animais e aqüicultura, geração de energia e navegação, recreação e uso ambiental, diluição de despejos, etc.) verifica-se que ela é um bem com usos alternativos. Além disso, é um recurso escasso no sentido de que ela não pode satisfazer a todos os seus usos alternativos simultaneamente.

"A água é um recurso natural finito, vulnerável, insubstituivel $e$ estratégico. É essencial à sustentação da vida, ao desenvolvimento sócioeconômico e ao meio-ambiente, sendo necessário controlá-la e preservála" (Declaração de Dublin, Irlanda, janeiro de 1992, referendada pela ECO-92, Agenda 21, capítulo 18, citado por Freitas, 1997, p.20).

13 "Outorga é "consentimento, concessão, aprovação, beneplácito". A Constituição Federal, em seu art. 21, XIX, disse competir à União definir os critérios de outorga dos direitos dos recursos hídricos". E, o art.11 da Lei 9.433/97, diz: "O regime de outorga de direitos de uso dos recursos hídricos tem como objetivo assegurar o controle quantitativo e qualitativo dos usos da água e o efetivo exercício dos direitos de acesso à água." (Setti, 1998., p.50). 
Dadas essas características, a água, como recurso, possui valor, devendo ser reconhecida como bem econômico.

Em todos os países, os usos da água são divididos em três categorias principais: agrícola, industrial e doméstico (incluindo o uso em residências, estabelecimentos comerciais, serviços públicos e abastecimento municipal). Desses, o setor agrícola, na maioria dos países em desenvolvimento, é o que mais usa água. Estima-se que, nesses países, entre os consumidores finais, a irrigação consuma $70 \%$ de toda a água derivada de rios, lagos e mananciais subterrâneos. No entanto, a produção industrial e a urbanização, com o aumento do nível de renda, levam a crescentes demandas de água por esses setores, que passam a competir com a agricultura irrigada. $O$ setor industrial é responsável por $23 \%$ do consumo enquanto o setor urbano consome $7 \%$ de toda a água disponível (Santos, 1998; Cardoso et al., 1998).

Apesar do elevado consumo de água, a irrigação, na agricultura moderna, proporciona altos índices de produtividade e maior estabilidade na oferta agrícola. Estimase que a área irrigada no mundo corresponda a $17 \%$ do total cultivado e seja responsável por $40 \%$ da produção total de alimentos. No Brasil, a área irrigada corresponde a $5 \%$ do total cultivado, respondendo por $16 \%$ da produção total e por $35 \%$ do seu valor (Santos, 1998).

A água é matéria-prima essencial para a maioria das atividades industriais, seja participando dos processos produtivos, integrada ao produto final, seja auxiliando a produção pela geração de vapor, sendo usada para refrigeração, para limpeza, etc. Em função das diferentes tecnologias utilizadas pelas indústrias, o consumo de água pode variar bastante entre os diferentes processos de produção de um mesmo produto. Abreu $(1990$, p.7) ressalta a importância do consumo de água para a produção industrial. Como exemplo, cita que para produzir $1 \mathrm{~kg}$ de papel são consumidos, em média, 40 litros de água; para $1 \mathrm{~kg}$ de açúcar 100 litros de água e para produzir $1 \mathrm{~kg}$ de aço 20 litros de água.

As necessidades domésticas de água atendem a várias funções. Sob o ponto de vista biológico, os seres humanos devem ingerir, em média, 2,5 litros de água por dia. 
Segundo Merrett (1997, p.55) no Reino Unido o setor doméstico consome, em média, 140 litros de água por dia, por pessoa.

Visando à comparação do consumo de água nos diferentes usos, segundo a CODEVASF (1998b), $15.000 \mathrm{~m}^{3}$ de água podem ser utilizados para:

- produzir em 1 hectare uma safra de arroz;

- abastecer 100 pessoas e 450 cabeças de gado em 3 anos;

- abastecer 100 famílias rurais durante 4 anos;

- abastecer 100 familias urbanas durante 3 anos.

Verificado o adensamento da população urbana, a intensificação da atividade industrial e agrícola, configura-se a competição entre os setores pelo uso da água. Como a exploração de fontes alternativas de oferta de água nem sempre é possível ou viável economicamente, os conflitos entre os usuários tendem a se exacerbar.

Entre os possíveis conflitos pode-se citar que o uso da água para irrigação passará a competir com o uso para geração de energia elétrica se a captação para a primeira finalidade for feita a montante da usina hidrelétrica. Um outro exemplo de uso competitivo seria o uso do mesmo corpo d'água para abastecimento urbano e para diluição de dejetos.

Existem, entretanto, usos complementares como, por exemplo, o uso da água para a produção de energia e o controle de enchentes.

$\mathrm{O}$ acelerado crescimento urbano no Brasil $^{14}$ e a expansão da produção industrial geraram a elevação do consumo de água por esses setores que, combinados com outros fatores, como a degradação dos recursos hídricos devido ao despejo de esgotos domésticos, resíduos industriais, agrotóxicos ou pelo carreamento dos solos, levarão à intensificação de disputas pelo uso do recurso.

\footnotetext{
14 Segundo dados do IBGE (1996), a população urbana brasileira, nas grandes regiões geográficas, apresentava a seguinte distribuição em 1980: Norte, 51,65\%; Nordeste, 50,46\%; Sudeste, 82,81\%; Sul, 74,12\%; Centro-Oeste, 67,79, que passou, em 1996, respectivamente, para $62,35 \%$; $65,21 \% ; 89,29 \%$; $77,21 \%$ e $84,42 \%$. O percentual da população urbana e rural com abastecimento de água em seus domicílios, nas grandes regiões, em 1995, foi de: Norte: 61,37\%; Nordeste: 52\%; Sudeste: 92,10\%; Sul: 91,15\% (CNI, 1996).
} 
Dessa forma, a análise de todas as possibilidades de aproveitamento dos recursos hídricos devem ser tratadas em conjunto se o que se deseja é alocá-los eficientemente (Pereira Jr., 1998).

O Rio São Francisco possui 168 afluentes, sendo 90 pela margem esquerda e 78 pela margem direita. Desses, 99 são rios perenes e 69 intermitentes. Os mais importantes afluentes perenes são os rios Paracatu, Urucuia, Cariranha, Corrente e Grande, à margem esquerda, e Paraopeba, das Velhas, Jequitaí e Verde Grande, à margem direita. Esses afluentes situam-se nas regiões do Alto e Médio São Francisco, entre os estados de Minas Gerais e Bahia. As vazões dos nove principais tributários do São Francisco variam entre $436 \mathrm{~m}^{3} / \mathrm{s} \mathrm{e} 19 \mathrm{~m}^{3} / \mathrm{s}$ (CODEVASF, 1998b).

O Rio São Francisco tem uma disponibilidade de água de 64,4 bilhões de $\mathrm{m}^{3} / \mathrm{ano} \mathrm{e}$ é o responsável por $73 \%$ da disponibilidade superficial garantida na Região Nordeste, cuja disponibilidade hídrica é de 97,3 bilhões de $\mathrm{m}^{3}$ /ano (CODEVASF, 1998b).

As vazões médias anuais observadas ao longo do São Francisco, durante os últimos 20 anos, variam de $707 \mathrm{~m}^{3} / \mathrm{s}$ até $2980 \mathrm{~m}^{3} / \mathrm{s}$ (Tabela 2.7).

Tabela 2.7 - Vazões médias anuais observadas ao longo do rio São Francisco (durante os últimos 20 anos).

\begin{tabular}{lc}
\hline \multicolumn{1}{c}{ Local } & Vazão $\left(\mathrm{m}^{3} / \mathrm{s}\right)$ \\
\hline Barragem de Três Marias & 707 \\
Pirapora & 768 \\
São Romão & 1.520 \\
São Francisco & 2.082 \\
Barragem de Sobradinho & 2.800 \\
Foz & 2.980 \\
\hline
\end{tabular}

Fonte: CODEVASF, 1998b.

Quanto aos recursos hídricos subterrâneos, segundo a CODEVASF (1998b) foram identificadas, na bacia, nove províncias, sendo quatro delas com uma reserva aqüífera explorável de 8,7 bilhões de $\mathrm{m}^{3} /$ ano. Essas reservas são importantes tanto para o abastecimento humano quanto para as atividades da Agropecuária (abastecimento animal e irrigação). As principais províncias da bacia são Coberturas Detríticas da Depressão 
Sanfranciscana, com uma reserva explorável de 477 milhões de $\mathrm{m}^{3} / \mathrm{ano}$, Zonas Aqüíferas Cársticas, com 780 milhões de $\mathrm{m}^{3} / \mathrm{ano}$, Aluviões e Dunas Litorâneas, com 1.630 milhões de $\mathrm{m}^{3}$ /ano e as Chapadas Areníticas, com 5.868 milhões.

As águas do rio São Francisco são usadas para geração de energia elétrica, para irrigação, para abastecimento doméstico (incluindo-se, neste, uso em residências, estabelecimentos comerciais, serviços públicos e abastecimento municipal), abastecimento industrial, abastecimento animal, navegação e recreação. Apresentam boa potabilidade, sendo necessário apenas o tratamento convencional para abastecimento humano. E, segundo a CODEVASF (1998b), a água do rio São Francisco é considerada como ótima para irrigação.

Na bacia do São Francisco, são seis as principais usinas hidrelétricas, destacandose a importância das usinas pertencentes ao sistema CHESF para o fornecimento de energia elétrica ao Nordeste. De acordo com Departamento Nacional de Águas e Energia Elétrica - DNAEE (1983), a geração de energia elétrica nas usinas da CHESF, na região do Submédio, "envolve um complexo de interfaces com as retiradas de água para irrigação no próprio vale ou para transposição para bacias vizinhas"(p.36).

Segundo o DNAEE (1983), na bacia do São Francisco, a área potencialmente irrigável corresponde a 2,3 milhões de hectares, nas regiões do semi-árido, no médio e submédio São Francisco, entre Pirapora (MG) e a Hidrelétrica de Paulo Afonso. Ressalta que "o balanço de necessidades e disponibilidades hídricas do São Francisco não pode ser realizado convertendo-se toda a vazão regularizável em área irrigável, uma vez que devem ser atendidos os múltiplos usos do recurso hídrico"(DNAEE, 1983).

Segundo o referido estudo, as retiradas de água no São Francisco para o abastecimento urbano e industrial são insignificantes em relação à vazão do rio, que sugere não haver maior preocupação com aumentos futuros desse consumo. Entretanto, caso os volumes consumidos sejam subestimados, o comprometimento dos recursos hídricos em outros usos poderá representar uma restrição ao desenvolvimento da região.

Considerando a possibilidade de intensificação de conflitos pelos diversos usos da água na Bacia do São Francisco - competição entre a geração de energia elétrica e a 
irrigação; uso dos corpos d'água da bacia para despejo de efluentes urbanos ou industriais; prejuízo de áreas à jusante dos rios em função de perdas em termos de quantidade e/ou qualidade; construção de reservatórios que prejudiquem a navegação; transposição para bacias vizinhas - a administração da oferta e do uso da água, num modelo integrado da bacia hidrográfica, deve visar ao estabelecimento de um equilíbrio tal que esses usos sejam compatibilizados e os conflitos administrados.

Atualmente, são vários os problemas na bacia. Tome-se, como exemplo, o Rio das Velhas que, no estado de Minas Gerais, é o maior afluente do São Francisco. Fornece água para o abastecimento da cidade de Belo Horizonte e outros municípios próximos, no entanto, apresenta elevado grau de contaminação de suas águas devido aos esgotos urbanos e efluentes industriais e à atividade de mineração em parte de seu curso. Nas subbacias dos rios Verde Pequeno e Salitre existem conflitos provocados pela demanda de água para irrigação, o mesmo ocorrendo no Verde Grande (Bernardo, 1997; Dias, 1998).

Por satisfazerem múltiplos usos, o planejamento da utilização dos recursos hídricos deve passar de uma abordagem setorial para uma abordagem global (Abreu, 1990, p.3).

Deduz-se, pois, que os usos múltiplos dos recursos de uma bacia hidrográfica devem ser considerados como uma variável básica no planejamento de políticas de desenvolvimento regional, conforme os objetivos da Política Nacional de Recursos Hídricos, que explicitam os princípios do desenvolvimento sustentável ${ }^{15}$ desses recursos.

Dessa forma, uma visão integrada da economia regional com os estudos sobre as interações do uso do recurso água irá ampliar a compreensão das necessárias proporções desse insumo para que se propiciem condições para o desenvolvimento sócio-econômico.

\footnotetext{
${ }^{15}$ Segundo Setti $(p .40,1998)$ os incisos I e II do art. $2 .^{\circ}$ da Lei 9.433/97 explicitam os princípios do desenvolvimento sustentável dos recursos hídricos, sendo objetivos da Política Nacional de Recursos Hidricos: "I - assegurar à atual e às futuras gerações a necessária disponibilidade de água em padrões de qualidade adequados aos respectivos usos; II - a utilização racional integrada dos recursos hídricos, incluindo o transporte aquaviário, com vistas ao desenvolvimento sustentável."
} 


\section{TEORIA BÁSICA E AS ANALISES REGIONAL E INTER-REGIONAL DO INSUMO PRODUTO}

Neste capítulo apresenta-se, sob forma de revisão de literatura, a teoria básica do modelo de insumo-produto, discorrendo-se, em seguida, sobre as análises regional e inter-regional.

\subsection{A teoria básica do modelo de insumo-produto}

Wassily Leontief apresentou várias contribuições importantes para o desenvolvimento da aplicação da modelagem matemática na economia e, sem dúvida, o modelo de insumo-produto tem sido sua principal colaboração para descrição quantitativa da estrutura econômica, bem como, para demonstrar como modelos com grandes aplicações práticas podem ser construídos e implementados. $\mathrm{O}$ modelo de insumo-produto foi elaborado para revelar todas as interdependências entre as várias indústrias de uma economia e as relações dessas indústrias como vendedoras para os consumidores finais (Carter \& Petri, 1989; Davis, 1968).

Sob o ponto de vista teórico, o modelo de insumo-produto é uma versão concreta e computável da teoria de equilíbrio geral, conforme os modelos desenvolvidos anteriormente por Quesnay - Tableau Economic - (1758) e Walras - Éléments d'Economie Politique Pure - (1874), adaptado às necessidades de se desenvolver cálculos econômicos de uma forma prática. Leontief foi, portanto, quem desenvolveu a estrutura analítica de insumo-produto; foi quem primeiro a implementou empiricamente, tendo como ponto de partida o artigo de 1936 "Quantitative Input and Output Relations in the Economic System of the United States". O maior destaque ocorreu quando da 
publicação de "The Structure of American Economy 1919-1939", em 1941. (Carter \& Petri, 1989; Davis, 1968).

O modelo de insumo-produto constitui-se em instrumento analítico que pode ser utilizado para examinar uma ampla variedade de problemas econômicos tratando desde análises estruturais até de questões relativas ao planejamento

Um modelo de insumo-produto pode ser construído para um país, uma região, um estado, etc. Sob o ponto de vista técnico, a base do sistema analítico de Leontief é a tabela de insumo-produto. Essa tabela mostra a forma como o produto de cada indústria é distribuído entre outras indústrias, como insumo para outros processamentos e também retrata como o produto é destinado para o consumo final sob suas várias formas, constituindo o "setor" demanda final. Os fluxos de produtos de um setor ${ }^{16}$ produtor para um setor comprador é conhecido como fluxo interindústria ou intersetorial e, geralmente, refere-se a um período de tempo correspondente a um ano, sendo expresso em termos monetários, ou seja, a análise de insumo-produto examina o fluxo de bens e serviços e todas as transações intermediárias entre os setores produtores e consumidores de um país ou região (Miller \& Blair, 1985; Leontief, 1983; Lofting \& McGauhey, 1963).

Uma tabela de insumo-produto pode ser, então, utilizada segundo duas funções principais: a primeira para fazer uma descrição da estrutura da economia mostrando as relações entre indústrias e setores e entre insumos e produtos, a segunda, considerando certos pressupostos econômicos sobre a natureza das funções de produção, é a de servir como instrumental analítico para mensuração de distúrbios sobre o produto e a renda da economia, podendo revelar todas as repercussões sobre o produto total e as transações da economia de um deslocamento da demanda final (Richardson, 1972).

\footnotetext{
${ }^{16}$ Segundo Miller \& Blair (1985) os termos indústria e setor, geralmente, são intercambiáveis em análises de insumo-produto. Para uma melhor compreensão, segundo Miernyk (1974), o termo indústria refere-se aos agregados de firmas que produzem produtos similares enquanto setor corresponde aos tipos de mercados que as indústrias servem.
} 


\subsubsection{O sistema de Leontief: o modelo aberto}

Como um instrumento de análise empírica, Leontief desenvolveu um sistema de relações interindustriais ou intersetoriais considerando as propriedades do equilibrio estático, com igualdade entre as demandas e ofertas intersetoriais, em um mercado com livre competição, no qual os preços são iguais aos custos médios e os coeficientes técnicos são fixos.

Os pressupostos básicos do modelo de insumo-produto são:

a) cada setor produz apenas um produto homogêneo por meio de um único processo de produção;

b) a função de produção associada ao modelo de insumo-produto é de proporções fixas, ou seja, os setores da economia utilizam os insumos em proporções fixas, essas funções são lineares e homogêneas para os j setores da economia;

c) em decorrência da função de produção do modelo, reflete-se a pressuposição de retornos constantes de escala.

Considerando-se, de forma simplificada, uma tabela de insumo-produto, as transações nela representadas expressam todas as transações interindustriais - demanda intermediária - e a produção destinada ao consumo das famílias e do governo, a parcela destinada para investimento privado e para exportação - demanda final. Então, para uma economia com $n$ setores, pode-se expressar essas transações por meio de ${ }^{17}$ :

$$
X_{i}=\sum_{j}^{n} x_{i j}+C_{i}+I_{i}+G_{i}+E_{i}
$$

onde:

$X_{i}$ é a produção total do setor $i$;

$x_{i j}$ é a produção do setor $i$ que é utilizada como insumo intermediário pelo setor $j$;

$C_{i}$ é a produção do setor $i$ que é consumida pelas familias;

\footnotetext{
${ }^{17}$ Tomou-se como base o exposto em Richardson (1972) e Miller \& Blair (1985).
} 
$I_{i}$ é a produção do setor $i$ que é destinada ao investimento privado;

$G_{i}$ é a produção do setor $i$ que é consumida pelo governo;

$E_{i}$ são as exportações líquidas do setor $i$.

Sendo $X_{j}$ a produção total do setor $j$ e considerando a suposição que os fluxos interindustriais de $i$ para $j$, para um dado período de tempo, dependem do produto total do setor $j$ dessa economia, pode-se definir os coeficientes técnicos $\left(a_{i j}\right)$ pela seguinte equação:

$$
x_{i j}=a_{i j} X_{j} \quad \text { e } \quad a_{i j}=x_{i j} / X_{j}
$$

sendo que $a_{i j}$ é a produção necessária do setor $i$ para a produção de uma unidade de produção total do setor $j$ e considerando que $a_{i j}<1$ e $\left(1-a_{i j}\right)>0$. 0 conjunto dos coeficientes técnicos constitui a matriz tecnológica $(A)$, de forma tal que os $a_{i j}$ descrevem a estrutura tecnológica do setor correspondente em cada coluna da matriz $A$. Essa matriz pode ser representada como:

$$
\left[\begin{array}{cccccc}
a_{11} & a_{12} & \cdots & a_{1 i} & \cdots & a_{1 n} \\
a_{21} & a_{22} & \cdots & a_{2 i} & \cdots & a_{2 n} \\
\vdots & \vdots & & \vdots & & \vdots \\
a_{n 1} & a_{n 2} & \cdots & a_{n i} & \cdots & a_{n n}
\end{array}\right]
$$

Miernyk (1974) destaca que a tabela de coeficientes técnicos deve satisfazer a determinadas condições de estabilidade, que são: (a) a soma de pelo menos uma coluna na tabela deve ser menor ou igual a unidade e (b) nenhuma coluna na tabela deve somar mais que a unidade.

Pode-se estabelecer o seguinte conjunto de equações lineares para as dependências dos fluxos interindustriais sobre o produto total de cada setor: 


$$
\begin{aligned}
& X_{I}=a_{11} X_{I}+a_{12} X_{2}+\ldots+a_{1 n} X_{n}+Y_{I} \\
& X_{2}=a_{21} X_{1}+a_{22} X_{2}+\ldots+a_{2 n} X_{n}+Y_{2} \\
& \dot{X_{i}}=a_{i 1} \dot{X}_{I}+a_{i 2} \dot{X}_{2}+\ldots+a_{i n} \dot{X}_{n}+\dot{Y}_{i} \\
& \dot{X}_{n}=a_{n 1} \dot{X}_{I}+a_{n 2} \dot{X}_{2}+\ldots+a_{n n} \dot{X}_{n}+\dot{Y}_{n}
\end{aligned}
$$

O sistema (3-4) pode ser expresso em termos matriciais como

$$
X=A X+Y
$$

onde

$A$ é a matriz de coeficientes técnicos diretos de insumos de ordem $(n \times n)$;

$Y$ é um vetor coluna de ordem $(n \times 1)$.

Se a demanda final, $Y$, pode ser estimada exogenamente para um dado período de tempo, por exemplo, de um ano, pode-se resolver a equação (3-5) para a produção total, $X$, que é necessária para satisfazer esse nível de demanda final nesse período, da seguinte forma:

$$
X=[I-A]^{-1} Y
$$

onde $[I-A]^{-1}$ é a matriz de coeficientes técnicos de insumos diretos e indiretos, ou a matriz inversa de Leontief. Essa matriz mostra os insumos direta e indiretamente requeridos pela indústria para atender à demanda final da indústria $i$, isto é, se a indústria $i$ sofre uma elevação na demanda final por seus produtos, ela elevará sua demanda de insumos. $\mathrm{E}$, desde que os insumos da indústria $i$ são os produtos das outras indústrias, elas também elevarão suas compras de insumos tendo em vista a elevação da demanda 
por seus produtos. Isso levará a uma reação em cadeia refletindo na elevação do produto e do emprego por toda a economia. Desse modo, os elementos $b_{\mathrm{ij}}$ da matriz $[I-A]^{-I}$ mostram os requerimentos diretos e indiretos da produção total da indústria $j$, para entregar o produto correspondente à uma unidade monetária de demanda final da indústria $i$. Esses elementos têm as seguintes características:

a) $b_{i j} \geq a_{i j}$, o que significa que cada elemento da matriz inversa de Leontief é maior ou igual ao respectivo elemento da matriz tecnológica, tendo em vista que o elemento $b_{i j}$ indica os efeitos diretos e indiretos sobre a produção da indústria $j$ para atender a uma unidade monetária de demanda final da indústria $i$, por sua vez, o elemento $a_{i j}$ indica apenas os efeitos diretos; se $b_{i j}=a_{i j}$, significa que, nesse caso, os efeitos indiretos são nulos;

b) $b_{i j} \geq 0$, significa dizer que desde que os coeficientes técnicos de produção são fixos, a proporção entre os insumos é fixa, não havendo possibilidade de substituição entre eles. Assim, uma expansão na demanda final da indústria $i$ irá provocar um efeito positivo ou nulo sobre a produção da indústria $j$, não podendo ocorrer um efeito negativo; no caso de $b_{i j}=0$ significa que não há interdependência direta entre as indústrias $i \mathrm{e} j$;

c) $b_{i j} \geq 1$, se $j=i$, ou seja, os elementos da diagonal principal da matriz inversa de Leontief serão sempre iguais ou maiores que 1 , tendo em vista que um acréscimo de uma unidade monetária na demanda final de uma indústria deverá provocar uma expansão na produção dessa indústria de pelo menos uma unidade monetária.

A solução de um sistema de insumo-produto mostra os princípios da interdependência econômica, a estrutura da economia e a forma pela qual seus setores se interagem. Os coeficientes expressos pela matriz inversa de Leontief indicarão as indústrias que apresentam maiores interdependências que outras na economia em que estão inseridas.

O modelo de insumo-produto conforme descrito até aqui é conhecido como modelo estático. 


\subsubsection{Uma ilustração do sistema de insumo-produto}

O modelo básico de insumo-produto construído por Leontief descreve as relações de demanda e oferta de uma economia em equilibrio, permitindo pois evidenciar a estrutura produtiva do sistema econômico, apresentando um quadro de como esse sistema está operando e a forma como o produto de cada indústria é distribuído entre outras indústrias ou setores da economia. A Tabela 3.1 apresenta esse sistema de forma simplificada, cujas transações correspondem a um fluxo monetário para um período de um ano.

Deve-se ressaltar a diferença entre a demanda final por bens e serviços representada pela Demanda Final, na Tabela 3.1, e a demanda por bens e serviços como insumos para o processo de produção dos produtos finais pelo Setor de Processamento (demanda intermediária). As indústrias, representadas na matriz, recebem seus insumos primários do setor de pagamentos $(M+V)$ e compram seus fatores de produção secundários das indústrias na matriz. Elas entregam seus produtos para outras firmas no Setor de Processamento e para os componentes da Demanda Final (Familias, Governo, Formação Bruta de Capital (FBK) Privado, Exportações).

Os valores ao longo das linhas do Setor de Processamento representam como as indústrias (ou setores), em particular, distribuem ou vendem seus produtos, enquanto a leitura da coluna revela o padrão de insumos da indústria, ou seja, as compras feitas por elas.

Para cada indústria do Setor de Processamento o gasto total é igual ao produto total $(\Sigma W=\Sigma U)$. No setor de pagamentos pode-se verificar, por exemplo, que a indústria 1 compra o equivalente a $\mathrm{M}_{1}$ de insumos importados e adiciona $V_{l}$ ao produto total $X_{l}$. 
Tabela 3.1 - Modelo de insumo-produto aberto estático simplificado

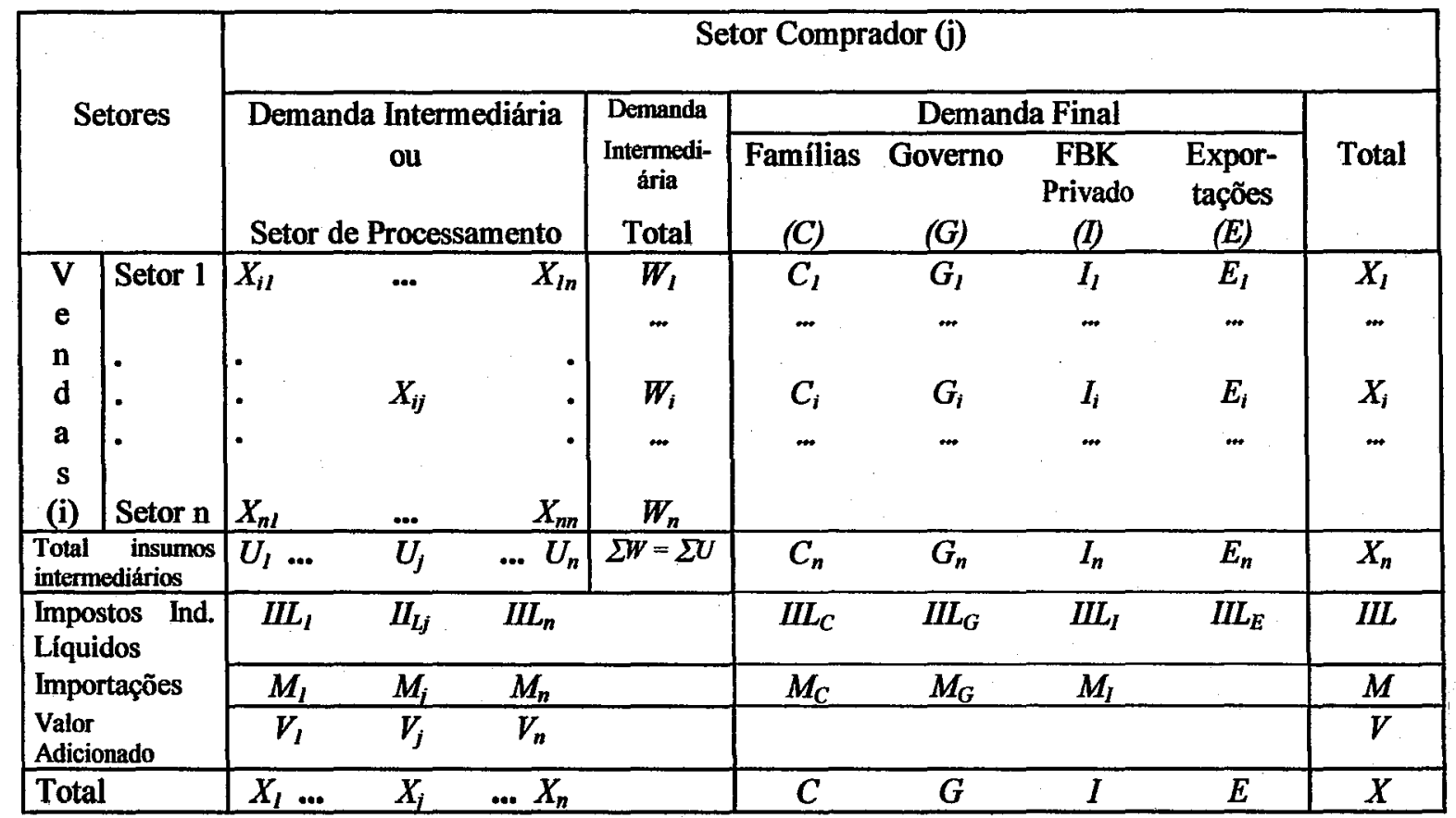

Fonte: Adaptada de Davis (1968).

O produto total na tabela, $X$, não corresponde ao produto nacional bruto da economia, pois na contabilização do PIB evita-se a dupla-contagem e, no caso da tabela de insumo-produto, todas as transações que ocorrem na economia são consideradas. Assim, as relações contábeis da tabela podem ser resumidas pela relação:

$$
\sum_{j} W_{j}+C_{j}+G_{j}+I_{j}+E_{j}=X=\sum_{j} U_{j}+V_{j}+M_{j}
$$

Como mencionado anteriormente, todas as transações registradas na tabela de insumo-produto são apresentadas sob a forma de fluxos monetários. No entanto, originalmente, sob o ponto de vista teórico, as variáveis seriam expressas em termos de relações físicas entre insumos e produtos, o que impossibilitaria a utilização dessas tabelas em termos empíricos. Devido a isso, muitas críticas são apresentadas sob a alegação de que, ao se estimar as matrizes do modelo a partir de fluxos monetários, os valores dos coeficientes poderiam ser afetados devido às mudanças nos preços relativos. 
Conforme Miller \& Blair (1985) uma forma encontrada para resolver esse problema foi assumir-se que os preços são constantes.

Outras críticas apresentadas ao modelo de insumo-produto referem-se ao período de análise. Nos modelos de insumo-produto estáticos, o fluxo de transações consideradas é o atual e, devido ao fato de os coeficientes técnicos serem fixos, as análises ficam restritas ao curto prazo.

Além disso, o modelo estático e aberto de insumo-produto considera os coeficientes técnicos fixos, o que significa que os insumos são utilizados em proporções fixas, isto é, retornos constantes de escala. Segundo Miernyk (1974), um argumento freqüentemente utilizado pelos críticos do modelo tem sido que, enquanto em uma economia algumas indústrias podem apresentar retornos de escala constantes, outras podem apresentar retornos crescentes ou decrescentes.

Outro ponto sujeito a crítica seria a utilização da técnica de insumo-produto como instrumento de previsão. Conforme enfatiza o mesmo autor

\footnotetext{
"devido d̀ incerteza e à presença de forças aleatórias, todas as previsões e projeções estão sujeitas a uma certa margem de erro". Acrescentando que "muitas técnicas de previsão são limitadas a amplos agregados, tais como o produto nacional bruto, a renda pessoal total $e$ emprego total. $O$ método de insumo-produto é empregado, no entanto, para fazer projeções altamente detalhadas de indústria por indústria, de setor por setor" (Miernyk, 1974, p.116).
}

Sonis \& Hewings, citados por Hewings (1991, p.7), consideram que uma das principais vantagens do sistema de insumo-produto tem sido a de representar, como uma fotografia, uma economia em um instante no tempo. Nesse modelo é relativamente fácil estabelecer as inter-relações que existem entre os setores da economia; no entanto, quanto mais os setores considerados tradicionalmente como componentes exógenas (demanda final ou insumos primários) são endogeneizados, re-especificados ou 
expandidos, o grau de complexidade aumenta. $\mathrm{E}$ quanto mais extensos e complexos, o 'grau de tratabilidade' desses modelos diminui.

Mesmo considerando essas limitações, os modelos de insumo-produto têm sido amplamente empregados pelos economistas para análises das relações interindustriais tanto em nível regional, quanto inter-regional e internacional.

E, conforme Hewings (1991, p.1) "a última década tem testemunhado um investimento substancial no desenvolvimento de novas abordagens para lidar com alguns dos principais problemas e limitações relativas ao uso dos modelos de insumo-produto, bem como tem-se desenvolvido novas formas em que esses modelos têm sido integrados com outras modelagens".

\subsection{Modelos de insumo-produto: uma análise regional e inter-regional}

As matrizes regionais e inter-regionais de insumo-produto vêm sendo amplamente utilizadas como instrumentos de análise econômica e de planejamento, voltados para estudos de diferenças regionais entre estruturas de produção, avaliação de efeitos interregionais de políticas de redistribuição geográfica de atividades econômicas, impacto de programas de investimentos públicos em diferentes regiões, elaboração de planos de desenvolvimento regional, entre outros.

A introdução teórica ao estudo de modelos de insumo-produto enfocando a análise inter-regional data de esforço conjunto de Leontief e Walter Isard. Do interesse pela análise multirregional, juntamente com Alan Strout (1963), Leontief desenvolveu um modelo de comércio inter-regional, conhecido como modelo gravitacional.

A respeito do modelo multirregional, Leontief e Strout caracterizam:

"Na análise multirregional de insumo-produto, o sistema econômico é descrito não apenas em termos de indüstrias interdependentes, mas também em termos de várias regiões inter-relacionadas. A produção de cada região é definida como uma combinação da produção de atividades 
econômicas realizadas dentro de suas fronteiras geográficas; conseqüentemente, seus insumos compreendem os insumos diretos dessas indústrias $e$ os bens e serviços absorvidos diretamente pelos setores de demanda final dessa região"(Leontief, 1983; p.117).

Ainda considerando o mesmo trabalho, esses autores ressaltam a questão das relações entre as regiões:

" $A$ interdependência econômica entre duas regiões e a interdependência entre as induistrias localizadas dentro de suas respectivas fronteiras é direta na medida em que os bens de consumo e serviços produzidos em uma região são absorvidos pelas indústrias ou pelos setores de demanda final da outra; é indireta (do ponto de vista regional) na medida em que a ligação entre tais insumos e produtos é estabelecida por meio de indústrias localizadas em outras regiões".

De acordo com Miller \& Blair (1985) são duas as características básicas da economia regional que influenciam os modelos regionais. A primeira, refere-se à estrutura de produção de uma região em particular, que pode ser idêntica à nacional ou extremamente diferente daquela representada na tabela de insumo-produto nacional; a segunda característica é que, em geral, as economias regionais são bem mais "abertas" que a economia nacional, isto é, dependem muito mais das relações de comércio com áreas fora da região - importação de insumos e exportação de produtos. A forma de incorporar as características regionais à estrutura de insumo-produto tem resultado em diferentes modelos, que podem se referir a uma única região - single region models - ou a duas ou mais regiões inter-relacionadas - many-region models - que compreendem os modelos inter-regionais e os modelos multi-regionais.

As principais vantagens de se construir matrizes de insumo-produto regionais, segundo Cao-Pinna (1961, p.305) são: 
a) a medida agregada do diferencial da renda entre as regiões de uma economia nacional não provêem a base necessária para a procura de uma abordagem racional para os problemas de alocação dos investimentos públicos. Uma descrição desagregada das estruturas das economias regionais e das capacidades atuais e potenciais dos mercados, provêem, entretanto, uma base real para uma discussão construtiva e crítica para a escolha da localização dos investimentos públicos;

b) o conhecimento da posição funcional de cada setor dentro da economia regional e nacional pode auxiliar no estabelecimento de prioridades de assistência financeira que possam ser concedidas aos programas de investimentos privados;

c) a construção de matrizes de insumo-produto regionais torna necessária a determinação dos fluxos inter-regionais de mercadorias e serviços individuais ou em grupo e, então, permite a mensuração das interdependências estruturais entre as regiões estudadas e o resto da economia nacional ou outras regiões;

d) sob o ponto de vista metodológico, a abordagem de insumo-produto oferece muitas vantagens associadas às facilidades de coordenação das estatísticas regionais e ao teste de consistência das estimativas diretas dos produtos brutos regionais. A segmentação do produto bruto por setor de origem provê um detalhado sistema de pesos que são necessários para a construção de índices de preços e de produção regional permitindo, então, um acompanhamento das mudanças reais na estrutura da economia regional, bem como nas tendências dos termos de comércio inter-regional com o resto da economia nacional ou com outras áreas.

Uma importante distinção entre os modelos regionais e inter-regionais é apresentada por Miernyk (1975, p.69), que considerou como modelos regionais aqueles semelhantes aos nacionais e, adicionalmente, pode ser um modelo equilibrado; enquanto nos modelos inter-regionais, um único modelo compreende mais de uma região, podendo ainda diferenciarem-se dos modelos regionais sendo classificados de modelos interregionais puros.

De acordo com o citado autor, os modelos regionais equilibrados são construídos através da desagregação da Matriz de Insumo Produto (MIP) nacional em suas regiões 
componentes. Já os modelos inter-regionais puros são obtidos a partir da agregação de um certo número de tabelas regionais.

Segundo a abrangência da análise de insumo-produto regional, Davis $(1968$, p.29) chamou a atenção para as três abordagens tradicionais de definição de uma região. A primeira delas enfatiza a homogeneidade, com respeito a características particulares tais como aspectos geográficos, critérios econômicos, características sociais, etc. A segunda concentra-se no conceito de polarização e, em geral, refere-se a um complexo urbano. $\mathrm{E}$ a terceira abordagem, a administrativa ou politicamente orientada, refere-se a uma área definida politicamente como uma cidade, um país, etc.

Isard (1960, p.311) em discussão sobre o uso da análise de insumo-produto para estudos regionais ou inter-regionais salientou que é desejável ver as regiões completamente e definir nações como aqueles tipos de regiões delimitadas politicamente, culturalmente, e com barreiras e linhas institucionais similares. Por essa definição, a análise de insumo-produto nacional torna-se uma forma especial da análise de insumoproduto regional que, por sua vez, é uma forma especial da análise inter-regional. Por essa convenção, a análise de insumo-produto internacional torna-se uma forma especial da análise de insumo-produto inter-regional - a forma mais geral. Ainda, segundo o autor, as convenções utilizadas dependem dos propósitos do estudo e das inclinações do investigador.

Os modelos, segundo sua abrangência, podem ser:

a) Modelo para Uma Região (Single-Region Model): segundo essa abordagem uma região de interesse é "desconectada" do resto do país no qual está inserida. Em geral esses estudos tentam quantificar os impactos sobre os setores da região de interesse que são causados por uma alteração na demanda final pelos produtos produzidos nessa região.

Os primeiros estudos que utilizaram essa abordagem utilizaram os coeficientes técnicos da tabela nacional com ajustamentos para capturar algumas características da economia regional. O principal problema desses estudos foi o fato de a matriz de coeficientes técnicos disponível ter sido a nacional e que, não necessariamente, mostrava 
os insumos das firmas na região usados para produção naquela mesma região. A obtenção da matriz de coeficientes técnicos regionais dessa forma, implicava em se assumir que a tecnologia de produção, de cada setor da região, seria a mesma da nação como um todo.

Outros estudos apresentaram uma variação utilizando uma estimativa do percentual do produto total de cada setor que poderia ter se originado na própria região e, uma vez determinado esse percentual, cada elemento da matriz de coeficientes técnicos nacional poderia ser utilizado para estimar a matriz de coeficientes técnicos regionais.

Um dos principais problemas dos modelos para uma única região é que eles ignoram os efeitos sobre a atividade regional induzidos pelos fluxos de comércio interregionais pelo mecanismo de realimentação (feed-back).

b) Modelo para Várias Regiões (Many-Region Model): esses modelos se aplicam para várias regiões e tentam captar as ligações inter-regionais bem como aspectos intraregionais da produção.

A principal dificuldade para implementação empírica desses modelos refere-se ao grande número de dados requeridos, principalmente os relativos aos fluxos de comércio inter-regionais.

Bulmer-Thomas (1982, p.169) ressaltou que na construção de uma tabela de insumo-produto regional muitas fontes que irão ser usadas serão similares às utilizadas para a construção das tabelas nacionais e muitos dados podem ser obtidos por meio de surveys (ou métodos censitários). Entretanto, dificilmente irão existir detalhes sobre as transações intra-regionais ou sobre os fluxos de comércio extra-regionais, incluindo aqueles para e do resto do mundo. Para evitar esse problema, muitos analistas têm assumido que os coeficientes técnicos regionais são os mesmos que os coeficientes técnicos nacionais; entretanto, não há nenhuma evidência de que esse pressuposto seja verdadeiro.

Numa tentativa de superar esse problema tem-se utilizado a matriz de insumoproduto nacional como ponto de partida e, embora persista o problema da estimativa das 
matrizes de transações intra-regionais e dos fluxos de comércio extra-regionais, têm sido propostos métodos nonsurvey (ou métodos não-censitários) para estimá-las.

Numa descrição sumária desses métodos tem-se:

a) Métodos Nonsurvey: Esses métodos podem ser utilizados na construção tanto de matrizes para modelos regionais ou inter-regionais, podem ainda ser classificados como técnicas de regionalização puramente nonsurvey ou parcial-survey. As técnicas puramente nonsurvey são aquelas que estimam os coeficientes de insumos regionais através do ajustamento dos coeficientes técnicos nacionais inteiramente com base em informações publicadas sobre o emprego, a renda ou o produto regional, por indústria.

Dentre os métodos nonsurvey destaca-se a versão do quociente locacional. A técnica do quociente locacional simples tem demonstrado empiricamente apresentar resultados tão bons ou melhores que várias outras técnicas de quocientes em versões mais complicadas. Conforme Souza (1997, p.2), o quociente locacional é uma técnica amplamente utilizada em estudos de Economia Regional cujo objetivo seria obter uma primeira aproximação dos valores de determinadas variáveis para uma região, cujos valores já são conhecidos no nível nacional e foram obtidos através de dados censitários. Ressaltando-se que a suposição implícita da técnica é a de que a economia regional mantém a mesma estrutura da economia nacional em relação ao setor $i$.

Segundo Miller \& Blair (1985, p.296-297), sendo dados o produto bruto do setor $i, X_{i}^{R}$, e o produto total, $X^{R}$, de uma determinada região $R$ e, similarmente, os produtos $X_{i}^{N}$ e $X^{N}$ representando estes os totais ao nível nacional, então, o quociente locacional para o setor $i$ na região $R$ pode ser definido como:

$$
L Q_{i}^{R}=\left[\frac{X_{i}^{R} / X^{R}}{X_{i}^{N} / X^{N}}\right]
$$

onde $L Q_{i}^{R}$ é o quociente de localização simples.

Numa estimativa dos coeficientes regionais a partir dos coeficientes nacionais, $o$ quociente locacional simples é interpretado como uma medida da capacidade da indústria 
regional $i$ atender às demandas feitas a ela por outras indústrias na região e à demanda final regional. Se a indústria $i$ for menos concentrada na região $R$ que no país $\left(L Q_{i}^{R}<1\right)$, ela será vista como menos capaz de satisfazer à demanda regional por seus produtos e, seus coeficientes técnicos regionais de insumos diretos, $a_{i j}{ }^{R R}$, serão estimados a partir dos coeficientes nacionais $\left(a_{i j}{ }^{N}\right)$ multiplicados por $L Q_{i}^{R}$. Entretanto, se a indústria está mais concentrada na região que no país como um todo $\left(L Q_{i}^{R}>1\right)$, então assume-se que os coeficientes nacionais serão aplicados para a região e o excedente regional produzido por $i$ será exportado para o resto do país. Então, para a linha $i$ da tabela regional estimada tem-se:

$$
a_{i j}^{R R}=\left\{\begin{array}{l}
a_{i j}^{N} \text { se } L Q^{R} \geq 1 \\
a_{i j}^{N}\left(L Q^{R}\right) \text { se } L Q^{R}<1
\end{array}\right.
$$

Um problema que pode surgir a partir das estimativas do produto da indústria regional, que são obtidas a partir dos coeficientes calculados pelo quociente locacional, é que tais estimativas de produto podem exceder o produto atual de algumas indústrias. Esses coeficientes deverão ser balanceados para que seja assegurado que o produto regional por setor não seja superestimado. $O$ método de balanceamento consiste em reduzir uniformemente as estimativas dos $a_{i j}{ }^{R R}$ quando os coeficientes regionais estimados geraram um produto muito grande para o setor $i$.

Bulmer-Thomas (1982, p.134-135) apresentou quatro formas de resolver o problema de balanceamento de uma matriz, podendo cada uma delas ser descrita formalmente como a minimização de uma função sujeita à restrição de uma linha ou coluna conhecidas. Entre essas técnicas, a mais comumente utilizada em análises de insumo-produto é o método $\mathbf{R A S}^{18}$ ou método biproporcional.

\footnotetext{
${ }^{18}$ Para maior detalhamento sobre o método RAS, ver Bacharach (1970), Miller \& Blair (1985) ou Bulmer-Thomas (1982).
} 
Mayer \& Pleeter (1975) criticaram as estimativas de matrizes regionais por meio da técnica do quociente locacional segundo sua definição tradicional. Esses autores consideraram que a orientação comercial de uma indústria em uma dada região depende não só do valor do quociente locacional mas, também, das diferenças entre as rendas per capitas e das diferenças nos gostos dos consumidores. Concluíram que, sendo a técnica do quociente locacional amplamente utilizada pelos economistas regionais, para melhorar seu suporte teórico, dever-se-ia incorporar a variável renda per capita (eliminando a suposição de que a renda média entre as regiões é zero - que, segundo os autores, é inconsistente) e as diferenças nos gostos dos consumidores (consideraram que essas diferenças afetam as exportações, influenciando, dessa forma, a orientação comercial da região em questão). Embora apresentassem tal argumentação, consideraram que as dificuldades para implementação empírica do modelo podem ser grandes face a insuficiência de dados estatísticos.

b) Métodos Survey: Esses métodos também se aplicam tanto à construção de matrizes de insumo-produto regionais quanto inter-regionais. Parece haver um consenso na literatura que a utilização dessa metodologia seria a mais apropriada para o estabelecimento das MIP's regionais ou inter-regionais. Entretanto, ao se enfocar o assunto sob o ponto de vista prático, a maioria das opiniões concentram-se nas dificuldades encontradas para sua aplicação, sendo enfatizada a grande quantidade e variedade de dados requeridos, quais sejam: a) dados quantitativos da produção de cada setor, por produto; b) dados quantitativos dos insumos consumidos por cada setor; c) preços praticados localmente, por produto, em nivel de produtor, atacado e varejo; d) impostos indiretos que incidem sobre os vários grupos de produtos; e) variações de estoques para os principais grupos de produtos; e f) dados sobre emprego e salário, relativos a cada setor.

\subsection{Os modelos de análises inter-regionais}

A teoria do insumo-produto regional é desenhada para revelar todas as interdependências diretas e indiretas entre as regiões. As análises de interdependências 
regionais desagregam os totais de produção e consumo em termos de produtos ou indústrias; a teoria inter-regional, da mesma forma, desagrega esses totais por produtos e, adicionalmente, os considera em termos de localização geográfica. $O$ modelo interregional concentra-se nas relações da economia não somente dentro de cada região mas, também, entre regiões. (Davis, 1968).

Segundo Bulmer-Thomas (1982; p.219) os modelos de insumo-produto interregionais são de três tipos:

a) os modelos que requerem a apresentação de uma matriz de fluxos inter-regionais completa, tendo como exemplo o modelo inter-regional "ideal" de Isard (1951);

b) os modelos que assumem uma certa estabilidade nos padrões de comércio dentro de uma região, tais como o modelo de coeficiente coluna de Chenery (1951) e Moses (1955), o modelo de coeficiente linha, de Hansen e Tiebout (1963) e Polenske (1970) e o modelo Gravitacional, de Leontief e Strout (1963);

c) aqueles que derivam os totais regionais essencialmente de um modelo de insumoproduto nacional, como o modelo intranacional de Leontief (1953).

Conforme Richardson (1972, p.56) o principal problema dos modelos interregionais refere-se ao fato de eles não terem um mecanismo para explicar os padrões de comércio, embora, ressalte que a derivação dos fluxos de comércio inter-regionais seja a principal característica que distingue os modelos de insumo-produto inter-regionais.

Para melhor compreensão dos modelos inter-regionais pode-se formalizar sua apresentação, reportando-nos à descrição apresentada em Miller \& Blair (1985; p.5459), conforme o que segue.

Considerando-se apenas duas regiões que produzem $n$ mercadorias, a estrutura básica do modelo inter-regional pode ser descrita como sendo as duas regiões representadas, respectivamente, por $G$ e $H$, e conhecidos os fluxos $z_{i j}{ }^{G H}, z_{i j}{ }^{G G}$, para a primeira região, e $z_{i j}^{H G}, z_{i j}^{H H}$, para a segunda, a equação básica do modelo, para a região $G$, por exemplo, pode ser expressa por:

$$
X_{i}^{G}=z_{i 1}^{G G}+z_{i 2}^{G G}+\ldots+z_{i i}^{G G} \ldots+z_{i n}^{G G}+z_{i 1}^{G H}+\ldots+z_{i n}^{G H}+Y_{i}^{G}
$$


Nesse modelo, exclui-se da demanda final, $Y_{i}^{G}$, as vendas para os setores produtivos da região $H$. Deve-se lembrar que os $z_{i j}{ }^{G H}$ e $z_{i j}{ }^{H G}$ explicitam as ligações interregionais, ou seja, referem-se ao comércio regional ou fluxos de comércio regional; e os elementos de $z_{i j}{ }^{G H}$, por exemplo, representam as exportações da região $G \mathrm{e}$ simultaneamente as importações da região $H$; o mesmo raciocínio se aplica para os $z_{i j}{ }^{H G}$.

$\mathrm{O}$ coeficiente de insumos regional para as regiões $G$ e $H$ é expresso por:

$$
a_{i j}^{G G}=\frac{z_{i j}^{G G}}{X_{j}^{G}} \quad \text { e } \quad a_{i j}^{H H}=\frac{z_{i j}^{H H}}{X_{j}^{H}}
$$

onde:

$z_{i j}^{G G}$ representa o fluxo, em unidades monetárias, dos produtos do setor $i$ da região $G$ para o setor $j$ da região $G\left(z_{i j}^{H H}\right.$ tem o mesmo significado para a região $\left.H\right)$; $X_{j}^{G}$ e $X_{j}^{H}$, representam, respectivamente, a produção total do setor $j$ nas regiões $G$ e $H$.

$O$ coeficiente de comércio inter-regional da região $G$ para a região $H$ é obtido por meio de:

$$
a_{i j}^{G H}=\frac{z_{i j}^{G H}}{X_{j}^{H}}
$$

onde:

$z_{i j}^{G H}$ representa o fluxo, em unidades monetárias, dos produtos do setor $i$ da região $G$ para o setor $j$ da região $H$; $X_{j}^{H}$ representa o valor da produção total do setor j da região $H$.

Uma matriz completa de coeficientes para as duas regiões no modelo interregional pode ser representada por quatro sub-matrizes como:

$$
A=\left[\begin{array}{c:c:c}
A G G & G H \\
\hdashline A \bar{H} \bar{G} & A \\
\hdashline A \bar{H}
\end{array}\right]
$$


O vetor do produto bruto regional, $(X)$, contém os produtos das duas regiões:

$$
X=\left[\begin{array}{l}
X_{-}^{G} \\
X^{\bar{H}}
\end{array}\right]
$$

Enquanto o vetor da demanda final regional contém os vetores das demandas finais das duas regiões:

$$
Y=\left[\begin{array}{l}
\underline{Y} \\
\underline{Y}^{-}
\end{array}\right]
$$

O modelo completo inter-regional pode ser representado por:

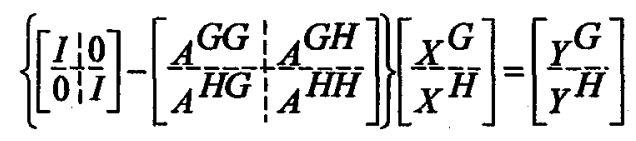

onde:

$I$, na primeira matriz, representa a matriz identidade. As demais matrizes foram definidas anteriormente.

Modelos de insumo-produto inter-regionais como (3-16) estão sujeitos às seguintes pressuposições: a) os coeficientes de insumos regionais $\left(a_{i j}{ }^{G G}\right.$ e $\left.a_{i j}{ }^{H H}\right)$, necessariamente, devem ser estáveis; b) os coeficientes inter-regionais de comércio $\left(a_{i j}{ }^{G H}\right.$ e $\left.a_{i j}{ }^{H G}\right)$ são estáveis ao longo do tempo. Essas pressuposições implicam em se assumir que tanto a estrutura de produção em cada região como os padrões de comércio entre elas não se alteram no período analisado.

Miller \& Blair (1985, p.58) apresentaram como uma grande vantagem desses modelos o fato de eles captarem a magnitude dos efeitos sobre cada região; as ligações inter-regionais especificadas por setor na região fornecedora e por setor na região receptora. Entretanto, apresentam as desvantagens de se necessitar de um grande volume 
de dados para executá-los empiricamente, além da necessidade de se pressupor que as relações de comércio entre as regiões sejam constantes.

Com base no exposto e visando apresentar as especificidades dos principais modelos inter-regionais far-se-á uma breve descrição dos mesmos na próxima seção.

\subsubsection{O modelo "ideal" de Isard}

O modelo proposto por Isard, em 1951, parte do pressuposto que os fluxos de comércio inter-regionais ocorrem devido a dois fatores básicos: i) a existência de desigualdades geográficas na população, renda e recursos; e ii) a indivisibilidade da produção, da especialização, e as conseqüentes economias de escala. Desse modo, sustenta que se deva considerar nos modelos inter-regionais a heterogeneidade do mercado e as diferenças entre os bens e serviços produzidos nas diversas regiões geográficas. Deverão ser construídas tabelas de insumo-produto para cada região e também os fluxos inter-regionais setor por setor, por região de origem e região de destino.

Um dos importantes pressupostos do modelo é que um dado bem ou serviço produzido por uma região é diferente do mesmo bem ou serviço produzido em outra região.

O modelo de "ideal" de Isard permite incorporar tantas matrizes tecnológicas diferentes como as existentes nas regiões analisadas, deriva os fluxos de comércio e suas origens e destinos a partir de dados primários e requer a especificação da demanda final para todos os bens nacionais. Isso significa que um aumento na demanda final por um bem nacional irá produzir diferentes resultados dependendo da distribuição geográfica desse aumento na demanda final.

De acordo com Richardson (1972, p.58-59), o modelo implica que a proporção de um dado insumo, $i$, importado de uma determinada região, $G$, para ser usado por um determinado setor "comprador", $j$, localizado em uma região, $H$, deve ser constante. 
Essa pressuposição estabelece que a estrutura espacial do sistema inter-regional, bem como a estrutura tecnológica em cada economia regional, deve ser mantida constante.

$O$ modelo pode ser expresso, considerando a equação básica de insumo-produto $($ Produto Bruto $=$ Demanda intermediária + Demanda final $)$, como:

$$
\begin{aligned}
X_{i}^{G}=\sum_{H}^{n} \sum_{j}^{m} X_{i j}^{G H}+\sum_{H}^{n} Y_{i}^{G H} & (i, j=1, \ldots, m) \\
& (G, H=1, \ldots, n)
\end{aligned}
$$

Existirão $\mathrm{nm}$ equações. $\mathrm{O}$ produto de cada indústria em cada região corresponde às suas vendas para todas as indústrias e para os setores da demanda final (incluindo os da própria região). Os coeficientes de comércio inter-regional interindustriais são obtidos por:

$$
a_{i j}^{G H}=\frac{x_{i j}^{G H}}{X_{j}^{H}}
$$

onde:

$x_{i j}^{G H}=$ a quantidade de produto da indústria $i$ na região $G$ vendida para a indústria $j$ na região $H$;

$X_{j}^{H}=$ ao produto total da indústria $j$ na região $H$.

Substituindo (3-18) em (3-17) obtém-se:

$$
X_{i}^{G}=\sum_{H}^{n} \sum_{j}^{m} a_{i j}^{G H} X_{j}^{H}+\sum_{H}^{n} Y_{i}^{G H}
$$

Um dos passos importantes do modelo é a derivação dos coeficientes $a_{i j}^{G H}$, uma vez que para sua obtenção são necessários os fluxos de comércio por região de origem e destino bem como por indústria/setor produtor e comprador. 
Deve-se ressaltar que um dos seus pontos críticos é a pressuposição de estabilidade dos coeficientes de comércio entre as regiões.

A implementação empírica desse modelo tem sido limitada pois exige um grande volume de informações, um grande esforço matemático para estimar os fluxos interregionais de mercadorias, além do custo elevado. Uma das primeiras tentativas para sua implementação empírica refere-se a uma série de surveys com tabelas de insumo-produto do Japão $(1960,1964,1969,1974)$, havendo também um esforço para a construção de matrizes inter-regionais para a Holanda (1981), conforme mencionaram Miller \& Blair (1985, p.54). Estudos recentes que utilizaram o modelo foram realizados por Montoya (1998), na construção e implementação do modelo insumo-produto internacional do Mercosul, e por Crocomo (1998), na construção da matriz inter-regional do Brasil de 1985.

Visando tornar o modelo de Isard operacional, vários modelos simplificados foram desenvolvidos. Uma breve descrição desses modelos será feita a seguir, enfatizando o tratamento dado aos fluxos de comércio inter-regionais e, em seguida, será selecionado aquele modelo que se mostra mais adequado aos propósitos do presente estudo.

\subsubsection{O modelo Chenery-Moses ou modelo modificado de Isard}

Os modelos de Chenery - desenvolvido para estudar as interdependências entre as regiões norte e sul da Itália, e Moses - uma análise das interdependências da economia dos EUA, cada qual desenvolvido independentemente do outro, representam esforços para satisfazer os requerimentos estatísticos do modelo básico de Isard, numa tentativa de simplificar os pressupostos do mesmo para torná-lo aplicável empiricamente ${ }^{19}$.

No modelo proposto - modelo de coeficiente coluna - estabelece-se a hipótese simplificadora que as importações da mercadoria $i$, na região $j$ irão ser distribuídas

\footnotetext{
${ }^{19}$ De acordo com Davis (1968, p.82), um modelo semelhante foi desenvolvido por Wonnacott (1961), para estudar as interdependências entre EUA e Canadá.
} 
através dos setores da região $j$ da mesma forma que o produto da mercadoria $i$ é produzido na região $j$, ou seja, o número de regiões e de setores é dado e cada região importa uma proporção fixa de suas necessidades de determinado produto, de uma região específica; desse modo, cada setor segue o mesmo padrão da região como um todo.

Tem-se, então que:

$$
X_{i}^{G H}=t_{i}^{G H} X_{i}^{H H}
$$

onde $X_{i i}^{G H}$ é a quantidade total da mercadoria $i$, produzida na região $G$, que é comprada pelo setor $j$ na região $H$ e $t_{i}^{G H}$ é a proporção das compras totais da mercadoria $i$ feitas pelo setor $j$ da região $H$ que vêm da região $G$. Os termos $t_{i j}^{G H}$ são os coeficientes de oferta do modelo de Chenery e os coeficientes de comércio do modelo de Moses. Notese que os modelos assumem que:

$$
t_{i}^{G H}=t_{i j}^{G H} \quad \text { para todo } j
$$

Nesses modelos, os fluxos de comércio inter-regional são definidos mais em termos de coeficientes de mercadorias do que coeficientes interindustriais devido a suposição que o fluxo de importação de cada setor regional segue o padrão médio da região como um todo.

Para que o modelo Chenery-Moses possa ser aplicado empiricamente necessitase, basicamente, de: a) que estimativas por mercadoria e por região de origem e destino do comércio inter-regional estejam disponíveis para um ano-base; b) a confiabilidade da estabilidade dos coeficientes de comércio. Essas informações nem sempre são obtidas diretamente. 
Usualmente, quando os fluxos de comércio não estão disponíveis, pode-se estimá-los por meio de métodos indiretos. $O$ modelo Gravitacional, que será apresentado nas próximas seções, é um dos métodos que permite tais estimativas.

Uma das principais críticas relativas ao modelo refere-se à manutenção da pressuposição da estabilidade dos coeficientes de comércio. Segundo Richardson (1972, p.64), Moses considerou a possibilidade de que sempre que houverem evidências que esses coeficientes se alteraram, devido a mudanças nos processos técnicos de produção ou nos padrões de transações inter-regionais, os coeficientes individuais poderão ser ajustados, e os novos coeficientes substituídos.

O modelo de Chenery-Moses tem sido aplicado em diversos estudos empíricos inter-regionais como o de Hartwick (1969), citado por Cavalcanti (1990), sobre o leste canadense, o de Haddad \& Andrade (1974), que construíram um modelo para examinar a questão da substituição do imposto de vendas e consignações (IVC) pelo imposto de circulação de mercadorias (ICM) que estaria prejudicando os estados menos desenvolvidos do Brasil, o de Cavalcanti (1990), que construiu um modelo inter-regional para examinar o impacto de mudanças exógenas sobre a produção, a renda e o emprego na região Nordeste brasileira, no período 1975 a 1980, o de Pereira (1993), que construiu um modelo multirregional para o Brasil, considerando duas regiões Nordeste e Resto do Brasil, utilizando-o para analisar os impactos econômicos da agricultura irrigada no Nordeste, e o de Fernandes (1997), que utilizou o modelo inter-regional para analisar o padrão da interação entre a economia de Minas Gerais e do Resto do Brasil.

Outros modelos que também seriam adequadamente classificados como aqueles que assumem certa estabilidade nos padrões de comércio seriam o modelo de coeficiente linha, proposto por Hansen \& Tiebout (1963) e aplicado por Polenski (1970) e o modelo multirregional - ou modelo gravitacional de comércio inter-regional - de Leontief \& Strout (1963). Esses modelos serão apresentados a seguir. 


\subsubsection{O modelo do coeficiente linha}

Esse modelo foi apresentado por Hansen \& Tiebout (1963), para aplicação em um modelo para uma região. Polenske (1970) também utilizou-o em seus estudos sobre a economia japonesa.

Basicamente o modelo coeficiente linha é análogo ao do coeficiente coluna, entretanto distribui a produção regional entre o mercado doméstico e as exportações para outras regiões. A principal característica do modelo é considerar que a proporção do produto vendido por uma região permanece constante independente do nível da demanda em qualquer uma das outras regiões.

Essa característica é teoricamente inaceitável, pois infringe as pressuposições Walrasianas dos modelos de insumo-produto segundo as quais mudanças no produto são geradas somente por deslocamentos na demanda e por mudanças nos preços por deslocamentos na oferta (Richardson, 1972, p.67).

\subsubsection{O modelo de Leontief-Strout ou modelo gravitacional de fluxo de comércio inter-regional}

Segundo Leontief \& Strout $(1967 ;$ p.119) a interdependência econômica entre duas regiões pode ser compreendida como a interdependência entre as indústrias localizadas dentro de suas fronteiras. Essa interdependência é direta na medida em que os bens e serviços produzidos em uma região são absorvidos por outras indústrias ou pelos setores da demanda final de outra; ela é indireta, sob o ponto de vista regional, na medida em que a conexão entre os insumos e produtos é estabelecida através de indústrias localizadas em outras regiões.

Os autores acrescentam que todos os movimentos de uma mercadoria ou serviços dentro de uma economia multirregional podem ser visualizados como deslocamentos de um "pool" de oferta para um "pool" de demanda regional daquele bem. Isso significa que as indústrias são indiferentes quanto à origem dos insumos que utilizam, desde que 
eles sejam idênticos. Da mesma forma, as indústrias fornecedoras não se preocupam com o destino do seu produto (Richardson, 1972, p.72). Partindo desse pressuposto, desenvolveu-se um sistema de equilibrio geral que consiste em um conjunto de sistemas de insumo-produto interindustrial regional desenhado para agrupá-los, ou seja, juntar um sistema de relações inter-regionais construído separadamente.

O modelo de Leontief-Strout ou modelo gravitacional de fluxo de comércio interregional, envolve a utilização de probabilidades para predizer os fluxos inter-regionais de mercadorias. Pressupõe que as exportações de mercadorias de uma região para outra são diretamente proporcionais à sua produção total na região de origem e ao seu consumo total na região de destino e inversamente proporcionais à distância entre as duas regiões.

A forma de estimar os fluxos inter-regionais, assumida pelos autores, exige poucas informações estatísticas e não apresenta maiores dificuldades para sua operacionalização computacional, facilitando sua implementação do ponto de vista empírico. Além disso, permite a existência de comércio simultâneo de uma mesma mercadoria entre duas regiões.

Considerando o seguinte sistema inter-regional no qual existem $n$ mercadorias comercializadas entre $m$ regiões, para qualquer bem $i$, considerado homogêneo, onde $X_{i}^{o g}$ é o produto total (produção + importações - exportações) do bem $i$ na região $g, X_{j}^{g o} o$ produto do bem $j$ na região $g$ e $Y_{i}^{g}$ a demanda final do bem $i$ na região $g$, sendo $a_{i j}^{g}$ os coeficientes técnicos descrevendo a quantidade do bem $i$ requerida para produzir uma unidade do bem $j$ na região $g$, tem-se:

$$
X_{i}^{o g}=\sum_{j=1}^{n}\left[a_{i j}^{g} X_{j}^{g 0}\right]+Y_{i}^{g}
$$

$$
\begin{aligned}
& (i=1, \ldots, n) \\
& (g=1, \ldots, m)
\end{aligned}
$$


O sistema de equações (3.22) descreve, para uma região $g$, o equilíbrio entre o total do insumo e produto interno do bem $i$, os produtos de todos os outros bens a a demanda (interna) final regional do bem $i$.

As equações estruturais do sistema que expressam todos os fluxos inter-regionais para qualquer mercadoria ou serviço $i$, têm a forma geral do conjunto (3.23) onde $X_{i}^{\text {go }}$ representa a produção total do bem $i$ na região $g, X_{i}^{\text {oh }}$ representa o consumo total do bem $i$ na região $h$ (ofertado pela região $g$ ), e $X_{i}^{o o}$ a quantidade agregada do bem $i$ produzido e consumido em todas as regiões da economia (ou seja, a produção agregada de $i=$ ao consumo agregado de $i$ ), sendo:

$$
\begin{aligned}
& X_{i}^{g h}=\frac{X_{i}^{g o} X_{i}^{o h}}{X_{i}^{o o}} Q_{i}^{g h} \\
& (i=1, \ldots, n) \\
& (g \neq h) \\
& (g, h=1, \ldots, m)
\end{aligned}
$$

O fluxo de um bem $i$ em particular, da região $g$ para qualquer outra região $h$ é considerado como sendo diretamente proporcional ao produto total da região $g$ para a região $h$, e inversamente proporcional à quantidade agregada da mercadoria $i, X_{i}^{o o}$ $\left(=\sum_{g=1}^{m} X_{i}^{g o}=\sum_{h=1}^{m} X_{i}^{a h}\right)$, produzida e consumida em todas as regiões da economia. Os coeficientes $Q_{i}^{g h}$ refletem os custos de transferência do bem $i$ da região $g$ para a região $h$. Considerando que a grande dificuldade para implementação empírica do modelo é a inexistência de informações estatísticas sobre os fluxos inter-regionais dos bens e serviços $i$, Leontief \& Strout (1967) sugeriram, como uma forma para superar essa dificuldade, estimar as constantes $Q_{i}^{g h}$ indiretamente. Entre os métodos sugeridos pelos autores, dois serão apresentados, o método de Estimativa no Ponto (Single Point Estimative Method) e o método da Solução Exata (Exact Solution Method). 
O primeiro método de estimativa dos $Q_{i}^{g h}$ consiste em, a partir dos valores do total regional de insumos e produtos regionais de um ano-base e de informações suplementares sobre as distâncias inter-regionais ou sobre os custos unitários de transporte, obter os valores correspondentes e aplicá-los ao sistema (3-23), estimando, então, os fluxos dos anos desejados.

Caso não estejam disponíveis informações sobre os fluxos de comércio em um ano-base, os valores dos $Q_{i}^{g h}$ podem ser estimados por meio de:

$$
\begin{array}{ll}
Q_{i}^{g h}=\left(C_{i}^{g}+K_{i}^{h}\right) d_{i}^{g h} \delta_{i}^{g h} & \\
& (g=1, \ldots, m) \\
& (h=1, \ldots, m)
\end{array}
$$

onde $d^{g h}$ é uma medida do inverso do custo de transporte de uma unidade da mercadoria $i$ da região $g$ para a região $h$. $\delta^{g h}$ é um parâmetro introduzido para limitar o número de variáveis no sistema. Se, por alguma razão econômica, nenhuma exportação da mercadoria $i$, de $g$ para $h$, ocorrer, então $\delta_{i}^{g h}=0$; caso contrário, $\delta_{i}^{g h}=1$. As constantes $C_{i}^{g}$ e $K_{i}^{h}$ são parâmentros que caracterizam de uma forma resumida a posição relativa das região $g$ vis-à-vis a todas as outras regiões como exportadora e, da região $h$, como ofertadora do bem $i$.

O conjunto de equações representado por (3-22) constitui a parte intra-regional do sistema. A parte inter-regional do sistema pode ser obtida por:

$$
X_{i}^{g o}=\frac{X_{i}^{g o} \sum_{r=1}^{m}\left[X_{i}^{o r} Q_{i}^{g r}\right]}{X_{i}^{o o}}+X_{i}^{g g}
$$

$$
\begin{aligned}
& \left(Q^{g g}=0\right) \\
& (g=1,2, \ldots, m) \\
& (i=1,2, \ldots, n)
\end{aligned}
$$




$$
X_{i}^{o h}=\frac{X_{i}^{o h} \sum_{r=1}^{m}\left[X_{i}^{r o} Q_{i}^{r h}\right]}{X_{i}^{o o}}+X_{i}^{h h}
$$

$$
\begin{aligned}
& \left(Q_{i}^{h h}=0\right) \\
& (h=1,2, \ldots, m) \\
& (i=1,2, \ldots, n)
\end{aligned}
$$

O termo $X_{i}^{g g}$ corresponde a parte do produto que é consumida pelas indústrias da região $g$. Similarmente, o termo $X_{i}^{h h}$ corresponde a parte do produto que é consumida pelas indústrias da região $h$, nos respectivos sistemas.

Tem-se, dessa forma, o modelo gravitacional de fluxo de comércio inter-regional completo.

\subsubsection{O modelo intranacional}

Esse modelo inter-regional é derivado a partir da desagregação da matriz de insumo-produto nacional, uma vez que separa a economia nacional em suas regióes componentes.

O modelo intranacional de Leontief (1953) parte da observação que enquanto alguns bens são consumidos próximos aos seus pontos de produção, outros são transportados por distâncias consideráveis antes de serem consumidos. As mercadorias são classificadas como locais ou nacionais, segundo o tamanho de seus mercados.

Deriva-se uma matriz de proporcionalidade nacional-regional cujos coeficientes indicam as diversas percentagens da produção de cada uma das mercadorias nacionais que serão atribuídas às diferentes regiões, ou seja, supõe-se que o padrão locacional de produção de todas as mercadorias nacionais é conhecido e permanece constante. Os bens nacionais são mercadorias cujo equilibrio entre produção e consumo ocorre no nível nacional, enquanto, para os bens regionais, considera-se que o equilibrio produçãoconsumo ocorra na região. 
O padrão de crescimento do produto regional é fixado, pois assume-se a hipótese que sempre que a produção total de um bem nacional aumentar ou diminuir, esse aumento ou redução irá ocorrer, na mesma proporção, em todas as regiões.

$O$ modelo tem o objetivo de determinar a quantidade de cada mercadoria (regional e nacional) que deverá ser produzida em cada região, sendo que a demanda final da mercadoria $i, Y_{i}$, é determinada exogenamente.

De acordo com Haddad (1976), o modelo não fornece nenhuma informação a respeito das origens e destinos dos fluxos de comércio, ou seja, o padrão de comércio estabelecido pelo modelo apresenta vetores de exportação e de importação de cada região, sem identificar a origem ou o destino desses fluxos. "É como se as mercadorias fossem colocadas pelos produtores em um fundo nacional comum para serem retiradas pelos vários consumidores, sem referência específica às regiões de origem" (p.225). Por esta razão, é denominado intranacional, e não inter-regional.

O modelo apresenta problemas conceituais para aplicação e dificuldades estatísticas para classificação de mercadorias bem como para obter uma hierarquia significativa de todas as regiões (Haddad, 1976, p.226).

\subsection{Os modelos de insumo-produto e o recurso água}

A implementação de um modelo de insumo-produto ao qual foi associada uma matriz de coeficientes diretos de um recurso natural - como a água, por exemplo, pode fornecer uma estrutura das interdependências interindustriais desse recurso. Um modelo assim construído pode revelar não só aqueles setores da economia diretamente responsáveis pelo consumo do recurso (água) mas também aqueles que apresentam altas demandas indiretas desse recurso, através de suas relações com outros setores da economia.

Considerando-se, então, os modelos de insumo-produto inter-regionais passa-se a dispor de uma base técnica para avaliação dos impactos de uma política regional sobre os setores das economias envolvidas. 
Nessa subseção faz-se uma digressão sobre a análise de insumo-produto aplicada ao estudo das inter-relações e crescentes articulações entre as atividades econômicas e os recursos naturais.

As aplicações do modelo de insumo-produto para estudar os recursos naturais e os problemas ambientais iniciaram-se com o trabalho de John H. Cumberland, em 1966, que foi o primeiro economista a incluir efeitos ambientais em um modelo de insumoproduto. Seguiram-se os modelos desenvolvidos por H. E. Daly, 1968, e Walter Isard, 1969, que apresentaram abordagens similares para resolver o problema sobre como incorporar o meio ambiente num modelo de insumo-produto (Richardson, 1972, p.215220). Os dois primeiros apresentam grandes dificuldades para aplicação empírica, tendo problemas com relação ao tratamento dos insumos ambientais.

Uma das principais questões a ser considerada é a da atribuição de valores aos recursos ambientais, tendo em vista que não estando inseridos nas transações de mercado, os preços de mercado não podem ser diretamente atribuídos aos mesmos, tornando-se dificil estabelecer-se um numerário que possa mensurar os insumos ambientais e aqueles dos setores econômicos para os quais já existem preços definidos.

O modelo desenvolvido por Isard adota a estrutura produto $x$ setor, reconhecendo, dessa forma, a produção secundária, o que permite que vários produtos, econômicos e ambientais, sejam classificados dentro de um único setor e que um produto seja produzido por mais de um setor da economia. O modelo é completamente integrado, e sua estrutura básica é representada por sub-matrizes com os fluxos entre os setores econômicos e os do meio ambiente ou do ecossistema. Os coeficientes técnicos do modelo de Isard são estimados diretamente a partir dos dados técnicos (Dabi \& Anderson, 1998; Abdallah \& Montoya, 1998; Miranda, 1980; Miller \& Blair, 1985).

Conforme ressaltado por Miranda (1980), mesmo apresentando grandes dificuldades para sua aplicação o modelo contribuiu para o desenvolvimento dos modelos de insumo-produto econômico-ecológicos.

Victor (1972), utilizando a abordagem de insumo-produto, desenvolveu um modelo relacionando o sistema econômico com o efeito poluição e o meio ambiente. Esse 
modelo é uma versão limitada do modelo econômico-ecológico completamente integrado de Isard. O modelo de Victor adiciona à tabela convencional de insumo-produto, segundo a estrutura produto $x$ setor, linhas correspondentes aos insumos ecológicos $\mathrm{e}$ colunas correspondentes aos produtos ecológicos, apresentando, desse modo, duas submatrizes, um subsistema econômico e um subsistema ecológico. Segundo Miller \& Blair (1985, p.253), pelo escopo da análise ser mais limitado, os dados geralmente estão disponíveis e o modelo pode ser implementado sem grandes dificuldades.

Miranda (1980, p. 609) ressaltou que a utilização de tabelas retangulares produto $x$ setor permitiu que se superasse a maior dificuldade desse tipo de abordagem que é exatamente a tentativa de valorar monetariamente insumos e produtos ecológicos. Assim, por esse critério, a produção principal e os equivalentes resíduos são explicitadas, podendo-se, prescindir da mensuração de toda produção numa mesma unidade.

Leontief também abordou a questão ambiental em seus estudos, construindo um modelo no qual a poluição ambiental foi integrada à uma tabela padrão de insumoproduto, tendo publicado dois artigos sobre o tema: "Environmental repercussions and the economic structure: an input-output approach", em 1970, e "Air pollution and the economic structure: empirical results of input-output computations", em 1972. Segundo o autor, a interdependência técnica entre os níveis de produtos desejáveis e indesejáveis pode ser descrita em termos de coeficientes estruturais similares àqueles usados para revelar a interdependência estrutural entre todos os ramos regulares de produção e consumo (Leontief, 1986; p.242).

Willian Miernyk, Bernard Udis e Clyde Stuart citados por Miernyk (1974) implementaram um modelo para uma única região, a da bacia do Rio Colorado, considerado como sendo uma variação do modelo inter-regional de Isard. $\mathrm{O}$ modelo foi construído a partir de seis tabelas de insumo-produto, uma para cada sub-bacia da bacia do Rio Colorado ${ }^{20}$. Cada tabela de insumo-produto regional foi elaborada separadamente e interligada às outras por meio de linhas de importação e colunas de exportação. Através

\footnotetext{
${ }^{20}$ A bacia do Rio Colorado inclui todo o estado do Arizona e parte dos estados da Califórnia, Nevada, Utah, Wyoming, Colorado e Novo México (Miernyk, 1974).
} 
desse sistema, foi possível mostrar como uma variação na demanda final em qualquer das sub-bacias afetaria o nível de atividade das outras. $\mathrm{O}$ modelo foi denominado "modelo inter-sub-regional" pois, segundo seus criadores, referia-se à interdependência intraregional.

Por abranger uma extensa região dos Estados Unidos e envolver um considerável volume de dados, as tabelas de insumo-produto das sub-bacias não foram agregadas em uma única tabela; para fins analíticos foram consideradas como partes da "tabela interdependente" da bacia do rio.

Cláudio da Rocha Miranda (1980) desenvolveu um modelo de insumo-produto e meio ambiente aplicado à região industrial do Médio Paraíba do Sul, no estado do Rio de Janeiro, visando auxiliar a administração daquela região no que diz respeito ao impacto da atividade industrial sobre a qualidade das águas desse rio. Conforme destacou o referido autor, o modelo, embora mais simplificado, apresenta grande semelhança com a metodologia de Victor, uma vez que não é feita nenhuma tentativa de relacionar os processos ecológicos entre si, como proposto por Isard.

Joel Hamilton, M. Henry Robison, Norman Whitlesey e John Ellis (1994) basearam-se em um modelo de insumo-produto multiregional construído por Carter e Ireri, em 1968, como parte de um estudo do impacto de alternativas de realocação de água entre a Califórnia e o Arizona (California-Arizona model), e em modelos de insumoproduto apresentados por Hamilton e Jensen, em 1983, para a Austrália, comparando-os com a análise de insumo-produto 'convencional' para a economia do Texas desenvolvida por Howe, em 1989, e utilizada para estimar os impactos diretos e indiretos sobre a renda e o produto.

O objetivo desses autores foi o de avaliar efeitos secundários inter-regionais na região formada pelos estados do Texas e do Novo México, dada a redução do volume de água do Rio Pecos no primeiro estado, devido a sua utilização para irrigação no segundo. Ressaltando a importância do reconhecimento das ligações através das fronteiras políticas desses estados para avaliação de impacto econômico, os autores tentaram responder à questão sobre quais teriam sido os beneficios líquidos para o Texas se ele tivesse recebido 
toda água, isto é, se não houvesse redução do volume da água do rio, e os impactos diretos e indiretos que isso implicaria, considerando, também, qual seria o custo da perda dos benefícios que transbordam, caso a área irrigada no Novo México fosse reduzida.

Concluíram que o reconhecimento e a quantificação dos impactos dos efeitos indiretos pode ser um componente importante para a estimação correta do impacto econômico de uma política ou evento; enfatizaram que a análise convencional de insumoproduto ignorou a estrutura espacial da região afetada e que o uso de um modelo interregional ou 'inter-comunitário' pode ser necessário para estimar as ligações e os efeitos secundários resultantes da adoção de uma determinada política. No caso da alocação da água do Rio Pecos para irrigação no Novo México, a análise sugeriu que os benefícios dos efeitos secundários para o Texas, a partir do uso da água para irrigação no Novo México, podem ser maiores ou iguais aos benefícios que aquele estado teria se a água fosse usada em seu território.

Xie Mei, Nie Guisheng e Jin Xianglan (1991) construíram um modelo de insumoproduto regional - Beijing Water-Economy Input-Output Model, que visava, além de refletir mudanças na economia, determinar os efeitos diretos e indiretos dessas mudanças sobre os recursos e o meio-ambiente. A demanda de água e os poluentes resultantes das descargas dos setores produtivos foram combinados em um modelo de insumo-produto unificado, constituindo um sistema de insumo-produto regional.

No modelo foram considerados três tipos de processos de usos da água: (1) retirada/captação de água; (2) usos da água (industrial, agrícola e urbano); e (3) perdas de água devido aos seus usos. Na tabela de insumo-produto, além dos setores tradicionais da economia foram incluídos o "setor água" e o "setor poluição", sendo estimadas as matrizes $A$, de coeficientes diretos; $W$, de coeficientes diretos de demanda de água, por produto; $\mathrm{e}, P$, de coeficientes diretos de descarga de poluentes.

O modelo foi aplicado para analisar as características das estruturas urbanas de uso de água, demanda de água e suas relações com mudanças na economia regional. 
Bernard Decaluwé, André Patry e Luc Savard (1997) construíram um modelo de equilíbrio geral (ou modelo aplicado de equilíbrio geral - AEG) para estudar o problema da gestão da água em Marrocos.

O estudo visou a análise das conseqüências da implantação de um novo sistema de tarifação do recurso água sobre a economia e, segundo os autores, um quadro de equilíbrio geral é o instrumento mais apropriado para a análise proposta, considerando o cálculo de uma tarifa ótima correspondente ao equilibrio total do recurso, que tenta captar a capacidade de pagamento dos usuários.

O modelo de equilibrio geral desenvolvido contemplou quatro categorias de agentes econômicos: as familias, as empresas, o governo e o resto do mundo. $\mathrm{O}$ país foi dividido em duas regiões: norte, com abundância de água e sul, com escassez do recurso. Consideraram que um mesmo bem seria produzido por dois setores distintos (um na região norte e outro na região sul); os segmentos agrícola e industrial totalizaram 14 setores divididos entre as duas regiões, tendo sido introduzidos no modelo dois setores "produtores de água", para representar as características de oferta do recurso. No que se refere ao fechamento do modelo, as dotações de trabalho, capital industrial, capital agrícola e capital utilizado para a construção de barragens (para água) foram fixadas, bem como a disponibilidade de terra para produção agrícola. Os preços das exportações e das importações, a poupança externa, o consumo e as transferências do governo, os índices de preços e as tarifas de água para os diversos consumidores foram, também, considerados variáveis exógenas.

Daniel Davou Dabi e William P. Anderson (1998) construíram um modelo econômico-ecológico, segundo a estrutura produto $x$ setor, para a demanda de água numa economia rural, numa região semi-árida do nordeste da Nigéria. $\mathrm{O}$ modelo foi utilizado para determinar os requerimentos diretos e totais dos produtos econômicos (transações interindustriais) e dos produtos ecológicos (água, terra e vegetação) usados na economia. Também foram considerados os despejos de produtos ecológicos (esgotos e resíduos sólidos) que retornam ao meio ambiente depois do processo produtivo. 
Davis (1968) desenvolveu um modelo multiregional para onze estados do oeste dos Estados Unidos, cujo objetivo foi o de analisar as interdependências inter-regionais, particularmente as relativas ao recurso água.

Devido a disponibilidade das tabelas de insumo-produto, foram considerados os estados de Washington, Oregon, California, Utah, Arizona, Novo México e Colorado como regiões componentes do modelo. Para os estados de Montana, Idaho, Wyoming e Nevada, que ainda não tinham suas tabelas de insumo-produto, foi elaborada uma única tabela, considerando-os como uma única região. Desse modo, o modelo foi constituído por oito regiões.

Os vetores de comércio de mercadorias foram construídos para cada estado e as origens e destinos dos fluxos de comércio que ocorrem na região foram determinados através do modelo gravitacional.

Foram calculados os coeficientes técnicos de uso de água e, a partir deles, construiu-se a matriz de "conteúdo de água" para a região estudada. A partir dessa matriz obteve-se um perfil do uso da água e as interdependências entre as regiões do oeste dos Estados Unidos.

O modelo que se pretendeu construir neste estudo teve como base o estudo de Davis considerando-se a importância da incorporação ao modelo de insumo-produto inter-regional de uma matriz de coeficientes de água para a bacia do rio São Francisco.

\subsection{A seleção de um modelo inter-regional}

A motivação para realização do presente estudo reside na falta de um modelo matemático que revele as inter-relações entre os setores da economia regional e que posssa se utilizado para auxiliar as decisões voltadas para seu desenvolvimento. Também considera-se a possibilidade de estudar as relações intersetoriais e os usos do recurso água.

Deve-se optar por um modelo cuja aplicação empírica permita captar, da melhor forma possível, essas inter-relações e investigar seus efeitos na economia. 
Considerando os modelos de insumo-produto apresentados em seção anterior, e conforme ressaltado por Montoya (1998), na seleção de um modelo deve-se considerar: (1) que o mesmo possibilite um nível de especificação da estrutura intersetorial da economia analisada de forma tal que permita testar os efeitos de políticas econômicas com os mais variados fins; (2) que o modelo seja consistente com a teoria do equilibrio geral e (3) a disponibilidade de dados estatísticos que permitam sua execução.

Com base no exposto, o modelo "ideal" de Isard, sob o ponto de vista teórico, é o mais indicado para a análise por não apresentar problemas de especificação. Entretanto, requer um grande volume de informações que, muitas vezes, não estão disponíveis, como é o caso dos fluxos de comércio inter-regionais.

O modelo de Chenery-Moses, por se tratar de uma simplificação do modelo de Isard, requer um número menor de informações que este. Apesar de ter como um dos seus principais pressupostos que cada indústria em todas as regiões segue um padrão regional fixo de importação de mercadorias - que é considerado forte, apresenta flexibilidades que facilitam sua implementação.

O modelo gravitacional de Leontief-Strout tem sido incorporado em estruturas inter-regionais como uma forma de superar o problema da escassez de dados. Além dessa vantagem, segundo Richardson (1972, p.73-74), conhecidas as demandas finais, os coeficientes de insumo-produto e os coeficientes de comércio, os produtos e o consumo regionais e os fluxos de comércio podem ser facilmente determinados. O problema crítico para aplicação empírica do modelo é a mensuração dos coeficientes de comércio.

Os modelos intranacional e do coeficiente linha são os que recebem as maiores críticas. No caso do primeiro, considera-se que além de exigir muitas informações, a classificação das indústrias em locais ou regionais foge à realidade, tendo em vista que a maioria delas transaciona seus produtos tanto em nível local quanto nacional. Ademais, conforme ressaltado por Richardson (1972, p.63), o modelo não satisfaz todas as condições de um modelo equilibrio geral visto que não determina os fluxos de comércio inter-regional e não faz referência à região de origem das mercadorias. No caso do segundo modelo, a principal crítica refere-se à hipótese de que as exportações de uma 
mercadoria de uma região seja uma proporção constante do total da sua produção naquela região, o que contraria as suposições walrasianas nos modelos de insumoproduto.

À luz da discussão acima e considerando-se as limitações impostas pelos dados disponiveis pretende-se construir um modelo inter-regional que possa ser entendido como uma "variação" do modelo inter-regional de Isard, pelo qual se norteará na construção do modelo proposto. Evidentemente, conforme ocorre na implementação empírica desses modelos, técnicas estatísticas para estimar e ajustar informações complementares à operacionalização do modelo, poderão ser utilizadas. 


\section{AS LIGAÇÕES INTERINDUSTRIAIS E OS SETORES-CHAVE NA ECONOMIA REGIONAL}

A identificação da interdependência setorial da economia regional por meio de setores-chave, ligações inter-setoriais e inter-regionais, campo de influência e interação entre as regiões, constitui-se em poderoso instrumental para análise do processo de interdependência das relações intersetoriais que podem sugerir perspectivas relevantes para fins de políticas de desenvolvimento industrial e planejamento econômico. Pois, espera-se que os recursos alocados em setores-chave, conforme a política a ser implementada, promovam o crescimento da produção mais rapidamente do que se esses recursos fossem aplicados em outros setores da economia.

Embora seja consensual na literatura a importância das ligações interindustriais de uma economia na determinação de estímulos ao crescimento econômico, bem como sobre o fato de os processos de mudança econômica serem, freqüentemente, estimulados por um número relativamente pequeno de setores, mesmo que toda a economia acabe experimentando uma mudança, muito ainda se discute sobre os métodos de identificação dos setores-chave, segundo a definição de Rasmussen (1956) e Hirschman (1958) ou pólos de crescimento, segundo Perroux (1955) e Myrdal (1957).

Conforme evidenciado por Bulmer-Thomas (1982; p.194-196) e em Montoya \& Guilhoto (1998) a divergência entre os métodos quanto à identificação dos setores-chave situa-se em questões como: a) não consideram variáveis determinantes no desenvolvimento econômico dos países, como, por exemplo, tamanho do mercado, ignoram qualquer critério de custos comparativos, eficiência na produção e no consumo e a disponibilidade de recursos naturais, ao se determinar que tipo de setor deve ser identificado como setor-chave, sob o enfoque Rasmussen/Hirschman; b) não há garantia 
que os estímulos potenciais, medidos pelas ligações para trás e para frente, irão se realizar, ou seja, se traduzirão em crescimento; c) quando se tem como objetivo o crescimento da renda per capita, os investimentos necessários deverão ser avaliados em termos dos impactos diretos e indiretos na renda (não no produto), o que pode ser feito considerando-se os multiplicadores da renda; d) tem-se dificuldade para se identificar quais seriam os setores que contribuem acima da média para a economia, tanto sob uma perspectiva ex-ante quanto ex-post (Guilhoto et. al., 1994).

Tendo em vista as divergências entre os métodos que mensuram as ligações intersetoriais, Guilhoto et. al. (1994; p.288) sugerem que diferentes métodos utilizados na mensuração de índices de ligações sejam considerados como enfoques complementares na análise e não como um sendo superior ao outro ${ }^{21}$. Essa argumentação é valida tendo em vista a ampliação da base teórica para a determinação dos setores-chave e a relevância das relações que podem ser extraídas das matrizes de insumo-produto, considerando-se essas como um primeiro passo para o delineamento de estratégias de desenvolvimento regional.

Neste trabalho pretende-se analisar a estrutura da economia regional a partir do método tradicional para identificação dos setores-chave, inicialmente identificado com o trabalho de Rasmussen e Hirschman, em seguida serão apresentados outros dois enfoques complementares para a identificação de setores-chave em uma economia, o do método do Campo de Influência de Sonis \& Hewings (1989) e o método desenvolvido por Guilhoto, Sonis e Hewings (1996) - método GHS, que permite separar os impactos de um setor específico do resto da economia, ou de uma única região do resto da economia, ou, ainda, de um país de um bloco de comércio ao qual ele está aliado.

\footnotetext{
${ }^{21}$ Para uma ampla discussão sobre o tema ver McGilvray (1976); Cella (1984); Hewings, Fonseca e Guilhoto (1989); Clements (1989); Clements e Rossi (1991); Guilhoto (1992); Sonis et. al. (1995); Guilhoto, Sonis e Hewings (1995).
} 


\subsection{A abordagem de Rasmussen/Hirschman}

Com base no modelo de insumo-produto inter-regional e considerando estritamente a estrutura interna da economia, adotando-se a metodologia de Rasmussen (1956) e Hirschman (1958), que tornou-se parte dos procedimentos geralmente aceitos para identificação dos setores-chave na economia, pode-se determinar quais os setores que teriam maior poder de encadeamento dentro da economia (Guilhoto, Hewings e Sonis, 1997). Os índices de ligações para trás, que indicam quanto um setor demanda dos outros, e os índices de ligações para frente, que indicam quanto este setor é demandado pelos outros. Valores maiores que 1 indicam setores acima da média e, portanto, setoreschave para o crescimento da economia.

Definindo-se $b_{i j}$ como um elemento da matriz inversa de Leontief, $B$; e $B_{* j}$ e $B_{i^{*}}$ como sendo, respectivamente, a soma de uma coluna e de uma linha típica de B e B como sendo a média de todos os elementos de $\mathrm{B}$, os índices de ligações poderão ser obtidos por meio de:

a) Índices de ligações para trás (poder da dispersão):

$$
U_{j}=\left[B_{* j} / n\right] / B^{*}
$$

b) Índices de ligações para frente (sensibilidade à dispersão):

$$
U_{i}=\left[B_{i *} / n\right] B^{*}
$$

sendo $n$ igual ao número de setores. 
Segundo Guilhoto et. al. (1997; p. 296) "um dos problemas dos indices de Rasmussen/Hirschman é que, apesar de avaliarem a importância de um dado setor em termos do impacto no sistema como um todo, é difícil visualizar os principais elos de ligações dentro da economia, ou seja, quais os coeficientes que, se alterados, teriam um maior impacto no sistema como um todo". O conceito de Campo de Influência, que será apresentado a seguir, aborda essa questão.

\subsection{Matriz de Intensidade}

Uma visão que foi proposta por Sonis, Hewings e Guo (1997) e por Sonis e Hewings (1999) para que a interações entre setores sejam arranjadas em uma figura hierarquicamente normalizada e apresentada em uma matriz tridimensional tem sido chamada de topografia econômica. Esta abordagem fornece uma estrutura de exploração consistente com uma abordagem mais tradicional da análise de setores-chave associada a Rasmussen e Hirschman. Entretanto, nesse caso, a atenção é direcionada para uma matriz derivada a partir do produto de linhas e colunas de multiplicadores obtidos da matriz inversa de Leontief. Essa matriz, denominada matriz de multiplicador de produto (MPM), revela a hierarquia das ligações para frente e para trás e a topografia econômica associada a ela, refletindo a estrutura cruzada da matriz de multiplicadores de produto.

Considerando a coluna e a linha de multiplicadores da matriz inversa de Leontief, conforme definido na seção 4.1, e definindo b.. como a soma de todos os elementos da matriz inversa de Leontief, a matriz de intensidade, ou matriz do produto dos multiplicadores de insumo-produto (MPM) é definida como:

$$
M=\frac{1}{b_{\bullet \bullet}}\left\|b_{i \bullet} b_{\bullet j}\right\|=\frac{1}{b_{\bullet \bullet}}\left(\begin{array}{l}
b_{1 \bullet} \\
b_{2 \bullet} \\
\ldots \\
b_{n \bullet}
\end{array}\right)\left(b_{\bullet 1} b_{\bullet 2} \ldots b_{\bullet n}\right)=\left\|m_{i j}\right\|
$$


A matriz $M$ contém uma seqüência de cruzamentos ordenados pelo tamanho. As localizações das linhas e colunas da matriz $M$ podem ser reorganizadas de tal forma que os centros dos cruzamentos correspondentes apareçam na diagonal principal. Desse modo, a matriz será reorganizada de uma forma que irá se obter uma topografia econômica com uma aparência descendente, baseada na ordenação das seqüências das linhas e colunas dos multiplicadores. Depois, adotando uma ordenação pelo tamanho a partir de uma economia escolhida como numeráire, as paisagens econômicas podem ser comparadas visualmente; desvios a partir da topografia suavemente descendente da economia numeráire irão refletir diferenças nas estruturas econômicas. Essas diferenças mostram variações no mix da indústria das regiões, variações nos graus das intermediações intra regional bem como as variações na tecnologia.

Uma das caracteristicas atrativas da análise das topografias econômicas é que os padrões revelados são consistentes com o procedimento de identificação dos setoreschave associado com Rasmussen/Hirschman.

Como tem sido ressaltado por Sonis, Hewings e Guo (1997) e por Sonis e Hewings (1999) a ordenação das hierarquias por tamanho dos índices Rasmussen/Hirschman coincide com a ordenação das hierarquias por tamanho das colunas e linhas dos multiplicadores da MPM. Este rearranjo também revela as hierarquias descendentes das ligações para frente e para trás de Rasmussen/Hirschman. Assim, uma importante contribuição da construção da topografia econômica para diferentes regiōes ou para a mesma região em diferentes períodos de tempo é a possibilidade de estabelecer uma taxonomia para essas economias.

Assim, a topografia econômica constitui-se num instrumento complementar na identificação de diferenças e semelhanças através das economia. Ela não irá substituir outras técnicas, mas irá servir como um filtro de primeiro estágio auxiliando a chamar a atenção sobre similaridades e diferenças através da economia. 


\subsection{O enfoque do Campo de Influência}

O conceito de Campo de Influência foi formalmente apresentado por Sonis e Hewings, em $1989^{22}$. Este enfoque descreve como se distribuem as mudanças dos coeficientes diretos no sistema econômico como um todo, permitindo determinar quais as relações entre os setores que seriam mais importantes no processo produtivo. $\mathrm{O}$ foco central desse conceito é a questão das influências das mudanças de um ou mais coeficientes da matriz inversa de Leontief a elas associada, pois mudanças em alguns coeficientes tendem a causar maiores alterações no sistema como um todo, do que se essas mudanças ocorressem em outros coeficientes. Desse modo, o conceito de campo de influência pode ser utilizado para determinar quais os setores que poderiam causar maiores mudanças na economia.

Esse enfoque apresenta-se como uma análise complementar aos índices de ligações para frente e para trás, segundo Rasmussen/Hirschman, para a determinação dos setoreschave em uma economia, haja vista que ambos consideram em seu cálculo a estrutura interna da economia.

O procedimento para o cálculo do campo de influência pode ser apresentado da seguinte forma: sendo $A=\left|a_{i j}\right|$ a matriz de coeficientes diretos e definindo-se $E=\left|\varepsilon_{i j}\right|$ como a matriz de mudanças incrementais nos coeficientes diretos de insumo, pode-se definir as correspondentes matrizes inversas de Leontief como:

$$
B=[I-A]^{-1}=\left|b_{i j}\right| \quad \text { e } \quad B(\varepsilon)=[I-A-\varepsilon]^{-1}=\left|b_{i j}(\varepsilon)\right| \quad \text { respectivamente. }
$$

Considerando-se uma variação suficientemente pequena no coeficiente direto, $a_{i j}$, e que

\footnotetext{
${ }^{22}$ Segundo Guilhoto et. al. (1994), o desenvolvimento do conceito do Campo de Influência teve como base os trabalhos desenvolvidos por Sherman e Morrison (1949 e 1950), Evans (1954), Park (1974), Simonovits (1975), Bullard e Sebald (1977 e 1988) e, de forma mais detalhada, por Sonis \& Hewings (1989 e 1994).
} 
essa variação ocorra em apenas um coeficiente direto ${ }^{23}$, conforme Sonis \& Hewings (1989 e 1994), tem-se que:

$$
\varepsilon_{i j}=\left\{\begin{array}{l}
\varepsilon i=i_{1}, j=j_{1} \\
0 \quad i \neq i_{1}, j \neq j_{1}
\end{array}\right.
$$

então, o campo de influência desta variação pode ser aproximado pela expressão:

$$
F\left(\varepsilon_{i j}\right)=[B(\varepsilon)-B] / \varepsilon_{i j}
$$

onde $F\left(\varepsilon_{i j}\right)$ é uma matriz, $(n x n)$, do campo de influência da mudança no coeficiente direto, $a_{i j}$. Dessa forma, pode-se inferir que para todo coeficiente, $a_{i j}$, existe uma matriz, (n $x \mathrm{n})$, do campo de influência deste coeficiente.

Para se determinar quais coeficientes possuem maior campo de influência, é necessário associar-se um valor a cada matriz $F\left(\varepsilon_{i j}\right)$. Este valor é dado por:

$$
S_{i j}=\sum_{k=1}^{n} \sum_{l=1}^{n}\left[f_{k l}\left(\varepsilon_{i j}\right)\right]^{2}
$$

onde $S_{i j}$ é o valor associado à matriz $F\left(\varepsilon_{i j}\right)$.

A partir dos valores de $S_{i j}$, identifica-se os coeficientes diretos com maior campo de influência, ou seja, pode-se identificar aquelas relações setoriais que apresentam maior sensibilidade a mudanças e que serão as responsáveis por maiores impactos na economia como um todo.

\footnotetext{
${ }^{23}$ Considerou-se nessa apresentação apenas o caso mais simples, isto é, o caso em que a mudança ocorre em apenas um coeficiente técnico. Conforme apresentado em Sonis \& Hewings (1989) as mudanças podem ocorrer não apenas em um único coeficiente, mas em linhas ou colunas inteiras e, até mesmo, em toda a matriz.
} 
Conforme ressaltaram Sonis et. al. (1995; p.241) esta metodologia não está limitada a mudanças induzidas por mudanças tecnológicas, melhoria na eficiência ou mudanças nas linhas de produto. Ela pode também indicar resultados de mudanças na posição competitiva de uma economia, resultante de decréscimos ou acréscimos nas compras feitas a partir da economia doméstica. Então, o enfoque do campo de influência é uma metodologia geral cujo emprego no contexto das análises das ligações é mais uma das suas muitas aplicações possíveis.

No contexto desta pesquisa, utilizando esse conceito poder-se-á identificar na economia regional quais são, dentre os setores-chave, os setores que apresentam maior sensibilidade a pequenas mudanças e que serão os responsáveis por maiores impactos induzidos na economia.

\subsection{O modelo GHS: os índices puros de ligações}

O modelo GHS, desenvolvido por Guilhoto, Sonis e Hewings (1996), consiste em um procedimento alternativo para a compreensão da estrutura da economia, permitindo separar os impactos de um setor ${ }^{24}$ específico do resto da economia. Esse modelo considera além do enfoque tradicional de Rasmussen/Hirschman, para identificação dos setores-chave na economia, as abordagens alternativas apresentadas por Cella (1984, 1986), Clements (1990), Clements e Rossi (1991, 1992), constituindo-se em um aperfeiçoamento da versão inicial do índice puro apresentado por Guilhoto et. al. (1994). O modelo explora, também, o papel das ligações internas e externas, conforme Miyazawa (1976), porém, enquanto aquele autor estava preocupado com a propagação das mudanças, o presente enfoque preocupa-se em identificar as fontes de mudança em uma economia.

Segundo os seus criadores, a principal contribuição do modelo GHS foi mostrar que usando diferentes decomposições de matrizes, uma ligação formal entre duas 
abordagens diferentes pode ser realizada; sendo, a primeira, direcionada à identificação dos setores-chave e, a segunda, direcionada para a identificação das fontes de mudança na economia. Desse modo, com esse modelo, é possível decompor o impacto de um setor/região na economia em seus vários componentes.

O modelo pode ser descrito da seguinte forma ${ }^{25}$ : considere um sistema de insumoproduto com duas regiões, representado pela seguinte matriz-bloco de insumos diretos:

$$
A=\left(\begin{array}{c|c}
A_{j j} & A_{j r} \\
\hline A_{r j} & A_{r r}
\end{array}\right)
$$

onde $A_{j j}$ e $A_{r r}$ são, respectivamente, matrizes quadradas de insumos diretos do setor $j$ e do resto da economia (menos o setor $j$ ); $A_{j r}$ e $A_{r j}$ são matrizes retangulares, respectivamente, mostrando os insumos diretos comprados pelo setor $j$ do resto da economia e os insumos diretos comprados pelo resto da economia do setor $j$.

A partir de (4-7) pode-se gerar a seguinte expressão:

$$
B=(I-A)^{-1}=\left(\begin{array}{ll}
B_{j} & B_{j r} \\
B_{r j} & B_{r r}
\end{array}\right)=\left(\begin{array}{cc}
\Delta_{j j} & 0 \\
0 & \Delta_{r r}
\end{array}\right)\left(\begin{array}{cc}
\Delta_{j} & 0 \\
0 & \Delta_{r}
\end{array}\right)\left(\begin{array}{cc}
I & A_{j r} \Delta_{r} \\
A_{r j} \Delta_{j} & I
\end{array}\right)
$$

onde os componentes de (4-8) podem ser definidos como:

$$
\begin{aligned}
& \Delta_{j}=\left(I-A_{j j}\right)^{-1} \\
& \Delta_{r}=\left(I-A_{r r}\right)^{-1} \\
& \Delta_{j j}=\left(I-\Delta_{j} A_{j r} \Delta_{r} A_{r j}\right)^{-1}
\end{aligned}
$$

\footnotetext{
${ }^{24}$ Ressalte-se que em vez de setor, poder-se-ia considerar uma região ou um país, dependendo do âmbito da análise.

${ }^{25}$ Para maior detalhamento do modelo GHS, ver Guilhoto, Sonis e Hewings (1996).
} 


$$
\Delta_{r r}=\left(I-\Delta_{r} A_{r j} \Delta_{j} A_{j r}\right)^{-1}
$$

A partir da equação (4-8) é possivel verificar como ocorre o processo de produção na economia, bem como derivar um conjunto de multiplicadores e/ou ligações.

Observe-se que a matriz

$$
\left(\begin{array}{cc}
\Delta_{j j} & 0 \\
0 & \Delta_{r r}
\end{array}\right)
$$

pode ser interpretada como os multiplicadores externos da região $j$ e o resto da economia, $r$, como em Miyazawa (1976). Do mesmo modo, a matriz

$$
\left(\begin{array}{cc}
\Delta_{j} & 0 \\
0 & \Delta_{r}
\end{array}\right)
$$

pode ser interpretada como multiplicadores internos da região $j$ e o resto da economia, $r$.

Na matriz

$$
\left(\begin{array}{cc}
I & A_{j r} \Delta_{r} \\
A_{r j} \Delta_{j} & I
\end{array}\right)
$$

a primeira linha separa a demanda final por origem, isto é, distingue entre a demanda final interna - dentro da região, $(I)$, da demanda final externa - fora da região, $\left(A_{j r} \Delta_{r}\right)$.

A partir do modelo de Leontief

$$
X=(I-A)^{-1} Y
$$

e usando as equações (4-8) e (4-16), pode-se derivar um conjunto de índices que podem ser usados para: a) ordenar as regiões em termos de sua importância na economia; b) verificar como o processo de produção ocorre na economia.

Assim, das equações (4-8) a (4-16), obtém-se:

$$
\left(\begin{array}{c}
X_{j} \\
X_{r}
\end{array}\right)=\left(\begin{array}{cc}
\Delta_{i j} & 0 \\
0 & \Delta_{r r}
\end{array}\right)\left(\begin{array}{cc}
\Delta_{j} & 0 \\
0 & \Delta_{r}
\end{array}\right)\left(\begin{array}{cc}
I & A_{j r} \Delta_{r} \\
A_{r j} \Delta_{j} & I
\end{array}\right)\left(\begin{array}{l}
Y_{j} \\
Y_{r}
\end{array}\right)
$$

$$
\text { e }
$$




$$
\left(\begin{array}{c}
X_{j} \\
X_{r}
\end{array}\right)=\left(\begin{array}{cc}
\Delta_{j j} & 0 \\
0 & \Delta_{r r}
\end{array}\right)\left(\begin{array}{cc}
\Delta_{j} & 0 \\
0 & \Delta_{r}
\end{array}\right)\left(\begin{array}{l}
Y_{j}+A_{j r} \Delta_{r} Y_{r} \\
A_{r j} \Delta_{j} Y_{j}+Y_{r}
\end{array}\right)
$$

onde

$$
A_{j r} \Delta_{r} Y_{r}
$$

é o impacto direto da demanda final do resto da economia sobre a região $j$, ou seja, representa o nível das exportações da região $j$ que é necessário para satisfazer às necessidades de produção do resto da economia, para um dado nível de sua demanda final, $Y_{r} ; \mathrm{e}$

$$
A_{r j} \Lambda_{j} Y_{j}
$$

é o impacto direto da demanda final da região $j$ sobre o resto da economia, ou seja, representa o nível das exportações do resto da economia que é necessário para satisfazer as necessidades de produção da região $j$, para um dado nível da sua demanda final, $Y_{j}$.

A partir da equação (4-18) obtém-se:

$$
\left(\begin{array}{c}
X_{j} \\
X_{r}
\end{array}\right)=\left(\begin{array}{cc}
\Delta_{j j} & 0 \\
0 & \Delta_{r r}
\end{array}\right)\left(\begin{array}{c}
\Delta_{j} Y_{j}+\Delta_{j} A_{j r} \Delta_{r} Y_{r} \\
\Delta_{r} A_{r j} \Delta_{j} Y_{j}+\Delta_{r} Y_{r}
\end{array}\right)
$$

a partir da qual obtém-se as definições do Índice Puro de Ligações para Trás (PBL) e do Índice Puro de Ligações para Frente (PFL), sendo:

$$
\begin{aligned}
& \mathrm{PBL}=\Delta_{r} A_{r j} \Delta_{j} Y_{j} \\
& \mathrm{PFL}=\Delta_{j} A_{j r} \Delta_{r} Y_{r}
\end{aligned}
$$


O PBL representa o impacto puro sobre o resto da economia do valor total da produção na região $j,\left(\Delta_{j} Y_{j}\right)$, dissociado: a) da demanda de insumos que a região $j$ realiza da própria região $j$, e b) dos retornos do resto da economia para a região $j$ e vice-versa.

Já o PFL corresponde ao impacto puro sobre a região $j$ do total da produção no resto da economia $\left(\Delta_{r} Y_{r}\right)$.

O Índice Puro do Total das Ligações (PTL) de cada setor da economia pode ser obtido adicionando-se o PBL ao PFL, tendo em vista que esses índices são expressos em valores correntes, assim:

$$
P T L=P B L+P F L
$$

Ainda considerando a equação (4-21), pode-se obter:

$$
\left(\begin{array}{c}
X_{j} \\
X_{r}
\end{array}\right)=\left(\begin{array}{c}
\Delta_{i j} \Delta_{j} Y_{j}+\Delta_{j j} \Delta_{j} A_{j r} \Delta_{r} Y_{r} \\
\Delta_{r r} \Delta_{r} A_{r j} \Delta_{j} Y_{j}+\Delta_{r r} \Delta_{r} Y_{r}
\end{array}\right)=\left(\begin{array}{c}
X_{j}^{j}+X_{j}^{r} \\
X_{r}^{j}+X_{r}^{r}
\end{array}\right)
$$

o que possibilita a divisão do nivel total da produção na região $j,\left(X_{j}\right)$, em dois componentes:

$$
\begin{aligned}
X_{j}^{j} & =\Delta_{i j} \Delta_{j} Y_{j} \\
X_{j}^{r} & =\Delta_{i j} \Delta_{j} A_{j r} \Delta_{r} Y_{r}
\end{aligned}
$$

onde $X_{j}^{j}$ representa o nível da produção total na região $\mathrm{j}$ que é devido ao nível da demanda final na região $j,\left(Y_{j}\right)$; e $\mathrm{X}_{j}^{r}$ representa o nível da produção total na região $j$ que é devido ao nivel da demanda final no resto da economia $\left(Y_{r}\right)$.

$\mathrm{E}$, do mesmo modo, o nível da produção total no resto da economia, $\left(X_{r}\right)$, pode ser dividido em dois componentes: 


$$
\begin{aligned}
& X_{r}^{j}=\Delta_{r r} \Delta_{r} A_{r j} \Delta_{j} Y_{j} \\
& X_{r}^{r}=\Delta_{r r} \Delta_{r} Y_{r}
\end{aligned}
$$

onde $X_{r}^{j}$ representa o nível da produção total no resto da economia que é devido ao nível da demanda final na região $j,\left(Y_{j}\right)$; e $X_{r}^{r}$ representa o nível da produção total no resto da economia que é devido ao nível da demanda final no resto da economia, $\left(Y_{r}\right)$.

Das aplicações do modelo GHS pode-se destacar o trabalho de Guilhoto, Hewings e Sonis (1997), em um modelo inter-regional de tabelas de insumo-produto construído para a Ásia, em que incluiu-se os Estados Unidos, para os anos de 1975 e 1985. Os trabalhos de Montoya (1998) e Montoya \& Guilhoto (1998), que com base na matriz de insumo-produto internacional do Mercosul de 1990 caracterizam o perfil das estruturas de transações internacionais dos países e os setores-chave na economia do Mercosul. E o trabalho de Crocomo (1998) que analisou a estrutura produtiva regional da economia brasileira em 1985.

\subsection{Interações sinergéticas dentro de uma hierarquia de pares de subsistemas econômicos}

A metodologia apresentada nesta seção foi desenvolvida por Sonis, Hewings e Miyazawa $(1997)^{26}$, baseando-se num sistema particionado de insumo-produto e explora técnicas que produzem multiplicadores à direita e à esquerda da inversa de Leontief, possibilitando, deste modo, classificar os tipos de interações sinergéticas dentro de uma hierarquia de pares de ligações de subsistemas econômicos. Utilizada na construção de indicadores de ligações entre regiões, esta metodologia permite examinar, através da estrutura das interdependências internas e externas das ligações, a estrutura das relações de comércio entre regiões.

\footnotetext{
${ }^{26}$ Uma descrição detalhada é apresentada pelos autores no referido artigo.
} 
Considerando um sistema de insumo-produto representado pelo bloco de matrizes, $A$, de insumos diretos:

$$
A=\left[\begin{array}{ll}
A_{11} & A_{12} \\
A_{21} & A_{22}
\end{array}\right]
$$

onde $A_{11}$ e $A_{22}$ representam matrizes quadradas de insumos diretos dentro da primeira e segunda regiōes, respectivamente, e $A_{12}$ e $A_{21}$ são matrizes retangulares dos insumos diretos adquiridos pela segunda região e vice versa. É possível interpretar a matriz $A$ como um sistema de duas regiões em que a segunda região representa 0 resto da economia menos a primeira região.

A construção dos blocos de pares de combinações hierárquicas dos subsistemas de ligações intra e inter-regionais, num sistema de insumo-produto, é dada pelas matrizes $A_{11}, A_{12}, A_{21}$ e $A_{22}$, que correspondem a quatro blocos básicos de matrizes:

$$
A_{11}=\left[\begin{array}{cc}
A_{11} & 0 \\
0 & 0
\end{array}\right] ; \quad A_{12}=\left[\begin{array}{cc}
0 & A_{12} \\
0 & 0
\end{array}\right] ; \quad A_{21}=\left[\begin{array}{cc}
0 & 0 \\
A_{21} & 0
\end{array}\right] ; \quad A_{22}=\left[\begin{array}{cc}
0 & 0 \\
0 & A_{22}
\end{array}\right]
$$

A decomposição do bloco de matrizes (4.27) pode ser feita por meio da soma de dois blocos de matrizes, sendo que cada um deles é a soma dos blocos de matrizes de (4.28).

Decompondo-se (4.27), são identificados 14 tipos de pares de combinações hierárquicas dos subsistemas econômicos, conforme apresentado na Figura 4.1 e na Tabela 4.2.

\subsubsection{Multiplicadores regionais internos}

Nesta subseção ${ }^{27}$, apresenta-se um conjunto de multiplicadores regionais internos, derivados das matrizes inversas, que são blocos construídos das interações sinergéticas entre os subsistemas econômicos. A Tabela 4.1 representa uma síntese desses

\footnotetext{
${ }^{27}$ Tomou-se como referência os trabalhos Guilhoto et. al. (1998) e (1999).
} 
multiplicadores. Para melhor compreendê-la, fazem-se necessários alguns comentários sobre suas entradas (os números em negrito correspondem às entradas da Tabela 4.1).

1. As matrizes $B_{1}=\left(I-A_{11}\right)^{-1}$ e $B_{2}=\left(I-A_{22}\right)^{-1}$ representam, respectivamente, as matrizes dos multiplicadores internos de Miyazawa da primeira e segunda regiões e mostram os efeitos de propagação interindustrial dentro de cada região, enquanto as matrizes $A_{21} B_{1}, B_{1} A_{12}, A_{12} B_{2}$ e $B_{2} A_{21}$ mostram os efeitos induzidos sobre a produção ou atividades produtivas nas duas regiões.

2. As expressões

$$
S_{1}=I-A_{11}-A_{12} B_{2} A_{2 l}, \quad S_{2}=I-A_{22}-A_{2 l} B_{1} A_{12}
$$

são, usualmente, chamadas de complementos de Schur. De (4.29), pode-se derivar

$$
\left[\begin{array}{cc}
I-A_{11} & -A_{12} \\
-A_{21} & I-A_{11}
\end{array}\right]=\left[\begin{array}{cc}
I & D_{1} A_{12} B_{2} \\
0 & D_{2}
\end{array}\right]\left[\begin{array}{cc}
B_{1} & 0 \\
A_{21} B_{I} & I
\end{array}\right]
$$

Sonis et al. (1997) referem-se a (4.30) como sendo a fórmula inversa de SchurBanachiewicz, que fornece as bases para a classificação das interações sinergéticas entre as ligações dos subsistemas econômicos.

As matrizes $D_{1}$ e $D_{2}$ dos complementos de Schur (4.29) são conhecidas como as inversas de Schur para a primeira e segunda regiões, respectivamente. Elas representam a inversa de Leontief ampliada para uma região e revelam a influência econômica induzida da outra região, ou seja, as inversas de Schur representam os efeitos de propagação total na primeira e segunda regiões.

3. Introduzidas por Miyazawa (1966), as matrizes de multiplicadores externos à esquerda e à direita da primeira e segunda regiões, $D_{l l}^{L}, D_{l l}^{R}, D_{22}^{L}$ e $D_{22}^{R}$, são incorporados na decomposição multiplicativa das inversas de Schur. Elas representam os efeitos de propagação total na primeira e segunda regiões, como os produtos internos e externos da matriz regional de multiplicadores.

4 e 5. Por meio da introdução das inversas de Schur abreviadas, $D_{11}, D_{22}$, e dos multiplicadores internos induzidos à esquerda e à direita para a primeira e segunda 
regiões, $B_{1}^{L}, B_{1}^{R}, B_{2}^{L}$ e $B_{2}^{R}$, pode-se obter a decomposição multiplicativa das inversas de Schur:

$$
D_{1}=B_{1}^{L} D_{11}=D_{11} B_{1}^{R} ; \quad D_{2}=B_{2}^{L} D_{22}=D_{22} B_{2}^{R}
$$

e suas correspondentes representações aditivas.

6 a 10. As fórmulas para este grupo de multiplicadores podem ser obtidas considerando-se os seguintes blocos de matrizes:

$$
M=\left[\begin{array}{cc}
A_{11} & A_{12} \\
A_{21} & 0
\end{array}\right], \quad N=\left[\begin{array}{cc}
0 & A_{12} \\
A_{21} & A_{22}
\end{array}\right], \quad S=\left[\begin{array}{cc}
0 & A_{12} \\
A_{21} & 0
\end{array}\right]
$$

que representam as ligações para trás e para frente da primeira e da segunda região, e as relações inter-regionais de ambas regiões.

A seguinte inversa de Schur

$$
D_{1}^{*}=\left(I-A_{11}-A_{12} A_{21}\right)^{-1}
$$

pode ser chamada de inversa de Leontief ampliada e, as inversas

$$
D_{11}^{* L}=\left(I-B_{1} A_{12} A_{21}\right)^{-1} ; \quad D_{11}^{* R}=\left(I-A_{12} A_{21} B_{1}\right)^{-1}
$$

\begin{tabular}{|c|c|}
\hline $\begin{array}{l}\text { 1. Multiplicadores regionais i } \\
B_{1}=\left(I-A_{11}\right)^{-1} ; \quad B_{2}=(I-\end{array}$ & \\
\hline 2. Complementos e inversas a & \\
\hline$S_{1}=I-A_{11}-A_{12} B_{2} A_{21}$ & $S_{2}=I-A_{22}-A_{21} B_{1} A_{12}$ \\
\hline$D_{1}=\left(I-A_{11}-A_{12} B_{2} A_{21}\right)^{-1}$ & $D_{2}=\left(I-A_{22}-A_{21} B_{1} A_{12}\right)^{-1}$ \\
\hline 3. Multiplicadores externos a & rda e a direita de Miyazawa: \\
\hline$D_{11}^{L}=\left(I-B_{1} A_{12} B_{2} A_{21}\right)^{-1}$ & $D_{22}^{L}=\left(I-B_{2} A_{21} B_{1} A_{12}\right)^{-1}$ \\
\hline$D_{11}^{R}=\left(I-A_{12} B_{2} A_{21} B_{1}\right)^{-1}$ & $D_{22}^{R}=\left(I-A_{21} B_{1} A_{12} B_{2}\right)^{-1}$ \\
\hline Principais Propriedades: & \\
\hline$D_{1}=B_{1} D_{11}^{R}=D_{11}^{L} B_{1}$ & $D_{2}=B_{2} D_{22}^{R}=D_{22}^{L} B_{2}$ \\
\hline 4. Inversas de Schur abrevia & \\
\hline$D_{11}=\left(I-A_{12} B_{2} A_{21}\right)^{-1}$ & $D_{22}=\left(I-A_{21} B_{1} A_{12}\right)^{-1}$ \\
\hline
\end{tabular}

são chamadas de matrizes de multiplicadores da inversa ampliada a esquerda e a direita.

Tabela 4.1 Multiplicadores regionais internos e suas propriedades 
Tabela 4.1 Multiplicadores regionais internos e suas propriedades.

(conclusão)

\begin{tabular}{|c|c|}
\hline \multicolumn{2}{|c|}{ 5. Multiplicadores internos induzidos a esquerda e a direita: } \\
\hline$B_{I}^{L}=\left(I-D_{I I} A_{I I}\right)^{-1}$ & $B_{2}^{L}=\left(I-D_{22} A_{22}\right)^{-1}$ \\
\hline$B_{1}^{R}=\left(I-A_{11} D_{n l}\right)^{-1}$ & $B_{2}^{R}=\left(I-A_{22} D_{22}\right)^{-1}$ \\
\hline Principais Propriedades: & \\
\hline$D_{1}=B_{1}^{L} D_{11}=D_{11} B_{1}^{R}$ & \\
\hline \multicolumn{2}{|c|}{ 6. Inversas de Leontief ampliadas: } \\
\hline \multirow{2}{*}{\multicolumn{2}{|c|}{$\begin{array}{l}D_{1}^{*}=\left(I-A_{21}-A_{12} A_{21}\right)^{-1} ; \quad D_{2}^{*}=\left(I-A_{22}-A_{21} A_{12}\right)^{-1} \\
\text { 7. Multiplicadores externos induzidos: }\end{array}$}} \\
\hline & \\
\hline$D_{11}^{*}=\left(I-A_{12} A_{2 I}\right)^{-1}$ & $D_{22}^{*}=\left(I-A_{21} A_{12}\right)^{-1}$ \\
\hline \multicolumn{2}{|c|}{ 8. Multiplicadores internos induzidos a esquerda e a direita: } \\
\hline$B_{1}^{*}=\left(I-D_{11}^{*} A_{11}\right)^{-1}$ & $B_{2}^{*}=\left(I-D_{22}^{*} A_{22}\right)^{-1}$ \\
\hline$B_{1}^{*_{R}}=\left(I-A_{11} D_{11}^{*}\right)^{-1}$ & $B_{2}^{* R}=\left(I-A_{22} D_{22}^{*}\right)^{-1}$ \\
\hline Principais Propriedades: & \\
\hline$D_{1}^{*}=B_{1}^{\mathrm{q}} D_{l 1}^{*}=D_{11}^{*} B_{1}^{*}$ & $D_{2}^{*}=B_{2}^{\text {* }} D_{22}^{*}=D_{22}^{*} B_{2}^{* R}$ \\
\hline \multicolumn{2}{|c|}{ 9. Inversas acrescentada a esquerda e a direita: } \\
\hline$D_{11}^{q}=\left(I-B_{1} A_{12} A_{21}\right)^{-1}$ & $D_{22}^{q}=\left(I-B_{2} A_{21} A_{12}\right)^{-1}$ \\
\hline$D_{11}^{* R}=\left(I-A_{12} A_{21} B_{1}\right)^{-1}$ & $D_{22}^{* R}=\left(I-A_{21} A_{12} B_{2}\right)^{-1}$ \\
\hline Principais Propriedades: & \\
\hline$D_{1}^{*}=B_{1} D_{11}^{*}=D_{11}^{*} B_{1}$ & $B_{2} D_{22}^{* R}=D_{22}^{* L} B_{2}$ \\
\hline \multicolumn{2}{|c|}{ 10. Inversas acrescentadas induzidas a esquerda e a direita: } \\
\hline$D_{11}^{*-L}=\left[I-D_{11}\left(A_{11}-A_{12} B_{2} A_{22} A_{2 l}\right)\right]^{-1}$ & $D_{22}^{* L}=\left[I-D_{22}\left(A_{22}-A_{21} B_{1} A_{11} A_{12}\right)\right]^{-1}$ \\
\hline$D_{11}^{* R}=\left[I-\left(A_{11}-A_{12} B_{2} A_{22} A_{21}\right) D_{11}\right]^{-1}$ & $D_{22}^{* * 2}=\left[I-\left(A_{22}-A_{21} B_{1} A_{11} A_{12}\right) D_{22}\right]^{-1}$ \\
\hline \multicolumn{2}{|l|}{ Principais Propriedades: } \\
\hline$D_{1}^{*}=D_{11}^{*-L} D_{11}=D_{11} D_{11}^{* * R}$ & $D_{2}^{*}=D_{22}^{* * L} D_{22}=D_{22} D_{22}^{* * R}$ \\
\hline
\end{tabular}


4.5.2 Bloco de matrizes inversas de Leontief e classificação do bloco de matrizes dos multiplicadores externos à esquerda e à direita

Considere a hierarquia dos subsistemas de insumo-produto representada pela decomposição de $A=A_{1}+A_{2}$. Introduzindo o bloco da inversa de Leontief $L(A)=L=(I-A)^{-1}$ e o bloco da inversa de Leontief $L\left(A_{1}\right)=L_{1}=\left(I-A_{1}\right)^{-1}$, correspondente ao primeiro subsistema, os blocos a esquerda e a direita da matriz de multiplicadores externos, $M_{L}$ e $M_{R}$, são definidos pelas igualdades:

$$
L=L_{1} M_{R}=M_{L} L_{1}
$$

A definição de (4.35) implica que:

$$
\begin{aligned}
& M_{L}=L\left(I-A_{1}\right)=\left(I-L_{1} A_{2}\right)^{-1} \\
& M_{R}=\left(I-A_{1}\right) L=\left(I-A_{2} L_{1}\right)^{-1}
\end{aligned}
$$

$\mathrm{O}$ cálculo do bloco de multiplicadores externos, $M_{L}$ e $M_{R}$, é baseado na forma particular do bloco inverso de Leontief $L(A)=L$. Assim, aplicando o bloco inverso de Leontief, tem-se:

$$
L=\left[\begin{array}{cc}
D_{1} & D_{1} A_{12} B_{2} \\
D_{2} A_{21} B_{1} & D_{2}
\end{array}\right]
$$

Esta fórmula pode ser verificada pela multiplicação direta de matriz, usando as definições das inversas de Schur e suas propriedades (Tabela 4.1, entradas 1 e 2).

A aplicação das fórmulas (4.36), (4.37) e (4.38) permitem derivar a ordenação das interações sinergéticas entre regiões. Os resultados são apresentados no primeiro e no segundo nivel da Tabela 4.2. 
Tabela 4.2* - Ordenação das interações sinergéticas entre os subsistemas econômicos.

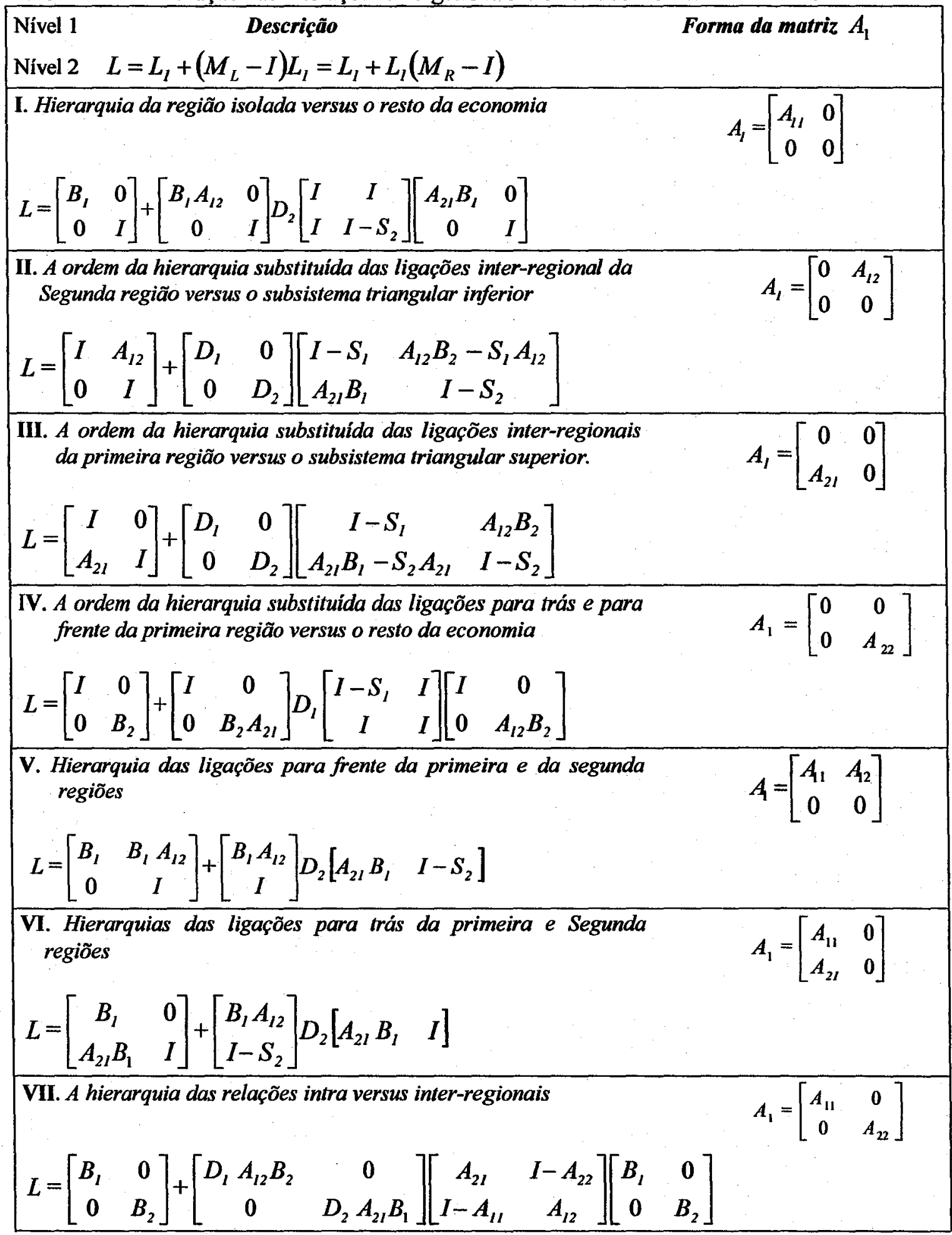


Tabela 4.2* - Ordenação das interações sinergéticas entre os subsistemas econômicos.

(conclusão)

\begin{tabular}{ll}
\hline VIII. A hierarquia das relações inter versus intra-regionais & $\mathrm{A}_{1}=\left[\begin{array}{cc}0 & A_{12} \\
A_{21} & 0\end{array}\right]$ \\
$L=\left[\begin{array}{cc}D_{11}^{*} & D_{11}^{*} A_{12} \\
D_{22}^{*} A_{21} & D_{22}^{*}\end{array}\right]+\left[\begin{array}{cc}I & B_{1} A_{12} \\
B_{2} A_{21} & I\end{array}\right]\left[\begin{array}{cc}D_{1} A_{11} D_{11}^{*} & 0 \\
0 & D_{2} A_{22} D_{22}^{*}\end{array}\right]\left[\begin{array}{cc}I & A_{12} \\
A_{21} & I\end{array}\right]$ \\
\hline IX. Ordem de hierarquia substituida de ligações para trás & $\mathrm{A}_{1}=\left[\begin{array}{ll}0 & \mathrm{~A}_{12} \\
0 & A_{22}\end{array}\right]$ \\
$L=\left[\begin{array}{ll}I & A_{12} B_{2} \\
0 & B_{2}\end{array}\right]+\left[\begin{array}{c}1-S_{1} \\
B_{2} A_{21}\end{array}\right] D_{1}\left[\begin{array}{ll}I & A_{12} B_{2}\end{array}\right]$ & $\mathrm{A}_{1}=\left[\begin{array}{cc}0 & 0 \\
A_{21} & A_{22}\end{array}\right]$ \\
\hline $\mathbf{X . ~ O r d e m ~ d e ~ h i e r a r q u i a ~ s u b s t i t u i d a ~ d e ~ l i g a c ̧ o ̃ e s ~ p a r a ~ f r e n t e ~}$ & \\
$L=\left[\begin{array}{cc}I & 0 \\
B_{2} A_{21} & B_{2}\end{array}\right]+\left[\begin{array}{c}1 \\
B_{2} A_{21}\end{array}\right] D_{1}\left[\begin{array}{ll}I-S_{1} & A_{12} B_{2}\end{array}\right]$ &
\end{tabular}

XI. A hierarquia das ligações para trás e para frente da primeira região versus o resto da economia

$A_{1}=\left[\begin{array}{cc}A_{11} & A_{12} \\ A_{21} & 0\end{array}\right]$

$L=\left[\begin{array}{cc}D_{1}^{*} & D_{1}^{*} A_{12} \\ A_{21} D_{1}^{*} & D_{22}\end{array}\right]+\left[\begin{array}{c}B_{1} A_{12} \\ I\end{array}\right] D_{2} D_{22} A_{22}\left[\begin{array}{ll}A_{21} B_{1} & I\end{array}\right]$

XII. $A$ hierarquia do subsistema triangular superior versus as ligações inter-regionais da primeira região

$$
A_{1}=\left[\begin{array}{cc}
\mathrm{A}_{11} & \mathrm{~A}_{12} \\
0 & \mathrm{~A}_{22}
\end{array}\right]
$$

$L=\left[\begin{array}{cc}B_{1} & B_{1} A_{12} B_{2} \\ 0 & B_{2}\end{array}\right]+\left[\begin{array}{c}B_{1} A_{12} \\ I\end{array}\right] D_{2} A_{21} B_{1}\left[\begin{array}{ll}I & A_{12} B_{2}\end{array}\right]$

XIII. A hierarquia do subsistema triangular inferior versus ligações inter-regionais da segunda região

$A_{1}=\left[\begin{array}{cc}A_{11} & 0 \\ A_{21} & A_{22}\end{array}\right]$

$L=\left[\begin{array}{cc}B_{1} & 0 \\ B_{2} A_{21} B_{1} & B_{2}\end{array}\right]+\left[\begin{array}{c}1 \\ B_{2} A_{21}\end{array}\right] D_{1} A_{12} B_{2}\left[\begin{array}{ll}A_{21} B_{1} & I\end{array}\right]$

XIV. Hierarquia do resto da economia versus a segunda região isolada

$A_{1}=\left[\begin{array}{cc}0 & A_{12} \\ A_{21} & A_{22}\end{array}\right]$

$L=\left[\begin{array}{cc}D_{11} & A_{12} D_{2}^{*} \\ D_{2}^{*} A_{21} & D_{2}^{*}\end{array}\right]+\left[\begin{array}{c}1 \\ B_{2} A_{21}\end{array}\right] D_{11} A_{11} D_{1}\left[\begin{array}{lll}I & A_{12} B & 2\end{array}\right]$

"Cada entrada na tabela consiste de dois níveis: o primeiro, descreve a estrutura e mostra a correspondente forma da matriz $A$, enquanto o segundo mostra as decomposições aditivas da matriz bloco de Leontief. 


\subsubsection{Decomposição hierárquica aditiva dos blocos inversos de Leontief}

Considerando a hierarquia do subsistema de insumo-produto representado pela decomposição $A=A_{1}+A_{2}$, e seu bloco inverso de Leontief sendo representado por $L(A)=L=(I-A)^{-1}$ e o bloco inverso de Leontief, relativo ao primeiro subsistema, sendo representado pela expressão $L\left(A_{l}\right)=L_{l}=\left(I-A_{I}\right)^{-1}$. A decomposição multiplicativa da inversa de Leontief $L=L_{l} M_{R}=M_{L} L_{l}$ pode ser convertida na soma:

$$
L=L_{1}+\left(M_{L}-I\right) L_{1}=L_{I}+L_{l}\left(M_{R}-I\right)
$$

Denotando $f$ o vetor de demanda final e $x$ o de produto total, pode-se decompor (4.39), dividindo o produto total em duas partes: $x_{1}=L_{1} f$ e o incremento $D x=x-x_{1}$. Esta decomposição é importante para analisar empiricamente a estrutura do produto total. No segundo nivel da Tabela 4.2, estão apresentadas as classificações das possiveis decomposições aditivas do bloco inverso de Leontief num sistema de insumo-produto dentro dos pares de combinações hierárquicas.

Embora 14 tipos de pares de combinações hierárquicas de ligações econômicas tenham sido apresentados (Tabela 4.2 e Figura 4.1), Sonis et al. (1997), Guilhoto et al. (1998) e Guilhoto et al. (1999), salientam que é possível sugerir uma tipologia de categorias nas quais elas podem ser situadas. A seguinte caracterização foi sugerida por esses autores:

1. tipo de ligação para trás (VI, IX): poder de dispersão;

2. tipo de ligação para frente $(\mathrm{V}, \mathrm{X})$ : sensibilidade de dispersão;

3. tipo de ligações intra e inter-regionais (VII, VIII): dispersão interna e externa;

4. estilo de interações de região isolada versus o resto da economia (I, XIV, IV, XI) e

5. estilo de subsistema triangular versus as interações inter-regionais (II, XIII, III, XII).

Pela visualização do sistema de hierarquias das ligações segundo esse modelo torna-se possível fornecer novas interpretações das propriedades das estruturas que são 
reveladas. Além disso, esses sistemas particionados de insumo-produto podem distinguir entre os vários tipos de dispersão (como 1,2 e 3) e entre os vários padrões de interações inter-regionais (como 4 e 5). Essencialmente, as 5 categorias e os 14 tipos de pares de combinações hierárquicas de ligações econômicas propiciam a oportunidade para escolher de acordo com as qualidades especiais das atividades de cada região e para o tipo de problema que se analisa.
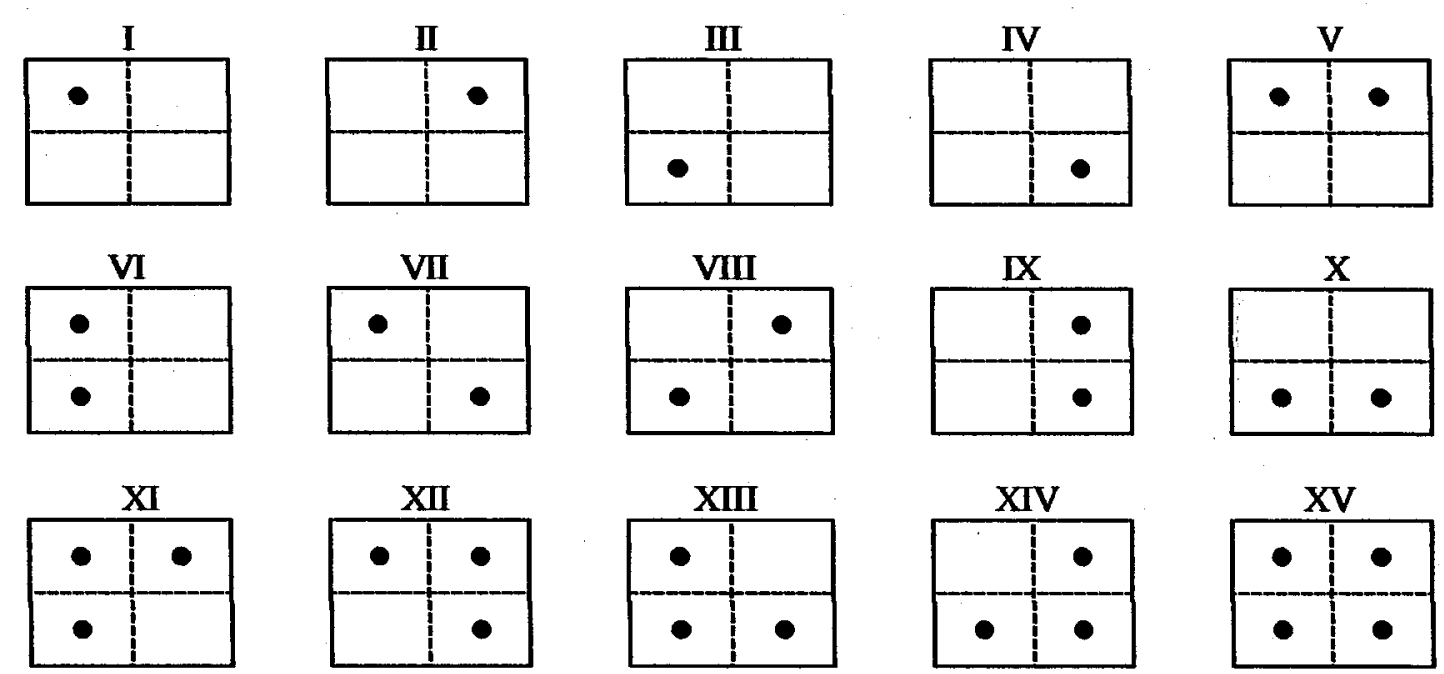

Fonte: Guilhoto, 1999.

Figura 4.1 - Representação esquemática das formas possíveis da matriz $A_{l}$ - o caso de 2 regiões.

\subsection{4 $O$ caso de $n$ regiōes}

A metodologia que classifica os tipos de interações sinergéticas e permite examinar a estrutura das relações de comércio entre regiões, inicialmente desenvolvida por Sonis, Hewings e Miyazawa (1997) para duas regiões, pode ser ampliada para o caso em que se deseja examinar essas relações considerando-se $n$ regiões.

Segundo Guilhoto (1998), o número de decomposições aumenta significativamente na medida em aumenta o números de regiões. Se se tem 15 decomposições (incluindo o 
sistema como um todo) para o caso de duas regiões, essas serão: a) 511 para o caso 3 regiões; b) 65.535 para o caso de 4 regiões; c) 33.554 .431 para o caso de 5 regiões e assim sucessivamente.

O sistema de equações para o caso de $n$ regiões torna-se muito complexo, dessa forma, no presente estudo será apresentada uma idéia geral de como o sistema trabalha, conforme a forma esquemática para o caso de 4 regiões representada na Figura 4.2.

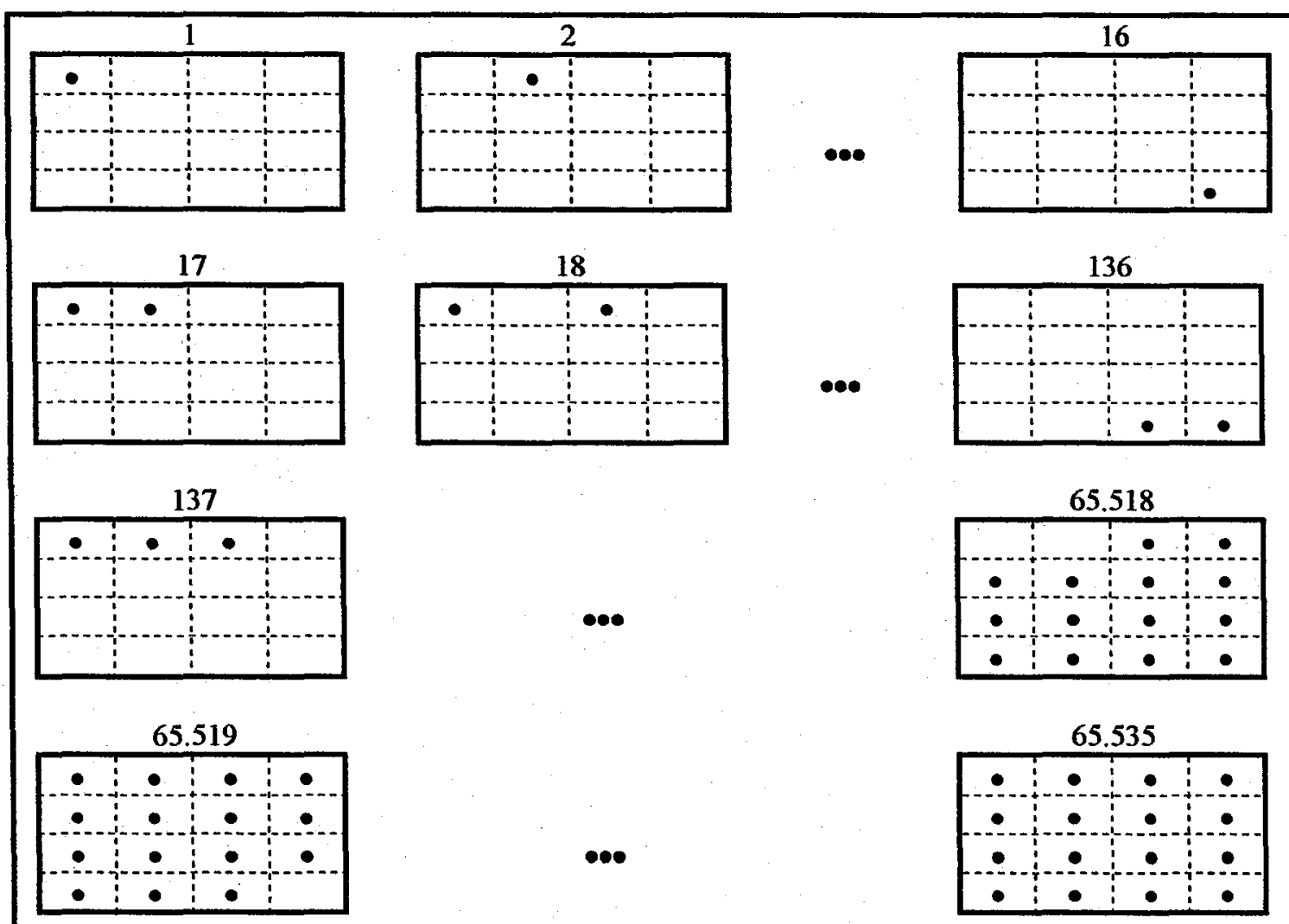

Fonte: Guilhoto (1999).

Figura 4.2 - Representação esquemática das formas possiveis da matriz $A_{1}$ - o caso de 4 regiões.

$\mathrm{Na}$ Figura 4.2 está representado um sistema inter-regional com 4 regiões, totalizando 16 blocos de matrizes. No primeiro passo, considera-se cada matriz 
isoladamente até completar o sistema. No segundo passo, considera-se as 16 matrizes combinadas 2 a 2, 3 a 3 e 4 a 4 até se obter o sistema como um todo. Para mensurar a contribuição de cada combinação para a produção no processo produtivo tem-se que subtrair do resultado da combinação de $k$ matrizes todas as possíveis combinações destas matrizes em nível inferior, isto é, do resultado de um conjunto de 4 matrizes deve ser subtraído o resultado de todas as possíveis combinações dessas 4 matrizes ao nível de 3 , 2 e 1 matrizes.

Guilhoto et al. (1998 e 1999) aplicaram essa metodologia para a economia brasileira, considerando o caso de duas regiões: Nordeste e Resto da Economia, usando dados da matriz inter-regional de insumo-produto referente ao ano de 1992, construída pelos autores. Concluíram que, em geral, o Nordeste tem maior dependência da região formada pelo Resto da Economia e, ainda, que o Resto da Economia parece ser mais desenvolvido, apresentando uma estrutura produtiva mais complexa do que a do Nordeste.

Guilhoto (1999) expandiu essa técnica para o caso de 4 e 5 regiões, utilizando-a estudar as cinco macro regiões da economia brasileira. Utilizando um sistema interregional, construído pelo autor, para o ano de 1995 para as cinco regiões, constatou que, em geral, a região Norte não tem, praticamente, relações com a região Nordeste e viceversa; enquanto a região Sul tem algum impacto sobre a produção da região Nordeste, essa não exerce nenhuma influência sobre aquela; a produção na região Centro-Oeste tem suas relações mais importantes com as regiões Sudeste e Sul; e, as regiões Sul e Sudeste mostraram-se como sendo as mais importantes no sistema. 


\section{METODOLOGIA}

O objetivo desta pesquisa foi o de construir um modelo de insumo-produto interregional para a região formada pelos estados de Minas Gerais, Bahia e Pernambuco.

O sistema inter-regional foi obtido a partir da regionalização da Matriz de Insumo-Produto do Brasil, para o ano de 1995, elaborada pelo IBGE ${ }^{28}$.

A pesquisa visou, também, à construção de uma matriz de coeficientes de água para a análise dos usos múltiplos do recurso na bacia do São Francisco.

Os procedimentos operacionais para construção do modelo podem ser divididos em três grupos:

a) regionalização da Matriz de Insumo-Produto do Brasil, do ano de 1995, (MIPBR/95), para os estados de Minas Gerais, Bahia e Pernambuco;

b) construção do modelo inter-regional, a partir das MIP's/95 dos estados;

c) construção uma matriz de coeficientes de uso de água, com base no modelo interregional de insumo-produto.

Tendo em vista que cada etapa apresentada acima será realizada segundo metodologias específicas, será feita uma sucinta apresentação de cada uma delas.

\footnotetext{
${ }^{28}$ Ressalte-se que na época em que a pesquisa foi iniciada, as informações mais recentes divulgadas pelo IBGE referiam-se ao ano de 1995.
} 


\subsection{Construção das matrizes regionais}

Segundo Considera et al. (1997, p.4), os modelos de insumo-produto foram, originalmente, desenvolvidos tomando-se como referência a economia de um determinado país, entretanto, a necessidade de análises mais localizadas resultou no desenvolvimento de modelos regionais (para uma unidade de Federação ou Região). 0 modelo de insumo-produto tem sua principal aplicação no planejamento econômico. Por meio de uma matriz regional, é possivel, por exemplo, comparar estruturas econômicas de produção, produtividade, etc., entre o país e a região ou entre regiões, bem como mensurar o impacto de políticas econômicas para o país e a região.

As fontes básicas dos dados utilizados no presente estudo foram a Matriz de Insumo-Produto do Brasil, 1995, os Censos Agropecuários do Brasil e dos Estados, 1995/96 e o Censo Econômico 1985, todos elaborados pelo IBGE, além de dados sobre exportação e importação dos estados e do Brasil, no ano de 1995, obtidos junto à Secretaria de Comércio Exterior (SECEX) e sobre fluxos de comércio (entradas e saídas) obtidos junto às Secretarias das Fazendas Estaduais.

Algumas das razões pelas quais se optou pela regionalização da matriz nacional foram: a necessidade de estudar as inter-relações entre as economias dos três principais estados da região da bacia do rio São Francisco; dificuldades técnicas e de recursos que envolveriam a construção das matrizes de insumo-produto a partir do levantamento de dados diretamente nos estados; a ampla aceitação e aplicação empírica da metodologia de regionalização de matrizes, conforme descrito na seção 3.2.

Segundo Souza $(1997$, p.2), as matrizes regionalizadas não passam de uma estimativa da "verdadeira" matriz de cada estado. No entanto, "por meio das técnicas dos quocientes de localização e pelo método RAS, é possível obter matrizes com coeficientes técnicos bastante próximos da realidade, possibilitando a análise regional e a formulação de sugestões de políticas locais de industrialização". 
As matrizes regionais (dos estados) originaram-se, então, das matrizes nacionais de produção [V] e de insumos [U], também chamada matriz de uso. As informações das matrizes nacionais são apresentadas numa abordagem do tipo enfoque produto por setor a preços básicos ${ }^{29}$, permitindo que cada produto seja produzido por mais de um setor e que cada setor produza mais de um produto. A dimensão da matriz de produção é de $\mathbf{4 2}$ setores por 80 produtos e a da matriz de uso, de 80 produtos por 42 setores.

Com o objetivo de simplificar a leitura das matrizes e ressaltar os setores mais importantes das economias estudadas, agregaram-se os setores (linhas da tabela de produção e colunas da tabela de uso) da matriz nacional de tal forma que foram reduzidos para 26 , sendo mantido o mesmo número de produtos das tabelas originais (Anexo B).

O Quadro 5.1 mostra a estrutura do sistema de relações de insumo-produto usada na construção das MIP's dos estados de Minas Gerais, Bahia e Pernambuco, e do Resto do Brasil, 1995.

Das tabelas básicas do Modelo de Insumo-Produto, denominadas Tabelas de Recursos e Usos, a Tabela de Produção, da qual se origina a matriz de produção $V_{(s \times p) \text {, }}^{N}$ fornece informações sobre a origem setorial dos bens e serviços produzidos em determinado ano na economia nacional. As linhas indicam em quais setores os produtos são produzidos, enquanto as colunas mostram a origem setorial dos produtos. Por outro lado, a Tabela de Uso, de que provém a matriz de uso $U_{(p \times s)}^{N}$, mostra, nas linhas, os produtos oferecidos para cada setor e, nas colunas, os produtos demandados em cada setor da economia nacional. ${ }^{30}$

\footnotetext{
${ }^{29}$ Preço Básico: "É o valor dos bens e serviços, computando-se apenas os custos de produção (que inclui os custos de bens e serviços intermediários e as remunerações dos fatores de produção), adicionado dos outros impostos sobre a produção, líquidos de outros subsídios à produção. Seria um preço dos bens e serviços na porta da fábrica" (Considera et al., 1997, p.11).

${ }^{30}$ Os sobrescritos $N$ e $R$ são usados para indicar, respectivamente, matrizes ou vetores nacionais e regionais, enquanto os subscritos $p$ e $s$ representam produto e setor, respectivamente.
} 
Quadro 5.1. Relações de insumo-produto usadas para regionalização da matriz nacional.

\begin{tabular}{|l|c|c|c|c|}
\hline & Produto & Setor & Demanda Final & Produto Total \\
\hline Produto & & $\boldsymbol{U}^{N}$ & $\boldsymbol{E}^{N}$ & $\boldsymbol{Q}^{N}$ \\
\hline Setor & $\boldsymbol{V}^{N}$ & $\boldsymbol{Z}$ & $\boldsymbol{Y}$ & $\boldsymbol{X}^{N}$ \\
\hline Importações & & $\boldsymbol{M}$ & $\boldsymbol{M D F}$ & \\
\hline Valor Adicionado & & $\boldsymbol{W}$ & & \\
\cline { 1 - 2 } Insumo Total & $\boldsymbol{Q}^{, N}$ & $\boldsymbol{X}^{, N}$ & & \\
\hline
\end{tabular}

Fonte: Adaptado de Miller \& Blair, 1985.

Tomando-se como base a matriz $U^{N}$ e o vetor $X^{N}\left(\begin{array}{lll}s & 1 & 1\end{array}\right.$, representando este último a produção por setor, calculou-se a matriz $B^{N}(p \times s)$ da seguinte forma:

$$
B^{N}=U^{N}\left(\hat{X}^{N}\right)^{-1}
$$

em que: $B^{N}$ é a matriz nacional dos coeficientes técnicos dos insumos domésticos por setor e $\left(\hat{X}^{N}\right)^{-1}$ é o vetor $X^{N}$ diagonalizado e invertido.

Para a estimativa das matrizes regionais $U^{R}$ e $V^{R}$, foi construído o vetor $X^{R}$ dos valores da produção estadual por setor.

$\mathrm{Na}$ construção do vetor $X^{R}$, utilizaram-se informações do Censo Agropecuário 1995/96 do IBGE, para se obter o valor da produção do setor Agropecuária, assim como para o valor da produção do setor Extrativa Mineral, obtido a partir dos dados do Anuário Mineral Brasileiro, 1995, do Departamento Nacional da Produção Mineral (Brasil, 1998).

Outra referência foi o trabalho de Considera e Medina (1998), no qual são estimados os PIBs setoriais, por unidade da Federação, para o período 1985/96. A participação dos estados no PIB do Brasil foi usada para calcular os valores das produções setoriais para os Estados, $X^{R}$, tomando-se, como referência, os valores da matriz de insumo-produto do Brasil. Esse procedimento foi utilizado para estimar o valor 
da produção dos setores que compõem os grupos da Indústria de Transformação e dos Serviços.

O próximo passo foi calcular a participação de cada elemento das linhas de $V^{N}$ em $X^{N}$, lembrando que o vetor $X^{N}$, de produção nacional por setor, foi obtido diretamente da Tabela de Produção da MIPBR/95. Obtida a matriz de participações, os valores do vetor $X^{R}$ foram distribuídos entre os produtos dos vários setores das economias estaduais, resultando a tabela $V^{R}$ e o vetor $Q^{R}{ }_{(l \times p)}$, que representa a produção estadual por produto.

Então, calculou-se $D_{(s \times p)}^{R}$ conforme:

$$
D^{R}=V^{R}\left(\hat{Q}^{R}\right)^{-1}
$$

em que: $D^{R}$ é a matriz de coeficientes técnicos de produto para os estados; e

$\left(\hat{Q}^{\prime R}\right)^{-1}$ é o vetor $Q^{, R}$ diagonalizado e invertido $(p \times p)$.

Com essas informações, o próximo passo foi calcular os quocientes locacionais setoriais, descritos no capítulo 3. A matriz $B^{N}$ foi pré-multiplicada pelos quocientes locacionais para se obter a matriz $B^{R}$, ou seja, a matriz dos coeficientes técnicos dos insumos para o estados e para o Resto do Brasil.

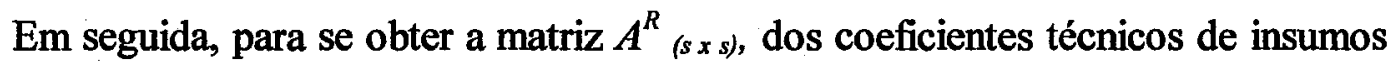
diretos, pré-multiplicou-se a matriz $B^{R}$ pela matriz $D^{R}$, ou seja, matrizes foram transformadas para o enfoque tecnológico original de Leontief, setor por setor, considerando-se que, cada setor produz um único produto e cada produto é produzido por um único setor. Assim,

$$
A^{R}=D^{R} B^{R}
$$

A partir da matriz $A^{R}$, obteve-se, então, a matriz dos coeficientes técnicos de insumo diretos e indiretos para os estados, ou matriz inversa de Leontief, $L_{(s \times s)}^{R}$ :

$$
L^{R}=\left(I-A^{R}\right)^{-1}
$$

Essa matriz é, também, chamada de matriz dos impactos diretos e indiretos, por permitir verificar o impacto na produção, renda e emprego de uma variação na demanda final. 
Para obter os valores das importações intermediárias $(M)$, componentes da matriz $U^{R}$, foi necessário subdividi-las em importações do resto do Brasil $^{31}$ (MRB) e importações do exterior (MEX). As primeiras foram obtidas por diferença, como:

$$
M R B=\bar{U}^{R}-U^{R}
$$

em que: $\bar{U}^{R}=B^{N} \times \hat{X}^{R}$ representa quanto o estado usou de insumos nacionais; e $U^{R}=B^{R} \times \hat{X}^{R}$ representa quanto o estado usou de insumos produzidos no próprio estado.

Para calcular os valores das importações do exterior, dos impostos indiretos líquidos (IIL) e dos componentes do valor adicionado $(W)$, ou seja, as remunerações, o excedente operacional bruto, outros impostos sobre a produção e outros subsídios sobre a produção, foram utilizadas as proporções dos valores da MIPBR/95.

No Quadro 5.1, representa-se, de forma simplificada, o modelo das matrizes regionais $^{32}$ construídas nesta pesquisa. A matriz $Z$ é a matriz de transações intersetoriais ( $s \times s)$, contendo a demanda ou consumo setorial intermediário, enquanto o vetor $M D F$ representa as importações finais de bens e serviços realizadas na economia em determinado ano.

A demanda final $(Y)$ é composta pela formação bruta de capital fixo, exportações para o exterior, exportações para o resto do Brasil, variação de estoque, consumo do governo e consumo das famílias. $O$ valor das exportações para o exterior e das exportações para o resto do Brasil foram estimados a partir de dados de exportações do Brasil e dos estados, no ano de 1995, da Secretaria de Comércio Exterior/Departamento de Comércio Exterior (SECEX/DECEX). Os demais componentes da demanda e a dummy financeiro foram calculados para os estados, tomando-se como base as

\footnotetext{
${ }^{31}$ Deve-se ressaltar que as importações do resto do Brasil foram estimadas apenas para as matrizes dos estados de Minas Gerias, Bahia e Pernambuco.

32 Nesta pesquisa, cada um dos três estados considerados na área da bacia hidrográfica do rio São Francisco constitui uma região. $\mathrm{O}$ restante do Brasil irá constituir outra região denominada Resto do
} 
proporções da MIPBR/95. Vale ressaltar que os valores do vetor variação de estoque foram obtidos por resíduo.

\subsection{0 modelo inter-regional proposto}

Os procedimentos descritos na seção 5.1 referem-se à construção de uma matriz regional, isto é, um modelo para uma única região.

Um dos aspectos interessantes dos modelos de insumo-produto inter-regionais é que eles permitem a modelagem e a mensuração das interconexões entre as regiões. As metodologias utilizadas nesse procedimento são conhecidas na literatura podendo-se encontrar exposições detalhadas em Miller \& Blair (1985), em Dixon et al. (1992) e em Isard et al. (1998).

Como um dos propósitos desta pesquisa é a construção de um modelo interregional, uma vez obtidas as matrizes regionais, foi necessário obter as matrizes de fluxos de comércio, ou seja, correspondentes às $Z^{H G}$ e $Z^{G H}$, conforme descrito na seção 3.3 do capítulo 3, para o caso de duas regiões.

Obtidas as matrizes $Z^{R}$, isto é, as matrizes das transações intersetoriais dentro de cada região ou matrizes de transações intra-regionais, pretende-se, agora, obter as transações de todos os setores entre todas as regiões do sistema, ou as matrizes das transações inter-regionais. As vendas para a demanda final, que uma região faz para outra, estarão contidas no vetor correspondente às exportações. Uma representação esquemática do modelo inter-regional construído, para quatro regiões, é apresentada na Tabela (5.1).

Brasil. Assim, o sistema inter-regional será composto por quatro regiões: Minas Gerais, Bahia, Pernambuco e Resto do Brasil. 


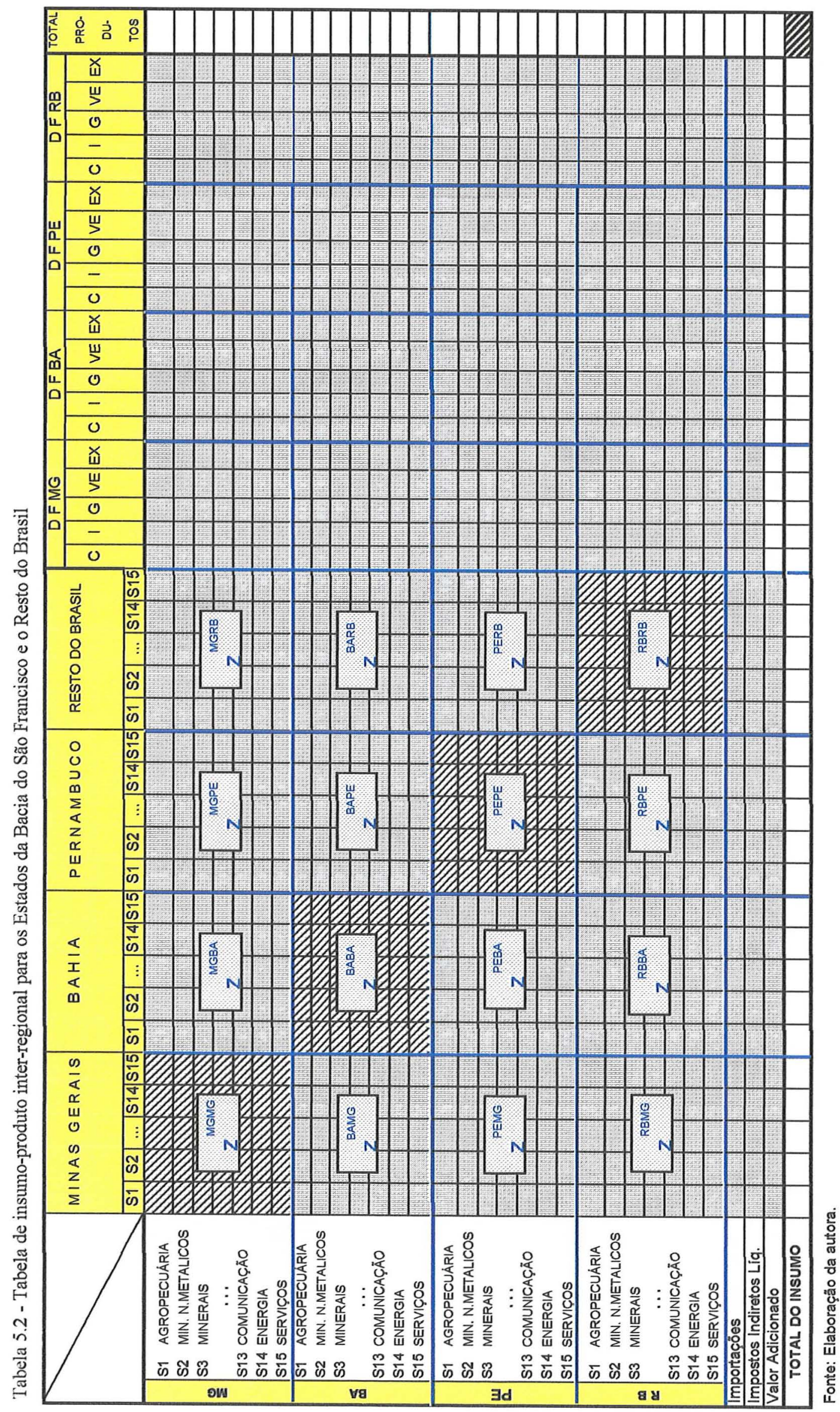


Para estimar os fluxos inter-regionais, estabeleceu-se a seguinte hipótese: as compras de determinado insumo (produtos) que dado setor de um estado, Minas Gerais, por exemplo, faz dos demais (Bahia, Pernambuco e Resto do Brasil), é proporcional à participação desses estados na produção do referido insumo. Por exemplo, sendo $B$ a matriz de insumos diretos, conforme equação (5-1), e $b_{i j}$ um elemento dessa matriz, definido como a participação do insumo $i$ na produção do setor $j$, e assumindo-se que $b_{i j}{ }^{\text {BRASL }}$ é igual a 0,3 e que $b_{i j}{ }^{\text {MG }}$ é igual a 0,2 , pode-se inferir que Minas Gerais importa 0,1 de $i$ dos outros estados do Brasil. Supondo-se, também, que a produção do insumo $i$, excluindo a parcela que é produzida no estado de Minas Gerais, seja distribuída da seguinte forma resulta que: a) o estado da Bahia produz $30 \%$ de $i$; b) o estado de Pernambuco produz $20 \%$ de $i$; c) o Resto do Brasil produz $50 \%$ de $i$, então, as compras do insumo $i$ feitas pelo setor $j$ de Minas Gerais serão distribuídas conforme:

$$
\begin{aligned}
& b_{i j}{ }^{B A M G}=0,1 \times 0,3=0,03 ; \\
& b_{i j}{ }^{\text {PEMG }}=0,1 \times 0,2=0,02 ; \\
& b_{i j}{ }^{\text {RBMG }}=0,1 \times 0,5=0,05 .
\end{aligned}
$$

Repetindo esse procedimento para as outras regiões, obteve-se as matriz de fluxos inter-regionais ${ }^{33}, B^{I R}(p x s)$. A matriz do sistema inter-regional foi, então, prémultiplicada pela matriz de transformação inter-regional, $D^{I R}$, para obtenção da matriz de coeficientes técnicos e de comércio do sistema ${ }^{34}, A^{I R}$.

Da mesma forma que para o caso de uma região, a partir da matriz $A^{I R}$, obtevese, então, a matriz dos coeficientes técnicos de insumo diretos e indiretos do sistema inter-regional, ou matriz inversa de Leontief, $L^{I R}{ }_{(s \times s)}$ :

\footnotetext{
${ }^{33}$ Os sobrescritos $I R$ significam que a matriz corresponde ao sistema Inter-Regional.

${ }^{34}$ Num modelo inter-regional, com duas regiões definidas como $G$ e $H$, por exemplo, ao se considerar os elementos da matriz $A$ deve-se ter em mente que os $a_{i j}^{G G}$ e os $a_{i j}{ }^{H H}$ representam os coeficientes de insumos diretos intra-regionais nas regiões $G$ e $H$, respectivamente. Os $a_{i j}{ }^{G H}$ representam os coeficientes de insumos diretos inter-regionais, às vezes chamados coeficientes de comércio (Isard et al., 1998).
} 


$$
L^{I R}=\left(I-A^{I R}\right)^{-1}
$$

A matriz inversa de Leontief constitui o elemento básico para o cálculo dos indicadores propostos no capítulo 4 .

Os componentes da demanda final do sistema inter-regional foram obtidos a partir de procedimentos semelhantes aos descritos na seção 5.1 e aos adotados para obtenção dos fluxos de comércio descritos anteriormente para o consumo intermediário.

Para calcular os valores dos componentes do valor adicionado para o sistema inter-regional, tomou-se como referência a MIPBR/95 e os procedimentos foram análogos aos da seção 5.1.

A Tabela 5.2 apresenta, de forma sintética, os valores da matriz de insumoproduto inter-regional construída nesta pesquisa. As matrizes do sistema inter-regional do São Francisco e o Resto do Brasil encontram-se no Anexo A. 


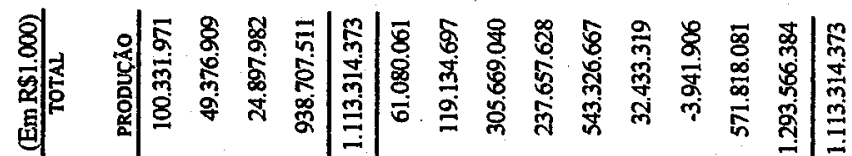

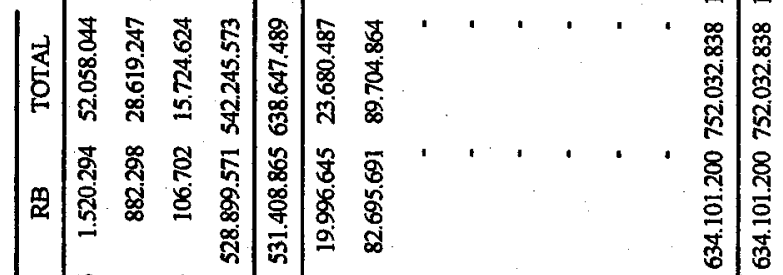

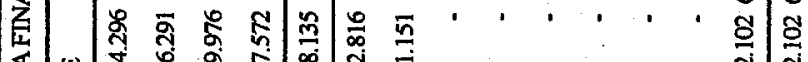

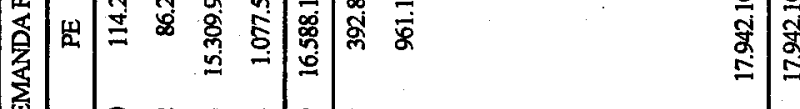
离

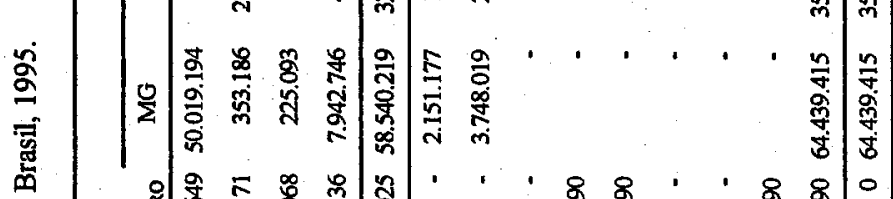

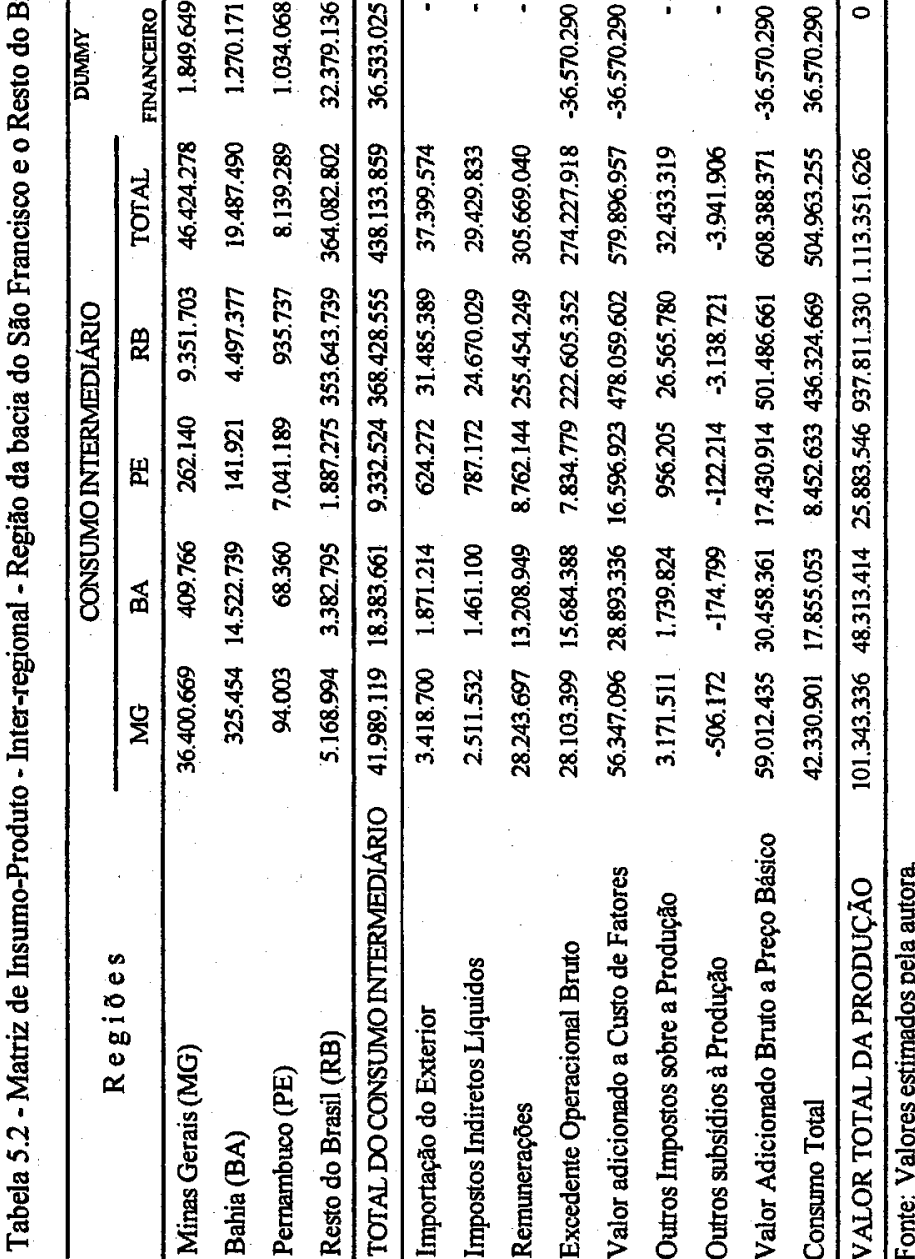




\subsection{A matriz de coeficientes de uso de água e a matriz de "conteúdo de água"}

Visando à obtenção do consumo de água, por setor do modelo inter-regional, foram utilizados coeficientes de consumo estimados com base em relações teóricas e em consultas realizadas às empresas responsáveis pelo abastecimento de água nos estados estudados.

Pelas respostas obtidas junto às empresas, verificou-se que, no Brasil, ainda são raros os estudos sobre os usos da água e as quantidades efetivamente consumidas pelos diversos setores da economia, contrariamente ao que ocorre em países como os Estados Unidos e o Canadá, por exemplo. Segundo Tate \& Scharf (1992), nos últimos 25 anos, desenvolveu-se no Canadá uma rica literatura sobre o uso industrial da água. Solley et al. (1998) relataram que, nos Estados Unidos, levantamentos sobre os usos da água são realizados desde 1950, em intervalos de 5 anos, pelo U.S. Geological Survey (USGS), constituindo-se em fonte de dados sobre os usos do recurso tanto em nível regional quanto nacional. No caso desta pesquisa, por se dispor de poucas informações sobre o consumo efetivo de água pelos setores das economias estudadas, a fonte básica dos dados foram as outorgas de usuários da Secretaria de Recursos Hídricos (SRH) do Ministério do Meio Ambiente, dos Recursos Hídricos e da Amazônia Legal. Também foram utilizados dados de abastecimento de água da Companhia de Saneamento de Minas Gerais (COPASA) e do Inventário dos Recursos Hídricos Regionais - Levantamento de Usuários, do Governo Federal / Governo do Estado de Minas Gerais (Fundação Rural Mineira Colonização e Desenvolvimento Agrário - RURALMINAS).

Os dados relativos ao abastecimento foram disponibilizados, por categoria de usuário, apenas pela COPASA, no estado de Minas Gerais. Essas categorias ${ }^{35}$ são constituídas por economias residenciais, economias comerciais, economias públicas e economias industriais. Do volume total captado na região da bacia do rio São Francisco, no ano de 1998 , e fornecido aos usuários pela referida companhia, $78 \%$ destinam-se ao 
abastecimento das economias residenciais, $11 \%$ às economias comerciais, $6 \%$ às economias industriais e 5\% às economias públicas. Quando se considera a razão entre o volume de água fornecido e o número de usuários atendidos, verifica-se que o maior consumo é o das economias industriais, que corresponde a $46 \%$ do total fornecido, seguido pelo das economias públicas, com $31 \%$ e pelo das economias comerciais, com 13\%. A última posição é ocupada pelo das economias residenciais devido ao grande número de unidades atendidas, correspondendo a $10 \%$ do total fornecido. A Figura 5.1 apresenta um perfil dos usos da água no estado de Minas Gerais.

Deve-se observar que, entre as categorias de usuários que recebem água da COPASA, não se inclui a agropecuária. Para atender às necessidades das atividades agropecuárias, a captação de água é feita diretamente nos corpos d'água pelos usuários.

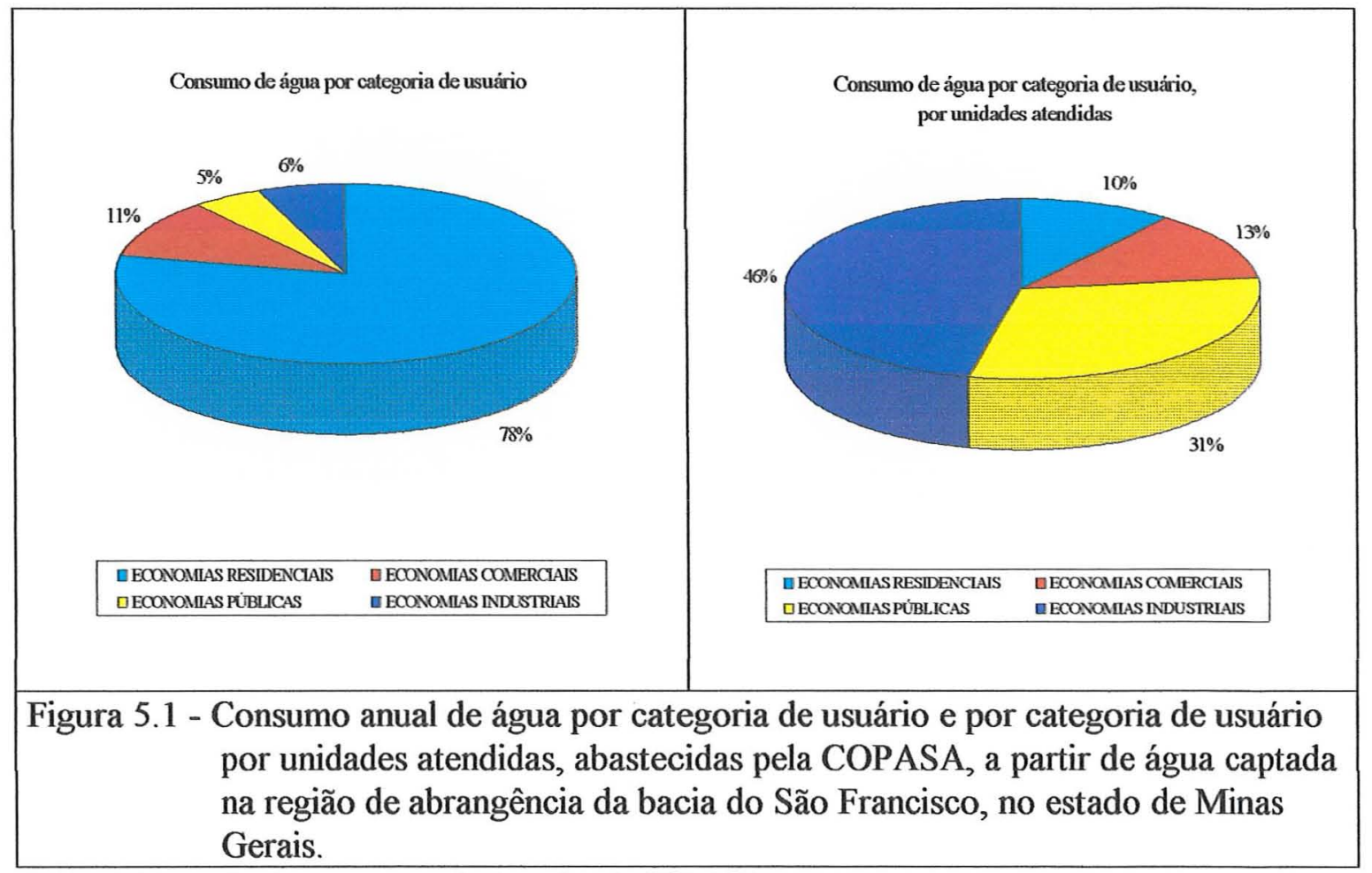

Fonte: Elaboração da autora a partir de dados da COPASA.

\footnotetext{
${ }^{35}$ As classificação das categorias de usuários apresentada nessa seção foi adotada pela Superintendência de Planejamento e Controle da COPASA MG.
} 
Os usos da água, objeto da presente pesquisa, são os que decorrem da sua captação direta nos corpos d'água superficiais da bacia hidrográfica e da que é realizada por meio da abertura de poços. Destinam-se ao atendimento das necessidades urbanas, industriais e da agropecuária. Associado a essas atividades está o uso consuntivo de cada setor. Entende-se por uso consuntivo aquele em que há perda de parte da água captada, seja por evaporação, nos sistemas de condução, seja pela incorporação ao processo produtivo. Outra questão importante é que os sistemas de captação, condução e distribuição da água para os diversos usos não são $100 \%$ eficientes pois existem perdas. Em estudo realizado pela secretaria do Meio Ambiente do estado de São Paulo (1994), considerou-se uma perda média de $35 \%$ do volume captado na estimativa do consumo urbano de água. Freitas (1997) ao estimar o consumo total de água no estado de Minas Gerais, considerou $27 \%$ de perda nos sistemas de abastecimento (urbano e industrial), percentual que se elevou para $35 \%$ nos sistemas de irrigação. Considerando-se esses aspectos, além de outros fatores que podem influenciar o consumo de água, assumiu-se a hipótese de que o volume da água utilizado pelos setores da economia na bacia corresponde a $65 \%$ da vazão de captação das outorgas concedidas.

Foram selecionados 26 setores produtivos e, para estimativa do consumo de água, buscou-se um critério em que se considerasse a localização da indústria na área geográfica da bacia hidrográfica do rio São Francisco. Portanto, para os estados da Bahia e de Pernambuco atribuiu-se zero ao consumo das indústrias cuja existência não foi identificada na região de abrangência da bacia.

Com o objetivo de se relacionar o consumo de água ao valor da produção, foram calculados coeficientes de consumo de água. $\mathrm{O}$ primeiro passo foi estimar o consumo médio da economia ( $\mathrm{CMe}$ ), para cada estado, por meio da divisão do volume total de água consumido no ano, pelo produto total anual da economia. Também calculou-se o consumo médio por setor da economia $\left(\mathrm{CMe}_{i}\right)$ procedendo-se a divisão do volume total de água consumido no ano, pelo produto total anual do setor $i$, para cada estado analisado. O passo seguinte foi a obtenção da relação $C M e_{i} / C M e$, cujo resultado expressa o coeficiente de consumo de água, em relação à média, por setor da economia 
$\left(C C A_{i}\right)$. Finalmente, os coeficientes de consumo de água para os setores do sistema interregional do São Francisco foram obtidos por meio da seguinte relação:

$$
C A_{i}=P_{i} \times C C A_{i} \times C M_{e}
$$

onde

$P_{i} \quad=$ valor da produção por setor, em $\mathrm{R} \$ 1.000$ por ano;

$C M_{e}=$ coeficiente médio de consumo de água na economia, $\mathrm{em} \mathrm{m}^{3} / \mathrm{R} \$ 1.000$ por ano;

$C C A_{i}=$ coeficiente de consumo de água em relação à média da economia, por setor (adimensional);

$C A_{i}=$ consumo de água por setor da economia, $\mathrm{em} \mathrm{m}^{3} /$ ano.

Para que se possa determinar o coeficiente de uso da água para um setor em particular da economia, divide-se a quantidade total de água consumida pelo setor pelo seu produto bruto total. Assim determinados, esses coeficientes relacionam os insumos fisicos com os produtos totais.

Os coeficientes de uso de água são importantes auxiliares para a determinação dos requisitos interindustriais de água, permitindo uma análise mais articulada do uso do recurso, principalmente em áreas nas quais ele é escasso. Podendo ser utilizados tanto para análise estrutural quanto para projeções.

Uma vez obtida a matriz de coeficientes de água, a correspondente matriz de "conteúdo de água" (water contents matrix) para a região deverá ser estimada. Essa matriz é determinada por meio da entrada consecutiva dos elementos do vetor de coeficientes de água ao longo da diagonal principal. Os elementos fora dessa diagonal assumem o valor zero. A matriz de "conteúdo de água" será, então, pré-multiplicada pela matriz inversa de Leontief transposta do modelo inter-regional para produzir a matriz inter-regional de uso de água ou tabela de insumos de água. 
A partir dessa matriz poderão ser derivadas as interdependências entre os setores da economia da região considerados seus requerimentos do "insumo" água, isto é, os usos do insumo água. 


\section{ANÁLISE DA ESTRUTURA PRODUTIVA: OS SETORES-CHAVE DA ECONOMIA BRASILEIRA E DAS ECONOMIAS DO SISTEMA INTER- REGIONAL}

Utilizando os instrumentais analíticos mais relevantes da literatura de insumoproduto, procurou-se identificar as relações intersetoriais da região econômica denominada, nesse estudo, região do São Francisco, constituída pelas economias dos estados de Minas Gerais, Bahia e Pernambuco.

A identificação das ligações e dos setores-chave de uma economia tem sido ressaltada na literatura como importante auxiliar para o planejamento e adoção de políticas de desenvolvimento regional.

Os instrumentais analíticos da teoria de insumo-produto permitem a identificação das ligações para frente e para trás de Rasmussen/Hirschman, do campo de influência, dos índices puros e da matriz de intensidade que, por sua vez, possibilitam a caracterização detalhada de importantes aspectos da estrutura produtiva inter-regional.

Ao se discutir as peculiaridades do sistema inter-regional buscou-se, quando possível, apresentar alguns aspectos da economia brasileira de 1995 de cuja matriz o modelo inter-regional foi derivado.

\section{1 Índices de Ligações de Rasmussen/Hirschman}

Visando identificar as interligações entre as economias dos três estados analisados na área da bacia hidrográfica do rio São Francisco e as da economia brasileira, no ano de 1995, foram estimados os índices de ligações segundo Rasmussen/Hirschman, cujos resultados são apresentados nas Tabela 6.1 e 6.2 e Figuras 6.1, 6.2, 6.3 e 6.4 para os 78 setores do sistema inter-regional, sendo 26 setores produtivos para cada região e para 0 Brasil. Na figura 6.5 apresentam-se, de forma resumida e padronizada, os índices de 
ligações para trás e para frente de cada estado que compõe o modelo inter-regional do São Francisco e do Brasil, incluindo-se o grau das ligações inter-regionais. Os estados que constituem o modelo inter-regional também são referenciados, nesse capítulo, como regiões econômicas.

A análise dos índices de ligações, segundo Rasmussen/Hischman, revela o grau de interação setorial da economia num determinado período de tempo. Aqueles setores da economia que apresentam índices de ligações para trás acima da média, são os que mais compram dos demais. Dessa forma, podem-se identificar os setores mais dinâmicos sob o ponto de vista da demanda. Os setores que apresentam ligações para frente, acima da média, são aqueles que mais vendem insumos e produtos para os demais, sendo, então, os mais dinâmicos sob a ótica da oferta.

Por serem normalizados, esses índices são independentes das unidades de medida, permitindo que se façam comparações interindustriais, inter-regionais, internacionais e intertemporais. Dados os objetivos deste estudo, a comparação da estrutura interna das economias do modelo inter-regional do São Francisco visou revelar seus encadeamentos.

Buscando traçar um perfil da economia das regiões que compõem o modelo interregional e identificar as ligações da economia brasileira, foram calculados os índices de Rasmussen/Hirschman para os 26 setores considerados nesse estudo (Tabela 6.1 e Figura 6.1).

Pode-se verificar que as ligações mais fortes para trás, no agregado nacional, são as da indústria de Produtos Alimentares (setor 16), com a segunda posição ocupada pela Siderurgia e Metalurgia (setor 4). É interessante ressaltar, aqui, a inversão da ordem de importância desses setores com relação às posições obtidas na economia da região do São Francisco, notadamente no estado de Minas Gerais, onde a Siderurgia e Metalurgia ocupa a primeira, cabendo à indústria de Produtos Alimentares a segunda posição. no ranking do sistema inter-regional do São Francisco (Tabela 6.2).

Ainda no que se refere às ligações para trás da economia brasileira, a terceira, quarta, quinta e sexta posições no ranking nacional, são ocupadas, respectivamente, pela 
Indústria Têxtil (setor 14), Material de Transporte (setor 7), Vestuário e Calçados (setor 15) e pela Indústria da Borracha (setor 10).

Tabela 6.1 - Índices de ligações de Rasmussen-Hirschman para o Brasil, 1995

\begin{tabular}{clcccc}
\hline \multicolumn{1}{c}{ Setor } & Trás & Ordem & Frente & Ordem \\
\hline 1 & Agropecuária & 0.873 & 20 & 1.502 & 3 \\
2 & Extrativa Mineral & 1.004 & 15 & 0.870 & 13 \\
3 & Minerais Não Metálicos & 1.082 & 10 & 0.881 & 12 \\
4 & Siderurgia e Metalurgia & 1.255 & 2 & 1.882 & 2 \\
5 & Mecânica & 0.959 & 17 & 0.916 & 11 \\
6 & Material Elétrico e Eletrôn. & 1.037 & 13 & 0.731 & 19 \\
7 & Material de Transporte & 1.192 & 4 & 0.839 & 16 \\
8 & Madeira e Mobiliário & 1.083 & 9 & 0.700 & 21 \\
9 & Papel e Gráfica & 1.142 & 7 & 1.014 & 9 \\
10 & Indústria da Borracha & 1.161 & 6 & 0.863 & 14 \\
11 & Indústria Química & 1.030 & 14 & 2.530 & 1 \\
12 & Farmacêutica e Perfumaria & 0.984 & 16 & 0.561 & 26 \\
13 & Artigos de Plástico & 1.054 & 11 & 0.747 & 18 \\
14 & Indústria Têxtil & 1.210 & 3 & 1.214 & 6 \\
15 & Vestuário e Calçados & 1.189 & 5 & 0.598 & 25 \\
16 & Produtos Alimentares & 1.266 & 1 & 0.965 & 10 \\
17 & Indústrias Diversas & 1.040 & 12 & 0.655 & 24 \\
18 & S I U P & 0.860 & 22 & 1.184 & 7 \\
19 & Construção Civil & 0.878 & 19 & 0.663 & 23 \\
20 & Comércio & 0.864 & 21 & 1.308 & 4 \\
21 & Transportes & 0.905 & 18 & 1.083 & 8 \\
22 & Comunicações & 0.677 & 25 & 0.677 & 22 \\
23 & Instituições Financeiras & 0.738 & 24 & 0.855 & 15 \\
24 & Administração Pública & 0.545 & 26 & 0.782 & 17 \\
25 & Aluguel de Imóveis & 1.119 & 8 & 0.710 & 20 \\
26 & Outros Serviços & 0.855 & 23 & 1.271 & 5 \\
\hline & Padrão médio das ligações & 1.000 & & 1.000 & \\
\hline Fon & Valores Etimas pa ara & & & &
\end{tabular}

Fonte: Valores estimados pela autora. 


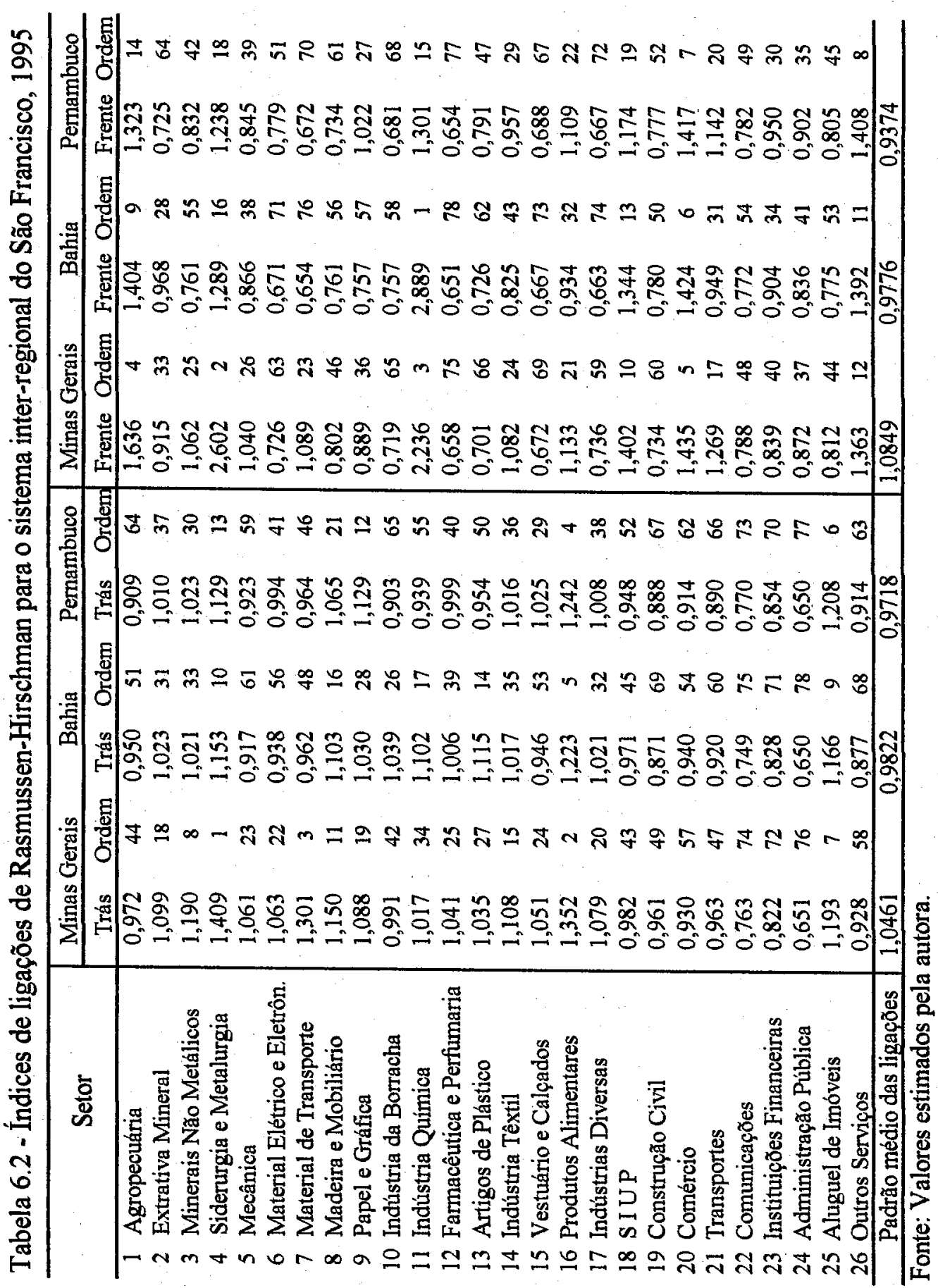




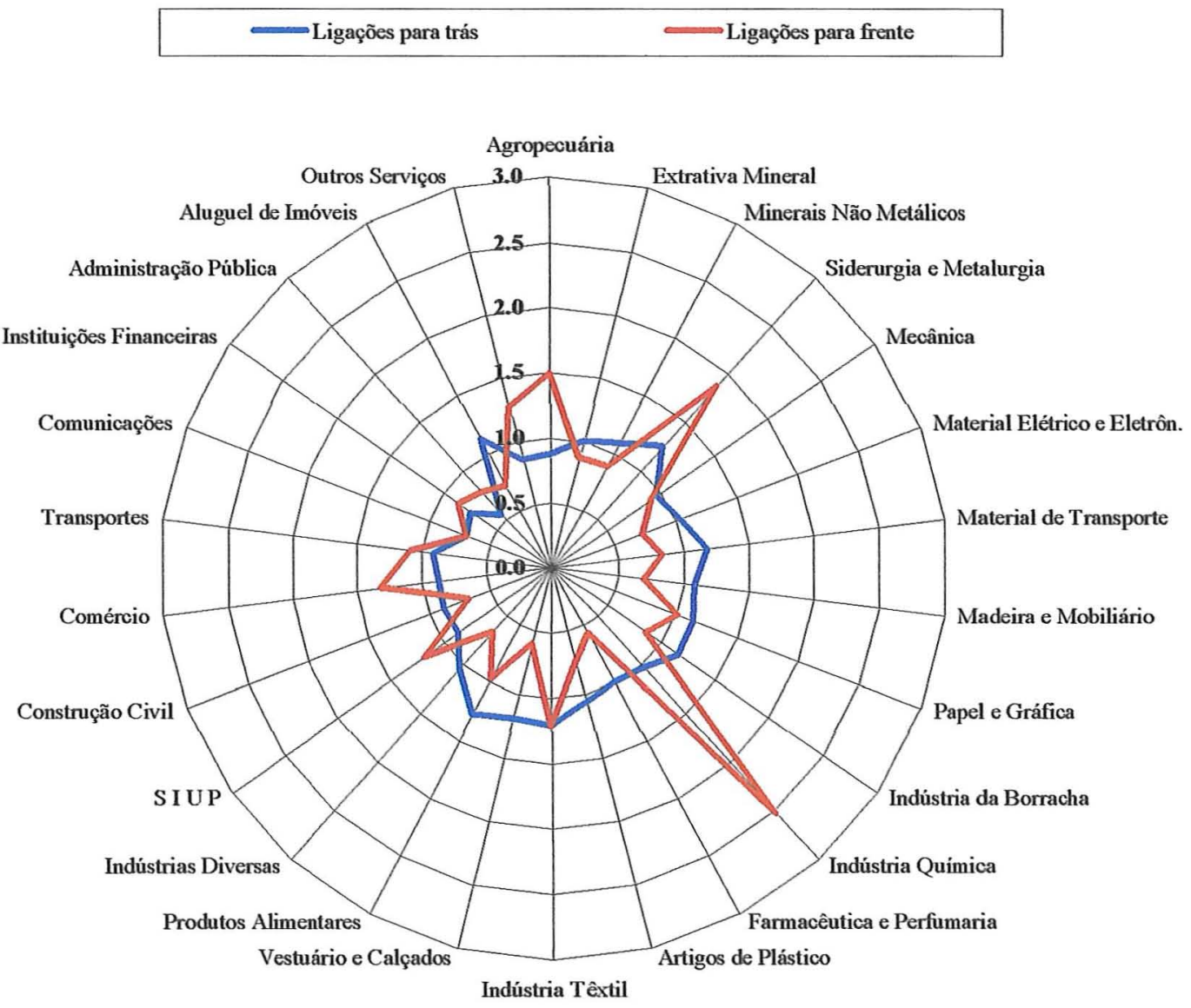

Figura 6.1 - Ligações para trás e para frente de Rasmussen/Hirschman para o Brasil.

Ao se observar as ligações para frente da economia brasileira percebem-se semelhanças do padrão das ligações regionais com o nacional. Os setores com as ligações para frente mais fortes na economia brasileira, Indústria Química (setor 11), primeira posição, e Siderurgia e Metalurgia (setor 4), segunda posição, também recebem a mesma ordenação no sistema inter-regional. 
Considerando as ligações para frente do sistema inter-regional, verifica-se que o setor mais dinâmico do conjunto, sob a ótica da oferta, é a Indústria Química (setor 11), do estado da Bahia, seguida pela Siderurgia e Metalurgia (setor 4), do estado de Minas Gerais. Esse comportamento dos índices sugere que o padrão das economias desses estados - o de fornecedoras de produtos básicos para a economia - dadas as características das duas principais indústrias do sistema, vem-se mantendo ao longo dos anos.

Novamente considerando as ligações para frente da economia brasileira, verifica-se que a Agropecuária (setor 1), o Comércio (setor 20), Outros Serviços (setor 26) e a Indústria Têxtil (setor 14) ocupam, respectivamente, da terceira à sexta posições na ordem da magnitude dos índices. No ranking das ligações para frente da economia regional, o padrão revela-se muito semelhante ao do país.

A Figura 6.1 permite a visualização conjunta do padrão das ligações para trás e para frente da economia brasileira, em 1995, exibindo os setores mais importantes no conjunto selecionado para esse estudo.

No caso do sistema inter-regional, considerando-se a ordenação dos valores dos índices de ligações para trás, na Tabela 6.2, os setores que ocupam as três primeiras posições são, respectivamente: Siderurgia e Metalurgia (setor 4), Produtos Alimentares (setor16) e Material de Transporte (setor 7) do estado de Minas Gerais. A quarta posição é ocupada pelo setor Produtos Alimentares (setor 16) do estado de Pernambuco. Esse mesmo setor do estado da Bahia ocupa a quinta posição no sistema inter-regional. Percebe-se, claramente, pelos setores assinalados, que outra ordem de importância é estabelecida na economia regional quando se compara com a do Brasil.

$\mathrm{Na}$ ordenação dos índices de ligações para frente, a primeira posição é ocupada pela Indústria Química (setor 11) do estado da Bahia, sendo a segunda, terceira, quarta e quinta posições ocupadas, respectivamente pelos setores Siderurgia e Metalurgia (setor 4), Indústria Química (setor 11), Agropecuária (setor 1), e Comércio (setor 20) do estado de Minas Gerais. Esse último setor também ocupa a sexta posição do ranking interregional no estado da Bahia e a sétima no estado de Pernambuco. 
Na Figura 6.2 pode-se observar que o estado de Minas Gerais é o que possui uma estrutura industrial mais articulada, apresentando os maiores índices de ligações para frente e para trás em relação à média no sistema inter-regional do São Francisco.

Os estados da Bahia e de Pernambuco exibem padrões de ligações mais fracas, com índices médios mais baixos (Tabela 6.2 e Figuras 6.3 e 6.4).

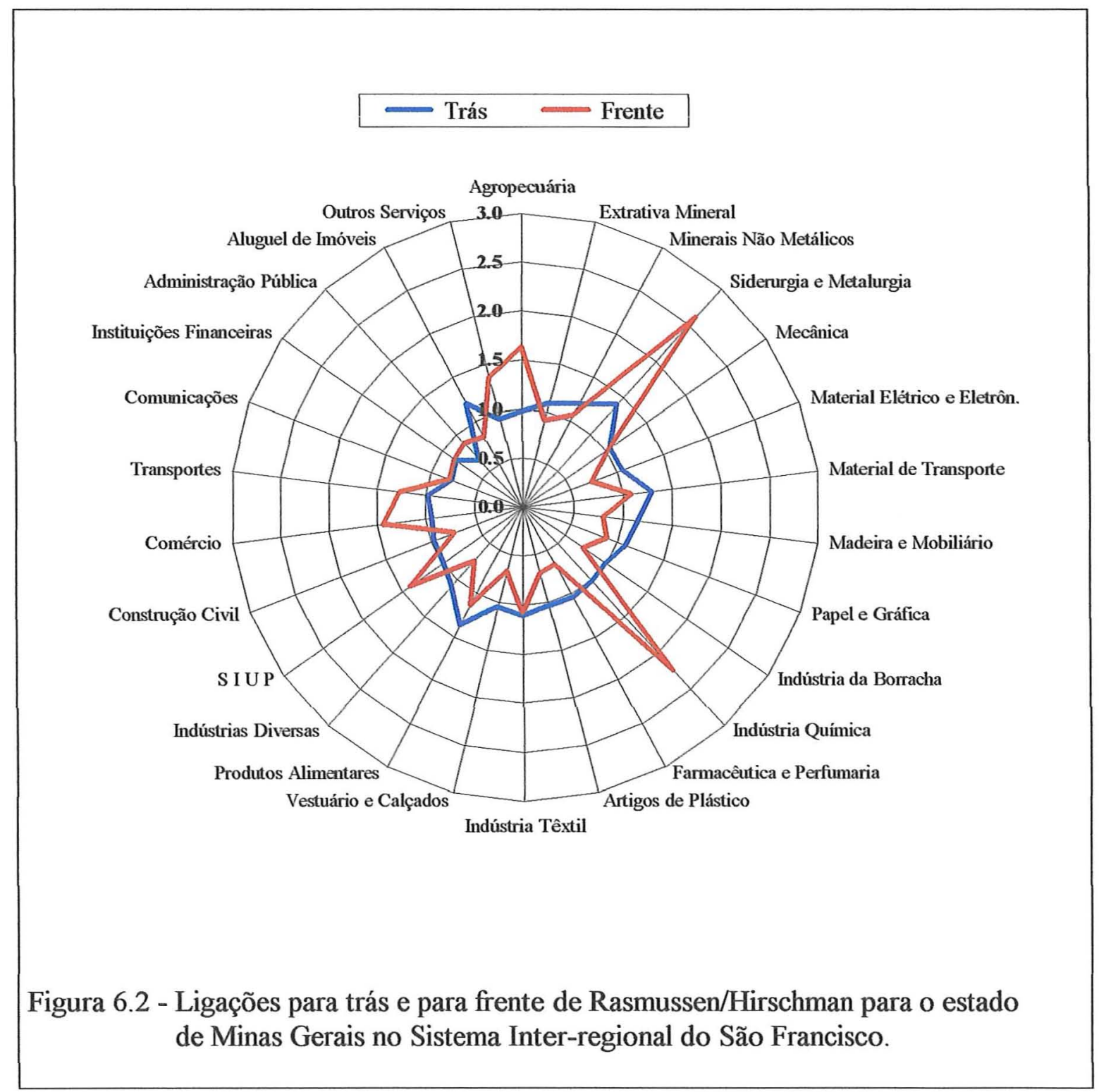


Segundo a proposição de uma definição mais estrita de setor-chave (McGilvray, 1977) que elege apenas aquele que apresenta, simultaneamente, índices de ligações para trás e para frente maiores que 1 , verifica-se a permanência do padrão de industrialização do estado de Minas Gerais, com ênfase no ramo de Bens Intermediários, destacando-se, como setor-chave no sistema inter-regional, o da Siderurgia e Metalurgia (setor 4), com fortes ligações para trás $(1,4088)$ e para frente $(2,6021)$.

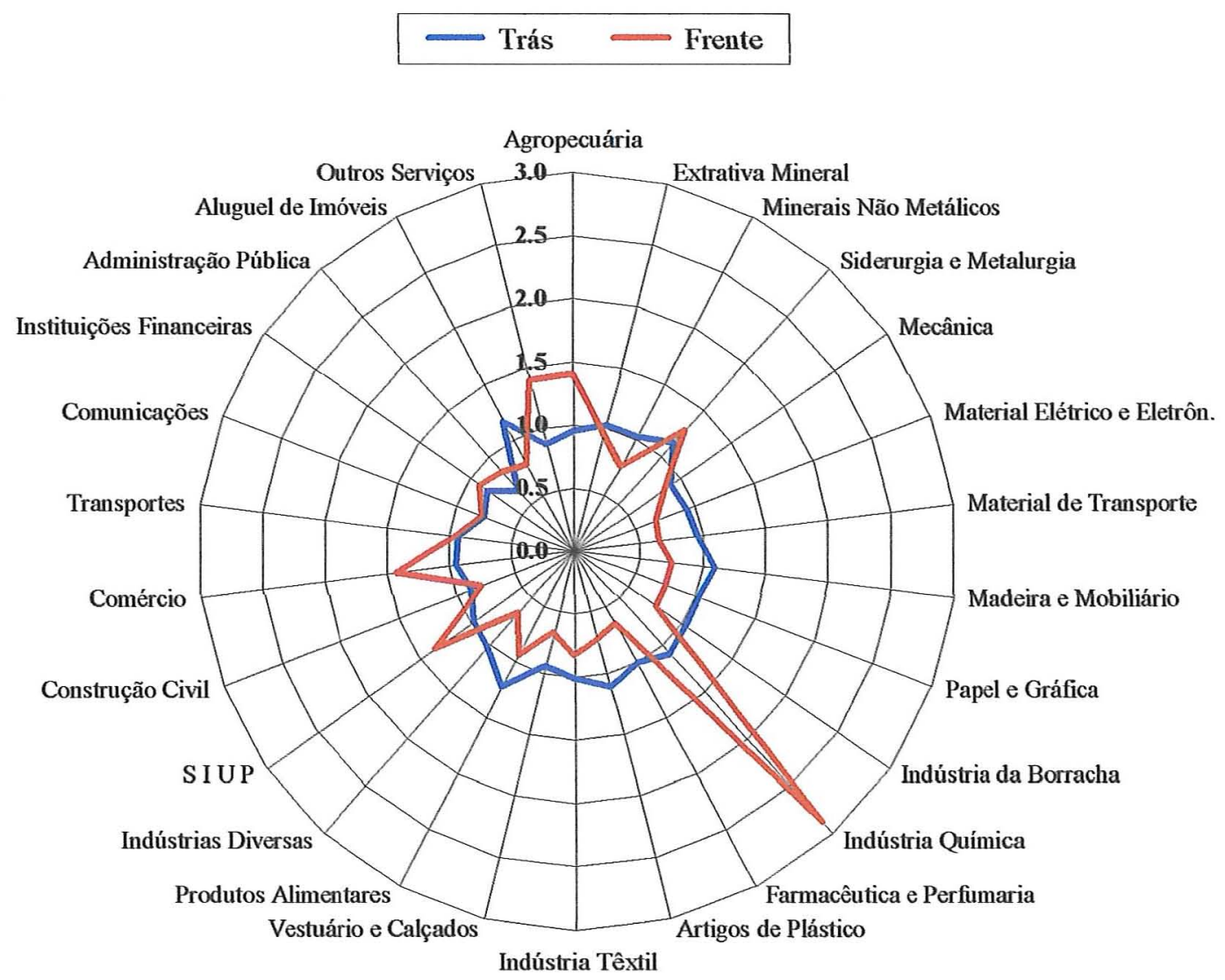

Figura 6.3 - Ligações para trás e para frente de Rasmussen/Hirschman para o estado da Bahia no Sistema Inter-regional do São Francisco. 
No contexto do sistema inter-regional, ainda são identificados, nesse mesmo estado, mais seis setores-chave (setores 3, 5, 7, 11, 14 e 16). Desses, a Indústria Química (setor 11) apresenta fortes ligações para frente $(2,2359)$. Essa mesma indústria também destaca-se como setor-chave no estado da Bahia, apresentando o mais alto índice de ligação para frente de todo o sistema inter-regional $(2,8886)$. Também um setor chave nesse estado é o da Siderurgia e Metalurgia (setor 4).

No estado de Pernambuco, são identificados três setores-chave, o da Siderurgia e Metalurgia (setor 4), o de Papel e Gráfica (setor 9) e o de Produtos Alimentares (setor 16), mesmo que na ordenação do modelo inter-regional ocupem posições mais baixas que os setores dos outros estados.

Sob o enfoque mais restrito da classificação de setor-chave, identificam-se quatro na economia brasileira: a Indústria Química (setor 11), a Siderurgia e Metalurgia (setor 4), a Indústria Têxtil (setor 14) e a de Papel e Gráfica (setor 9). As ligações intersetoriais mais fortes ocorrem para os setores da Indústria de Transformação, tanto para o Brasil quanto para as economias do sistema inter-regional do São Francisco.

Considerando-se o sistema inter-regional, o estado de Minas Gerais é o que apresenta maior número de setores-chave (sete) e, desses, apenas três recebem a mesma classificação na economia brasileira (setores 4, 11 e 16), demonstrando características intrinsecamente regionais na economia desse estado. A Bahia apresenta apenas dois setores-chave (setores 4 e 11), coincidindo com os do Brasil. $O$ estado de Pernambuco apresenta três setores-chave (setores 4,9 e 16) e, dentre eles, apenas a indústria de Produtos Alimentares não recebe a mesma classificação no contexto nacional (Tabela $6.1)$.

Pode-se, ainda, delinear o perfil das estruturas das transações inter-regionais, optando-se pela classificação dos setores-chave segundo os critérios de Rasmussen/Hischman, de forma menos rigida que a do conceito restrito. Este estabelece que aqueles que apresentarem índices de ligações maiores que 1 constituem setores-chave 
para o crescimento da economia. Dessa forma, no modelo inter-regional do São Francisco, um maior número de indústrias fará parte desse grupo.

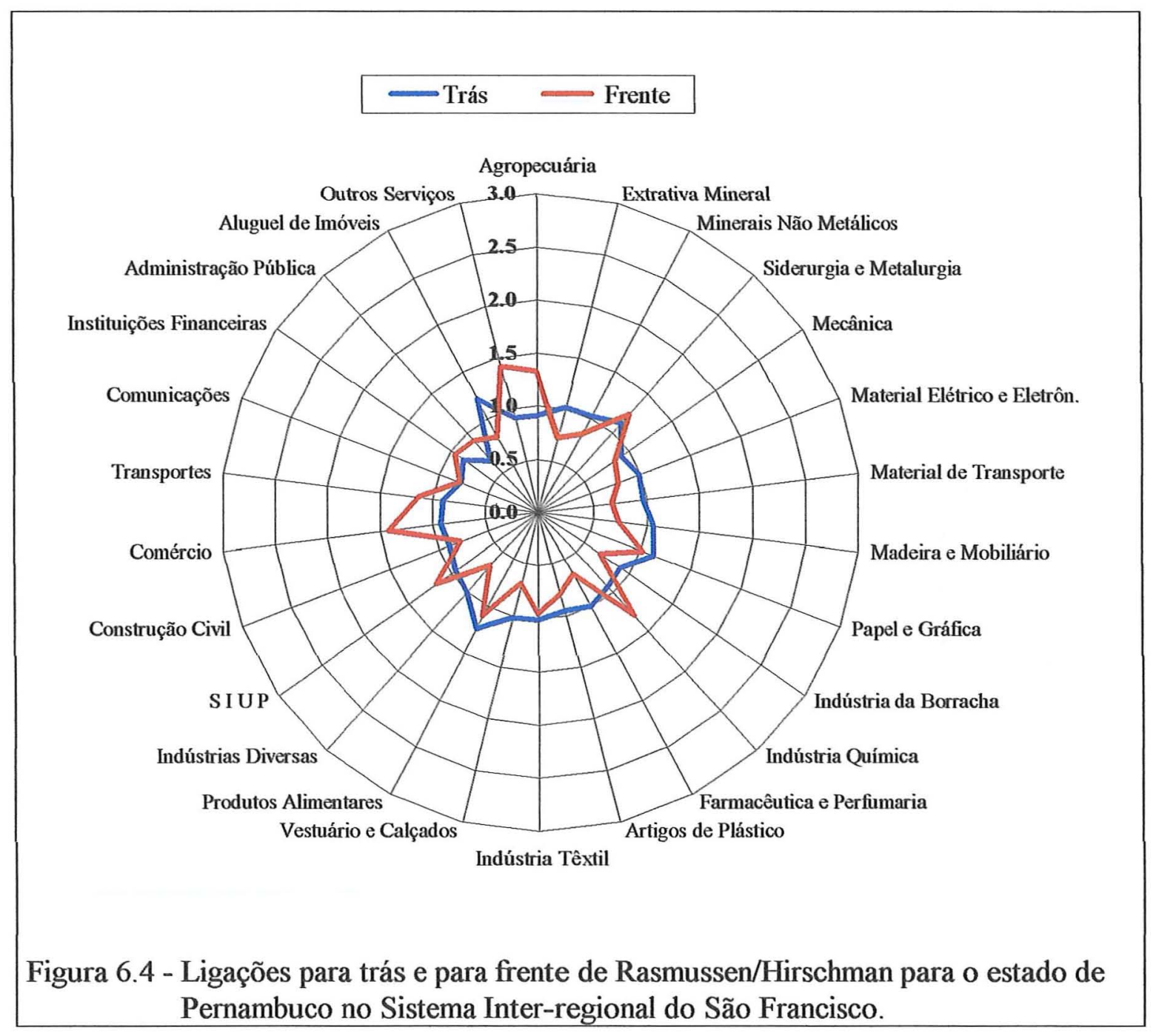

Sob o conceito menos restrito, no estado de Minas Gerais são identificados, além daqueles já mencionados, mais quatorze setores-chave, sendo nove com ligações para trás mais fortes (setores $2,6,8,9,12,13,15,17$ e 25 ) e cinco com ligações mais fortes para frente (setores 1, 17, 20, 21 e 26). No estado da Bahia são, sob esse enfoque, mais onze os setores com ligações para trás mais elevadas (setores $2,3,8,9,10,12,13,14$, 
16,17 , e 25) e quatro com as ligações para frente elevadas (setores $1,18,20$ e 26 ). Pernambuco apresenta mais sete setores com índices de ligações para trás maiores que a unidade (setores $2,3,8,14,15,17$ e 25) e seis setores com ligações para frente acima desse valor (setores $1,11,18,20,21$ e 26).

Para o Brasil, contabilizam-se, sob esse critério mais amplo, mais onze setores com ligações para trás maiores que a unidade e mais cinco setores com ligações para frente acima desse valor.

O setor Agropecuária apresenta ligações para frente acima da média em todos os estados do sistema inter-regional. $\mathrm{O}$ mesmo ocorre quando se considera a economia brasileira como um todo. Torna-se evidente o importante papel desse setor, sob a ótica da oferta de insumos e produtos. Na região estudada, a Agropecuária tem desempenhado um importante papel como indutora do crescimento, especialmente quando se considera o potencial da agricultura irrigada, principalmente no norte de Minas Gerais, na região do Médio São Francisco no estado da Bahia e na região do Sub-Médio São Francisco, em Pernambuco, além de outras áreas de expansão da agropecuária nesses estados.

Observa-se que a participação do grupo das indústrias pertencentes ao Setor Terciário (setores 20, 21, 25 e 26) apresenta-se, na economia inter-regional, com ligações para frente acima da média, comportamento que também é verificado nos setores 20,21 e 26 da economia brasileira. Fica claro o predomínio dos setores compradores pertencentes à Indústria de Transformação - os de ligações para trás mais elevadas - como setoreschave da economia inter-regional e também na economia nacional.

Em síntese, pode-se verificar que, na economia inter-regional, o estado de Minas Gerais apresenta uma indústria diversificada, seguida pela indústria do estado da Bahia. $O$ estado de Pernambuco é o que apresenta o padrão de ligações intersetoriais mais fraco do conjunto. O Brasil apresenta o padrão médio das ligações. Por meio do perfil apresentado, verifica-se que, no sistema inter-regional, o estado de Minas Gerais é o único a apresentar um padrão acima da média, refletindo uma economia mais articulada que a dos outros dois estados da região consideradas nesta pesquisa (Figura 6.5). 


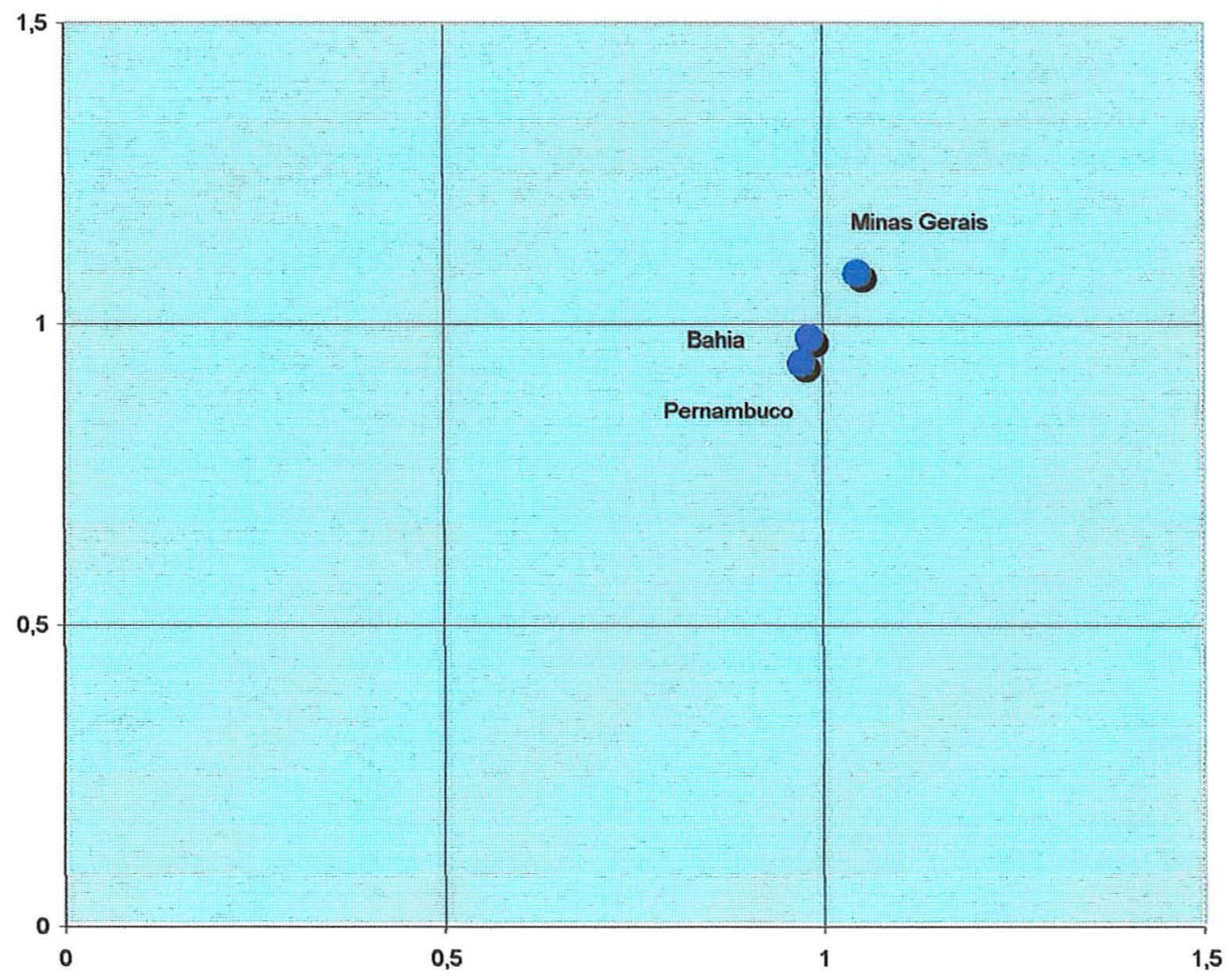

Figura 6.5 - Síntese do padrão médio das ligações de Rasmussen/Hirschman para o Sistema Inter-regional do São Francisco e o Brasil.

\subsection{Matrizes de Intensidade - Aplicação ao Sistema Inter-regional do}

\section{São Francisco}

Usando as matrizes insumo-produto construídas para os estados que constituem o sistema inter-regional da bacia hidrográfica do São Francisco e as medidas de intensidade descritas na seção 4.2, buscou-se comparar suas estruturas econômicas.

Segundo Sonis, Hewings e Guo (1997) a abordagem das "topografias econômicas" da estrutura de produção é consistente com a abordagem de Rasmussen e Hirschman, constituindo um instrumento complementar para identificação de diferenças e 
similaridades entre as economias estudadas, sem, contudo, substituir as outras abordagens. Sua aplicação empírica deve ser, então, considerada como um primeiro estágio de análise, que pode ajudar ao chamar a atenção para as diferenças e semelhanças que irão emergir entre as estruturas das economias estudadas.

O estado de Minas Gerais, pelas características de sua economia, foi o escolhido como base de comparação, ou seja, a economia mineira foi escolhida como numeráire. Desse modo, a hierarquia dos fluxos retratada pela matriz de intensidade de Minas Gerais foi associada com uma ordenação de linhas e colunas. Para os outros dois estados, essa ordenação foi mantida, permitindo que os desvios da hierarquia do estado de Minas Gerais se tornassem mais explícitos, possibilitando, dessa forma, o exame da natureza das diferenças entre as três economias.

A estrutura da economia do estado de Minas Gerais está retratada na Figura 6.6, onde as linhas representam a hierarquia das ligações para frente, enquanto as colunas mostram detalhes similares para as ligações para trás. $O$ pico mais alto da hierarquia da estrutura econômica de Minas Gerais ocorreu no cruzamento das ligações para frente e para trás do setor Siderurgia e Metalurgia (setor 4), seguido da interseção entre Indústria Química (setor 11) e Siderurgia e Metalurgia (setor 4). Observa-se que as maiores elevações ocorrem nos três primeiros cruzamentos. A partir deles há uma queda, e os cruzamentos seguintes vão decrescendo de forma mais suave.

As matrizes de intensidade dos estados da Bahia e de Pernambuco, construídas e ordenadas hierarquicamente segundo o ordenação estabelecida pelo estado de Minas Gerais estão representadas nas Figuras 6.7 e 6.8. Pode-se constatar que essas duas economias apresentam estruturas nitidamente diferentes das do estado de Minas Gerais. Se as três economias apresentassem estruturas similares, as hierarquias seriam idênticas e as "topografias", bastante similares. 


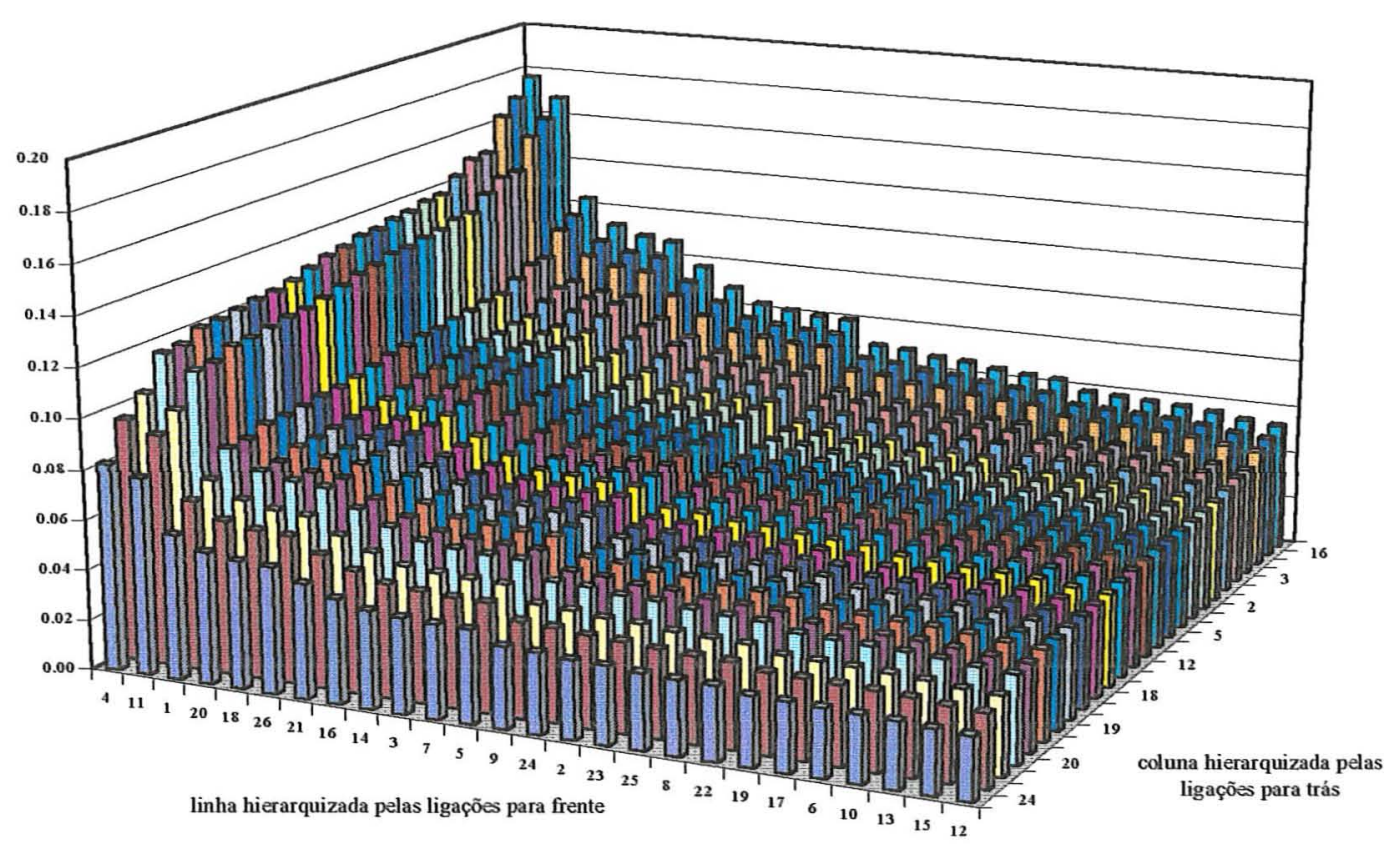

Figura 6.6 - Minas Gerais: Topografia das estruturas cruzadas para campos de intensidade de primeira ordem.

No caso da Bahia, o pico mais elevado apareceu no cruzamento da Indústria Química (setor 11) com Produtos Alimentares (setor 16), seguido pelo cruzamento entre a Indústria Química (setor 11) e Aluguel de Imóveis (setor 25). A partir deles, os cruzamentos seguintes apresentam ondulações, delineando uma estrutura bem diferente da apresentada pelo estado de Minas Gerais. Na Figura 6.7, pode-se observar que, pelas fortes ligações que a Indústria Química (setor 11) daquele estado possui, mesmo obedecendo à hierarquia da economia de Minas Gerais, os cruzamentos mais elevados ocorrem entre esse setor e os demais. Assim, fica evidenciada a diferença entre as estruturas produtivas desses estados. 
A estrutura econômica do estado de Pernambuco também é representada graficamente por uma superfície bastante ondulada (Figura 6.8). Nesse estado, o cruzamento mais elevado ocorre entre os setores Comércio (setor 20) e Aluguel de Imóveis (Setor 25), revelando pontos altos também para o cruzamento entre Comércio (setor 20) e Produtos Alimentares (setor 16). Podem-se destacar, ainda, os cruzamentos do setor Outros Serviços (setor 26) e Aluguel de Imóveis (setor 25) e, novamente, Outros Serviços (setor 26) e Produtos Alimentares (setor 16). Pela observação da Figura 6.8, percebe-se que os setores que apresentam os cruzamentos mais elevados são Comércio (setor 20) e Outros Serviços (setor 26). A topografia da economia de Pernambuco é bem diferente da apresentada pela economia do estado de Minas Gerais, verificando-se, naquele estado, as ligações mais fortes dos setores que compõem o grupo dos Serviços (como no caso dos setores 20 e 26).

Pelas estruturas apresentadas, pode-se constatar que as economias dos três estados apresentam diferenças significativas. Minas Gerais apresenta uma estrutura industrial mais interligada, com nítida predominância do setor Siderurgia e Metalurgia. No estado da Bahia as maiores interligações ocorrem com a Indústria Química, entretanto o estado exibe uma estrutura econômica menos interligada do que a de Minas Gerais. $\mathrm{O}$ estado de Pernambuco apresenta uma estrutura menos interligada, com cruzamentos intersetoriais menores que os dos dois primeiros. Verifica-se que há um predomínio dos setores que compõem o Setor Terciário na economia desse estado. 


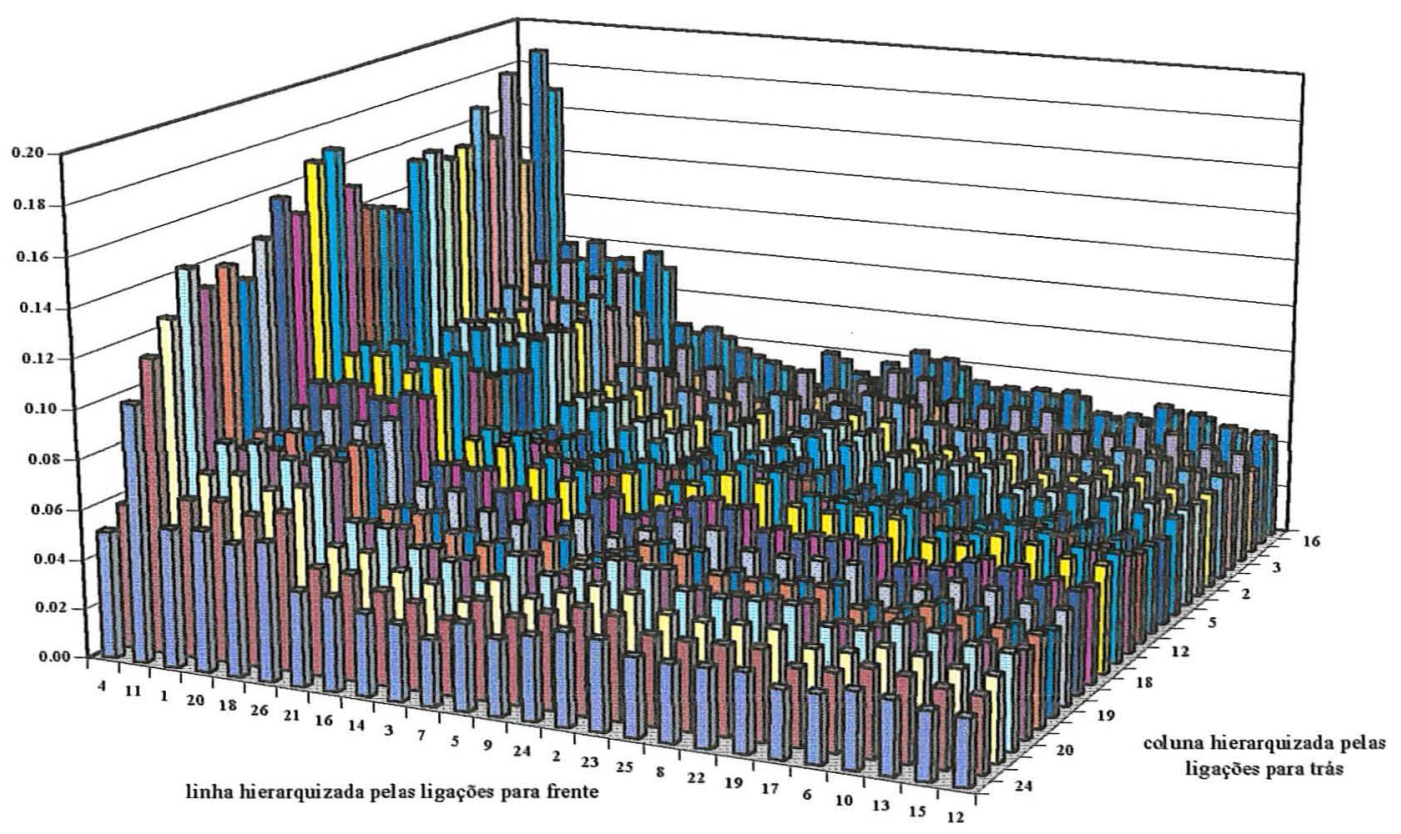

Figura 6.7 - Bahia: Topografia das estruturas cruzadas usando a hierarquia de Minas Gerais

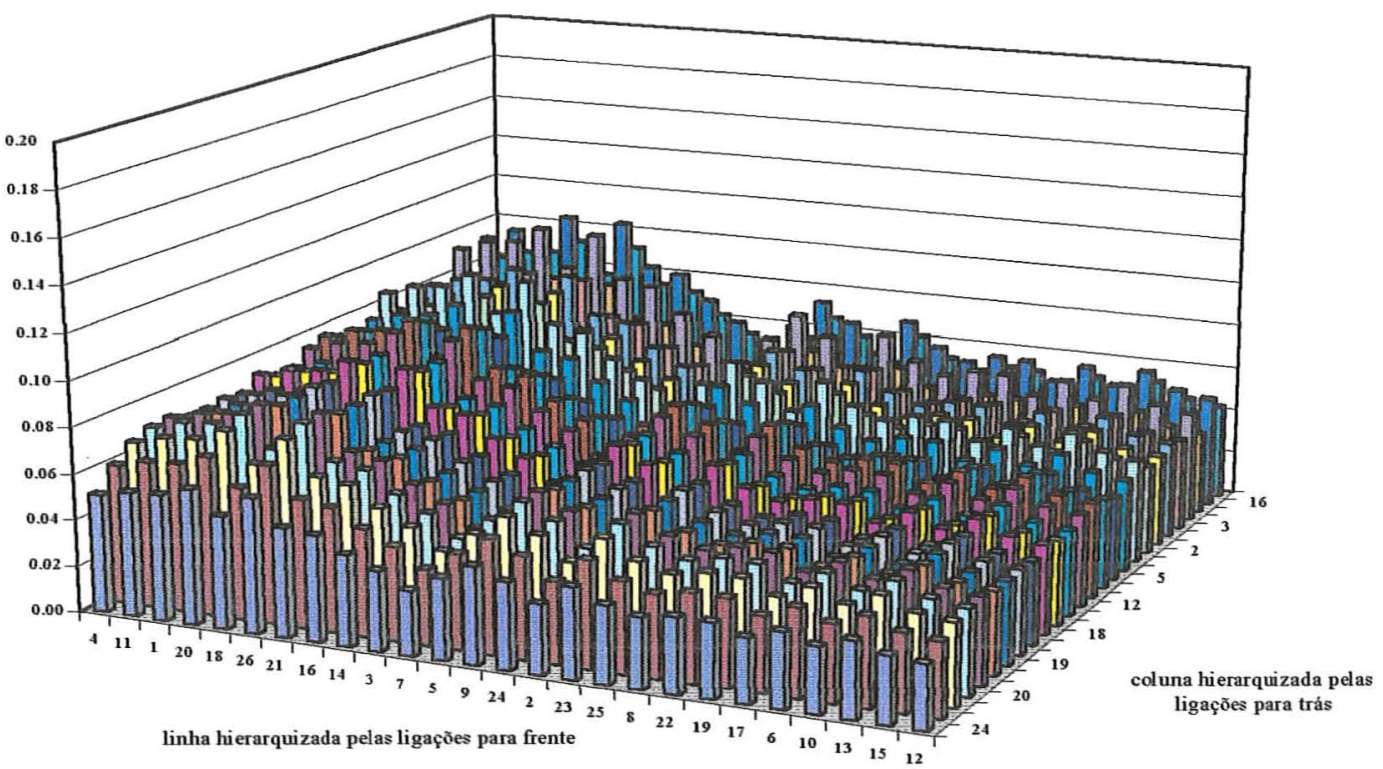

Figura 6.8 - Pernambuco: Topografia das estruturas cruzadas usando a hierarquia de Minas Gerais 


\subsection{Campo de Influência}

Visando complementar a análise dos índices de ligações de Rasmussen-Hirschman, aplicou-se o conceito de campo de influência para identificar quais setores-chave do sistema inter-regional do São Francisco apresentarão maior sensibilidade, se ocorrerem pequenas mudanças nos coeficientes de produção, que poderão afetar o resto da economia regional.

Nesta pesquisa, a técnica do campo de influência mostra-se especialmente interessante por possibilitar a identificação das relações de comércio intra e interregionais para a região do São Francisco.

No cálculo do campo de influência para a matriz de coeficientes técnicos do Brasil e do sistema inter-regional do São Francisco, considerou-se uma pequena variação, assumindo-se $\varepsilon$ de 0.001 . Nas Figuras 6.9 e 6.10 estão representados, respectivamente para o Brasil e para a região do São Francisco, os 67 e os 125 coeficientes setoriais com maior campo de influência.

Na Figura 6.9, pode-se verificar quais setores com maior influência sobre os demais na economia brasileira. São eles: Siderurgia e Metalurgia (setor 4), Indústria Química (setor 11) e Indústria Têxtil (setor 14). Confirmaram-se como setores-chave da economia segundo o conceito mais restrito dos índices de ligações de Rasmussen/Hirschman, ou seja, setores para os quais tanto os índices de ligações para frente quanto para trás são maiores que 1.

No rol dos setores com maior campo de influência, também sobressaem a indústria de Produtos Alimentares (setor 16) e os Serviços Industriais de Utilidade Pública - SIUP - (setor 18). Esses dois últimos são setores-chave segundo o conceito mais amplo dos índices de Rasmussen/Hirschman.

Dos 67 maiores coeficientes selecionados, a Siderurgia e Metalurgia (setor 4) apresenta 12 coeficientes de venda e 22 de compra, demonstrando sua importância quando se considera a estrutura interna da economia, ou seja, no caso de alterações na estrutura produtiva, esse setor apresenta-se como um dos responsáveis pela indução de 
maiores impactos na economia como um todo. Também revelando sua importância na estrutura interna da economia brasileira, a Indústria Química (setor 11) e a Indústria Têxtil (setor 14) apresentam, respectivamente, 3 e 10 coeficientes de venda e 13 e 12 coeficientes de compra de insumos.

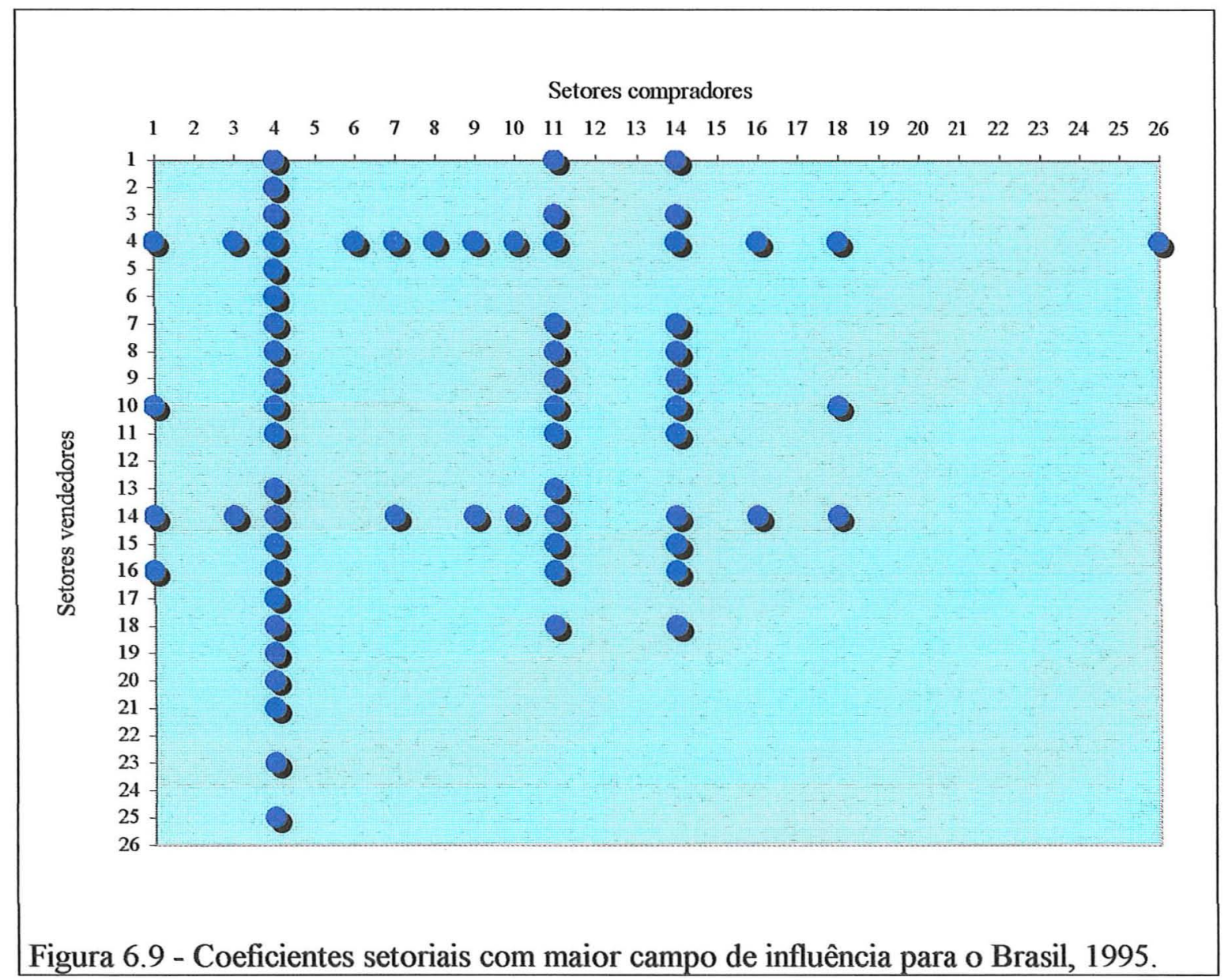

Numa análise para fins do estabelecimento de políticas industriais, é importante mencionar que as relações setoriais representadas pelos maiores valores no campo de influência, para obtenção de melhores resultados com sua implantação, requereriam que os setores fossem caracterizados como compradores de insumos, o que ocorre com os três principais setores assinalados. 
No sistema inter-regional, os principais elos de ligação da economia refletem o predomínio dos dois principais setores-chave, segundo os índices de Rasmussen/Hirschman: a Siderurgia e Metalurgia (setor 4), do estado de Minas Gerais, e a Indústria Química (setor 37), da Bahia, conforme a ordenação dos setores apresentada na Figura 6.10. Pode-se dizer, então, que se ocorrerem mudanças nos coeficientes desses dois setores, elas provocarão maior impacto na economia regional como um todo.

O setor Siderurgia e Metalurgia relaciona-se com a maioria dos, senão todos, outros setores do sistema inter-regional, o mesmo acontecendo com a Indústria Química. Com menos intensidade que os dois primeiros, o setor de Serviços Industriais de Utilidade Pública - SIUP - (setor 18) também distingue-se no modelo.

No contexto inter-regional, vê-se que, pelos coeficientes apresentados, os estados de Minas Gerais e da Bahia possuem elos de ligações mais fortes entre si, relacionando-se com menor intensidade com o estado de Pernambuco. Portanto, pela observação da Figura 6.10, constata-se que o estado de Minas Gerais apresenta-se como a regiáo mais dinâmica do sistema tanto sob o ponto de vista intra quanto inter-regional. $\mathrm{O}$ estado da Bahia apresenta-se, no sistema, com alguns setores dinâmicos tanto intra quanto interregionalmente. Já o de Pernambuco apresenta relações fracas internamente o mesmo acontecendo com as relações inter-regionais.

A Siderurgia e Metalurgia do estado de Minas Gerais, por meio dos insumos que demanda, aciona a maioria dos setores produtivos do próprio estado, bem como os da Bahia e de Pernambuco.

Tomando-se como exemplo a Indústria Química (setor 37) do estado da Bahia, e considerando a ordenação dos setores da Figura 6.10, para ilustrar as relações intersetoriais intra e inter-regionais, vê-se que ela aciona, pelos insumos que demanda, a Agropecuária (setor 1), Minerais Não Metálicos (setor 3), Siderurgia e Metalurgia (setor 4), Material de Transporte (setor 7), Indústria Química (setor 11), Indústria Têxtil (setor 14), Produtos Alimentares (setor 18), no estado de Minas Gerais. Também compra da Siderurgia e Metalurgia (setor 56), Papel e Gráfica (setor 61), Indústria Têxtil (setor 66), Produtos alimentares (setor 68) e do SIUP (setor 70), do estado de Pernambuco. 


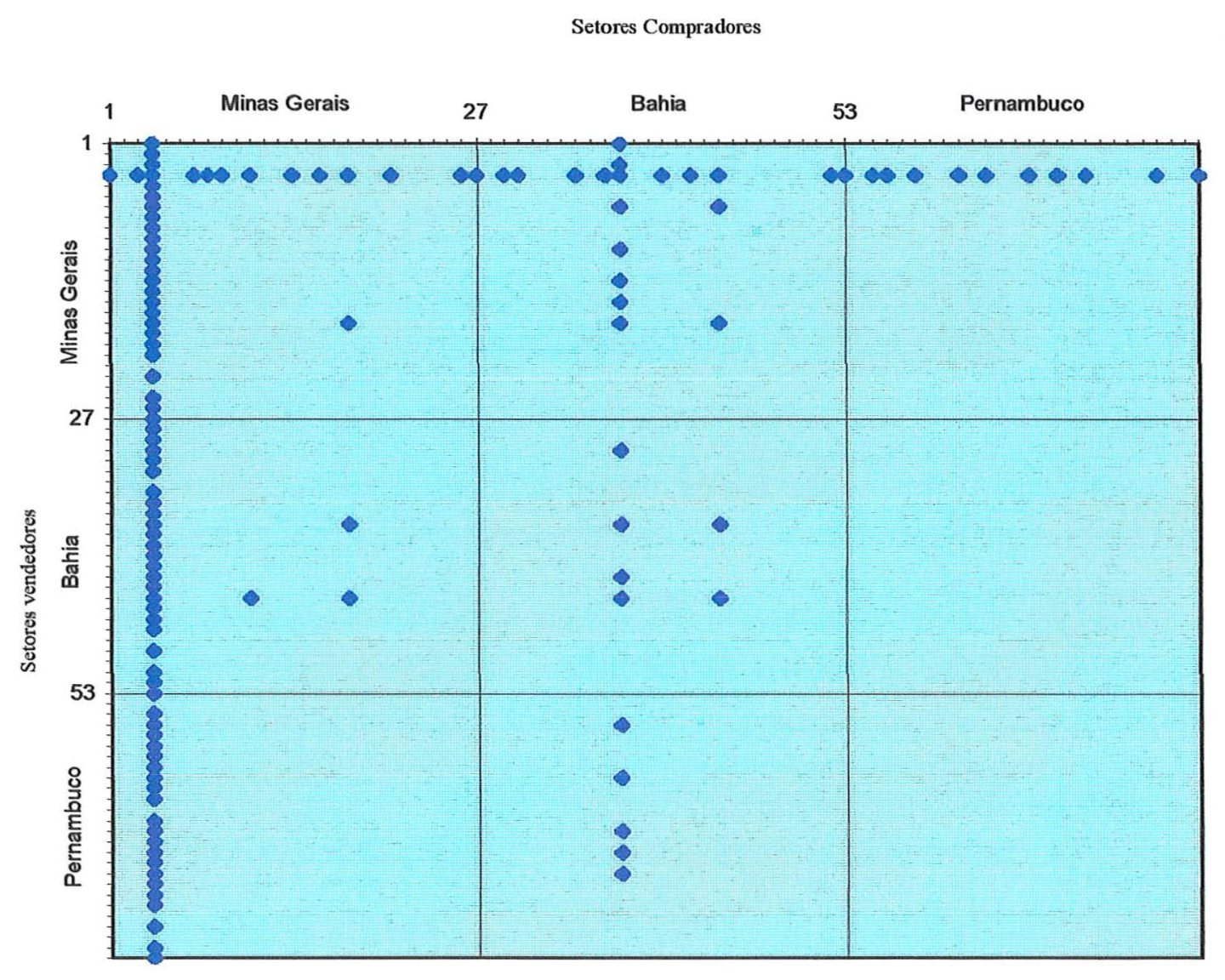

Figura 6.10 - Coeficientes com maior campo de influência para o Sistema Inter-regional do São Francisco.

Internamente, demanda insumos da Siderurgia e Metalurgia (setor 30), Produtos alimentares (setor 42) e do SIUP (setor 44). Considerando sua oferta de insumos, é acionada pela Siderurgia e Metalurgia (setor 4) e SIUP (setor 18) em Minas Gerais, além do SIUP (setor 44), do próprio estado.

O enfoque desenvolvido por Rasmussen (1956) e Hirschman (1958) para determinação das ligações intersetorias e identificação dos stores-chave na economia tem sido amplamente utilizado nas análises de insumo-produto, evidenciando a economia de um país, de uma ou várias regiões ou países. Embora amplamente reconhecido na 
literatura, esse enfoque não está isento de criticas, havendo uma ampla discussão a respeito da forma de identificação dos setores-chave. Uma das críticas apresentadas é que tanto a abordagem dos índices de ligações de Rasmussen/Hirschman quanto a do campo de influência consideram apenas a estrutura interna da economia na identificação desses setores, não levando em conta o volume de atividade.

Assim, visando complementar a análise, será apresentado, na próxima seção, o enfoque das ligações puras (GHS), desenvolvido por Guilhoto et. al. (1996), como um procedimento alternativo, em que, usando diferentes decomposições de matrizes, apresenta-se uma ligação formal entre duas abordagens: uma identificando os setoreschave da economia e outra, as fontes de mudança na economia.

\section{4Índices Puros de Ligações}

O conceito utilizado para estimar os índices puros foi o da abordagem GHS, desenvolvida por Guilhoto, Sonis e Hewings (1996).

Os índices puros de ligações para frente demonstram, em valor da produção, 0 impacto puro da produção total do restante da economia sobre um determinado setor. Por sua vez, os índices puros de ligações para trás exibem o impacto puro do valor da produção total de determinado setor na economia. $\mathrm{O}$ índice puro total, resultante da soma dos dois primeiros, revela os setores dinâmicos da economia.

\subsubsection{Indices puros de ligações para o Brasil}

Os resultados dos cálculos dos índices puros de ligações para a economia brasileira são apresentados em reais correntes de 1995. Na Tabela 6.3 e na Figura 6.11, estão expressos, por setor, os índices puros de ligações para trás, para frente e total.

A partir dos valores obtidos para o índice puro de ligações total (PTL), aqueles setores que apresentaram valores acima da média nacional foram considerados setoreschave. 
O Brasil apresentou 10 setores-chave, segundo o grupo de setores selecionados neste estudo. São eles: Agropecuária (setor 1), Siderurgia e Metalurgia (setor 4), Material de Transporte (setor 7), Indústria Química (setor 11), Produtos Alimentares (setor 16), SIUP (setor 18), Comércio (setor 20), Transportes (setor 21), Aluguel de Imóveis (setor 25) e Outros Serviços (setor 26).

É interessante ressaltar a composição do PTL desses setores. Na Agropecuária, por exemplo, $79 \%$ do PTL da provém das ligações para frente, evidenciando que o maior impacto sobre sua produção provém das demandas que os outros setores da economia fazem dos produtos deste. Já na composição do PTL da indústria de Produtos Alimentares, a maior parcela provém das ligações para trás, $82 \%$, ou seja, nesse caso é a produção gerada nesse setor que impacta o resto da economia, pois os acionados pela demanda da indústria de alimentos serão diretamente afetados no caso de uma expansão ou redução de suas compras (Tabela 6.3).

Ainda considerando a composição do PTL, verifica-se que seis, dos dez setoreschave da economia brasileira, apresentam maior participação das ligações para frente, ou seja, a dinâmica desses setores ocorre pelo lado da oferta. Para os quatro setores-chave restantes, a maior participação na composição do PTL é das ligações para trás (todas acima dos 70\%), impactando os demais setores da economia pelo lado da demanda.

Observe-se que dos setores-chave identificados, cinco pertencem ao grupo da Indústria de Transformação e quatro, ao grupo dos Serviços. Fica, também, evidente a importância da produção Agropecuária para a economia brasileira, que participa com um valor 2,03 vezes acima do valor médio do PTL, enquanto a maior contribuição é da indústria de Produtos Alimentares, 2,7 vezes acima da média, seguida de perto pelo valor da produção gerada pelo setor Outros Serviços, 2,5 vezes acima do valor médio.

Pode-se afirmar, então, que considerando o valor da produção, esses são os setores mais dinâmicos da economia brasileira. Os setores-chave estão indicados pelas áreas hachuradas na coluna dos índices puros totais da Tabela 6.3. 
Tabela 6.3 - Índices puros de ligações para trás, para frente e total, Brasil, 1995.

\begin{tabular}{|c|c|c|c|c|c|c|c|c|}
\hline \multirow{2}{*}{ Setor } & \multirow{2}{*}{ Trás } & \multirow{2}{*}{ Ordem } & \multirow{2}{*}{ Frente } & \multirow{2}{*}{ Ordem } & \multirow{2}{*}{ Total } & \multirow{2}{*}{ Ordem } & \multicolumn{2}{|c|}{$(\%)$} \\
\hline & & & & & & & PBL & PFL \\
\hline 1 Agropecuária & 11955898 & 10 & 45631854 & 2 & 57587752 & 4 & 20,76 & 79,24 \\
\hline 2 Extrativa Mineral & 1945957 & 21 & 7406267 & 15 & 9352225 & 21 & 20,81 & 79,19 \\
\hline 3 Minerais Não Metálicos & 1107692 & 23 & 12833905 & 10 & 13941596 & 17 & 7,95 & 92,05 \\
\hline 4 Siderurgia e Metalurgia & 5951877 & 14 & 34775285 & 4 & 4072716 & 8 & $14,6 \mathrm{~J}$ & 85,39 \\
\hline 5 Mecânica & 7935864 & 12 & 10089228 & 13 & 18025092 & 14 & 44,03 & 55,97 \\
\hline 6 Material Elétrico e Eletrôn. & 15118321 & 7 & 5305067 & 22 & 20423387 & 12 & 74,02 & 25,98 \\
\hline 7. Material de Transporte & 21805254 & 6 & 6839040 & 16 & 28644294 & 10 & 76,12 & 23,88 \\
\hline 8 Madeira e Mobiliário & 5696183 & 15 & 4033474 & 23 & 9729657 & 20 & 58,54 & 41,46 \\
\hline 9 Papel e Grálica & 3440585 & 17 & 13285087 & 9 & 16725672 & 15 & 20,57 & 79,43 \\
\hline 10 Indústria da Borracha & 584495 & 26 & 5463846 & 21 & 6048342 & 26 & 9,66 & 90,34 \\
\hline 11 Indústria Química & 5475286 & 16 & 49725302 & 1 & 55200588 & 6 & 9,92 & 90,08 \\
\hline 12 Farmacêuti & 7156876 & 13 & 977807 & 25 & 8134683 & 22 & 87,98 & 12,02 \\
\hline 13 Artigos de Plástico & 1081636 & 24 & 6482326 & 17 & 7563963 & 23 & 14,30 & 85,70 \\
\hline 14 Indústria Têxtil & 3098941 & 18 & 10192854 & 12 & 13291795 & 18 & 23,31 & 76,69 \\
\hline 15 Vestuário e Calçados & 14431358 & 8 & 475931 & 26 & 14907289 & 16 & 96,81 & 3,19 \\
\hline 16 Produtos Alimentares & 61850337 & 1 & 13712884 & 8 & 75563221 & 1 & 81,85 & 18,15 \\
\hline 17 Indústrias Diversas & 2464777 & 19 & 3586407 & 24 & 6051184 & 25 & 40,73 & 59,27 \\
\hline 18 SIUP & 2237174 & 20 & 15854375 & 7 & 18091549 & 13 & 12,37 & 87,63 \\
\hline 19 Construção Civil & 47797971 & 3 & 5514333 & 20 & 53312304 & 7 & 89,66 & 10,34 \\
\hline 20 Comércio & 27492487 & 5 & 29614473 & 5 & 57106959 & 5 & 48,14 & 51,86 \\
\hline 21 Transportes & 11865645 & 11 & 18350609 & 6 & 3021625 & 9 & 39,27 & 60,73 \\
\hline 22 Comunicaçōes & 1187278 & 22 & 5831887 & 19 & 7019166 & 24 & 16,91 & 83,09 \\
\hline 23 Instituições Financeiras & 14047672 & 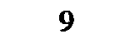 & 9328869 & 14 & 23376541 & 11 & 60,09 & 39,91 \\
\hline 24 Administração Pública & 925416 & 25 & 10397701 & 11 & 11323117 & 19 & 8,17 & 91,83 \\
\hline 25 Aluguel de Imóveis & 57348219 & 2 & 6427985 & 18 & 63776204 & 3 & 89,92 & 10,08 \\
\hline 26 Outros Serviços & 35737244 & 4 & 36165471 & 3 & 71902715 & 2 & 49,70 & 50,30 \\
\hline Média & 14220786 & & 14165472 & & 28386258 & & 50,10 & 49,90 \\
\hline
\end{tabular}

Fonte: Valores estimados pela autora. 
Com relação aos índices puros de ligações para trás (PBL), os setores mais relevantes são: Produtos Alimentares (setor 16), Aluguel de Imóveis (setor 25), Construção Civil (setor 19), Outros serviços (setor 26), Comércio (setor 20) e Material de Transporte (setor 7), que, segundo a ordenação pelo valor da produção, ocupam, respectivamente, da primeira à sexta posições. Considerando que o PBL mostra o impacto puro sobre a economia do valor da produção do respectivo setor ou, em outras palavras, o impacto que é isolado da demanda de insumos que o setor realiza dele próprio e dos feedbacks da economia para ele e vice-versa, verifica-se, pelos valores apresentados que os setores mencionados são os principais demandantes na economia brasileira.

Os setores mais importantes, em termos das ligações para frente (PFL), considerando as seis primeiras posições do ranking nacional são Indústria Química (setor 11), Agropecuária (setor 1), Outros Serviços (setor 26), Siderurgia e Metalurgia (setor 4), Comércio (setor 20) e Transportes (setor 21). Relembrando que o PFL mostra o impacto puro da produção total do resto da economia sobre o respectivo setor , constatase que os setores mencionados desempenham um papel fundamental na oferta para $o$ demais setores da economia brasileira. Numa situação de crescimento da economia, esses serão os primeiros a serem impactados pelas demandas dos outros setores do conjunto. 


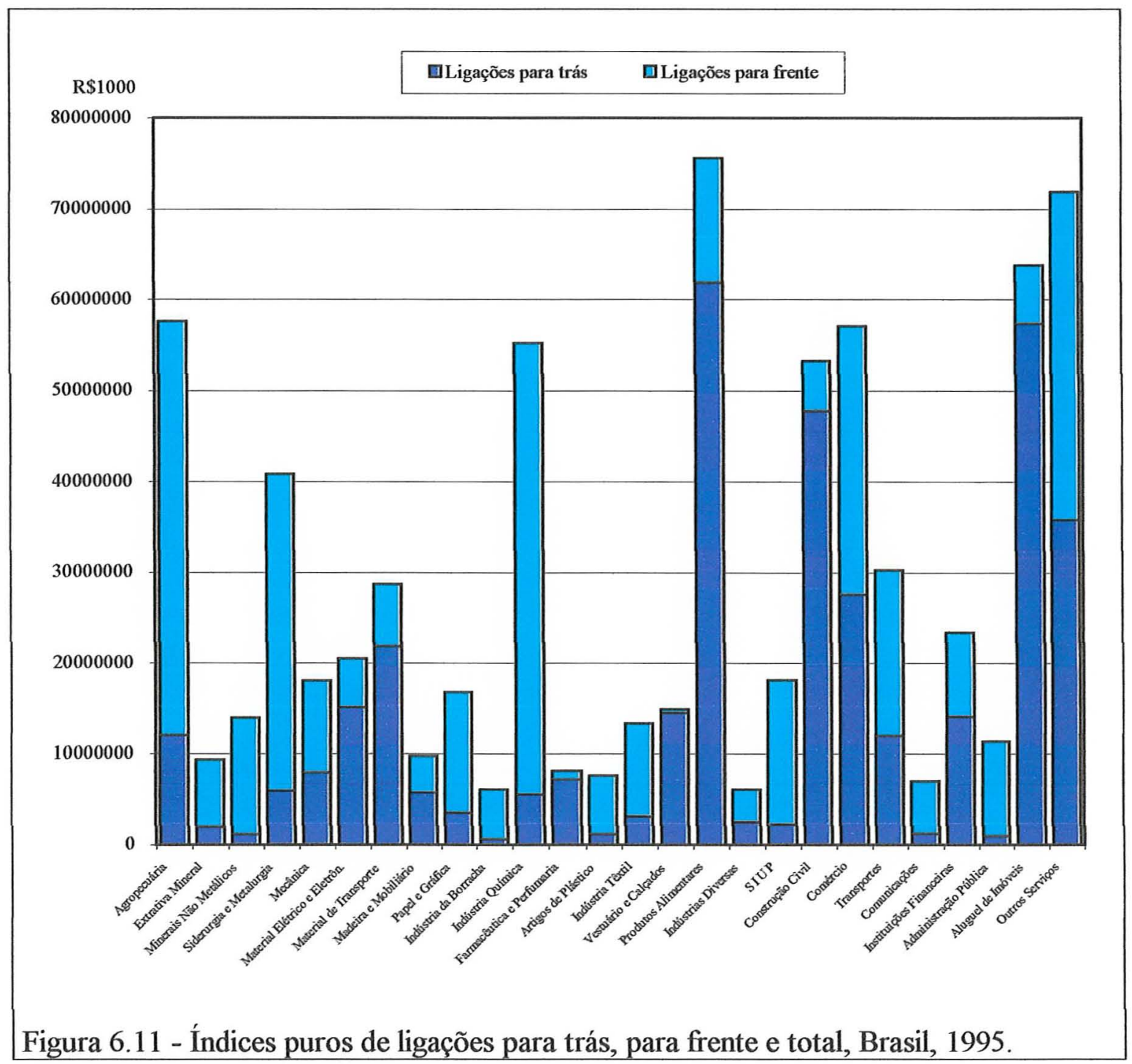

Em síntese, de acordo com o valor da produção gerada pelos setores, os índices puros revelam a importância relativa de cada um deles sobre os demais setores da economia - seja como compradores (ligações para trás), seja como vendedores (ligações para frente), reforçando as indicações das ligações dos índices de Rasmussen/Hirschman e dos valores do campo de influência. 


\subsection{2 Índices puros de ligações para o Sistema Inter-regional do São Francisco}

Os índices puros de ligações para trás e para frente, quando todos os setores são considerados, independentemente de sua região de origem e sua importância relativa dentro do sistema inter-regional, são apresentados, respectivamente, na Tabela 6.4 e nas Figuras 6.11 e 6.13. Observando os efeitos do valor da produção gerada pelas economias setoriais e estaduais pode-se verificar a importância diferenciada de cada uma delas para a economia da região do São Francisco.

Considerando-se o índice puro de ligações para trás, em nível setorial, pode-se constatar que os setores que mais se destacam são os da economia mineira. Os mais relevantes são; Produtos Alimentares (setor 16), Aluguel de Imóveis (setor 25), Material de Transporte (setor 7), Siderurgia e Metalurgia (setor 4), Outros Serviços (setor 26) e Construção Civil (setor 19). Os impactos do valor da produção da Agropecuária (setor 1) e do Comércio (setor 20) sobre o os outros setores da economia regional também são relevantes.

Mesmo com o maior número de setores cuja produção tem maior impacto sobre a economia regional pertencendo ao grupo da Indústria de Transformação, pode-se perceber a importância daqueles pertencentes ao grupo dos Serviços, haja vista a posição de destaque de Aluguel de Imóveis, dos Outros Serviços e do Comércio no ranking do sistema inter-regional, como também a da Agropecuária. No ranking inter-regional das ligações para trás, os setores que ocupam da primeira à sexta posições estão no estado de Minas Gerais. Somente a partir da sétima posição é que se destaca, em termos de impacto de sua produção sobre os demais setores da economia do sistema inter-regional, a Indústria Química do estado da Bahia (Tabela 6.4 e Figura 6.12). 


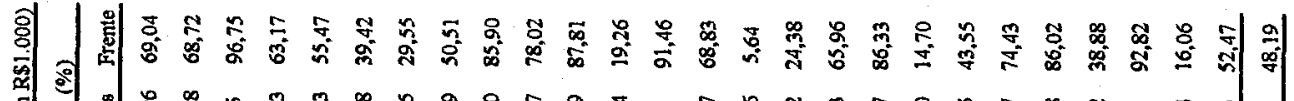

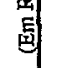
㯖

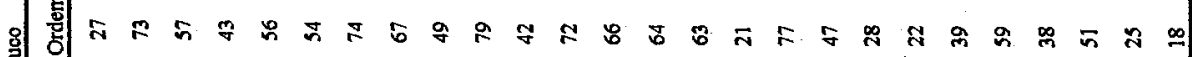

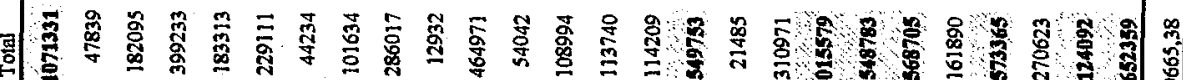
氙苞 斻 营

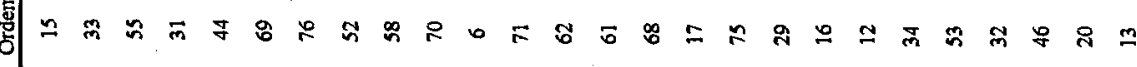
递旁 彭点 จ 参 胥

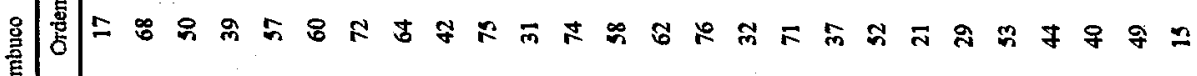

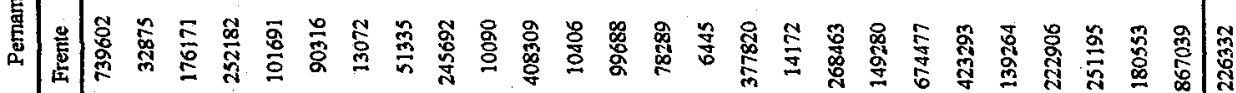
急

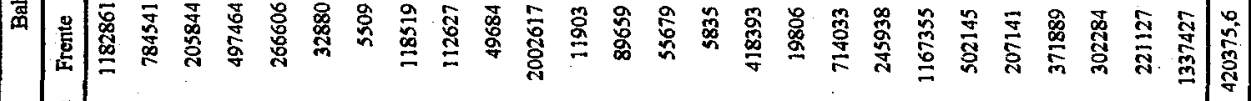

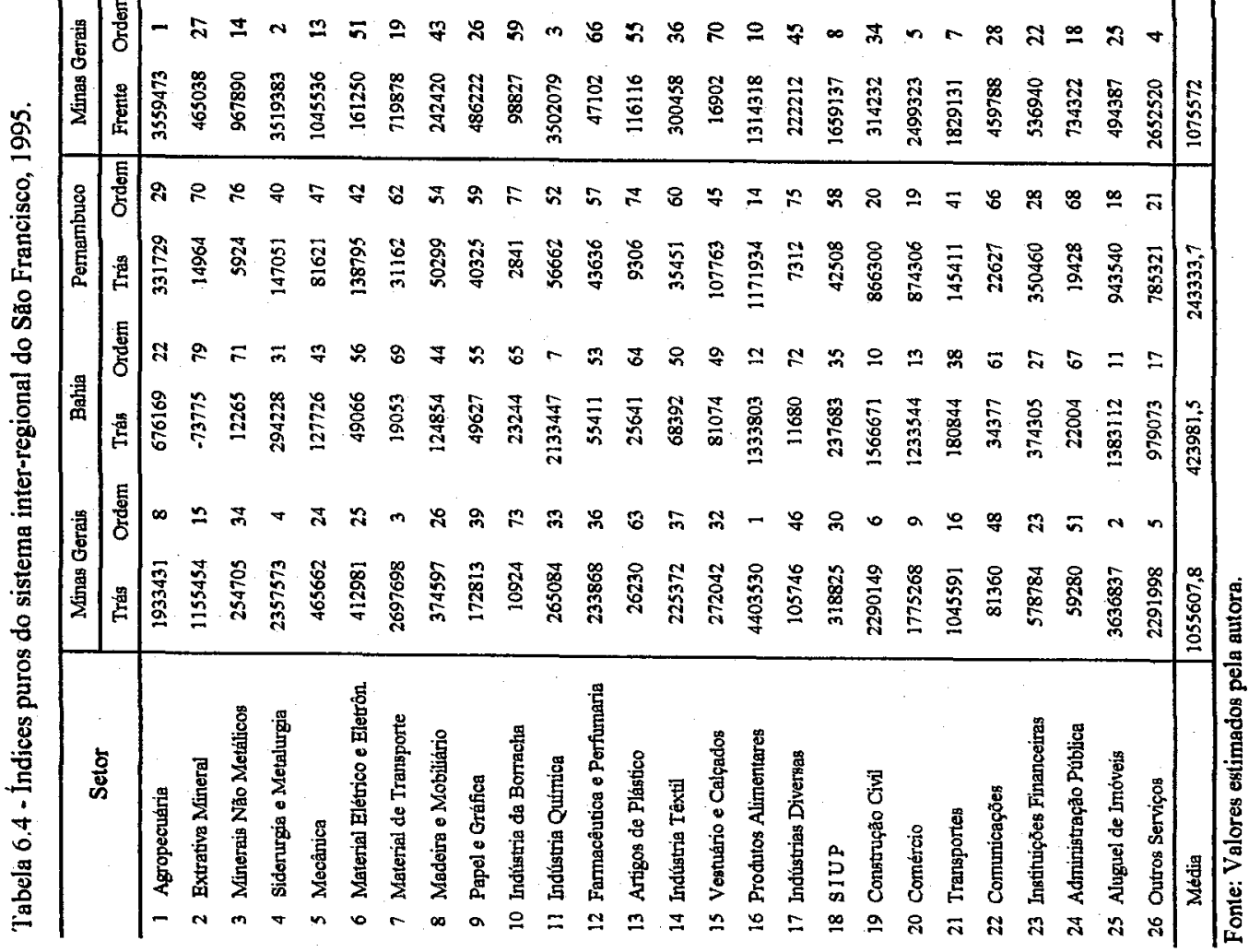


Além da Indústria Química (setor 37, considerando-se a ordenação da Figura 6.12), na economia baiana destacam-se os setores: Construção Civil (setor 45), Aluguel de Imóveis (setor 51), Produtos Alimentares (setor 42) e Comércio (setor 46). Mesmo apresentando valores menores que os primeiros colocados no ranking inter-regional, quando se considera a implantação de políticas de incentivos à produção industrial, devese considerar que setores produtivos, como os referenciados, têm uma maior capacidade de acionar outros setores do sistema por meio de suas compras.

Em termos de impacto sobre a produção dos demais setores do sistema interregional, os destaques da economia pernambucana são os setores da indústria de Produtos Alimentares (setor 68), que apresenta o maior valor das ligações para trás desse estado, Construção Civil (setor 71), Comércio (setor 72), Aluguel de Imóveis (setor 77) e Outros Serviços (setor 78), conforme se observa na Figura 6.12.

A indústria de Produtos Alimentares do estado de Minas Gerais é aquela cujo valor da produção causa maior impacto sobre todos os outros setores da economia regional. Fica explícita sua relevância, também, na Bahia e em Pernambuco, o que chama a atenção para as características desse setor ao se considerar políticas que visem à promoção do desenvolvimento regional.

No contexto das economias do sistema inter-regional, os cinco maiores valores do índice puro de ligações para frente (PFL) são apresentados por setores do estado de Minas Gerais, sendo a primeira posição ocupada pela Agropecuária (setor 1), seguida pela Siderurgia e Metalurgia (setor 4), Indústria Química (setor 11), Outros Serviços (setor 26) e Comércio (setor 20), respectivamente (Figura 6.13).

No estado da Bahia, os setores que ocupam, respectivamente, a sexta, nona e décima primeira posições no ranking inter-regional, são os que apresentam maior valor das ligações para frente, sendo a Indústria Química (setor 37), Outros Serviços (setor 52) e Agropecuária (setor 27).

Do conjunto, o estado de Pernambuco apresenta os menores valores das ligações para frente, destacando-se os Outros Serviços (setor 78, segundo a numeração dos setores na Figura 6.13), com o índice de maior valor, ocupando a décima quinta posição 
no ranking inter-regional, seguido pela Agropecuária (setor 53), na décima sétima posição no ranking inter-regional.

Os setores listados são os que recebem o maior impacto puro em suas próprias regiões de origem devido à produção total no resto da economia, no caso, a da região do São Francisco. Note-se que o setor Agropecuária do estado de Minas Gerais é o que recebe o maior impacto em sua produção devido às produções dos outros setores de todo o sistema inter-regional, reforçando, assim, a característica de forte fornecedor de insumos e produtos, como já se havia ressaltado na análise dos índices de ligações para frente de Rasmussen/Hirschman. Essa característica também é revelada pelo setor Siderurgia e Metalurgia e pela Indústria Química desse mesmo estado. Também a Indústria Química do estado da Bahia é a que recebe o maior impacto puro, naquele estado, da produção dos demais setores do conjunto.

Exceto a Agropecuária, os demais setores referenciados pertencem ao grupo da Indústria de Transformação e são os que receberão o maior impacto, caso ocorra um crescimento na atividade econômica regional.

Nas economias dos estados que compõem o sistema inter-regional, os setores pertencentes ao grupo dos Serviços apresentam altos valores de ligações para frente, com destaque para o Comércio, Transportes e Outros Serviços, nos três estados, demonstrando, como os do grupo anterior, situarem-se entre os que serão mais impactados caso ocorra algum crescimento (o mesmo se aplica no caso de uma retração do nível de atividade econômica).

Os valores dos índices puros totais maiores que a média indicam os setores-chave, no sistema inter-regional, ou seja, os setores mais dinâmicos da economia. Os setores cujos valores do PTL estão hachurados na Tabela 6.4 são setores-chave do sistema.

No conjunto da economia da região do São Francisco, foram identificados 10 setores-chave no estado de Minas Gerais, 8 no estado da Bahia e 7 no estado de Pernambuco. 

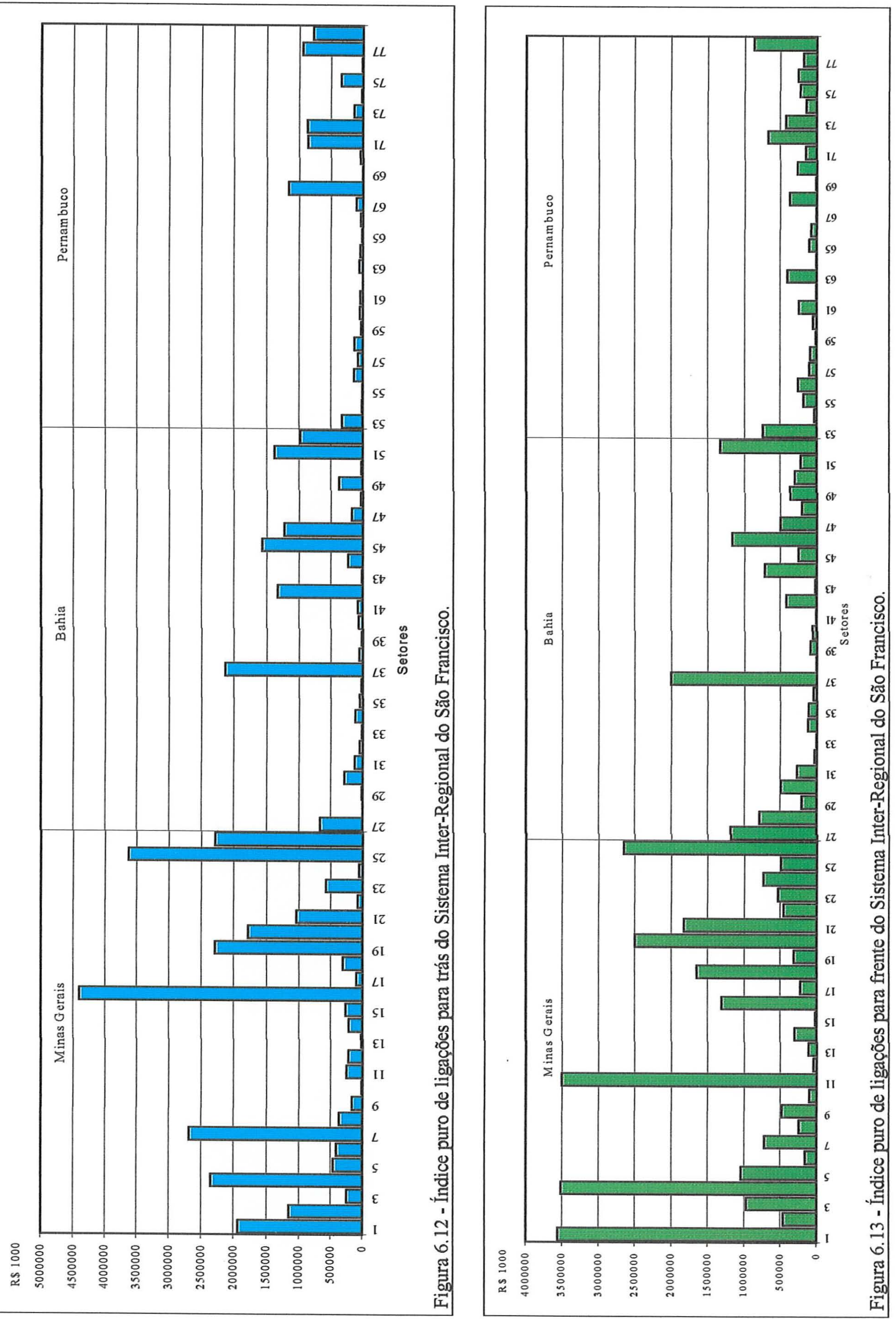
Em Minas Gerais, os setores-chave são, segundo a ordenação inter-regional, Siderurgia e Metalurgia (setor 4), Produtos Alimentares (setor 16), Agropecuária (setor 1), Outros Serviços (setor 26), Comércio (setor 20), Aluguel de Imóveis (setor 25), Indústria Química (setor 11), Material de Transporte (setor 7), Transportes (setor 21) e Construção Civil (setor 19).

Em seis dos setores elencados, a participação das ligações puras para frente na composição do PTL ultrapassa 50\%, revelando que a dinâmica desses setores é dada pelas vendas que realizam para os demais, enquanto para os quatro setores-chave restantes, as ligações puras para trás estão acima de $70 \%$, revelando que é a produção gerada por eles que causa impactos sobre o demais setores do conjunto (Tabela 6.4).

$\mathrm{Na}$ Bahia, são oito os setores cujo PTL está acima do valor médio: Indústria Química (setor 37), Comércio (setor 46), Outros Serviços (setor 52), Agropecuária (setor 27), Construção Civil (setor 45), Produtos Alimentares (setor 42), Aluguel de Imóveis (setor 51) e SIUP (setor 44).

Segundo a composição do PTL de cada setor, indicada na Tabela 6.4, na maioria dos setores assinalados, a participação das ligações para trás é maior, revelando que a maior dinâmica se dá pelo impacto da sua produção sobre o resto da economia, ou seja, sobre os que são acionados pelas compras desses setores-chave da Bahia.

Quando se considera o nivel da produção em cada setor, a economia de Pernambuco, segundo revela o PTL, possui oito setores-chave: Outros Serviços (setor 78), Produtos Alimentares (setor 68), Comércio (setor 20), Aluguel de Imóveis (setor 25), Agropecuária (setor 53), Construção Civil (setor 71), Instituições Financeiras (setor 75) e Transportes (setor 73).

Observe-se que cinco dos setores mais dinâmicos da economia pernambucana, no sistema inter-regional, pertencem ao grupo dos Serviços e apenas dois estão no grupo da Indústria de Transformação.

Quanto à composição do PTL, em cinco setores-chave, a maior participação é das ligações para trás. Isso demonstra que são os setores compradores do estado que dinamizam a economia. 
Uma característica interessante da economia do sistema inter-regional é que, nas três regiões (os estados de Minas Gerais, Bahia e Pernambuco), a Agropecuária, a indústria de Produtos Alimentares, a Construção Civil, o Comércio, Aluguel de Imóveis e Outros Serviços são setores-chave.

Percebe-se que, ao se considerar o valor da produção na identificação dos setoreschave do sistema inter-regional, identificam-se mais claramente os principais responsáveis pelas mudanças no nível do PIB e de outros agregados da economia.

Confirmando os setores anteriormente revelados pelas análises, segundo o enfoque de Rasmussen-Hirschman e do campo de influência, e revelando outros setores dinâmicos, o modelo GHS, dos índices puros, conforme afirmam seus autores, deve ser considerado como uma análise complementar às duas primeiras, para análise da estrutura da economia.

\subsection{Comparação dos resultados dos indices de Rasmussen/Hirschman e os dos indices Puros de Ligações}

As abordagens dos índices de Rasmussen/Hirschman e do campo de influência são usadas para se verificar como a estrutura interna da economia se comporta, sem levar em consideração o nivel de produção em cada setor. A abordagem dos índices puros de ligações (modelo GHS) é usada para examinar o comportamento da estrutura produtiva quando diferentes níveis de produção em cada setor são levados em consideração. Assim, as duas primeiras identificam o que pode ser chamado de impactos potenciais a partir de mudanças em qualquer setor da economia, enquanto a última examina os efeitos das mudanças ao considerar o volume da produção (Sonis et. al., 1995, p. 243-244).

Deve-se notar que a abordagem dos índices puros de ligações revela a importância dos setores para uma economia derivada do volume de produção desses setores, efeito que não é totalmente capturado nas abordagens de Rasmussen/Hirschman e do campo de influência. Entretanto, outros setores fundamentais para o crescimento da economia, mas 
que apresentam baixos valores de produção quando comparados com os demais, não são capturados pela abordagem dos índices puros de ligações. Assim, não se pode esperar que os mesmos setores sejam indicados como setores-chave ao se adotar um ou outro enfoque.

Nesta seção far-se-á uma breve comparação dos resultados dessas abordagens, destacando-se os setores-chave revelados pelas mesmas, conforme apresentados na Tabela 6.5 e na Tabela 6.6.

Ao se analisar os resultados dos índices de ligações comparativamente, verifica-se um número maior de setores-chave, quando se considera apenas a estrutura interna da economia. Tanto sob o conceito mais restrito, quanto sob o conceito mais amplo dos índices de ligações para trás e para frente de Rasmussen-Hirschman, para os três estados do sistema inter-regional foram revelados mais setores-chave do que quando se realiza a análise segundo o enfoque dos índices puros de ligações, o mesmo ocorrendo quando se analisa a economia brasileira.

O estado de Minas Gerais apresentou nove setores-chave segundo os dois enfoques, de Rasmussen/Hirschman e GHS, sendo os mesmos setores dinâmicos da economia brasileira. Já nos estados da Bahia e de Pernambuco apenas seis setores recebem a mesma indicação pelos dois enfoques.

Do ponto de vista do volume da produção, tanto nos estados do sistema interregional quanto no Brasil, a Construção Civil (setor 19) revelou-se um setor dinâmico na economia. Também a indústria de Produtos Alimentares, sob o enfoque dos índices puros, apareceu como um setor dinâmico na Bahia, o mesmo ocorrendo com as Instituições Financeiras (setor 23) de Pernambuco (Tabela 6.5 e Tabela 6.6).

Quando se comparam os setores do sistema inter-regional que apresentam as mais fortes ligações para trás e para frente, tanto sob o enfoque de Rasmussen-Hirschman, do campo de influência ou dos índices puros (modelo GHS), percebe-se a importância relativa do estado de Minas Gerais no conjunto das economias da bacia hidrográfica do São Francisco. 
Embora ocupando posições diferentes no ranking dos índices do sistema, os setores que mais se destacam são o da Siderurgia e Metalurgia (setor 4), do estado de Minas Gerais, e o da Indústria Química (setor 11), do estado da Bahia.

É importante ressaltar que, pela concentração ocorrida nos dois estados, a maioria das indústrias que compõem o setor Indústria Química no estado da Bahia não estão localizadas na área da bacia hidrográfica do rio São Francisco, entretanto, o mesmo não ocorre com as que compõem o setor Siderurgia e Metalurgia do estado de Minas Gerais, que tem o maior número de indústrias na referida região. 


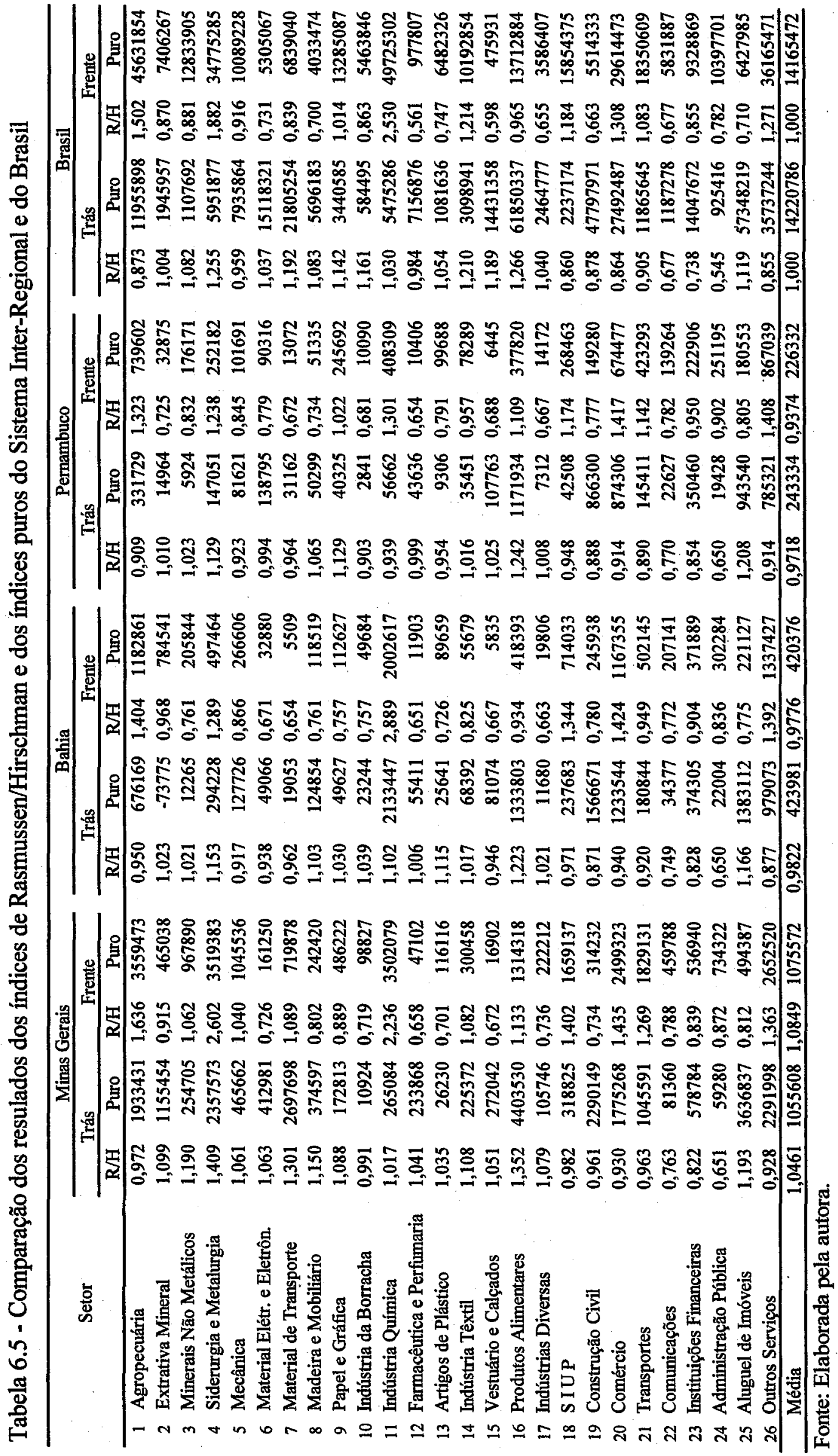


Tabela 6.6 - Setores-chave consolidados - índices de ligações de Rasmussen/Hirschman (R/H) e os índices puros totais (PTL), Brasil e Sistema Inter-regional do São Francisco.

\begin{tabular}{|c|c|c|c|c|c|c|c|c|c|c|c|c|c|}
\hline & \multirow[b]{2}{*}{ Setor } & \multicolumn{3}{|c|}{ Minas Gerais } & \multicolumn{3}{|c|}{ Bahia } & \multicolumn{3}{|c|}{ Pernambuco } & \multicolumn{3}{|c|}{ Brasil } \\
\hline & & $\begin{array}{c}\mathrm{R} / \mathrm{H} \\
\text { restrito }\end{array}$ & $\begin{array}{c}\mathrm{R} / \mathrm{H} \\
\text { amplo }\end{array}$ & PTL & \begin{tabular}{c|}
$\mathrm{R} / \mathrm{H}$ \\
restrito
\end{tabular} & $\begin{array}{c}\mathrm{R} / \mathrm{H} \\
\text { amplo }\end{array}$ & PTL & $\begin{array}{c}\mathrm{R} / \mathrm{H} \\
\text { restrito }\end{array}$ & $\begin{array}{c}\mathrm{R} / \mathrm{H} \\
\text { amplo }\end{array}$ & PTL & \begin{tabular}{|c|}
$\mathrm{R} / \mathrm{H}$ \\
restrito
\end{tabular} & $\begin{array}{c}\mathrm{R} / \mathrm{H} \\
\text { amplo } \\
\end{array}$ & PTL \\
\hline 1 & Agropecuária & & $\infty$ & $\overline{7}$ & & 8 & & & $\infty$ & & & $\otimes$ & \\
\hline 2 & Extrativa Mineral & & $\otimes$ & & & $\otimes$ & & & $\infty$ & & & 8 & \\
\hline 3 & Minerais Não Metálicos & 6 & & & & $\otimes$ & & & 8 & & & 8 & \\
\hline 4 & Siderurgia e Metal urgia & $\Delta$ & & & $\mathbf{A}$ & & & $\Delta$ & & & $\Delta$ & & \\
\hline 5 & Mecânica & 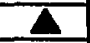 & & & & & & & & & & & \\
\hline 6 & Material Elétr. e Eletrôn. & & $(8)$ & & & & & & & & & 8 & \\
\hline 7 & Material de Transporte & $\Delta$ & & & & & & & & & & $\otimes$ & \\
\hline 8 & Madeira e Mobiliário & & $\otimes$ & & & $\otimes$ & & & $\Phi$ & & & 8 & \\
\hline 9 & Papel e Gráfica & & $\otimes$ & & & 8 & & $\mathbf{A}$ & & & $\Delta$ & & \\
\hline 10 & Indústria da Borracha & & & & & $Q$ & & & & & & 8 & \\
\hline 11 & Indústria Química & $\Delta$ & & & $\Delta$ & & & & & & $\Delta$ & & \\
\hline 12 & Farmacêutica e Perfumaria & & 8 & & & 8 & & & & & & & \\
\hline 13 & Artigos de Plástico & & $\otimes$ & & & $\$$ & & & & & & $\infty$ & \\
\hline 14 & Indústria Têxtil & $\mathbf{A}$ & & & & $\otimes$ & & & 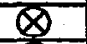 & & $\Delta$ & & \\
\hline 15 & Vestúário e Calçados & & $\otimes$ & & & & & & 8 & & & 8 & \\
\hline 16 & Produtos Alimentares & $\Delta$ & & 0 & & & & $\Delta$ & 8 & & & 8 & \\
\hline 17 & Indústrias Diversas & & $\otimes$ & & & 8 & & & & & & $Q$ & \\
\hline 18 & SIUP & & 8 & & & 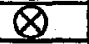 & & & 8 & & & 8 & \\
\hline 19 & Construção Civil & & & & & & & & & & & & \\
\hline 20 & Comércio & & 8 & & & $\otimes$ & & & 8 & & & 8 & \\
\hline 21 & Transportes & & $\otimes$ & & & & & & $(8)$ & & & 8 & \\
\hline 23 & Instituiçōes Financeiras & & & & & & & & & & & & \\
\hline 25 & Aluguel de Imóveis & & 8 & 0 & & 8 & D & & 8 & C & & 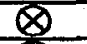 & $=$ \\
\hline 26 & Outros Serviços & & $\infty$ & & & $\otimes$ & & & 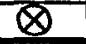 & & & $\infty$ & \\
\hline
\end{tabular}

\begin{tabular}{|l|}
\hline \multirow{2}{8}{$\begin{array}{l}\text { Setor-chave segundo o conceito mais restrito do indice de Rasmussen/Hirschman; } \\
\text { Setor-chave segundo o conceito mais amplo do indice de Rasmussen/Hirschman; } \\
\text { Setor-chave segundo o conceito do indice puro total; }\end{array}$} \\
\hline
\end{tabular}

Fonte: Tabela 6.5 .

$\mathrm{Na}$ análise das ligações para frente e para trás do sistema inter-regional, é importante destacar que para os três estados, o setor Agropecuária apresenta fortes ligações para frente. No estado de Minas Gerais, a área de expansão agrícola, principalmente da agricultura irrigada, localiza-se, em grande parte, na área geográfica do São Francisco. No estado da Bahia, as atividades voltadas para o cultivo de grãos, a fruticultura e a agropecuária também têm se expandido na área da bacia, com destaque para o pólo de irrigação formado pelos municípios de Juazeiro, na Bahia e de Petrolina, em Pernambuco. Principalmente nesse último estado, uma das atividades alavancadoras 
do desenvolvimento da região do São Francisco é a agricultura irrigada em larga escala. Com ênfase para a fruticultura (manga, melão, melancia, uva, goiaba e banana) e para a horticultura (tomate e cebola), induz o crescimento da agroindústria e das indústria de apoio à irrigação, bem como as atividades do comércio.

Com base nas analises apresentadas foi possível identificar as relações intra e interregionais da região estudada. Também foi possível identificar os setores mais dinâmicos da economia da regional e da economia brasileira. Entretanto, o enfoque GHS permite identificar e avaliar a importância de cada região na produção induzida, por meio das demandas finais regionais e setoriais.

No próximo capítulo desse estudo será apresentada uma discussão a respeito desse desdobramento do enfoque GHS, aplicada ao sistema inter-regional do São Francisco, visando explorar a natureza das ligações internas e externas que caracterizam as economias das regiões que compõem o sistema (Minas Gerais, Bahia e Pernambuco), incorporando ao modelo, como uma única região, as outras regiões brasileiras (Resto do Brasil). 


\section{INFLUÊNCLA DAS DEMANDAS FINAIS SOBRE A PRODUÇÃO: UMA APLICAÇÄO DO MODELO GHS}

O modelo GHS, além de calcular os índices puros de ligações, possibilitando a identificação dos setores-chave, também explora o papel das ligações internas e externas, permitindo a identificação das fontes de mudança na economia.

Nas seções do capítulo anterior foram apresentadas as principais características das regiões do sistema inter-regional do São Francisco, considerando suas estruturas internas e o valor da produção. Foram identificados os setores mais dinâmicos do sistema, tornando explícita a importância relativa do estado de Minas Gerais no conjunto das economias da região da bacia do São Francisco. Entretanto, para complementar a análise, a identificação da interação dos mercados pode trazer maiores subsídios para a compreensão da dimensão da economia regional e de suas potencialidades. Adicionalmente, uma análise das interações e dependências entre as regiões irá contribuir para melhor compreensão das estruturas produtivas das economias analisadas.

Neste capítulo, buscou-se, inicialmente, por meio da aplicação do método GHS, identificar o nível de integração dos mercados das regiões do sistema. Em seguida, visando apresentar um quadro das relações das economias da região do São Francisco com as outras regiões do Brasil, buscou-se identificar a produção induzida pelas demandas finais num sistema inter-regional com quatro regiões: Minas Gerais, Bahia, Pernambuco e Resto do Brasil. Por último, utilizando-se a metodologia desenvolvida por Sonis, Hewings e Miyazawa (1997), examinou-se a estrutura das relações de comércio entre as quatro regiões. 


\subsection{Demanda final e produção induzida no sistema inter-regional do São Francisco}

Das diferentes decomposições de matrizes apresentadas pelo modelo GHS é possível determinar o nível total da produção, setorial ou regional, decorrente da sua própria demanda ou devido à demanda final do resto da economia.

Considerando as três regiões do sistema inter-regional do São Francisco - Minas Gerais, Bahia e Pernambuco - e aplicando-se as equações (4.24) e (4.25), foi possível decompor a produção gerada em cada região nas parcelas induzidas pelas suas próprias demandas finais e nas parcelas decorrentes das demandas finais das outras regiões.

Uma síntese dos resultados é apresentada nas tabelas 7.1 e 7.2. Observando-se a Tabela 7.1, pode-se classificar cada região segundo seu grau de dependência no sistema inter-regional. A demanda final do estado de Minas Gerais induz $\mathbf{9 8 , 8 \%}$ da produção total, sendo pouco mais que $1 \%$ da produção induzida pelas demandas finais dos outros dois estados considerados. Na Bahia, sua própria demanda final induz $98,5 \%$ da produção estadual, enquanto $1,5 \%$ é induzido pelas demandas finais dos outros estados. Em Pernambuco a influência das demandas das outras regiões é menor que $1 \%$ pois a demanda final daquele estado induz $99 \%$ da sua produção.

Tabela 7.1 - Produção total induzida pela demanda final no Sistema Inter-regional do São Francisco, 1995.

Fonte: Estimativas da autora. 
As elevadas participações das demandas dos próprios estados, nas suas produções, conforme os resultados da Tabela 7.1, mostram um pequeno grau de integração entre as três regiões, em termos de estrutura produtiva ${ }^{27}$.

O modelo GHS permite a desagregação dos resultados, possibilitando estimar a produção induzida pela demanda final, segundo a região de origem, conforme a Tabela 7.2. Ao longo das linhas dessa tabela, estão expressas as produções totais de cada região e, ao longo das colunas, as regiões cujas demandas deram origem às produções nas regiões designadas no alto da coluna. Observa-se que o valor total da produção de cada estado é consistente com o apresentado na Tabela 7.1, com pequenas diferenças decorrentes de arredondamentos.

Tabela 7.2 - Produção das regiōes do sistema inter-regional do São Francisco segundo indução da própria demanda e pelas demandas finais das outras regiões

(em $\mathrm{R} \$ 1000)$

\begin{tabular}{|c|c|c|c|c|c|}
\hline \multirow{2}{*}{\multicolumn{2}{|c|}{ Regiões }} & \multicolumn{3}{|c|}{ Origem das demandas finais } & \multirow{2}{*}{ Total } \\
\hline & & Minas Gerais & Bahia & Pernambuco & \\
\hline \multirow{4}{*}{ 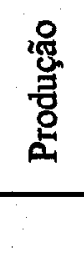 } & Minas Gerais & 100.161 .806 & 729.354 & 452.175 & 101.343 .335 \\
\hline & Bahia & 505.015 & 47.577 .503 & 230.890 & 48.313 .408 \\
\hline & Pernambuco & 131.764 & 101.121 & 25.650 .659 & 25.883.544 \\
\hline & Total & 100.798 .585 & 48.407 .978 & 26.333.724 & 175.540 .287 \\
\hline
\end{tabular}

Fonte: Estimativas da autora.

Pode-se observar, pela leitura da primeira linha da Tabela 7.2, que foi gerada, no estado de Minas Gerais, em 1995, uma produção total da ordem de 101,3 bilhões de reais, sendo que, destes, 100,2 bilhões de reais foram induzidos por sua própria demanda final, cerca de 729 milhões pela demanda final do estado da Bahia e 452 milhões pela do estado de Pernambuco.

\footnotetext{
${ }^{27}$ É importante lembrar que, entre os componentes da Demanda Final, estão incluídas as exportações dessas regiões tanto para o exterior quanto para as outras regiões brasileiras.
} 
Mesmo representando uma pequena parcela da produção total, em termos relativos, as interações entre os mercados dos estados de Minas Gerais e da Bahia são muito mais fortes que com os do estado de Pernambuco. Os volumes de produção induzidos se distribuem pelas economias do sistema segundo suas estruturas intersetoriais e inter-regionais e, conforme evidenciado no capítulo anterior, o estado de Minas Gerais é o que possui as ligações intersetoriais mais fortes, seguido pelo estado da Bahia. Assim, os resultados apresentados, refletindo os efeitos diretos e indiretos das demandas finais desses dois estados sobre a produção no sistema inter-regional, demonstram de que modo esses efeitos se distribuem nos mercados regionais.

\subsection{Produção setorial induzida pelas demandas finais do sistema inter- regional do São Francisco}

Com o objetivo de analisar de forma mais desagregada as relações entre as demandas finais das regiões que compõem o sistema inter-regional e a produção dos diversos setores da economia, calculou-se a participação da produção induzida pela demanda final de cada região na produção setorial. Para apresentação dos resultados, foram selecionados os setores para os quais a demanda final do próprio estado induziu uma produção maior ou igual a $5 \%$ (Figura 7.1).

Em Minas Gerais, a produção dos oito setores selecionados corresponde a $67,4 \%$ da produção total induzida pela demanda final desse estado (demanda final doméstica). A produção da Agropecuária (setor 1) induzida pela demanda final doméstica corresponde a $10,9 \%$, enquanto a da Siderurgia e Metalurgia (setor4) atinge $11 \%$. Também a dependência doméstica da produção da Administração Pública (setor 24) corresponde a $11 \%$, enquanto as dependências dos demais setores selecionados pela demanda do próprio estado situa-se abaixo da faixa de 9\% (Figura 7.1).

$\mathrm{Na}$ Bahia, a produção da Indústria Química (setor 11) induzida pela demanda final doméstica é a mais alta de todo o conjunto de setores selecionados, superando $20 \%$. Também as produções da Construção Civil (setor 19) e da Administração Pública (setor 
24) apresentam um grau de dependência elevado, com, respectivamente, $11,7 \%$ e $10,5 \%$. Os demais setores selecionados mesmo apresentando graus de dependência da demanda doméstica acima de 5\%, não atingem a faixa dos 10\%, como se observa na Figura 7.1.

Minas Gerais

Bahia

Pernambuco

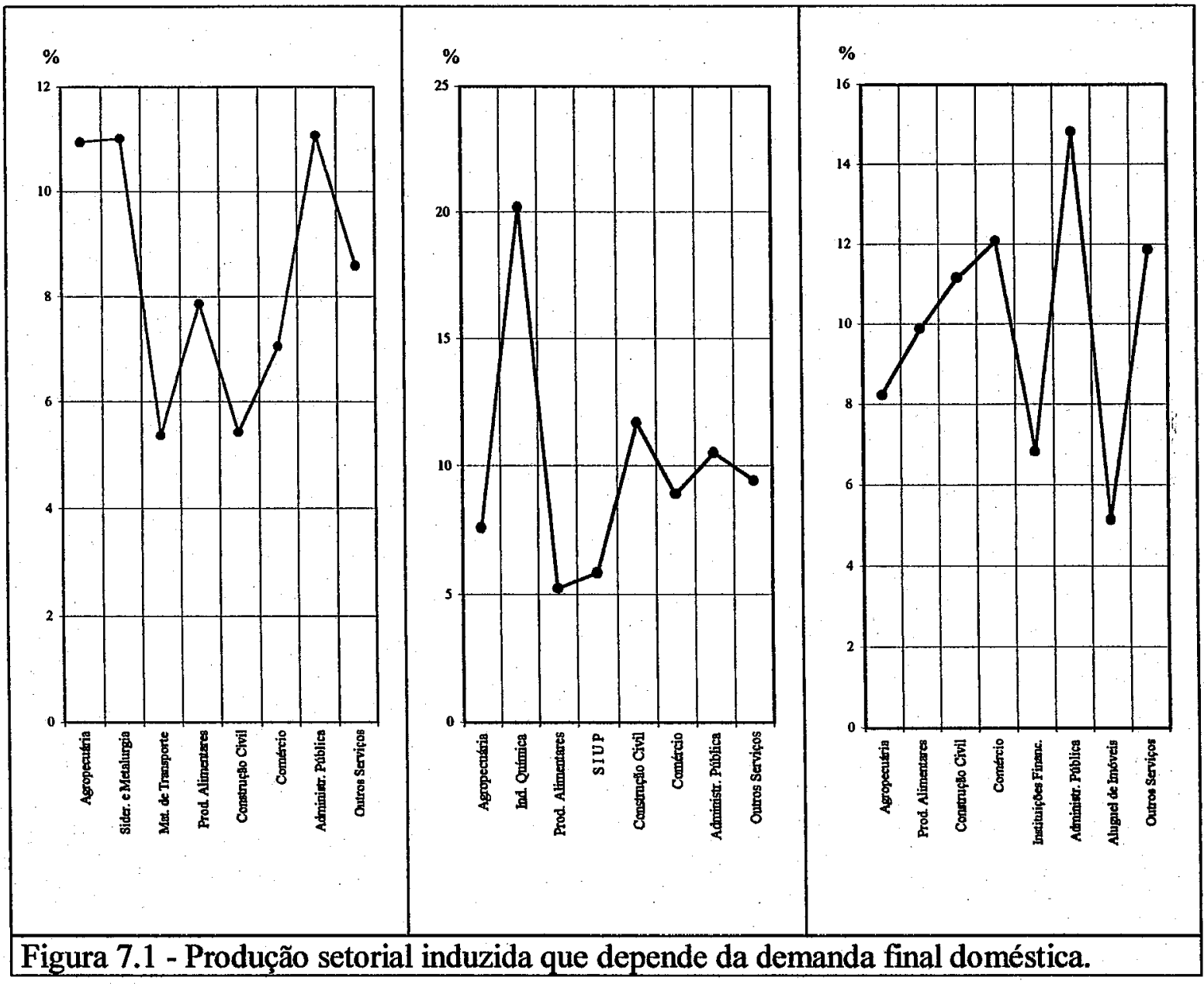

Em Pernambuco, dos oito setores produtivos selecionados, cinco pertencem ao grupo dos serviços e, destes, três, cuja produção apresenta 0 grau dependência da demanda final do próprio estado acima dos 10\%: o Comércio (setor 20), com 12\%; a Administração Pública (setor 24), com 14,8\% e os Outros Serviços (setor 26), com $11,9 \%$, os setores (Figura 7.1). 
Percebe-se que, das três regiões estudadas no sistema inter-regional do São Francisco, a de Pernambuco revela uma economia com características bem diferentes das demais. Como se pôde observar na análise dos índices puros, quando se verificou o comportamento da estrutura produtiva, levando em consideração o volume da produção, e quando se identificou o grau de dependência da produção da demanda doméstica, os setores do grupo dos Serviços são os que mais sobressaem, revelando sua importância para a economia estadual. Essas características são importantes para se compreender as especificidades de cada região e o tipo de orientação que pode ser dado aos projetos destinados ao desenvolvimento regional.

Embora os resultados apresentados sejam consistentes, é importante determinar a dimensão da economia das três regiões estudadas, no sistema inter-regional do São Francisco, frente às demais regiões da economia brasileira. Visando complementar a análise e fornecer indicações do comportamento da economia regional no conjunto da economia brasileira, ampliou-se o modelo inter-regional inserindo mais uma região no conjunto - o Resto do Brasil.

\subsection{Interações entre as regiões econômicas da bacia do são Francisco e o resto do Brasil: impactos da demanda final sobre a produção}

Visando mensurar os efeitos diretos e indiretos das demandas finais do sistema econômico constituído pelas três regiões que compõem o sistema inter-regional do São Francisco e o Resto do Brasil, ampliou-se o modelo inter-regional que, nesta análise, passa a ser constituído por quatro regiões: Minas Gerais, Bahia, Pernambuco e Resto do Brasil. Para facilitar a análise dos resultados, os mesmos setores produtivos considerados para as análises anteriores foram mantidos, assim, o sistema inter-regional passou de 78 setores produtivos, para 104, sendo considerados 26 setores por região.

Na Tabela 7.3 e na Figura 7.2, são apresentados os resultados para as regiões do sistema inter-regional.

A produção induzida pela própria demanda do estado de Minas Gerais corresponde a $90,9 \%$ do total, com $8,4 \%$ induzida pela demanda final do Resto do 
Brasil, $0,5 \%$ pela da Bahia e apenas $0,1 \%$ da produção induzida pela demanda final de Pernambuco. Quando se considera o conjunto da economia, a dependência da própria demanda final do estado de Minas Gerais é menor do que a apresentada na seção 7.1, quando se consideravam apenas três regiões, da mesma forma que diminuiu a dependência das demandas finais dos estados da Bahia e de Pernambuco. Note-se que a interação com o Resto do Brasil é maior.

Há que se ponderar, quando se observa esse resultado, que, nessa última região, estão inseridos importantes mercados do país como os dos estados de São Paulo, Rio de Janeiro e outros. Entretanto manteve-se a constatação de que o grau de dependência do estado de Minas Gerais das demandas da Bahia e de Pernambuco é pequeno (Figura 7.2).

A produção induzida pela demanda final doméstica do estado da Bahia corresponde a $86,6 \%$. A demanda final de Minas Gerais induz $1,6 \%$ da produção daquele estado, enquanto a de Pernambuco induz $0,2 \%$. A dependência da economia baiana da demanda do Resto do Brasil é de 11,6\%. Esse estado revela uma dependência maior que a do estado de Minas Gerais, pois $13,4 \%$ de sua produção é induzida pelas demandas de outras regiões.

Aproximadamente $86 \%$ da produção do estado de Pernambuco é induzida pela demanda doméstica. Esse estado revela uma maior dependência, comparativamente aos demais, do comércio com Minas Gerais, 2\%, e com a Bahia, 1\%. A produção induzida pela demanda final do Resto do Brasil corresponde a 11\%. Assim, sua dependência das demandas das outras economias totaliza $14 \%$.

Como se pode verificar na Figura 7.2, a demanda final do estado de Minas Gerais induz uma produção de 1,7\% no Resto do Brasil, a da Bahia induz, aproximadamente, $0,8 \%$ e Pernambuco, apenas $0,1 \%$. 


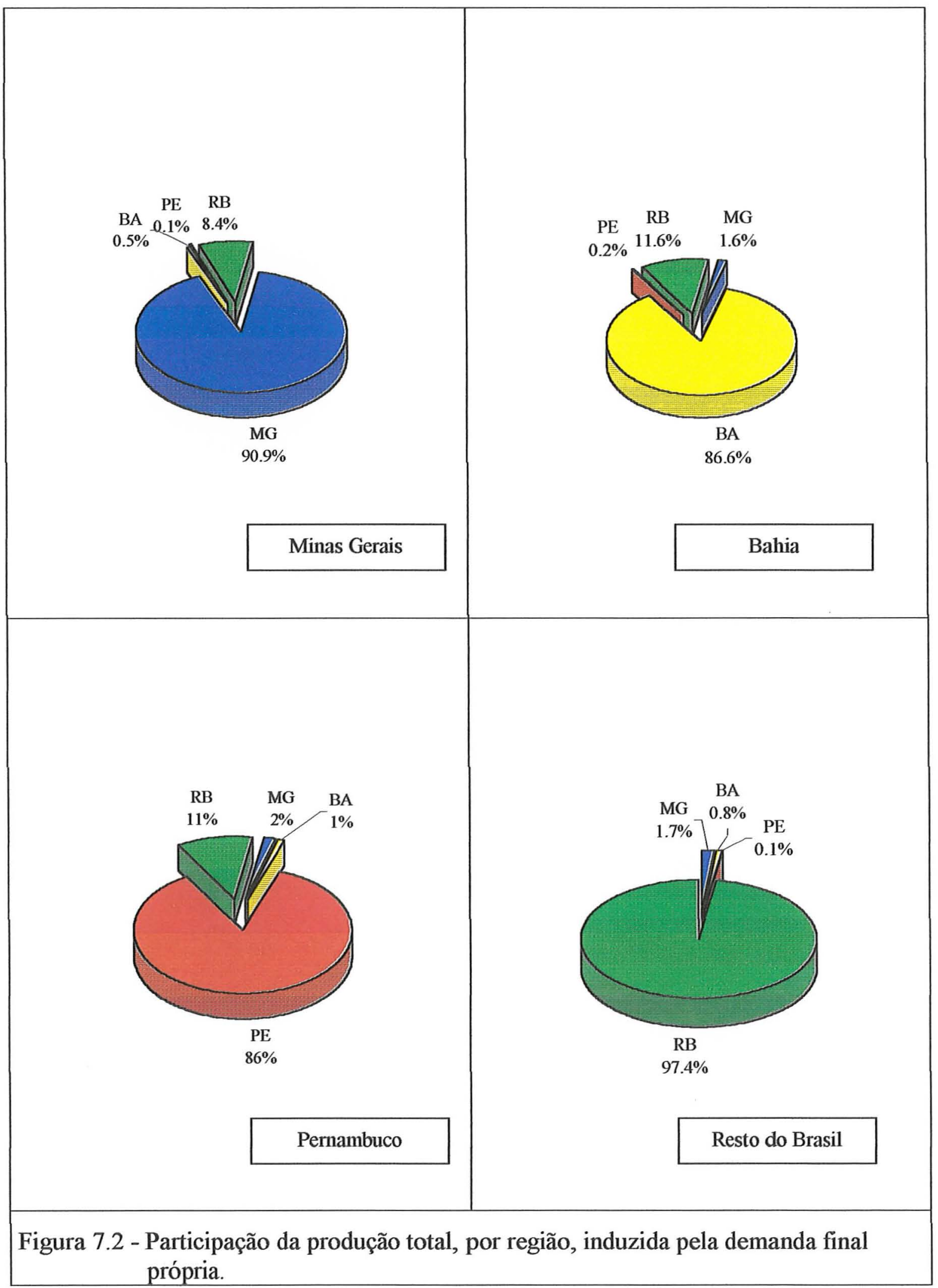


Surge, pois, a questão da necessidade da integração das atividades econômicas na região da bacia hidrográfica do Rio São Francisco para promoção do desenvolvimento dos mercados regionais.

Na tabela 7.3, apresenta-se o valor da produção total gerada em cada região e o valor da produção desagregada pela região de origem da demanda final indutora de tal produção.

O estado da Bahia, em 1995, gerou um volume de produção equivalente a 48,3 bilhões de reais. Desses, 40,4 bilhões foram induzidos por sua própria demanda final; 492,4 milhões de reais foram induzidos pela demanda final de Minas Gerais; 254,2 milhões, pela demanda de Pernambuco, enquanto aproximadamente 7,1 bilhões de reais foram induzidos pela demanda final do Resto do Brasil.

Tabela 7.3 - Produção das regiões do sistema inter-regional segundo indução da própria demanda e pelas demandas finais das outras regiões

$(\mathrm{emR} \$ 1000)$

\begin{tabular}{|c|c|c|c|c|c|c|c|c|c|c|}
\hline & ais & $\%$ & hia & $\%$ & $\infty$ & $\%$ & sil & $\%$ & latal & 0 \\
\hline & & 8273 & 8.994 & 0,74 & & 0,49 & & 16 & 36 & 100,00 \\
\hline B & 92400 & 1,02 & 20.333 & 83,66 & & 0,53 & & 9 & 14 & 0,00 \\
\hline Eerma & 127.240 & 0,49 & 96.953 & 0,37 & 24.326 .678 & 93,99 & & 5,15 & 25.883.546 & 100,00 \\
\hline Restod & 7.726 .810 & 0,82 & 5.42172 & 0,58 & 3.223 .029 & 0,34 & 921.4 & 98,25 & 937.811 .330 & 100,00 \\
\hline Total & 2192660 & 8,28 & 46688452 & 4,19 & 28304125 & 2,54 & 946.166389 & 84,98 & 1.113 .351 .626 & 100,00 \\
\hline
\end{tabular}

Fonte: Estimativas da autora.

Nota-se que os valores apresentados são coerentes com o produto total gerado pelos estados e pelo Brasil durante o ano de 1995. A inserção da região Resto do Brasil no sistema inter-regional possibilitou dimensionar o grau de dependência das economias dos estados da região do São Francisco entre si e em relação ao resto do Brasil. Embora os valores apresentados na Tabela 7.3 sejam diferentes dos da Tabela 7.2, verifica-se que o perfil das relações se manteve, ou seja, os três estados da região do São Francisco demonstram que há pouca interação entre seus mercados. 


\subsection{Desagregações setoriais das produções induzidas: impactos da própria demanda final}

A desagregação da parcela da produção total induzida pela demanda final da própria região, segundo a produção setorial, permite identificar qual a participação de cada setor da economia, revelando as características da estrutura produtiva de cada uma das regiões do sistema inter-regional.

Para melhor visualização dos resultados, optou-se por apresentar apenas os setores cuja produção induzida pela demanda final da própria região foi igual ou maior que 3\%. Dessa forma, a soma das porcentagens por região indutora não irá atingir $100 \%$. Na Figura 7.3, estão representadas as participações setoriais na produção total induzida pela demanda final da própria região.

No sistema inter-regional, dos treze setores que receberam maior impacto da demanda final da região na qual estão localizados, seis pertencem ao grupo da Indústria de Transformação e seis ao dos Serviços.

Observando a Figura 7.3, vê-se que a produção da Agropecuária (setor 1), das quatro regiões que compõem o sistema, é impactada pelas demandas das próprias regiões. Da produção induzida pela demanda final de Minas Gerais, naquele mesmo estado, cerca de $9 \%$ do total corresponde à produção da Agropecuária; do total da produção induzida pela demanda final da Bahia no próprio estado, $7 \%$ corresponde à resposta da produção Agropecuária a esse estímulo; o mesmo percentual corresponde à produção desse setor em função da demanda de Pernambuco e do Resto do Brasil sobre suas próprias economias.

A dependência da produção da Indústria Química do estado da Bahia de sua própria demanda é uma das mais altas do sistema inter-regional, cerca de $15 \%$, sendo que a participação na produção induzida total, nesse mesmo estado, do setor Construção Civil (setor 19), é de $14 \%$. 


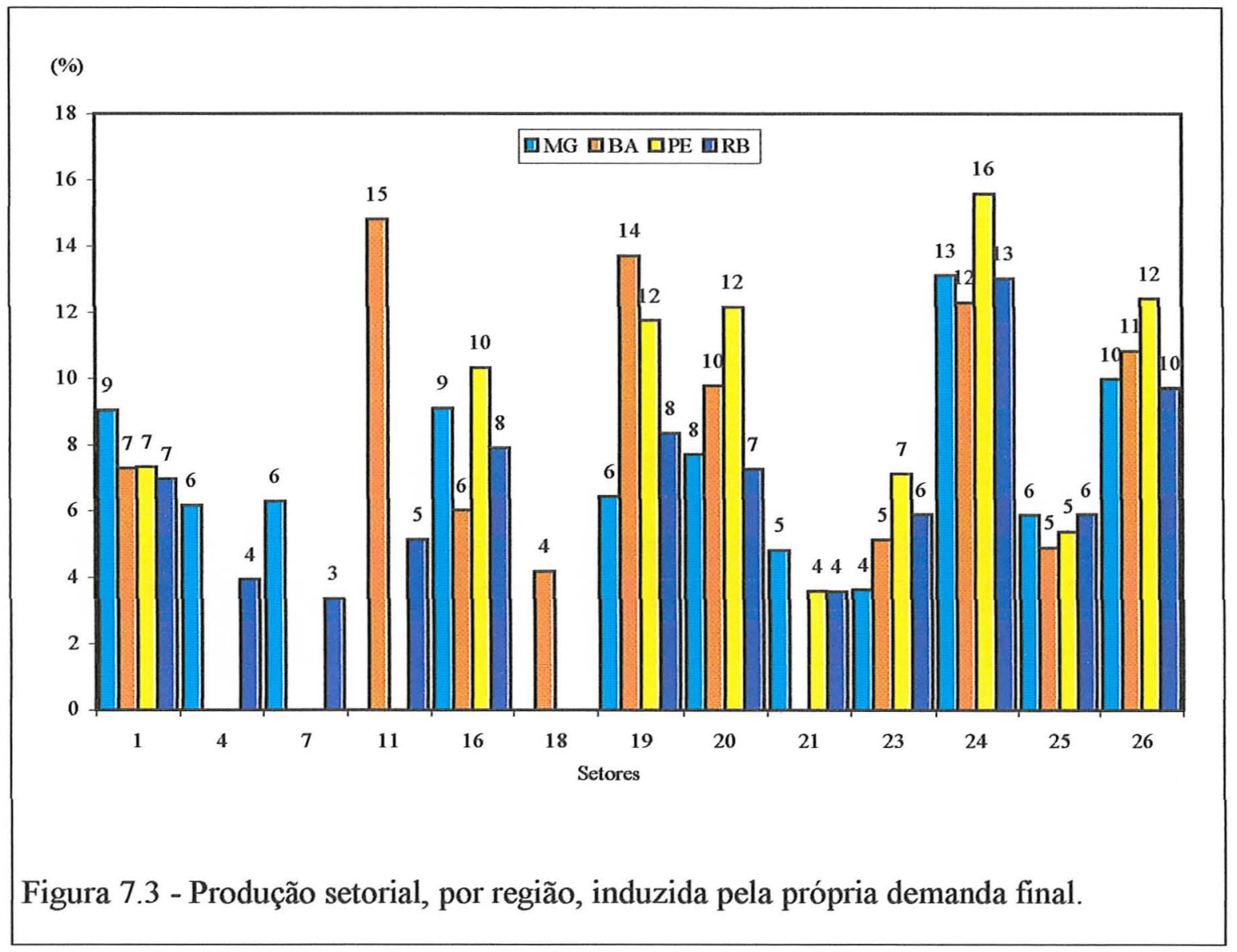

A indústria de Produtos Alimentares (setor 16) responde com produções induzidas pelas demandas finais próprias das quatro regiões, com participações na produção total da ordem de $9 \%$ em Minas Gerais, $6 \%$ na Bahia, 10\% em Pernambuco e $8 \%$ no Resto do Brasil.

No grupo dos Serviços, a Administração Pública (setor 24) apresenta as mais altas participações da produção induzida pelas demandas finais de cada região, 13\%, $12 \%, 16 \%$ e $13 \%$, respectivamente, sendo seguida pelos Outros Serviços (setor 26) nas quatro regiões: $10 \%$ em Minas Gerais; $11 \%$ na Bahia; $12 \%$ em Pernambuco e $10 \%$ no Resto do Brasil. O Comércio (setor 20) é responsável por, respectivamente, $8 \% \mathrm{em}$ Minas Gerais, $10 \%$ na Bahia, $12 \%$ em Pernambuco e $7 \%$ no Resto do Brasil, da produção total induzida pela demanda final da própria região. (Figura 7.3). 
Ainda considerando os setores do grupo dos Serviços, dos seis plotados na Figura 7.3, o estado de Pernambuco apresenta quatro setores com maior grau de dependência da demanda doméstica em todo o sistema inter-regional, revelando forte dependência de estímulos da economia do próprio estado.

\subsection{Desagregações setoriais das produções induzidas: impactos da demanda final de outras regiōes}

Nesta seção, são apresentados os resultados, por região, das produções setoriais induzidas pelas demandas finais das outras regiões, ilustrados pelas Figuras 7.4 a 7.7. É necessário, novamente, atentar para o fato de que a soma dos percentuais, por região indutora, não totalizam $100 \%$, uma vez que se considerou, na análise, apenas os setores sobre os quais o percentual da demanda final foi maior ou igual a $3 \%$.

No estado de Minas Gerais, fica evidenciada a influência das demandas finais das outras regiões sobre a produção da Siderurgia e Metalurgia (setor 4), como se observa na Figura 7.4. Pode-se verificar que dos efeitos das demandas finais das outras regiões do sistema sobre a economia de Minas Gerais, 29\% da demanda final da Bahia induz a produção da Siderurgia e Metalurgia; $27 \%$ da demanda final de Pernambuco e $36 \%$ da do Resto do Brasil impactam a produção desse mesmo setor.

O segundo setor, cuja produção recebe maiores estímulos das demandas finais das outras regiões é a Agropecuária (setor 1). Verifica-se que $13 \%$ da demanda final da Bahia e $21 \%$ das demandas finais de Pernambuco e do Resto do Brasil induzem a produção da Agropecuária em Minas Gerais.

Com menor magnitude que nos dois setores mencionados, as demandas finais das outras regiões também são importantes para a produção dos setores Extrativa Mineral (setor 2), Mecânica (setor 5), Material de Transporte (setor 7), Indústria Química (setor 11), Produtos Alimentares (setor 16), SIUP (setor 18), Comércio (setor 20) e Transportes (setor 21) em Minas Gerais. Todos esses setores receberam estímulos em suas produções em percentuais acima dos $3 \%$ das demandas finais das outras regiões do sistema. 
A análise da produção desagregada, por setor e por região de origem, do efeito indutor revelou que, entre os setores selecionados (setores cujas demandas das outras regiões situaram-se na faixa igual ou maior que 3\%) foram as demandas do estado da Bahia que induziram a produção de um maior número de setores no estado de Minas Gerais (9 dos 10 setores selecionados). Também demonstrou a importância das demandas finais das demais regiões do sistema inter-regional para as produções da Siderurgia e Metalurgia (setor 4) e da Agropecuária (setor 1), notadamente setores dinâmicos da economia mineira, conforme indicado pelas análises dos setores-chave segundo Rasmussen/Hirschman e dos índices puros.

Considerando o efeito indutor das demandas finais das outras regiões sobre o estado da Bahia, fica explícito o papel relevante da Indústria Química (setor 11) daquele estado frente às demandas das outras regiões. A Figura 7.5 ilustra como as demandas finais das outras regiões se distribuem pelos setores da economia da Bahia induzindo as suas produções. Como pode ser constatado, $53 \%$ da demanda final de Minas Gerais por produtos da Bahia induzem a produção da Indústria Química (setor 11) e $59 \%$ da demanda de Pernambuco induzem a produção desse mesmo setor. Também recaem sobre a produção da Indústria Química $51 \%$ do total da demanda final do Resto do Brasil por produtos da economia baiana. Esses resultados demonstram o papel fundamental desse setor como fornecedor de insumos e produtos para as demais regiões brasileiras, bem como sua relevância para a economia do estado em que está localizado.

Num outro patamar, também as produções dos setores Agropecuária (setor 1), Extrativa Mineral (setor 2), Siderurgia e Metalurgia (setor 4), SIUP (setor 18), Construção Civil (setor 19), Comércio (setor 20), Instituições Financeiras (setor 23) e Outros Serviços (setor 26), são acionadas pelas demandas finais das outras regiões.

Outra constatação importante é a de que, entre os nove setores selecionados, as demandas de Minas Gerais acionaram as produções de sete. Assim, em que pesem os efeitos das demandas das demais regiões, da análise das produções setoriais emerge uma interação entre os mercados de Minas Gerais e da Bahia, o que não havia sido explicitado nas análises anteriores. 


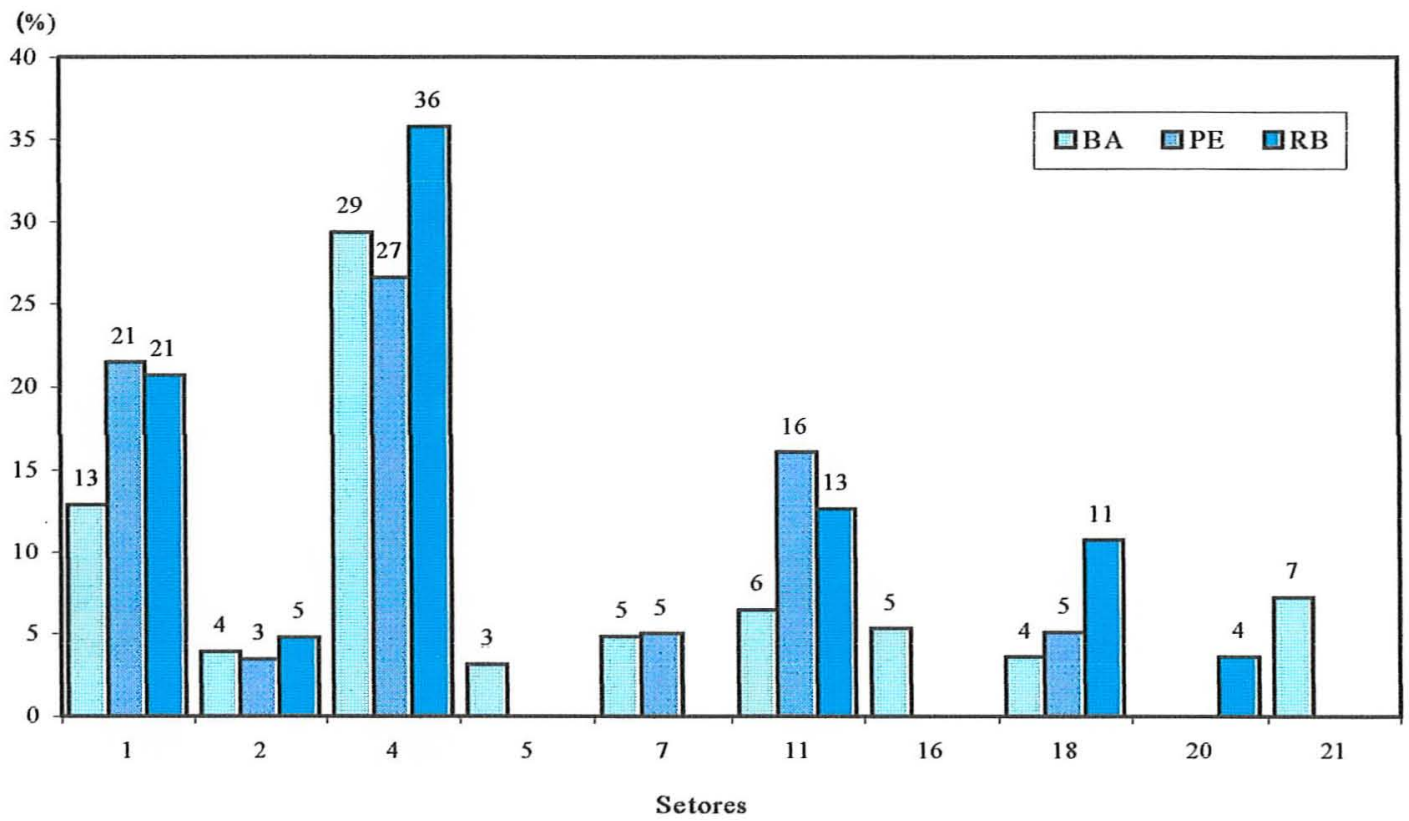

Figura 7.4 - Participação da demanda final das outras regiões na indução da produção setorial de Minas Gerais.

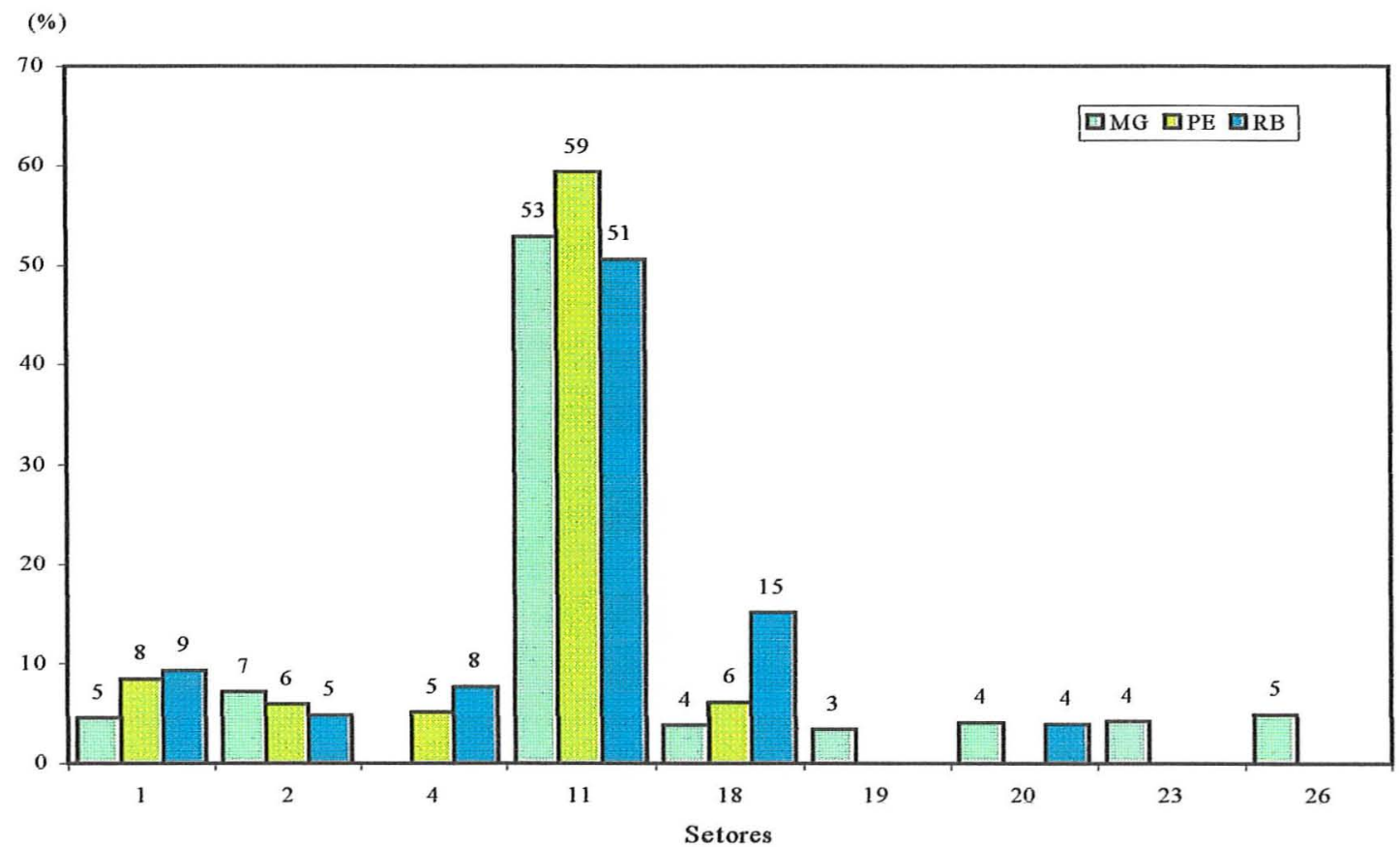

Figura 7.5 - Pạrticipação dạ demandạ finạl das outrạs regiộes nạ indụçạao dạ produção setorial da Bahia. 
As distribuições das demandas finais das outras regiões pelos setores da economia de Pernambuco estão ilustradas na Figura 7.6. Dos dezesseis setores acionados por essas demandas, apenas dois respondem simultaneamente às demandas das outras três regiões do sistema, a Agropecuária (setor 1) e a Indústria Química (setor 11).

A produção da Agropecuária recebe os maiores estímulos das demandas finais das outras regiões. Da demanda final de Minas Gerais, $9 \%$ induz a produção da Agropecuária em Pernambuco. No caso da demanda final da Bahia, esse percentual sobe para $16 \%$, sendo superado pelos estímulos à produção pernambucana pela demanda do Resto do Brasil, que, nesse caso, eqüivale a $25 \%$.

A produção Siderurgia e Metalurgia (setor 4) é acionada pelas demandas finais da Bahia e do Resto do Brasil, que correspondem, respectivamente, a $10 \%$ e a $19 \%$. Verifica-se que $44 \%$ da demanda do Resto do Brasil de produtos de Pernambuco é distribuída entre a Agropecuária e a Siderurgia e Metalurgia.

Outro setor cuja produção é acionada por percentuais mais elevados das demandas finais das outras regiões é a Indústria Química (setor 11). Do total das compras de Minas Gerias, $12 \%$ recaem sobre esse setor; no caso das compras da Bahia, a parcela destinada à Indústria Química é de 4\%; já o percentual das compras do Resto do Brasil corresponde a $15 \%$ da demanda final dessa região destinada aos produtos de Pernambuco.

Cabe destacar, ainda, que $12 \%$ da demanda final da Bahia sobre produtos da economia pernambucana impactam indústria de Produtos Alimentares (setor 16), assim como $15 \%$ da demanda do Resto do Brasil recaem sobre a Construção Civil (setor 19).

Ao se considerar a produção induzida desagregada em nível setorial, constata-se que o estado de Minas Gerais é um importante parceiro comercial do estado de Pernambuco, pois suas demandas acionam a produção de doze, dentre os dezesseis setores selecionados da economia desse último.

A Figura 7.7 exibe as participações percentuais das demandas finais das outras regiões que induzem a produção setorial da região Resto do Brasil. Três setores dessa região são acionados simultaneamente pelas demandas das outras três regiões, Agropecuária (setor 1), Indústria Química (setor 11) e Indústria Têxtil (setor 14). 
Do total da demanda final de Pernambuco no Resto do Brasil, $23 \%$ impacta a produção da Indústria Química (setor 11). Sobre a produção desse mesmo setor, recaem $18 \%$ da demanda final de Minas Gerais e 7\% da Bahia.

A produção da Agropecuária (setor 1) também é induzida por significativos percentuais das demandas finais das outras regiões. Da demanda final de Minas Gerais no Resto do Brasil, $10 \%$ aciona a produção da Agropecuária. No caso da demanda da Bahia, esse percentual corresponde a $12 \%$, sendo superado pelos estímulos à produção do Resto do Brasil pela demanda de Pernambuco, que, nesse caso, atinge $25 \%$. 0 mesmo se aplica aos demais setores da região (Figura 7.7).

É interessante notar que a demanda final de Minas Gerais acionou, entre os setores selecionados, a produção em doze setores do Resto do Brasil, enquanto a da Bahia acionou dez e a de Pernambuco, oito. Também, nesse caso, o estado de Minas Gerais demonstra estar integrado à região Resto do Brasil, sendo uma região importante tanto no aspecto da demanda quanto no aspecto da oferta, como se verificou na análise dos setores acionados naquele estado pelas demandas das outras regiões.

Uma outra característica revelada pela análise da produções induzidas em nível setorial é a da Indústria Química (setor 11) do estado da Bahia. Esse setor além de ser impactado pelas demandas de todas as outras regiões do modelo inter-regional, também é acionado pela demanda da própria região em que está localizado. Das demandas finais das outras regiões por produtos da economia da Bahia, mais de $50 \%$ destinaram-se aos produtos desse setor, demonstrando sua relevância como fornecedor para as economias de todas as regiões do sistema.

As demandas do estado de Pernambuco acionaram um menor número de setores na economia inter-regional que as de Minas Gerais e da Bahia. Entretanto, foi evidenciado o importante papel das demandas dos setores do grupo dos Serviços na produção induzida pela demanda final da própria região. Essa característica é importante, em termos de políticas setoriais de desenvolvimento, haja vista as atividades que esse grupo abrange, como, por exemplo, o turismo. 

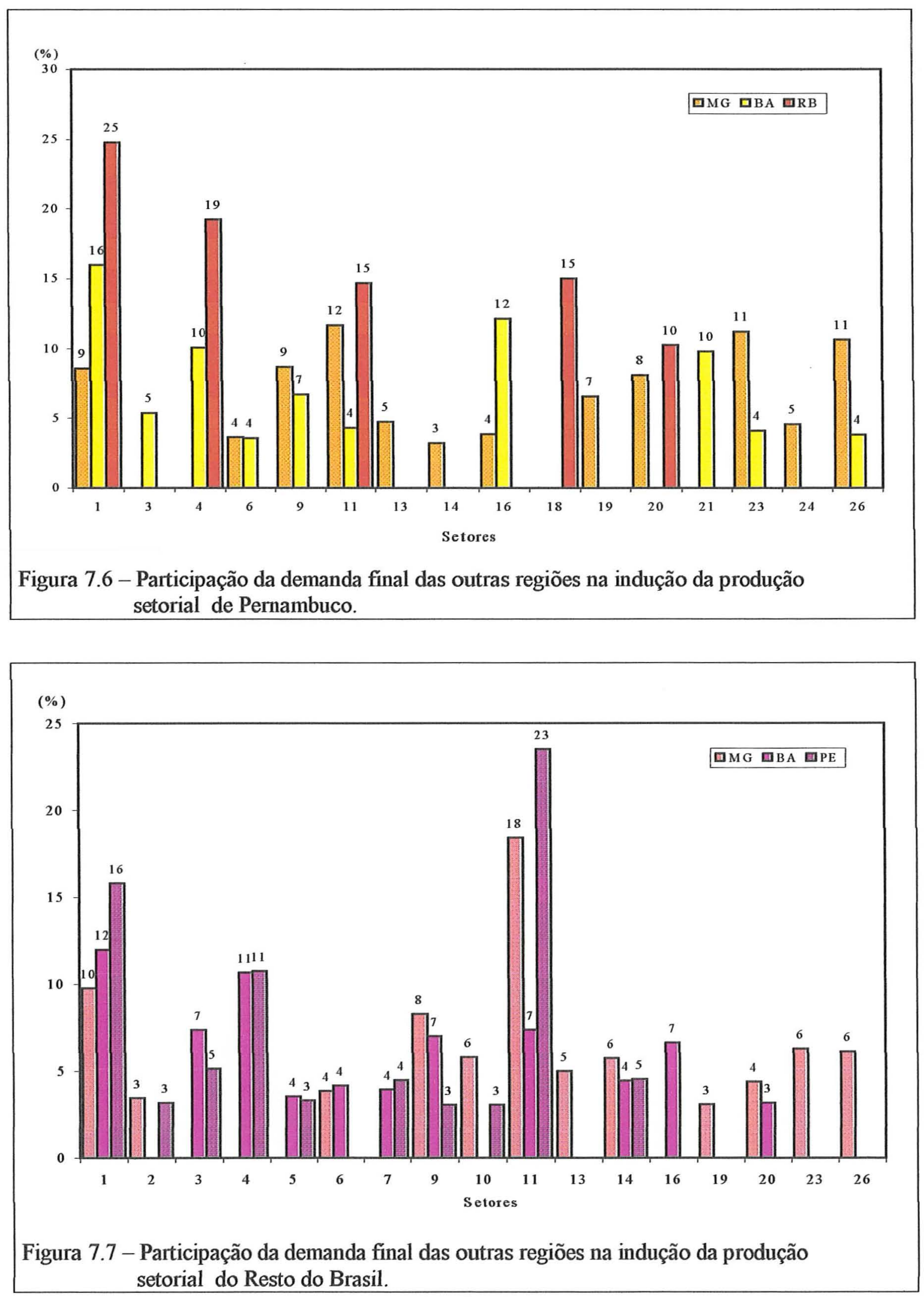
A análise desagregada das produções setoriais induzidas pelas demandas finais revelou importantes composições da estrutura produtiva das regiões do sistema interregional que não haviam sido captadas ao se fazer a análise global. Essas características fornecem elementos importantes para o estabelecimento de políticas setoriais voltadas para o desenvolvimento regional.

\subsection{Interações sinergéticas entre as regiões do sistema inter-regional}

Nesta seção, ainda considerando-se o sistema inter-regional do São Francisco e o Resto do Brasil, aplicou-se a metodologia desenvolvida por Sonis, Hewings e Miyazawa (1997), conforme descrição apresentada na seção 4.5, a fim de construir indicadores entre as regiões, de forma tal que fosse possível examinar, através da estrutura das interdependências internas e externas dada pelas ligações, a estrutura das relações de comércio entre as quatro regiões.

Os resultados obtidos estão apresentados nas Tabelas 7.4 e 7.5 e nas Figuras 7.8 a 7.11. Verificou-se, ao se aplicar o modelo para as regiões estudadas, que as combinações de 1, 2, 3, 4 e 5 matrizes geraram mais que $99,9 \%$ (100\%, no caso do Resto do Brasil) da explicação da produção para as regiões estudadas, permitindo considerar como residuais todas as outras combinações, uma vez que elas explicam apenas $0,01 \%$ da produção gerada.

Observando-se a Tabela 7.4, verifica-se que a primeira combinação dos blocos de matrizes representou acima de $\mathbf{7 0 \%}$ da produção interna de cada região, destacando-se a região do Resto do Brasil para a qual a primeira combinação dos blocos de matrizes representou mais de $96 \%$ da produção interna. Deve-se ressaltar que, na primeira combinação, parte-se de uma região isolada (um bloco), não havendo, portanto, nenhuma interação com as demais, ou seja, não há sinergia entre as regiões. A partir da segunda combinação, são mensuradas as interações entre elas. É possível, então, medir quanto cada interação adiciona ao total da produção. Assim, o que se pretende é medir 
quanto as relações do processo produtivo de uma região irão influenciar a produção de outra região.

Tabela 7.4 - Contribuição (\%) das combinações 1, 2, 3, 4 e 5 dos blocos de matrizes para a produção em cada região da bacia do São Francisco e o Resto do Brasil, 1995.

\begin{tabular}{ccccc}
\hline $\begin{array}{c}\text { Número de } \\
\text { Matrizes }\end{array}$ & $\begin{array}{c}\text { Região de } \\
\text { Minas Gerais }\end{array}$ & $\begin{array}{c}\text { Região da } \\
\text { Bahia }\end{array}$ & $\begin{array}{c}\text { Região de } \\
\text { Pernambuco }\end{array}$ & $\begin{array}{c}\text { Região do Resto } \\
\text { do Brasil }\end{array}$ \\
\hline 1 & 72,18 & 70,15 & 87,52 & 96,42 \\
2 & 18,40 & 20,08 & 9,15 & 2,25 \\
3 & 8,80 & 8,95 & 2,99 & 1,07 \\
4 & 0,48 & 0,63 & 0,26 & 0,24 \\
5 & 0,12 & 0,17 & 0,07 & 0,01 \\
Resíduo & 0,02 & 0,02 & 0,01 & 0,00 \\
\hline Total & 100,00 & 100,00 & 100,00 & 100,00 \\
\hline
\end{tabular}

Fonte: Estimativas da autora.

A partir da segunda interação, quando são consideradas duas regiões, verifica-se que as regiões da Bahia, com 20,08\%, e de Minas Gerais, com $18,40 \%$, são as que apresentam maiores aumentos na produção, comportamento que se repete, embora com menor magnitude ( $8,95 \%$ e $8,80 \%$ respectivamente), na terceira interação.

As relações sinergéticas entre as quatro regiões estão representadas na Tabela 7.5 e nas Figuras 7.8 a 7.11. Observa-se que, para a região de Minas Gerais, as 3 principais relações (maiores que 1\%) representam 97,55\% da produção. Para as regiões da Bahia e de Pernambuco, as 4 maiores relações representam $97,78 \%$ e $98,44 \%$ da produção, respectivamente. Para a região formada pelo Resto do Brasil, $98,4 \%$ da produção é induzida pelas 3 maiores relações.

Considerando-se a região de Minas Gerais, verifica-se que a relação mais importante no processo produtivo deveu-se às suas relações internas, ou seja, $68,71 \%$ da sua produção total foi gerada pelas relações do processo produtivo dentro da própria região. 
Quanto às suas vendas para as demais regiões do sistema inter-regional, a mais importante relação ocorre com o Resto do Brasil. As vendas de insumos que Minas Gerais faz para o Resto do Brasil são responsáveis por $20,93 \%$ da sua produção total. No que se refere às demais regiões; as vendas de insumos de Minas Gerais para a Bahia respondem por 0,93\% de sua produção, enquanto as para Pernambuco respondem por $0,61 \%$ da produção total de Minas Gerais, demonstrando fracas relações entre as regiões (Tabela 7.5 e Figura 7.8).

Tabela 7.5 - Contribuição (\%) de cada bloco de matriz para a parte total de $\left(x_{1}-f\right)$ em $x$ Para as regiões do São Francisco e Resto do Brasil, 1995.

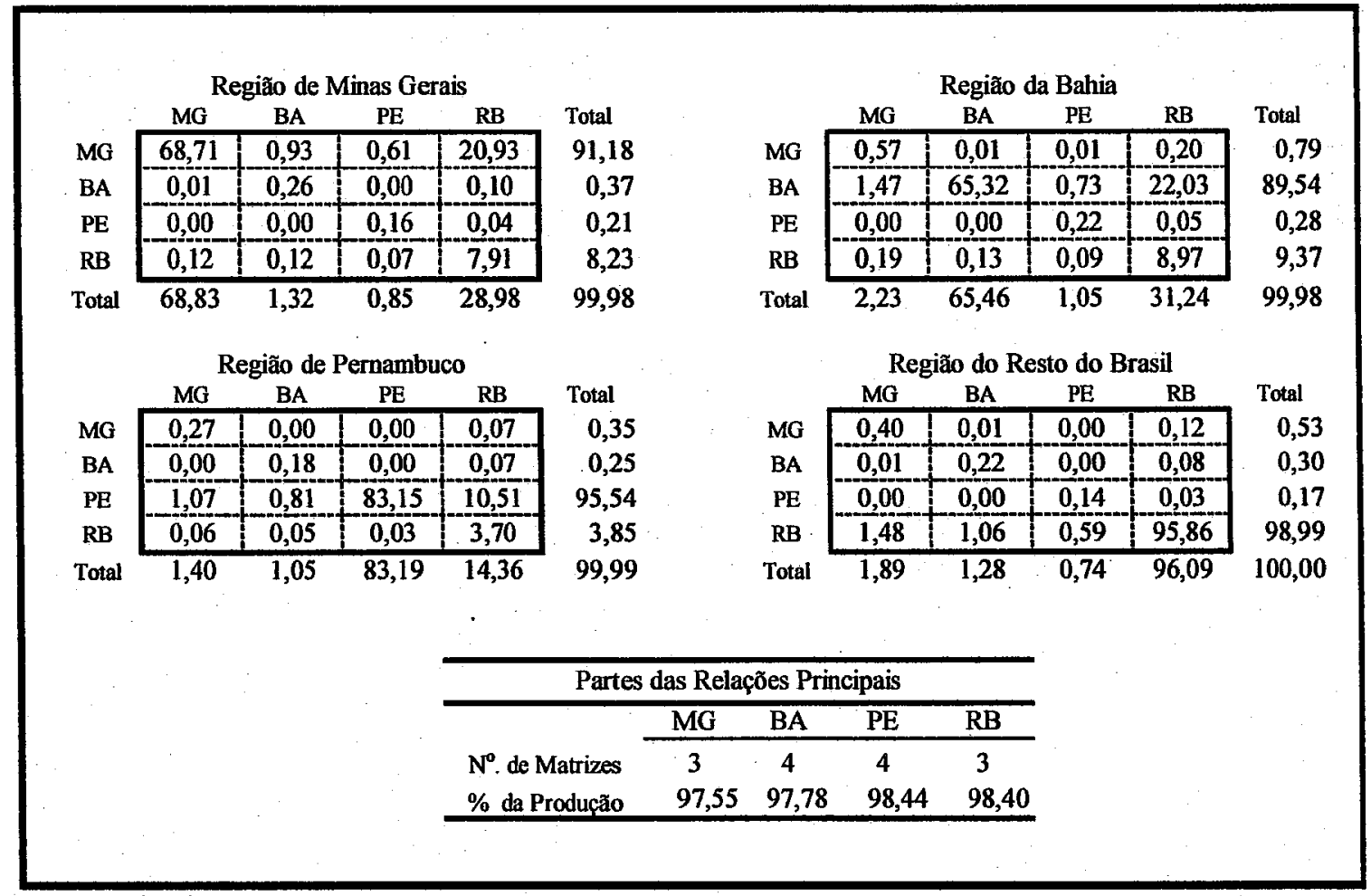

Fonte: Estimativas da autora.

Verifica-se que $91,18 \%$ da produção de Minas Gerais é influenciada pelas vendas que ela faz dentro da própria região e para as outras regiões do sistema inter-regional. Também constata-se que $\mathbf{6 8 , 8 3 \%}$ da produção da região é influenciada pelas compras de insumos que são feitas dentro dela própria e das outras regiões do sistema. Destacam-se, 
também, as compras de insumos que o Resto do Brasil faz da região de Minas Gerais, uma vez que $28,98 \%$ da produção desta foi influenciada pelas suas relações comerciais com o Resto do Brasil.

Ainda considerando Minas Gerais, ficou explícito que as relações entre as regiões estudadas influenciam em $99,98 \%$ da produção dessa região (Tabela 7.5 e Figura 7.8).

É importante ressaltar que as relações internas do processo de produção do Resto do Brasil geram 7,91\% da produção da região de Minas Gerais. Esses resultados das interações evidenciam que as mais importantes relações da região de Minas Gerais, no sistema inter-regional, ocorrem com a região constituída pelo Resto do Brasil, revelando uma estrutura produtiva dependente dessa região e pouco interligada com as outras regiões (BA e PE).

Os resultados para a região da Bahia mostram que $65,32 \%$ da sua produção ocorreu com as relações internas do processo produtivo. Dos percentuais relativos às suas vendas de insumos, as realizadas para o Resto do Brasil impactaram sua produção em 22,03\%. As relações com Minas Gerais responderam por $1,47 \%$ da produção da Bahia, demonstrando a importância das relações entre as duas regiões, principalmente para essa última (Tabela 7.5 e Figura 7.9).

Pode-se observar que $89,54 \%$ da produção total da Bahia ocorreu devido às vendas de insumos tanto dentro da própria região quanto para as outras regiões do sistema. No tocante às compras de insumos realizadas pela região da Bahia, observa-se que $65,46 \%$ da sua produção foi influenciada pelas compras realizadas dentro da própria região e das regiões de Minas Gerais e do Resto do Brasil. Outra relação importante evidenciada, refere-se às compras de insumos feitas pelo Resto do Brasil que impactaram $31,24 \%$ da produção da Bahia.

Merece destaque o fato de a região baiana exibir uma forte relação com a região formada pelo Resto do Brasil, podendo-se verificar que as relações de produção dessa última induzem $8,97 \%$ da produção da primeira. 


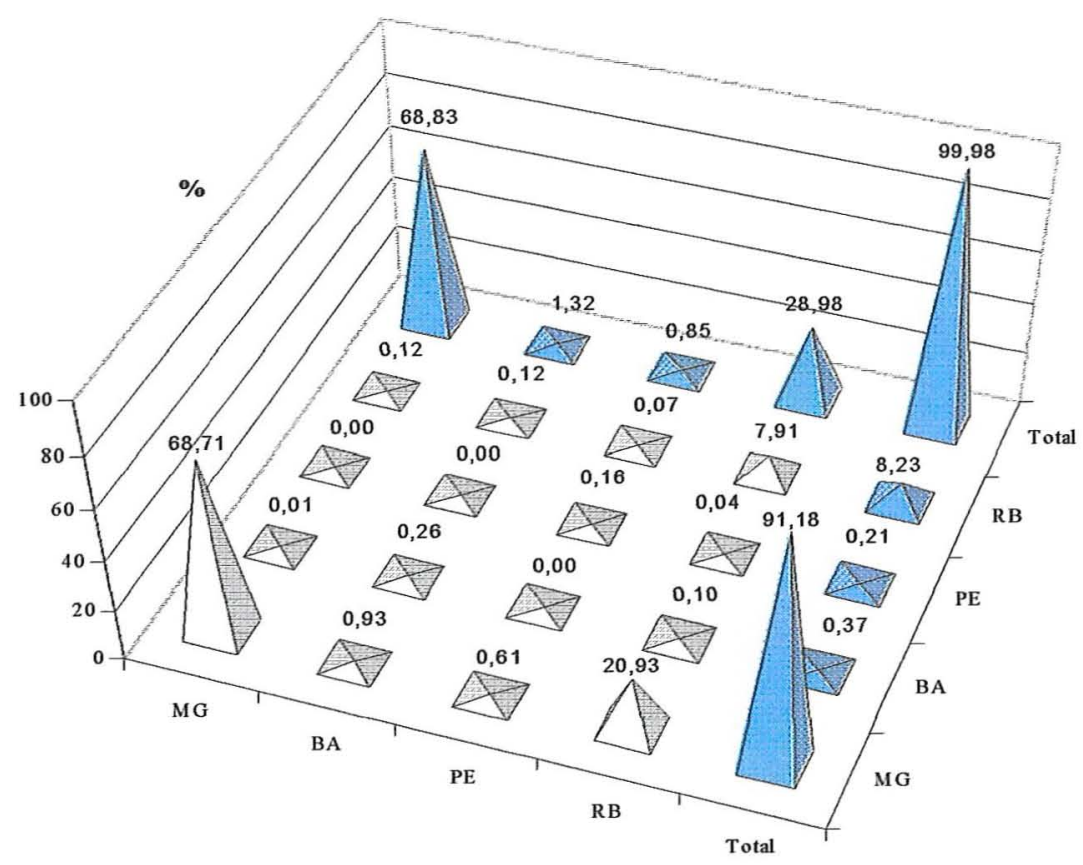

Figura 7.8 - Contribuição (\%) de cada bloco de matriz para a parte total de $\left(x_{1}-f\right)$ em $x$ na Região de Minas Gerais, 1995.

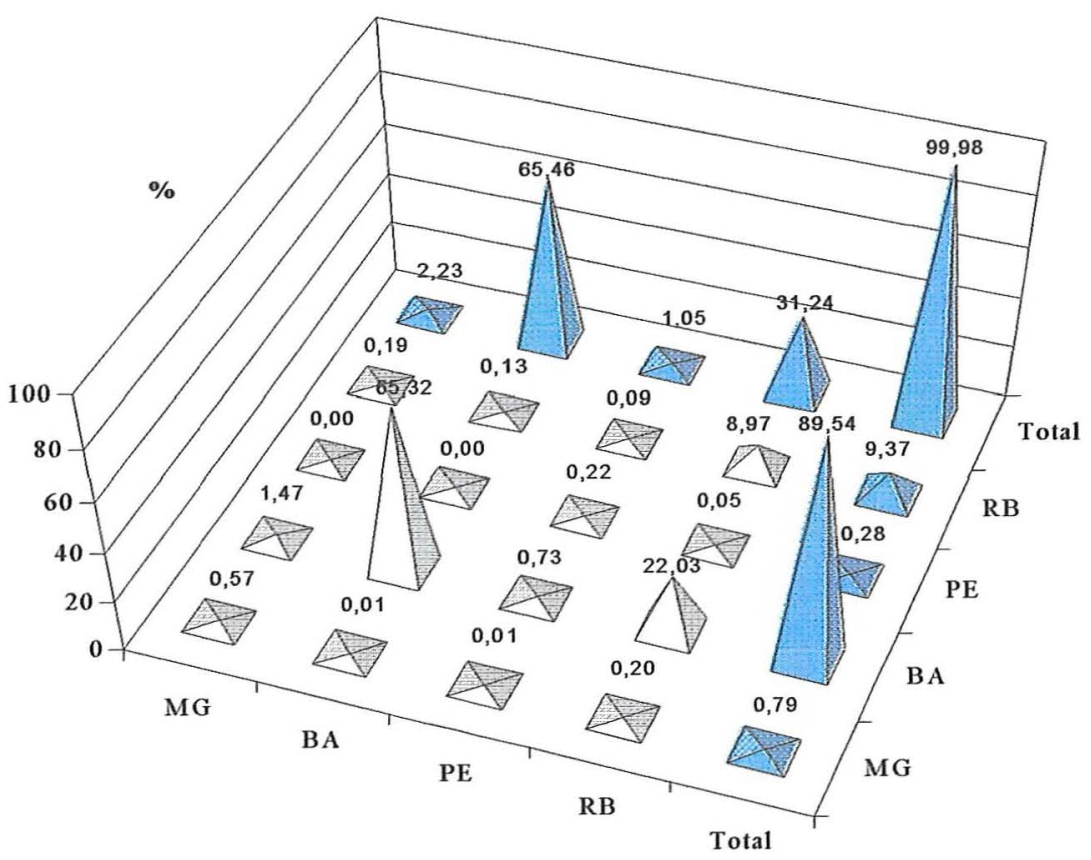

Figura 7.9 - Contribuição (\%) de cada bloco de matriz para a parte total de $\left(x_{1}-f\right)$ em $x$ na Região da Bahia, 1995. 
Os resultados das interações realizadas mostram que as regiões da Bahia e de Pernambuco exibem relações fracas. Apenas $0,73 \%$ da produção da primeira região é impactada pelas compras da segunda.

Das regiões do sistema, a Bahia foi a que apresentou a estrutura produtiva mais aberta, pois $34,66 \%$ de sua produção total depende das relações de produção das outras regiões.

Ao se observar o quadro das relações da região de Pernambuco vê-se que 83,15\% da produção são resultantes das relações internas do processo produtivo da própria região. Esse resultado é interessante, revelando que, embora sendo a que possui menor volume de produção no sistema, essa economia apresenta como característica o fato de ser mais fechada do que as de Minas Gerais e da Bahia, por exemplo. Isso significa que as relações dentro do processo produtivo da própria região respondem por um maior percentual da sua produção do que as outras duas (Tabela 7.5 e Figura 7.10).

Ao estudar as interações e a dependência entre as cinco macro regiões brasileiras, Guilhoto (1999) constatou que o tamanho da economia tem um impacto sobre os resultados, pois as regiões Norte e Centro Oeste mostraram ser economias mais abertas enquanto as regiões Sudeste e Sul mostraram ser mais fechadas. A região Nordeste mostrou situar-se em uma posição intermediária em relação às das demais.

No caso da economia pernambucana, o fato de as relações, dentro do processo produtivo, revelarem uma economia mais fechada talvez possa ser explicado pelas ligações dos setores do grupo dos Serviços serem fortes naquela região, como, por exemplo, as ligações para trás do setor Aluguel de Imóveis (setor 25) e as ligações para frente dos setores Comércio (setor 20) e Outros Serviços (setor 26), (ver Tabela 6.2). Esses setores são principalmente orientados para os consumidores finais, ou seja, seu mix de produção é diferente do dos setores que compõem a Indústria de Transformação, cujas vendas são orientadas para outras indústrias. Assim, os resultados expressos por essa economia podem estar revelando esse outro aspecto das relações, haja vista que o estudo considera as relações dentro do processo produtivo.

No tocante às vendas de insumos, as relações entre o Resto do Brasil e Pernambuco geram 10,51\% da produção desta última. As vendas de insumos para Minas 
Gerais geram 1,07\% da produção de Pernambuco. Novamente são evidenciadas as fracas relações entre as regiões de Pernambuco e da Bahia, quando as compras desta última impactam apenas $0,81 \%$ da produção total de Pernambuco.

$\mathrm{Na}$ economia pernambucana, as vendas de insumos internamente e para as outras regiões influenciam $95,54 \%$ da produção total. As compras de insumos da própria região e do Resto do Brasil impactam 83,19\% da produção da região.

As interações revelam que as relações de produção da região Resto do Brasil induzem 3,70\% da produção da região de Pernambuco. Pode-se observar, também, que as compras de insumos feitas pelo Resto do Brasil influenciam 14,36\% da produção de Pernambuco (Tabela 7.5 e Figura 7.10).

Os resultados para a região Resto do Brasil revelam que $1,48 \%$ da sua produção ocorre devido às vendas de insumos para Minas Gerais, $1,06 \%$ devido às vendas para a Bahia, enquanto apenas $0,59 \%$ da sua produção decorre das vendas para a região de Pernambuco. Observa-se que as interações sinergéticas são fracas, ou seja, as relações de produção das demais regiões impactam em pouco mais de $3 \%$ a produção desta região. Fica evidente que a região Resto do Brasil é a menos dependente das demais, uma vez que $95,86 \%$ de sua produção total ocorre devido às relações do processo produtivo dentro dela própria ( Tabela 7.5 e Figura 7.11).

Vale ressaltar que $98,99 \%$ da produção total do resto do Brasil é influenciada pelas vendas que são feitas internamente e para as outras regiões do sistema. Verifica-se, também, que as compras de insumos dentro da própria região e das demais regiões geram $96,09 \%$ da sua produção.

De certo modo, esses resultados não surpreendem, tendo em vista a importância econômica da região constituída pelo Resto do Brasil que abrange importantes economias do território nacional. Entretanto, as interações revelaram a importante participação das economias das regiões de Minas Gerais e Bahia, cujas compras totalizam $2,54 \%$ da produção dessa região. 


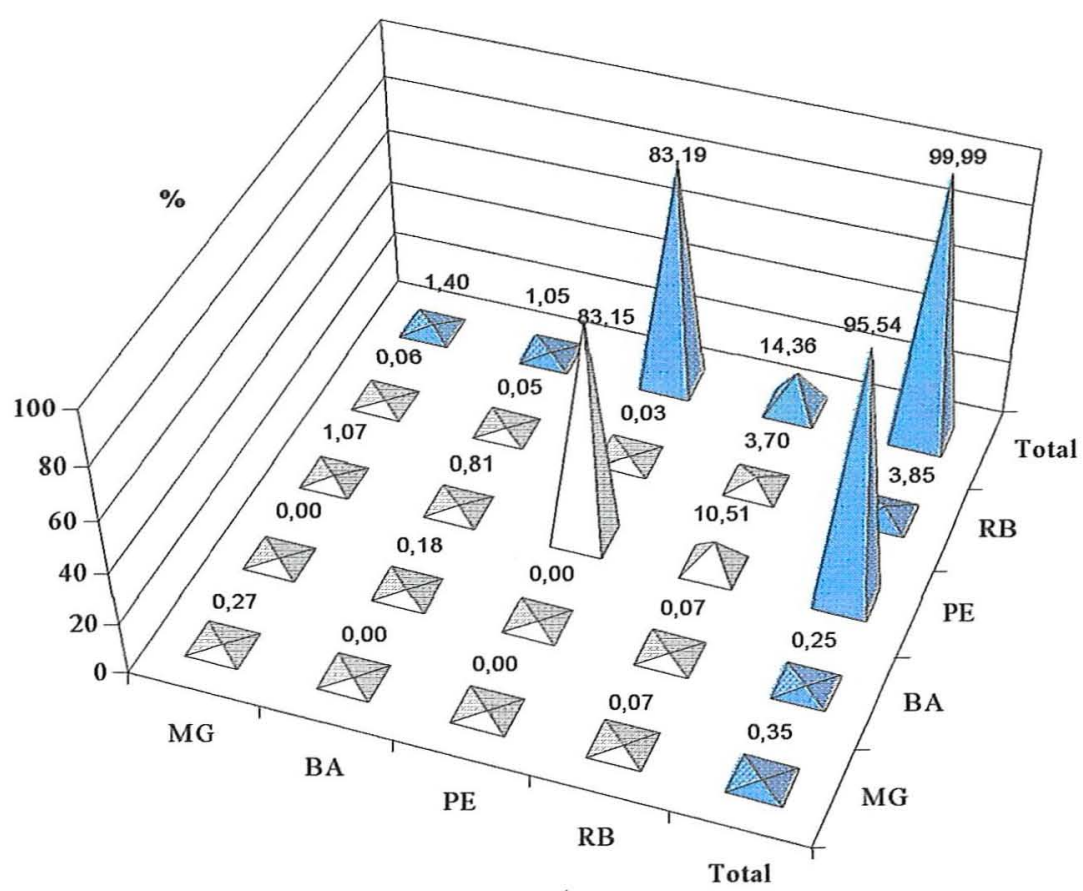

Figura 7.10 - Contribuição (\%) de cada bloco de matriz para a parte total de $\left(x_{1}-f\right)$ em $x$ na Região de Pernambuco, 1995.

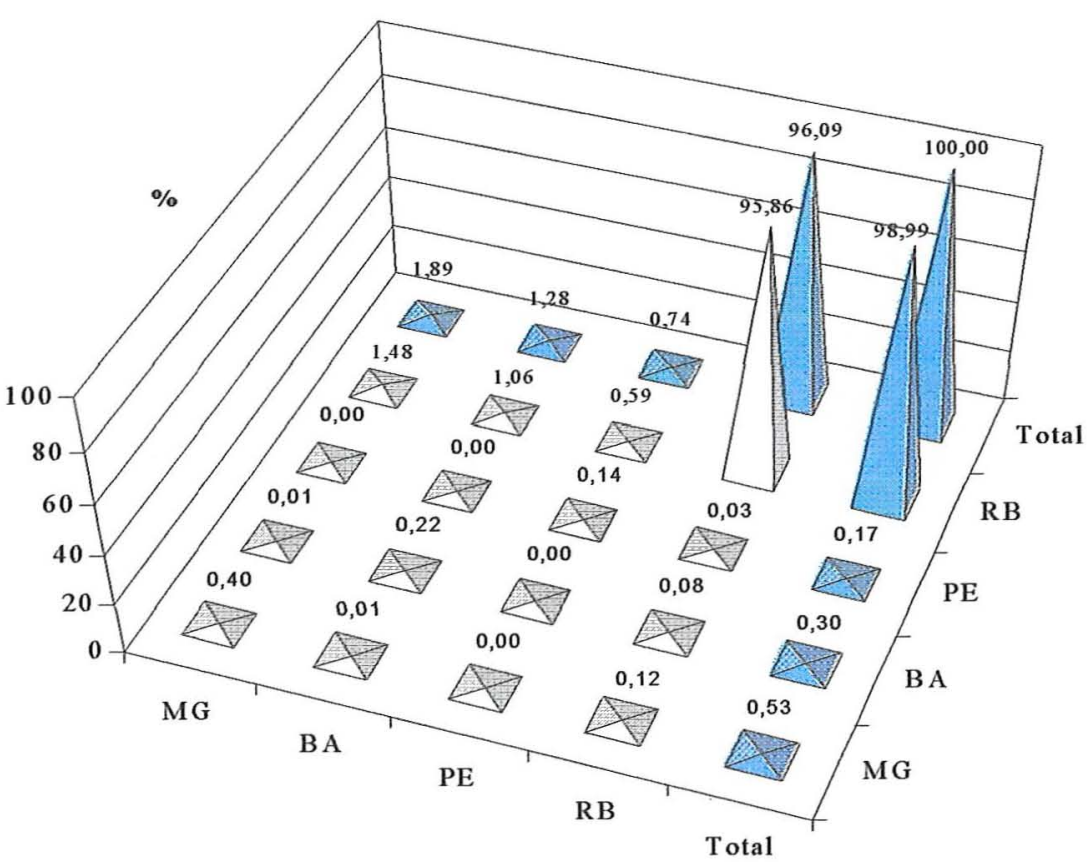

Figura 7.11 - Contribuição (\%) de cada bloco de matriz para a parte total de $\left(x_{1}-f\right)$ em $x$ na Região do Resto do Brasil, 1995. 
Ao se analisar as relações entre as regiões, no processo produtivo, verificou-se que: a) a demanda por insumos do Resto do Brasil proporciona impactos na produção das outras três regiões do sistema; b) as compras de insumos pela região de Minas Gerais são importantes para a produção das regiões da Bahia e de Pernambuco; c) a região de Pernambuco exibiu fracas relações com as regiões de Minas Gerais e da Bahia; d) a região da Bahia mostrou-se como a mais dependente no sistema; e) a região de Pernambuco apresentou a característica de ser mais fechada que as economias de Minas Gerais e da Bahia no sistema inter-regional.

A presente aplicação das ligações de insumo-produto para identificação das relações sinergéticas entre as regiões permitiu não só revelá-las, como, também, verificar a consistência das análises anteriores, quando se identificou, exceto a região Resto do Brasil, Minas Gerais como a que apresenta importantes relações de comércio com as demais. Também se constatou que a estrutura da economia da região da Bahia é a mais aberta, com maior dependência das demais regiões do sistema, enquanto a economia de Pernambuco, apresenta uma estrutura mais fechada que as de Minas Gerais e da Bahia. Esses resultados constituem importantes indicadores de direções de políticas que visem ao desenvolvimento dessas regiões, notadamente aquelas que constituem o sistema do São Francisco, pois permitem verificar o quanto as relações de produção de uma região afetam a produção de outra. 


\section{USOS DA AGUA NA BACLA DO RIO SÄO FRANCISCO}

Os recursos naturais têm um papel relevante no desenvolvimento econômico para a maioria dos países. A água é um desses recursos cuja oferta é importante para as mais diversas atividades, como, por exemplo, as da agropecuária, as urbanas e industriais, para geração de energia elétrica (como no Brasil), para navegação, recreação, enfim, para múltiplos usos. Entretanto, os usos da água são tão importantes quanto a quantidade ofertada e a qualidade que ela possa apresentar.

O modelo inter-regional de insumo-produto permitiu a identificação das relações intra e inter-regionais das regiões que compõem o sistema econômico da bacia do São Francisco. Nesse contexto, a proposta deste capítulo é a de associar à tradicional matriz de insumos do sistema econômico, uma matriz de insumos considerando o recurso água. $\mathrm{E}$, a partir desta, estimar os coeficientes de uso da água e seus multiplicadores.

O modelo apresentado pode ser classificado, sob o ponto de vista da teoria dos modelos ambientais de insumo-produto (Miller \& Blair, 1985, p.237), como uma versão do modelo de insumo-produto generalizado.

Os resultados que serão apresentados são considerados preliminares, haja vista que os dados básicos utilizados foram os das outorgas de uso da água na bacia do rio São Francisco. Assim, nesta pesquisa, está sendo considerado o volume de água captado nos estados de Minas Gerais, Bahia e Pernambuco.

É importante ressaltar que o conceito de uso da água utilizado é o do consumo, isto é, refere-se à quantidade de água utilizada por um consumidor ou conjunto de consumidores num dado período de tempo. Portanto, nesta pesquisa, as expressões "consumo" e "uso" têm o mesmo significado.

Segundo os procedimentos descritos na Seção 5.3 do Capitulo 5, foram estimados os volumes de água consumidos pelos setores do sistema inter-regional do São Francisco, a matriz inter-regional de consumo de água e os multiplicadores 
intersetoriais. Os resultados obtidos são analisados nas seções seguintes. Por se dispor de poucas informações sobre o consumo efetivo de água pelos setores das economias estudadas, os valores apresentados devem ser considerados indicadores preliminares, uma vez que a fonte básica dos dados são as outorgas de usuários da Secretaria de Recursos Hídricos (SRH) do Ministério do Meio Ambiente, dos Recursos Hídricos e da Amazônia Legal.

\subsection{Consumo de água por setor no sistema inter-regional}

Os volumes de água captados na bacia do rio São Francisco pelos estados de Minas Gerais, Bahia e Pernambuco, segundo dados da Secretaria de Recursos Hídricos, demonstram que o maior consumidor de água da bacia é o estado da Bahia, com um volume de captação de 359.874 1/s, seguindo-se o estado de Minas Gerais, com 184.700 1/s e o estado de Pernambuco, com 145.145 1/s.

Os principais setores consumidores de água no estado de Minas Gerias são, respectivamente: Agropecuária (setor 1), consumindo aproximadamente $95 \%$ do total anual; Extrativa Mineral (setor 2), com um consumo correspondente a 2,6\%; Indústria Química (setor 11), com 0,6\%; e os Serviços Industriais de Utilidade Pública -SIUP (setor 18), com um consumo anual eqüivalente a $0,2 \%$ do total. Esses mesmos setores são os principais consumidores de água no estado da Bahia, com a Agropecuária (setor 1) consumindo $95 \%$ do total anual do estado, a Indústria Química (setor 11) com o equivalente a $3,4 \%$, a Extrativa Mineral (setor 2 ), com $1,2 \%$ e o SIUP com $0,2 \%$. No estado de Pernambuco, a Agropecuária (setor 1) permanece ocupando a primeira posição, consumindo $99 \%$ do total do estado na região da bacia; o segundo maior consumidor é a Extrativa Mineral (setor 2), com 0,27\% e, o terceiro, o de Produtos Alimentares (setor 16), com $0,2 \%$, conforme apresentado na Tabela 8.1. 
Tabela 8.1 - Consumo de água por setor da economia no sistema inter-regional do São Francisco.

(Em mil $\mathrm{m}^{3} /$ ano)

\begin{tabular}{|c|c|c|c|c|c|c|c|}
\hline & SETOR & Minas Gerais & $(\%)$ & Bahia & (\%) & Pernambuco & (\%) \\
\hline 1 & AGROPECUÁRIA & 3.180 .119 & 95,12 & 6.357 .762 & 94,71 & 2.512 .313 & 98,99 \\
\hline 2 & EXTRATIVA MINERAL & 85.213 & 2,55 & 77.133 & 1,15 & 11.926 & 0,47 \\
\hline 3 & MINERAIS NÃO METÁLICOS & 19.570 & 0,59 & 9.903 & 0,15 & 0 & 0 \\
\hline 4 & SIDERURGIA E METALURGIA & 5.041 & 0,15 & 1.897 & 0,03 & 0 & 0 \\
\hline 5 & MECÂNICA & 60 & 0,002 & 64 & 0,001 & 0 & 0 \\
\hline 6 & MATERIAL ELĖTRICO E ELETRÔNICO & 24 & 0,001 & 0 & 0 & 0 & 0 \\
\hline 7 & MATERIAL DE TRANSPORTE & 467 & 0,01 & $\mathbf{0}$ & $\mathbf{0}$ & $\mathbf{0}$ & $\mathbf{0}$ \\
\hline 8 & MADEIRA E MOBILIARIO & 1.092 & 0,03 & 1.407 & 0,02 & 1.005 & 0,04 \\
\hline 9 & PAPEL E GRAFICA & 1.494 & 0,04 & $\mathbf{0}$ & 0 & 0 & $\mathbf{0}$ \\
\hline 10 & INDÚSTRIA DA BORRACHA & 9 & 0,0003 & $\mathbf{0}$ & $\mathbf{0}$ & $\mathbf{0}$ & $\mathbf{0}$ \\
\hline 11 & INDÚSTRIA QUUMMICA & 31.011 & 0,93 & 227.098 & 3,38 & $\mathbf{0}$ & $\mathbf{0}$ \\
\hline 12 & FARMACÊUTICA E PERFUMARIA & 2.961 & 0,09 & 2.535 & 0,04 & 0 & 0 \\
\hline 13 & ARTIGOS DE PLASTICO & 1.105 & 0,03 & 0 & 0 & 0 & $\mathbf{0}$ \\
\hline 14 & INDÚSTRIA TÊXTIL & 16 & 0,0005 & 13 & 0,0002 & 18 & 0,001 \\
\hline 15 & VESTUÁRIOE CALÇADOS & 30 & 0,001 & 39 & 0,001 & 74 & 0,003 \\
\hline 16 & PRODUTOS ALIMENTARES & 2.766 & 0,08 & 2.899 & 0,04 & 4.978 & 0,20 \\
\hline 17 & INDÚSTRIAS DIVERSAS & 15 & 0,0005 & 5 & 0,0001 & 6 & 0,0002 \\
\hline 18 & SERV. INDUST.UTILID, PÚBLICA & 7.581 & 0,23 & 16.196 & 0,24 & 3.372 & 0,13 \\
\hline 19 & CONSTRUÇÃOCIVIL & 104 & 0,003 & 355 & 0,01 & 308 & 0,01 \\
\hline 20 & COMÉRCIO & 2.272 & 0,07 & 3.216 & 0,05 & 2.444 & 0,10 \\
\hline 21 & TRANSPORTES & 173 & 0,01 & 223 & 0,003 & 42 & 0,002 \\
\hline 22 & COMUNICAÇŌES & 7 & 0,0002 & 41 & 0,001 & 3 & 0,0001 \\
\hline 23 & INSTITUIÇÕES FINANCEIRAS & 86 & 0,003 & 1.073 & 0,02 & 157 & 0,01 \\
\hline 24 & ADMINISTRAÇAO PÚBLICA & 1.047 & 0,03 & 5.676 & 0,08 & 724 & 0,03 \\
\hline 25 & ALUGUEL DE IMÓVEIS & 213 & 0,01 & 916 & 0,01 & 87 & 0,003 \\
\hline \multirow[t]{2}{*}{26} & OUTROS SERVIÇOS & 631 & 0,02 & 4.605 & 0,07 & 467 & 0,02 \\
\hline & CONSUMO TOTAL & 3.343 .105 & 100,00 & 6.713 .057 & 100,00 & 2.537 .926 & 100,00 \\
\hline
\end{tabular}

Fonte: Elaboração da autora.

$\mathrm{Na}$ Tabela 8.2, pode-se observar o consumo dos setores da indústria de transformação nos três estados. Desse grupo, no estado de Minas Gerias o principal consumidor é o setor Extrativa Mineral, com 53,74\%; a segunda posição é a da Indústria Química, com 19,56\%; e a terceira, do setor Minerais Não Metálicos, com 12,34\%. No estado da Bahia, o maior consumo é o da Indústria Química, com 66,88\%; o segundo maior consumidor é o setor Extrativa Mineral, com 22,72\% e o terceiro, o setor Serviços Industriais de Utilidade Pública (SIUP), com 4,77\%. O estado de Pernambuco é o que apresenta o menor número de setores da indústria de transformação que consomem água na região da bacia do São Francisco. Naquele estado, o maior consumidor é o setor 
Extrativa Mineral, com 54,99\%, seguido pelo setor Produtos Alimentares, com 22,95\% e pelo SIUP, com $15,55 \%$.

Tabela 8.2 - Consumo de água por setor da Indústria de Transformação no sistema interregional do São Francisco.

(Em mil $\mathrm{m}^{3} /$ ano)

\begin{tabular}{|c|c|c|c|c|c|c|}
\hline SETOR & Minas Gerais & $(\%)$ & Bahia & $(\%)$ & Pernambuco & $(\%)$ \\
\hline 2 EXTRATIVA MINERAL & 85.213 & 53,74 & 77.133 & 22,72 & 11.926 & $\overline{54,99}$ \\
\hline 3 MINERAIS NÃO METÁLICOS & 19.570 & 12,34 & 9.903 & 2,92 & $\mathbf{0}$ & 0,00 \\
\hline 4 SIDERURGIA E METALURGIA & 5.041 & 3,18 & 1.897 & 0,56 & $\mathbf{0}$ & 0,00 \\
\hline 5 MECÂNICA & 60 & 0,04 & 64 & 0,02 & 0 & 0,00 \\
\hline 6 MATERIAL ELÉTRICO E ELETRÔNICO & 24 & 0,02 & 0 & 0,00 & 0 & 0,00 \\
\hline 7 MATERIAL DE TRANSPORTE & 467 & 0,29 & 0 & 0,00 & 0 & 0,00 \\
\hline 8 MADEIRA E MOBILIÁRIO & 1.092 & 0,69 & 1.407 & 0,41 & 1.005 & 4,63 \\
\hline 9 PAPEL E GRÁFICA & 1.494 & 0,94 & 0 & 0,00 & 0 & 0,00 \\
\hline 10 INDÚSTRIA DA BORRACHA & 9 & 0,01 & 0 & 0,00 & 0 & 0,00 \\
\hline 11 INDÚSTRIA QUIMMICA & 31.011 & 19,56 & 227.098 & 66,88 & $\mathbf{0}$ & 0,00 \\
\hline 12 FARMACẼUTICA E PERFUMARIA & 2.961 & 1,87 & 2.535 & 0,75 & 0 & 0,00 \\
\hline 13 ARTIGOS DE PLÁSTICO & 1.105 & 0,70 & 0 & 0,00 & $\mathbf{0}$ & 0,00 \\
\hline 14 INDÚSTRIA TÊXTIL & 16 & 0,01 & 13 & 0,00 & 18 & 0,09 \\
\hline 15 VESTUÁRIO E CALÇADOS & 30 & 0,02 & 39 & 0,01 & 74 & 0,34 \\
\hline 16 PRODUTOS ALIMENTARES & 2.766 & 1,74 & 2.899 & 0,85 & 4.978 & 22,95 \\
\hline 17 INDÚSTRIAS DIVERSAS & 15 & 0,01 & 5 & 0,00 & 6 & 0,03 \\
\hline 18 SERV. INDUST.UTILID. PÚBLICA & 7.581 & 4,78 & 16.196 & 4,77 & 3.372 & 15,55 \\
\hline 19 CONSTRUÇÃO CIVIL & 104 & 0,07 & 355 & 0,10 & 308 & 1,42 \\
\hline TOTAL DA IND. TRANSFORMAÇÃO & 158.558 & 100,00 & 339.544 & 100,00 & 21.687 & 100,00 \\
\hline
\end{tabular}

Fonte: Elaboração da autora.

\subsection{Matriz inter-regional de consumo de água}

Obtido o consumo da água por setor, foram estimados os coeficientes de consumo de água $(\mathrm{CW})$ por valor do produto, em metros cúbicos por real $\left(\mathrm{m}^{3} / \mathrm{R} \$\right)$. Esses coeficientes irão constituir a diagonal principal de uma matriz com dimensão (78x78), cujos elementos fora dela têm valor zero, denominada Matriz Inter-regional de Consumo de Água. Essa matriz possibilita identificar o perfil do consumo da água para cada região e cada setor. $\mathrm{Na}$ Tabela 8.3, estão listados os coeficientes de consumo de água por unidade de valor de produto gerado. 
Tabela 8.3 - Consumo setorial de água por unidade de produto, no sistema interRegional do São Francisco.

\begin{tabular}{|c|c|c|c|c|}
\hline & SETOR & MINAS GERAIS & BAHIA & PERNAMBUCO \\
\hline 1 & AGROPECUÁRIA & 285,157 & 1738,036 & $\longdiv { 1 1 7 4 , 3 1 6 }$ \\
\hline 2 & EXTRATIVA MINERAL & 35,491 & 117,632 & 198,021 \\
\hline 3 & MINERAIS NÃO METÁLICOS & 12,840 & 42,556 & 0 \\
\hline 4 & SIDERURGIA E METALURGIA & 0,444 & 1,471 & 0 \\
\hline 5 & MECÂNICA & 0,032 & 0,106 & 0 \\
\hline 6 & MATERIAL ELÉTRICO E ELETRÔNICO & 0,028 & 0 & 0 \\
\hline 7 & MATERIAL DE TRANSPORTE & 0,086 & $\mathbf{0}$ & $\mathbf{0}$ \\
\hline 8 & MADEIRA E MOBILIÁRIO & 1,228 & 4,070 & 6,851 \\
\hline 9 & PAPEL E GRÁFICA & 1,773 & 0 & $\mathbf{0}$ \\
\hline 10 & INDÚSTRIA DA BORRACHA & 0,070 & $\mathbf{0}$ & $\mathbf{0}$ \\
\hline 11 & INDÚSTRIA QUIMMICA & 6,845 & 22,687 & $\mathbf{0}$ \\
\hline 12 & FARMACÊUTICA E PERFUMARIA & 6,845 & 22,687 & 0 \\
\hline 13 & ARTIGOS DE PLÁSTICO & 6,845 & 0 & 0 \\
\hline 14 & INDÚSTRIA TÊXTIL & 0,017 & 0,056 & 0,095 \\
\hline 15 & VESTUÁRIO E CALÇADOS & 0,061 & 0,203 & 0,341 \\
\hline 16 & PRODUTOS ALIMENTARES & 0,349 & 1,157 & 1,948 \\
\hline 17 & INDÚSTRIATS DIVERSAS & 0,039 & 0,129 & 0,216 \\
\hline 18 & SIUP & 1,849 & 5,761 & 5,943 \\
\hline 19 & CONSTRUÇÃO CIVIL & 0,019 & 0,064 & 0,107 \\
\hline 20 & COMÉRCIO & 0,320 & 0,755 & 0,785 \\
\hline 21 & TRANSPORTES & 0,038 & 0,224 & 0,046 \\
\hline 22 & COMUNICAÇÕES & 0,008 & 0,097 & 0,013 \\
\hline 23 & INSTITUIÇÕES FINANCEIRAS & 0,027 & 0,492 & 0,088 \\
\hline 24 & ADMINISTRAÇĀO PÚBLICA & 0,094 & 1,131 & 0,190 \\
\hline 25 & ALUGUEL DE IMÓVEIS & 0,042 & 0,454 & 0,066 \\
\hline \multirow[t]{2}{*}{26} & OUTROS SERVIÇOS & 0,073 & 1,019 & 0,152 \\
\hline & CONSUMO MÉDIO DA ECONOMIA & 32,988 & 138,948 & 98,052 \\
\hline
\end{tabular}

Fonte: Elaboração da autora.

No estado de Minas Gerais, como se pode observar na Tabela 8.3, para cada $\mathrm{R} \$ 1.000$ de produto gerados pela Agropecuária (setor1) são consumidos $285,157 \mathrm{~m}^{3}$ de água, enquanto, para gerar o mesmo valor, o setor Extrativa Mineral (setor 2) consome $35,491 \mathrm{~m}^{3}$ de água e o setor Minerais Não Metálicos (setor 3) consome $12,840 \mathrm{~m}^{3} \mathrm{de}$ água. Os dois primeiros setores apresentam um consumo acima do consumo médio da economia daquele estado, enquanto todos os outros apresentam um consumo abaixo da média. 
$\mathrm{Na}$ Bahia, verifica-se que a Agropecuária (setor 1) consome $1.738,036 \mathrm{~m}^{3} \mathrm{de}$ água para gerar $\mathrm{R} \$ 1.000$ de produto. Naquele estado, apenas a Agropecuária apresenta um consumo bem superior ao consumo médio da economia. Todos os outros setores apresentam valores abaixo da média. O setor Extrativa Mineral (setor 2) consome $117,632 \mathrm{~m}^{3}$ para gerar $\mathrm{R} \$ 1.000$ de produto e o de Minerais Não Metálicos (setor 3) consome $42,556 \mathrm{~m}^{3}$.

Em Pernambuco, conforme ocorre na Bahia, a Agropecuária (setor 1) também apresenta alto consumo de água. Para cada $\mathrm{R} \$ 1.000$ produzidos consome $1.174,316 \mathrm{~m}^{3}$. Para gerar o mesmo valor de produção, o setor Extrativa Mineral (setor 2) daquele estado consome $198,021 \mathrm{~m}^{3}$. Esses dois setores apresentam um consumo acima da média da economia, como se pode observar na Tabela 8.3.

Para se chegar a esses resultados buscou-se relacionar o consumo de água na bacia do São Francisco com o produto estadual ${ }^{36}$. Isso significa que os valores da produção setorial considerados abrangem a produção total de cada estado.

É interessante notar as diferenças entre os volumes de água, por unidade de valor do produto, requeridos por um mesmo setor em regiões diferentes. Tomando-se como exemplo a indústria de Produtos Alimentares (setor 16), verifica-se que, em Minas Gerais, são necessários $0,349 \mathrm{~m}^{3} / \mathrm{R} \$ 1.000$, na Bahia esse mesmo setor requer 5,761 $\mathrm{m}^{3} / \mathrm{R} \$ 1.000$ e em Pernambuco, $1,948 \mathrm{~m}^{3} / \mathrm{R} \$ 1.000$. Deve-se notar que, embora se trate de uma mesma indústria, em cada estado, ela apresenta composições diferentes. Um outro aspecto importante, que certamente implica maior consumo de água pelas indústrias da Bahia e de Pernambuco, é o clima. Na região do Médio São Francisco, que se inicia a partir de Pirapora (MG) e se estende até Remanso (BA) o clima é o tropical semi-árido; na região do Submédio São Francisco, que abrange áreas dos estados da Bahia e de Pernambuco, o clima predominante é o semi-árido. Nessas áreas, qualquer atividade produtiva irá consumir mais água do que em outras áreas da bacia. Uma subdivisão das regiões, segundo suas características climáticas, poderia revelar aspectos importantes do consumo de água, entretanto, essa possibilidade não foi explorada nessa pesquisa.

\footnotetext{
${ }^{36}$ Uma descrição dos procedimentos adotados para estimar o consumo de água, por setor da economia, foi apresentada na Seção 5.3 do Capítulo 5.
} 
No caso da Agropecuária (setor 1), as diferenças entre os volumes de água por unidade de valor do produto gerado no setor, são grandes entre as regiões. Deve-se considerar, além de outros fatores, que a produção agropecuária numa região com maior regularidade de chuvas, como em algumas áreas do estado de Minas Gerais, por exemplo, certamente necessitará da aplicação de um volume de água menor que a produção em local onde as chuvas não ocorrem com a mesma regularidade, como no caso da Bahia e de Pernambuco. Essas diferenças podem, também, ser parcialmente atribuídas às diferentes estruturas de preços regionais, tecnologias e eficiência de produção.

Mesmo considerando esses aspectos, a matriz inter-regional de consumo de água irá possibilitar uma visão mais integrada da economia regional com o consumo de água, por meio dos multiplicadores de consumo que são gerados a partir dela.

\subsection{Dependência inter-regional e multiplicadores do consumo de água}

Uma vez que se obteve a matriz inter-regional de consumo de água, é possível estimar os multiplicadores inter-regionais. Por meio da pré-multiplicação da Matriz inter-regional de consumo de água pela transposta da matriz inversa de Leontief obtémse a tabela dos multiplicadores, ou tabela do insumo água (TMA). A leitura dos valores, ao longo da linha da tabela, revela o volume de água requerido do setor que está no topo da coluna pelo setor que está na linha para entregar $R \$ 1.000$ de produção à demanda final (Apêndice C).

Se, por exemplo, sabe-se que o setor $i$ na região $S$ utiliza, em seu processo de produção, insumos do setor $j$ da região $R$, um aumento na demanda final pelo produto $i$ irá causar uma expansão na produção do setor $j$. Considerando-se que a água é um dos insumos utilizados no processo de produção dos dois produtos, então, um aumento na demanda desses produtos resultará num aumento da quantidade de água utilizada na produção. Os multiplicadores dão a medida quantitativa desse aumento (ver Tabela de Multiplicadores Inter-Regionais do Insumo Água (TMA) no Apêndice C). 
Para facilitar a análise, os totais de TMA, para os estados que compõem o sistema inter-regional, são apresentados nas Tabelas 8.4 a 8.6. Nessas tabelas, podem-se verificar as interações do consumo de água entre a regiões devido a uma mudança na demanda final. A totalização das linhas de TMA fornece o agregado do consumo de água em cada estado para atender às mudanças na demanda final. Os valores nas colunas representam os totais requeridos pelo estado ao qual a tabela se refere, entre os estados relacionados no topo da coluna. Dessa forma, na Tabela 8.4, por exemplo, estão representadas as quantidades totais de água que cada setor produtivo irá requerer do estado indicado no topo da coluna, caso ocorra uma variação na demanda final. A mesma interpretação deve ser feita no caso das Tabelas 8.5 e 8.6 considerando-se os estados a que se referem.

Para análise dos resultados da Tabela 8.4, suponha-se que ocorra uma elevação de $\mathbf{R} \$ 1.000$ na demanda final da Indústria Química (setor 11) do estado de Minas Gerais. Para atender à maior demanda, esse setor iria requerer mais $19,866 \mathrm{~m}^{3} / \mathrm{ano}$ de água desse próprio estado, mais $2,828 \mathrm{~m}^{3} /$ ano de água do estado da Bahia e mais 1,062 $\mathrm{m}^{3}$ /ano do estado de Pernambuco, resultando em um aumento total do consumo de $23,756 \mathrm{~m}^{3} /$ ano de água.

Observe-se que para variações na demanda final dos setores no estado de Minas Gerais, aqueles que receberão maiores impactos (efeitos diretos e indiretos) são, além da Indústria Química (setor 11), já mencionada, os setores 16 e 14. Uma elevação de $\mathrm{R} \$ 1.000$ na demanda final da indústria de Produtos Alimentares (setor 16) redunda em maior consumo de água do estado da Bahia, da ordem de $3,082 \mathrm{~m}^{3} / \mathrm{ano}$ e de Pernambuco, de $0,873 \mathrm{~m}^{3} / \mathrm{ano}$, além de serem necessários $127,979 \mathrm{~m}^{3} / a n o$ de água do próprio estado, resultando em uma elevação total do consumo de água de 131,934 $\mathrm{m}^{3} /$ ano por ano.

No caso da Indústria Têxtil (setor 14), os impactos de um aumento na sua demanda final, da mesma magnitude que para o setor 11, sobre o consumo de água são da ordem de 2,061 $\mathrm{m}^{3} /$ ano na Bahia e 0,266 $\mathrm{m}^{3} /$ ano em Pernambuco e de $19,698 \mathrm{~m}^{3} /$ ano em Minas Gerais. $O$ impacto da elevação da demanda final desse setor no estado de 
Minas Gerais sobre o consumo de água implica em uma elevação do consumo de água de $22,025 \mathrm{~m}^{3}$ /ano.

Tabela 8.4 - Multiplicadores inter-regionais do insumo água - Minas Gerais

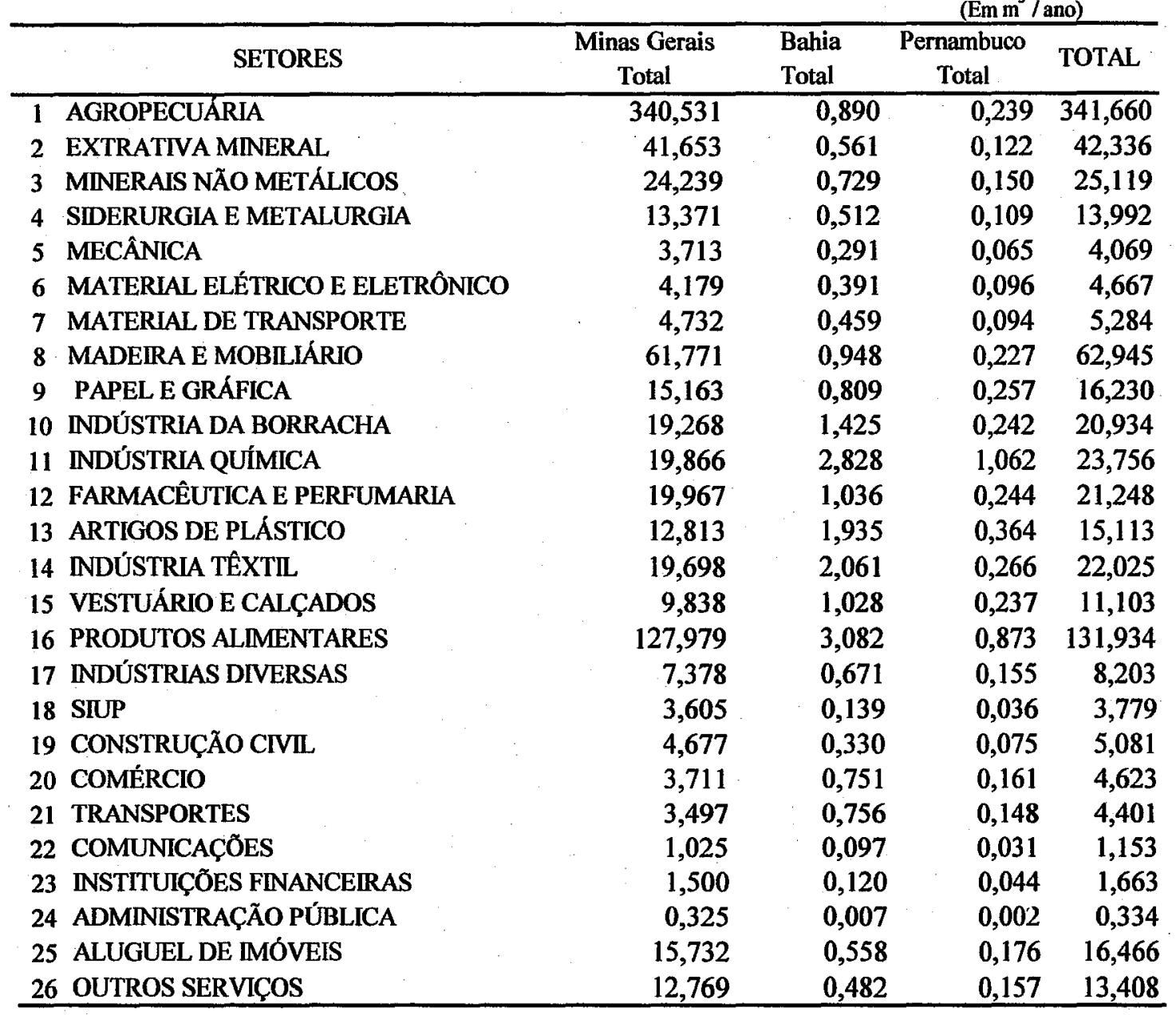

Fonte: Valores estimados pela autora.

A Tabela 8.5 mostra os multiplicadores inter-regionais do insumo água para o estado da Bahia. Vê-se que, naquele estado, o setor mais impactado por uma elevação da demanda final é a Agropecuária (setor 1). Considerando um aumento da ordem de R\$1.000 na demanda final da Agropecuária, o consumo anual, no próprio estado, aumentará em 2.002,8 $\mathrm{m}^{3} /$ ano. Para atender a essa demanda são requeridos mais 2,436 
$\mathrm{m}^{3} / \mathrm{ano}$ em Minas Gerais e $0,892 \mathrm{~m}^{3} / \mathrm{ano}$ em Pernambuco. O aumento do consumo de água total será de $2.006,140 \mathrm{~m}^{3} / \mathrm{ano}$.

Tabela 8.5 - Multiplicadores inter-regionais do insumo água - Bahia

\begin{tabular}{|c|c|c|c|c|c|}
\hline & & & & \multicolumn{2}{|c|}{$\left(\mathrm{Em} \mathrm{m}^{3} / \mathrm{ano}\right)$} \\
\hline & SETORES & $\begin{array}{c}\text { Minas Gerais } \\
\text { Total }\end{array}$ & $\begin{array}{l}\text { Bahia } \\
\text { Total }\end{array}$ & $\begin{array}{c}\text { Pernambuco } \\
\text { Total }\end{array}$ & TOTAL \\
\hline 1 & AGROPECUÁRIA & 2,436 & $2.002,812$ & 0,892 & $2.006,140$ \\
\hline 2 & EXTRATIVA MINERAL & 1,407 & 135,023 & 0,191 & 136,621 \\
\hline 3 & MINERAIS NÃO METÁLICOS & 0,627 & 78,371 & 0,252 & 79,250 \\
\hline 4 & SIDERURGIA E METALURGIA & 1,177 & 52,348 & 0,238 & 53,763 \\
\hline 5 & MECÂNICA & 0,435 & 10,514 & 0,124 & 11,074 \\
\hline 6 & MATERIAL ELÉTRICO E ELETRÔNICO & 0,399 & 12,911 & 0,161 & 13,471 \\
\hline 7 & MATERIAL DE TRANSPORTE & 0,546 & 11,801 & 0,143 & 12,490 \\
\hline 8 & MADEIRA E MOBLIÁRIO & 0,833 & 347,500 & 0,452 & 348,786 \\
\hline 9 & PAPEL E GRÁFICA & 0,373 & 69,377 & 0,383 & 70,134 \\
\hline 10 & INDÚSTRIA DA BORRACHA & 0,421 & 113,778 & 0,384 & 114,582 \\
\hline 11 & INDÚSTRIA QUÍMICA & 0,860 & 87,800 & 1,583 & 90,244 \\
\hline 12 & FARMACÊUTICA E PERFUMARIA & 0,736 & 74,003 & 0,614 & 75,353 \\
\hline 13 & ARTIGOS DE PLÁSTICO & 0,356 & 32,129 & 0,567 & 33,052 \\
\hline 14 & INDÚSTRIA TÊXTIL & 0,596 & 118,333 & 0,383 & 119,312 \\
\hline 15 & VESTUÁRIO E CALÇADOS & 0,641 & 37,406 & 0,436 & 38,483 \\
\hline 16 & PRODUTOS ALIMENTARES & 5,248 & 643,091 & 2,620 & 650,959 \\
\hline 17 & INDÚSTRIAS DIVERSAS & 0,401 & 30,902 & 0,261 & 31,564 \\
\hline 18 & SIUP & 0,062 & 13,064 & 0,055 & 13,181 \\
\hline 19 & CONSTRUÇÃO CIVIL & 0,355 & 13,301 & 0,126 & 13,781 \\
\hline 20 & COMÉRCIO & 0,189 & 17,865 & 0,248 & 18,302 \\
\hline 21 & TRANSPORTES & 0,230 & 16,112 & 0,238 & 16,580 \\
\hline 22 & COMUNICAÇÕES & 0,065 & 4,595 & 0,046 & 4,706 \\
\hline 23 & INSTITUIÇÕES FINANCEIRAS & 0,082 & 8,062 & 0,065 & 8,209 \\
\hline 24 & ADMINISTRAÇÃO PÚBLICA & 0,010 & 2,223 & 0,007 & 2,240 \\
\hline 25 & ALUGUEL DE IMÓVEIS & 0,474 & 82,716 & 0,346 & 83,536 \\
\hline 26 & OUTROS SERVIÇOS & 0,559 & 62,910 & 0,393 & 63,861 \\
\hline
\end{tabular}

Fonte: Valores estimados pela autora.

As inter-relações da indústria de Produtos Alimentares (setor 16) da Bahia também implicariam um aumento do consumo total de água elevado em relação aos outros setores do sistema inter-regional, caso houvesse uma elevação em sua demanda final. Para atender a um aumento de $\mathrm{R} \$ 1.000$, o consumo no próprio estado aumentaria $643,091 \mathrm{~m}^{3} /$ ano, requerendo uma elevação no estado de Minas Gerais de $5,248 \mathrm{~m}^{3} /$ ano 
de água e em Pernambuco de $2,620 \mathrm{~m}^{3}$ /ano . O consumo total de água do setor se elevaria para $650,959 \mathrm{~m}^{3} / \mathrm{ano}$.

O impacto de uma elevação da ordem de $R \$ 1.000$ na demanda final do setor Madeira e Mobiliário (setor 8) do estado da Bahia, resultaria em uma elevação do consumo de água nesse estado de $347,500 \mathrm{~m}^{3} /$ ano. Os aumentos nos outros estados do sistema inter-regional seriam pequenos, $0,833 \mathrm{~m}^{3} /$ ano no estado de Minas Gerais e 0,452 $\mathrm{m}^{3}$ /ano no estado de Pernambuco. O consumo total se elevaria, então, para 348,786 $\mathrm{m}^{3}$ /ano (Tabela 8.5).

Analisando os resultados apresentados na Tabela 8.6 verifica-se que, também no estado de Pernambuco, o setor cuja elevação da demanda final induziria maiores aumentos no consumo de água no próprio estado seria a Agropecuária (setor 1).

Para atender a uma elevação da ordem de $\mathbf{R} \$ 1.000$ na demanda final da Agropecuária (setor 1), do estado de Pernambuco, o consumo de água desse setor, no próprio estado, passaria para $1.329,741 \mathrm{~m}^{3} /$ ano. Também nos estados de Minas Gerais $\mathrm{e}$ da Bahia se elevaria, passando para $4,819 \mathrm{~m}^{3} / \mathrm{ano}$, no primeiro, e para $4,201 \mathrm{~m}^{3} / \mathrm{ano}$, no segundo. Entretanto, uma elevação na demanda final da indústria de Produtos Alimentares (setor 16) registraria, para o estado de Minas Gerais, $10,604 \mathrm{~m}^{3} / \mathrm{ano}$; e para a Bahia, 12,689 $\mathrm{m}^{3} / \mathrm{ano}$, com um efeito total sobre o consumo de $365,4 \mathrm{~m}^{3} /$ ano de água.

Assim, obtém-se um perfil do uso de água pelos setores do sistema interregional, identificando-se as interdependências entre as regiões que compõem a bacia do São Francisco.

Comparando-se os valores da Tabela 8.3 com os das Tabelas 8.4, 8.5 e 8.6, por exemplo, pode-se ter uma idéia das alterações do consumo de água dos setores do sistema inter-regional em resposta às variações nas suas demandas finais. Por exemplo, no estado da Bahia (Tabela 8.3), a Indústria Química (setor 11) apresenta um consumo de água da ordem de $22,687 \mathrm{~m}^{3} / \mathrm{R} \$ 1.000$. No sistema inter-regional, pode-se verificar que esse mesmo setor consome $90,244 \mathrm{~m}^{3} / \mathrm{R} \$ 1.000$ (Tabela 8.5 ). Tem-se, dessa forma, um efeito multiplicador do consumo de água de 3,98 vezes quando considerados os efeitos diretos e indiretos das economias do sistema inter-regional, ou seja, o consumo desse setor irá aumentar, aproximadamente, $297 \%$ para cada $\mathbf{R} \$ 1.000$ de elevação na 
demanda final. Efeitos semelhantes acontecem para os demais setores do sistema. Alguns apresentam alterações moderadas, enquanto outros apresentam variações substanciais no consumo de água.

Tabela 8.6 - Multiplicadores inter-regionais do insumo água - Pernambuco.

\begin{tabular}{|c|c|c|c|c|c|}
\hline & & & & \multicolumn{2}{|c|}{$\left(\mathrm{Em} \mathrm{m}^{3} / \mathrm{ano}\right)$} \\
\hline & SETORES & $\begin{array}{l}\text { Minas Gerais } \\
\text { Total }\end{array}$ & $\begin{array}{l}\text { Bahia } \\
\text { Total }\end{array}$ & $\begin{array}{c}\text { Pernambuco } \\
\text { Total }\end{array}$ & TOTAL \\
\hline 1 & AGROPECUÁRIA & 4,819 & 4,201 & $1.329,741$ & $1.338,761$ \\
\hline 2 & EXTRATIVA MINERAL & 1,473 & 0,977 & 208,208 & 210,657 \\
\hline 3 & MINERAIS NÃO METÁLICOS & 0,678 & 1,401 & 22,697 & 24,777 \\
\hline 4 & SIDERURGIA E METALURGIA & 1,294 & 1,094 & 32,279 & 34,667 \\
\hline 5 & MECÂNICA & 0,472 & 0,564 & 5,903 & 6,938 \\
\hline 6 & MATERIAL ELÉTRICO E ELETRÔNICO & 0,456 & 0,778 & 7,685 & 8,919 \\
\hline 7 & MATERIAL DE TRANSPORTE & 0,579 & 0,698 & 6,105 & 7,382 \\
\hline 8 & MADEIRA E MOBILIÁRIO & 1,338 & 2,268 & 228,333 & 231,939 \\
\hline 9 & PAPEL E GRÁFICA & 0,483 & 1,494 & 48,943 & 50,920 \\
\hline 10 & INDÚSTRIA DA BORRACHA & 0,596 & 2,325 & 65,639 & 68,561 \\
\hline 11 & INDÚSTRIA QUÍMICA & 0,682 & 3,690 & 59,624 & 63,996 \\
\hline 12 & FARMACÊUTICA E PERFUMARIA & 1,031 & 2,329 & $34,361^{\circ}$ & 37,721 \\
\hline 13 & ARTIGOS DE PLÁSTICO & 0,479 & 3,431 & 10,488 & 14,397 \\
\hline 14 & INDÚSTRIA TÊXTIL & 1,176 & 4,131 & 43,857 & 49,164 \\
\hline 15 & VESTUARIO E CALÇADOS & 0,836 & 1,874 & 24,871 & 27,581 \\
\hline 16 & PRODUTOS ALIMENTARES & 10,604 & 12,689 & 342,122 & 365,415 \\
\hline 17 & INDÚSTRIAS DIVERSAS & 0,523 & 1,261 & 20,400 & 22,184 \\
\hline 18 & SIUP & 0,106 & 0,287 & 10,799 & 11,192 \\
\hline 19 & CONSTRUÇÃO CIVIL & 0,374 & 0,635 & 7,207 & 8,216 \\
\hline 20 & COMÉRCIO & 0,251 & 1,306 & 9,370 & 10,927 \\
\hline 21 & TRANSPORTES & 0,291 & 1,307 & 7,210 & 8,808 \\
\hline 22 & COMUNICAÇÕES & 0,082 & 0,163 & 3,213 & 3,458 \\
\hline 23 & INSTITUIÇÕES FINANCEIRAS & 0,105 & 0,176 & 5,372 & 5,654 \\
\hline 24 & ADMINISTRAÇÃO PÚBLICA & 0,013 & 0,017 & 0,953 & 0,984 \\
\hline 25 & ALUGUEL DE IMÓVEIS & 0,668 & 1,099 & 55,607 & 57,373 \\
\hline 26 & OUTROS SERVIÇOS & 0,804 & 1,109 & 41,001 & 42,915 \\
\hline
\end{tabular}

Fonte: Valores estimados pela autora.

A partir da tabela de multiplicadores, podem-se calcular coeficientes setoriais de dependência de água, conforme os apresentados na Tabelas 8.7. Para ilustração, podemse verificar as dependências relativas das indústrias de cada estado da oferta de água no sistema inter-regional. Tomando-se, como exemplo, a Indústria Química (setor 11), verifica-se que, para satisfazer a uma elevação no nível da demanda final desse setor da 
ordem de $\mathrm{R} \$ 1.000$, a dependência da oferta do recurso água será suprida da seguinte forma: $83,62 \%$ da oferta será feita pelo estado de Minas Gerias para esse setor no próprio estado; $11,90 \%$ será feita por Minas Gerais para esse setor no estado da Bahia e $4,47 \%$, por Minas Gerais para o mesmo setor no estado de Pernambuco.

Considerando a oferta de água pelo estado da Bahia, pode-se verificar, por exemplo, que, no caso do setor de Material de Transporte (setor 7), para atender a uma elevação da demanda final de $\mathrm{R} \$ 1.000$ por seus produtos, $94,49 \%$ da oferta de água provém do próprio estado; $4,37 \%$ da oferta de água para esse mesmo setor, no estado de Minas Gerais, provém da Bahia e $1,14 \%$ da oferta do recurso para esse setor em Pernambuco é feita pela Bahia.

Um último exemplo da dependência da oferta do recurso água pode ser ilustrado por meio das relações do setor Artigos de Plástico (setor 13), também considerando a hipótese de que ocorra uma elevação da demanda final dos produtos desse setor da ordem de $\mathrm{R} \$ 1.000$. O estado de Pernambuco irá ofertar $72,84 \%$ desse recurso para 0 setor 13 nesse mesmo estado. Pernambuco também irá ofertar $23,83 \%$ da água necessária à produção desse setor na Bahia e 3,32\% das suas necessidades de água no estado de Minas Gerais.

Os multiplicadores de consumo de água fornecem um perfil do uso da água que é útil para a derivação de informações a respeito das interdependências do uso da água entre as regiões. Todos esses encadeamentos são importantes quando se elaboram políticas de desenvolvimento regional e fornecem subsídios importantes para $\mathrm{o}$ delineamento das políticas de gestão de recursos hídricos.

Para análise das relações intra-regionais, serão utilizados os resultados da tabela de multiplicadores (TMA) no Anexo C. Convém lembrar que cada entrada nessa tabela significa o volume total de água, $\mathrm{em}^{3}$ /ano, requerido do setor no topo da coluna pelo setor que está à esquerda da linha, para entregar $\mathrm{R} \$ 1.000$ de produto à demanda final.

Tendo em mente as considerações sobre a tabela TMA, deve-se, ainda, alertar para o fato de que a numeração dos setores na referida tabela corresponde à seqüência do sistema inter-regional (de 1 a 78), diferindo, portanto, da apresentada até então no presente capítulo. Dessa forma, os setores da economia do estado de Minas Gerais 
correspondem à numeração de 1 a 26, os do estado da Bahia correspondem aos de 27 a 52 e, finalmente, os do estado de Pernambuco correspondem aos de 53 a 78.

Na tabela TMA, verifica-se que, no estado de Minas Gerais, a Agropecuária (setor 1) foi o setor mais "demandado" pelos demais naquele estado. Particularmente, o maior consumo do recurso água foi o do setor de Produtos Alimentares (setor 16), excetuando-se o da Agropecuária. Para responder a uma elevação da ordem de R\$1.000 em sua demanda final, o referido setor irá requerer da Agropecuária (setor 1), 126,569 $\mathrm{m}^{3} /$ ano de água, necessitando consumir mais $127,978 \mathrm{~m}^{3} / \mathrm{ano}$, no total, naquele estado.

No estado da Bahia, são três os setores mais demandados pelos demais: a Agropecuária (setor 27), Extrativa Mineral (setor 28) e Indústria Química (setor 37). Para atender a uma elevação de $\mathbf{R} \$ 1.000$ em sua demanda final, dos volumes de água requeridos pela Agropecuária na Bahia, com exceção do que esse setor consome dele mesmo, o maior consumo é o do setor Produtos Alimentares (setor 42), que requer $638,231 \mathrm{~m}^{3} /$ ano. O segundo maior consumidor é o setor Madeira e Mobiliário (setor 34), que, para atender a uma elevação eqüivalente em sua demanda final, irá requerer $338,802 \mathrm{~m}^{3} / a n o$ de água da Agropecuária.

Vale ressaltar, também, que, para satisfazer uma elevação de $\mathrm{R} \$ 1.000$ em sua demanda final, a Indústria Química (setor 37) da Bahia irá requer do setor Extrativa Mineral (setor 28), 10,869 $\mathrm{m}^{3}$ /ano de água.

Outro setor que recebe as maiores demandas de água dos demais setores, no estado da Bahia, é o da Indústria Química (setor 37). Observe-se que, depois das requisições de água do próprio setor, aquele que mais irá precisar desse recurso, para atender a uma elevação em sua demanda final, é o setor de Artigos de Plástico (setor 39), necessitando de $10,122 \mathrm{~m}^{3} /$ ano da Indústria Química, naquele estado.

No estado de Pernambuco, o setor mais demandado pelos demais é a Agropecuária (setor 53), destacando-se, também, as demandas recebidas pelo setor Extrativa Mineral (setor 54). 


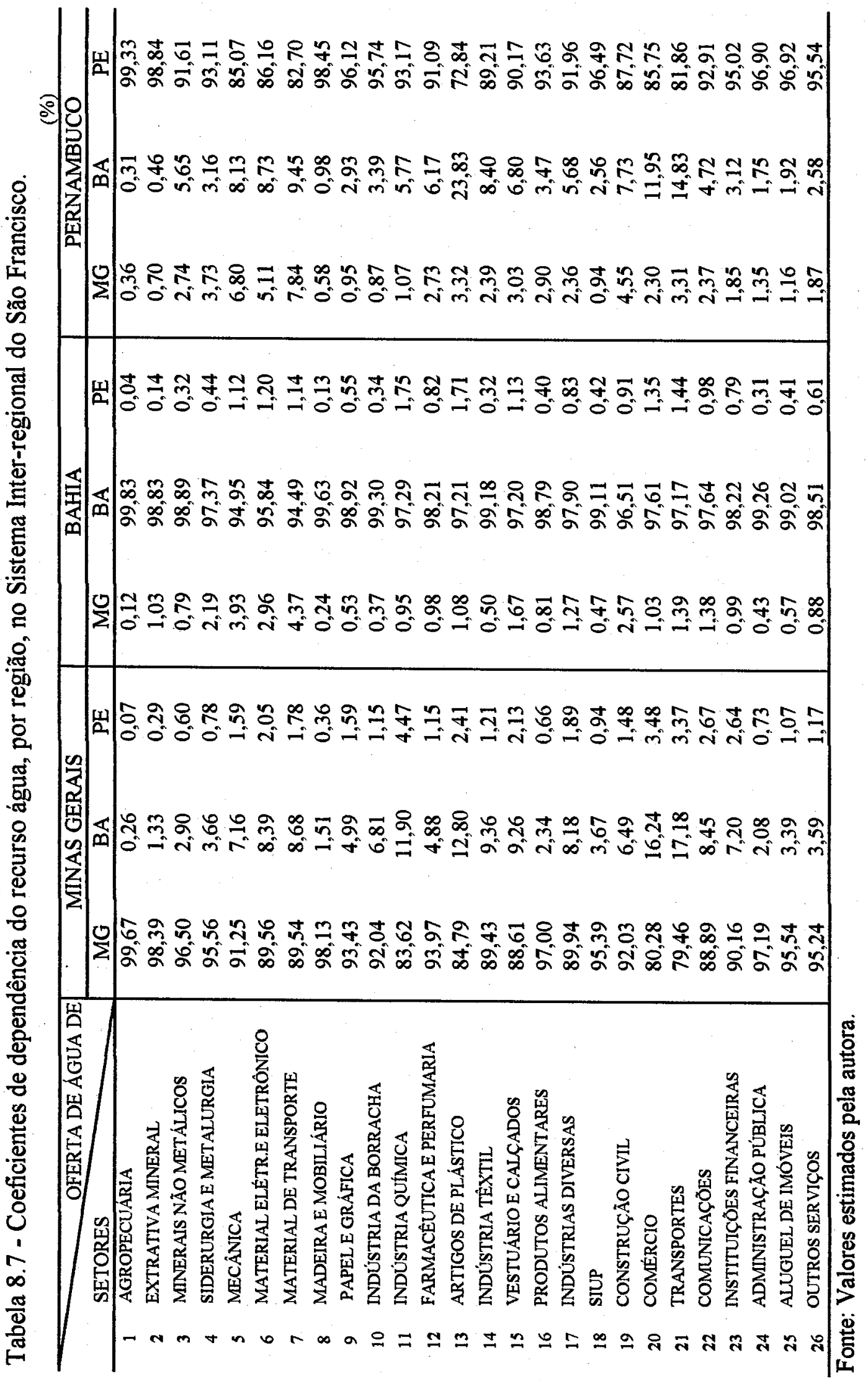


Note-se que, para satisfazer a uma elevação da ordem de $\mathrm{R} \$ 1.000$ em sua demanda final, o setor Madeira e Mobiliário (setor 60) irá requisitar da Agropecuária $220,517 \mathrm{~m}^{3} / a n o$ de água. Também se destaca o volume de água requerido da Agropecuária pelo setor Produtos Alimentares (setor 68), para atender a uma mesma variação em sua demanda final. Esse setor irá demandar daquele um volume de água de $338,986 \mathrm{~m}^{3}$ /ano. Com exceção do setor Administração Pública (setor 76), todos os demais irão necessitar de quantidades de água razoavelmente altas da Agropecuária naquele estado.

Essas relações proporcionam uma visualização das interações dos usos do recurso água na economia inter-regional e auxiliam a compreensão das proporções em que esse insumo deve ser ofertado no caso de uma expansão da atividade econômica na região.

Este capítulo constitui um esforço da pesquisa para apresentar um "padrão médio" do consumo interindustrial de água num modelo inter-regional. Os coeficientes obtidos revelam que as inter-relações entre as economias exigem um consumo de água muito acima daquele que é observado quando se considera um setor da economia isoladamente. Embora se considere que os resultados obtidos constituem uma primeira indicação, não resta dúvida que estudos que contemplem as relações intersetoriais e inter-regionais constituir-se-ão em poderoso instrumento analítico para o planejamento da economia regional, principalmente quando se discute, no contexto da gestão dos recursos hídricos do país, a cobrança pelos usos do recurso água. 


\section{CONCLUSÃO}

Esta pesquisa teve o propósito de construir um modelo inter-regional para a região da bacia hidrográfica do São Francisco visando identificar e avaliar a importância das relações das economias naquela área.

Ao analisar as economias regionais, a aplicação empírica do modelo de insumoproduto permitiu identificar e mensurar as interdependências entre os setores produtivos das diferentes regiões. Foram incorporados novos métodos de análise buscando melhor compreender as estruturas dessas economias.

Também foi possível examinar as inter-relações entre as economias dos estados da região e os usos do insumo água, por meio de uma matriz inter-regional de uso da água.

Nas análises em que se consideraram as estruturas internas e o valor da produção das regiões, foram identificados os setores mais dinâmicos do sistema, tornando-se explícita a importância relativa do estado de Minas Gerais no conjunto das economias da região da bacia do são Francisco.

Em um nível maior de desagregação das economias regionais, buscou-se identificar as interações e dependências das suas estruturas produtivas, por meio da produção induzida pelas demandas finais regionais e setoriais. Sob esse enfoque, constatou-se que a produção, em cada estado do sistema inter-regional do São Francisco, é mais dependente da demanda final do próprio estado do que das demandas finais dos outros estados componentes do sistema.

Visando mensurar os efeitos diretos e indiretos das demandas finais do sistema econômico constituído pelas três regiões que compõem o sistema inter-regional do São Francisco e as demais regiões do Brasil, ampliou-se o modelo inter-regional, que passou a ser constituído de quatro regiões: Minas Gerais, Bahia, Pernambuco e Resto do Brasil. Constatou-se que o grau de dependência das produções das economias dos estados de Minas Gerais, Bahia e Pernambuco, das demandas finais dos seus vizinhos é pequena e 
que a interação com o Resto do Brasil é maior. Dessa forma, pode-se concluir que o grau de integração das atividades econômicas na região da bacia do São Francisco é pequeno.

Para investigar, de forma mais detalhada, os impactos das demandas finais de cada região sobre a sua própria produção e sobre as produções das demais, desagregouse a parcela da produção induzida pela demanda final da própria região e a parcela induzida pelas demandas finais das demais regiões, segundo a produção setorial. A análise desagregada das produções setoriais induzidas pelas demandas finais revelou importantes composições da estrutura produtiva das regiões do sistema. Pode-se concluir que a economia pernambucana é a mais dependente, em todo o sistema inter-regional, dos estímulos da economia do próprio estado. Os efeitos da demanda final da economia de Minas Gerais sobre as produções de diversos setores das economias dos estados da Bahia e de Pernambuco demonstraram a importância da economia daquele estado para a região do São Francisco. Além disso, a economia mineira mostrou-se mais integrada à região Resto do Brasil. Ao se observar os setores das economias das outras regiões que são acionados pela economia do estado de Minas Gerais e os setores dessa região que são acionados pelas economias das outras, verifica-se a economia mineira tem um importante papel tanto sob a ótica da demanda quanto pela ótica da oferta no contexto economia regional.

Ao se examinar, por meio da estrutura das dependências internas e externas dada pelas ligações, a estrutura das relações entre as quatro regiões do sistema inter-regional, conclui-se que as demandas por insumos da região Resto do Brasil proporcionaram os maiores impactos nas produções das outras três regiões do sistema; as compras de insumos realizadas pela economia da região Minas Gerais são importantes para a produção da Bahia e de Pernambuco; a economia pernambucana exibiu fracas relações com as das regiões de Minas Gerais e da Bahia; a economia da Bahia mostrou-se a mais dependente das relações com outras regiões do sistema; a economia de Pernambuco apresentou-se como mais fechada que as economias de Minas Gerais e da Bahia no sistema inter-regional. Assim, afora a região Resto do Brasil, Minas Gerais é a que apresenta as mais importantes relações de comércio com as demais regiões do sistema. 
O modelo permitiu constatar que as estruturas das economias das regiões Minas Gerais, Bahia e Pernambuco apresentaram diferenças significativas. Minas Gerais apresenta uma estrutura industrial mais interligada, com predominância do setor Siderurgia e Metalurgia. A Bahia exibe uma estrutura industrial menos interligada que a de Minas Gerais, na qual se destaca a Indústria Química. A economia da região de Pernambuco é a que apresenta a estrutura menos interligada do sistema inter-regional do São Francisco, na qual se sobressaem os setores do grupo dos Serviços.

As relações de comércio entre essas três economias são fracas. As maiores interações ocorrem com a economia de Minas Gerais, no entanto, as mais importantes relações comerciais ocorrem entre as três regiões da bacia do São Francisco com o Resto do Brasil.

Uma característica relevante da economia do sistema inter-regional é que nas três regiões (Minas Gerais, Bahia e Pernambuco), a Agropecuária revelou-se como um dos setores mais dinâmicos. Considerando-se que é no estado de Minas Gerais onde se concentra a principal área de atividade industrial da região de abrangência da bacia do São Francisco e que no restante da bacia, em áreas como os cerrados baianos e na região do Médio São Francisco, as maiores expressões são as atividades agrícola e agroindustriais, essa é uma característica importante para o delineamento de políticas que visem incentivar a expansão da economia regional.

Em resumo, a presente pesquisa permitiu revelar a estrutura das economias dos estados que compõem a região da bacia hidrográfica do São Francisco e identificar as ligações intersetoriais e setores-chave de alcance inter-regional da economia mineira. A análise das relações entre as regiões possibilitou identificar que, embora mais interligadas à região Resto do Brasil, há uma certa interação entre as economias de Minas Gerais e da Bahia. Assim, essas duas regiões, por apresentarem melhor articulação de suas indústrias e possuírem maior poder de encadeamento inter-regional $\mathrm{e}$ interdependência comercial, têm potencial para promover o desenvolvimento regional, desde que providas de medidas direcionadas para os estímulo das atividades dos setores com maior potencial de crescimento na região. Então, embora as relações que emergiram das análises realizadas nessa pesquisa levem a constatação que nas regiões 
que constituem o sistema inter-regional do São Francisco, repete-se a característica histórica de desenvolvimento desigual e desequilibrado das grandes regiões brasileiras, a melhor articulação dos setores que possuem maior poder de encadeamentos na economia regional pode contribuir para a expansão da atividade econômica em toda a região.

As identificação das inter-relações entre os setores da economia do sistema inter-regional e os usos da água, permitiu o tratamento desse recurso como um dos fatores de produção, proporcionando a mensuração dos usos da água pelos diferentes setores produtivos.

Ao se avaliar os usos da água, segundo as inter-relações setoriais das economias do sistema inter-regional (considerando-se Minas Gerais, Bahia e Pernambuco), verificou-se, por meio da estimativa dos multiplicadores, que os volumes de água consumidos no sistema são muito maiores do que os estimados quando se considera um setor da economia isoladamente. Pode-se afirmar que mesmo que os atuais volumes de água consumidos pelos diferentes usuários (agricultura, indústria, abastecimento urbano, geração de energia elétrica e outros) não cheguem a comprometer a oferta de água ao longo da bacia hidrográfica, a análise dos encadeamentos entre os setores da economia constitui-se em bom indicador do impacto que poderá ocorrer sobre o consumo de água na bacia caso ocorra um crescimento nas atividades de um ou vários setores da economia regional.

Esta pesquisa permitiu identificar importantes relações entre as economias estudadas, entretanto, apresenta algumas limitações devido a obstáculos encontrados na busca de dados. Uma dessas questões refere-se à incorporação ao modelo inter-regional do recurso água. A inexistência de dados sobre o consumo de água pelos setores da economia, notadamente o consumo industrial, dificultou a construção do modelo. Assim, sugere-se que sejam realizados estudos que complementem e aprofundem as análises realizadas visando auxiliar o delineamento de políticas de desenvolvimento regional, no sentido de: a) desenvolver um modelo inter-regional considerando o setor Agropecuária com maior nível de desagregação, computando-se o produto da agricultura irrigada; b) ampliar o número de regiões do modelo, considerando os outros estados da bacia; c) em conjunto com outras instituições, buscar a determinação do consumo efetivo de água 
pelos setores da indústria na região da bacia, além de outros setores da economia, para posterior elaboração de um modelo inter-regional, do ponto de vista do insumo-produto, que, em conjunto com outros instrumentos de análise (modelos de otimização, por exemplo), permita determinar o valor da água em diferentes setores da economia. 


\begin{abstract}
ANEXOS
Anexo A Matriz de insumo-produto do sistema inter-regional do São Francisco e o Resto do Brasil, 1995.

Anexo B Agregações de setores e produtos da matriz de insumo-produto.

Anexo C Matriz de coeficientes de consumo de água (CW) do sistema inter-regional do São Francisco, 1995.

Tabela de multiplicadores inter-regionais do insumo água (TMA), 1995.
\end{abstract}




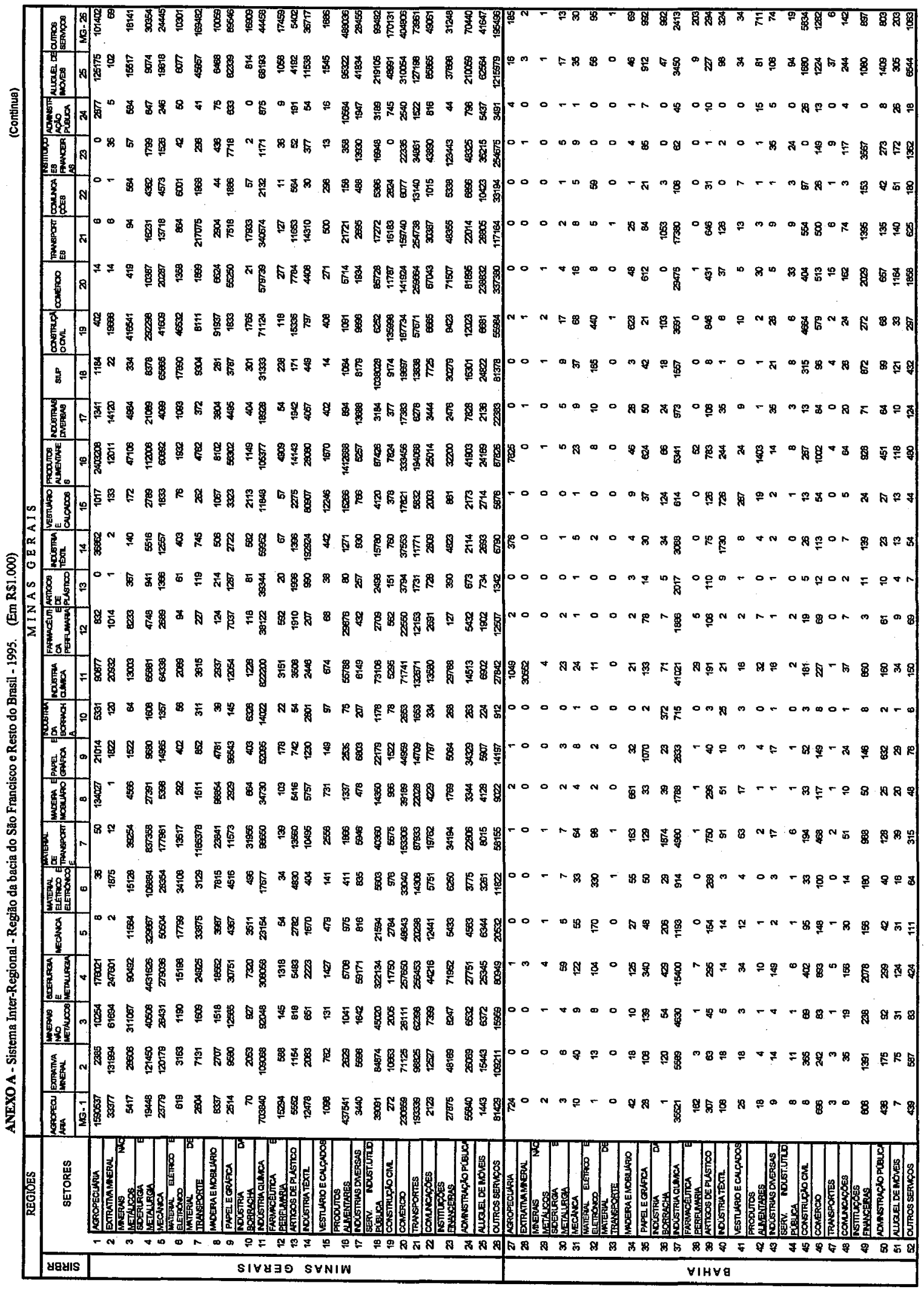




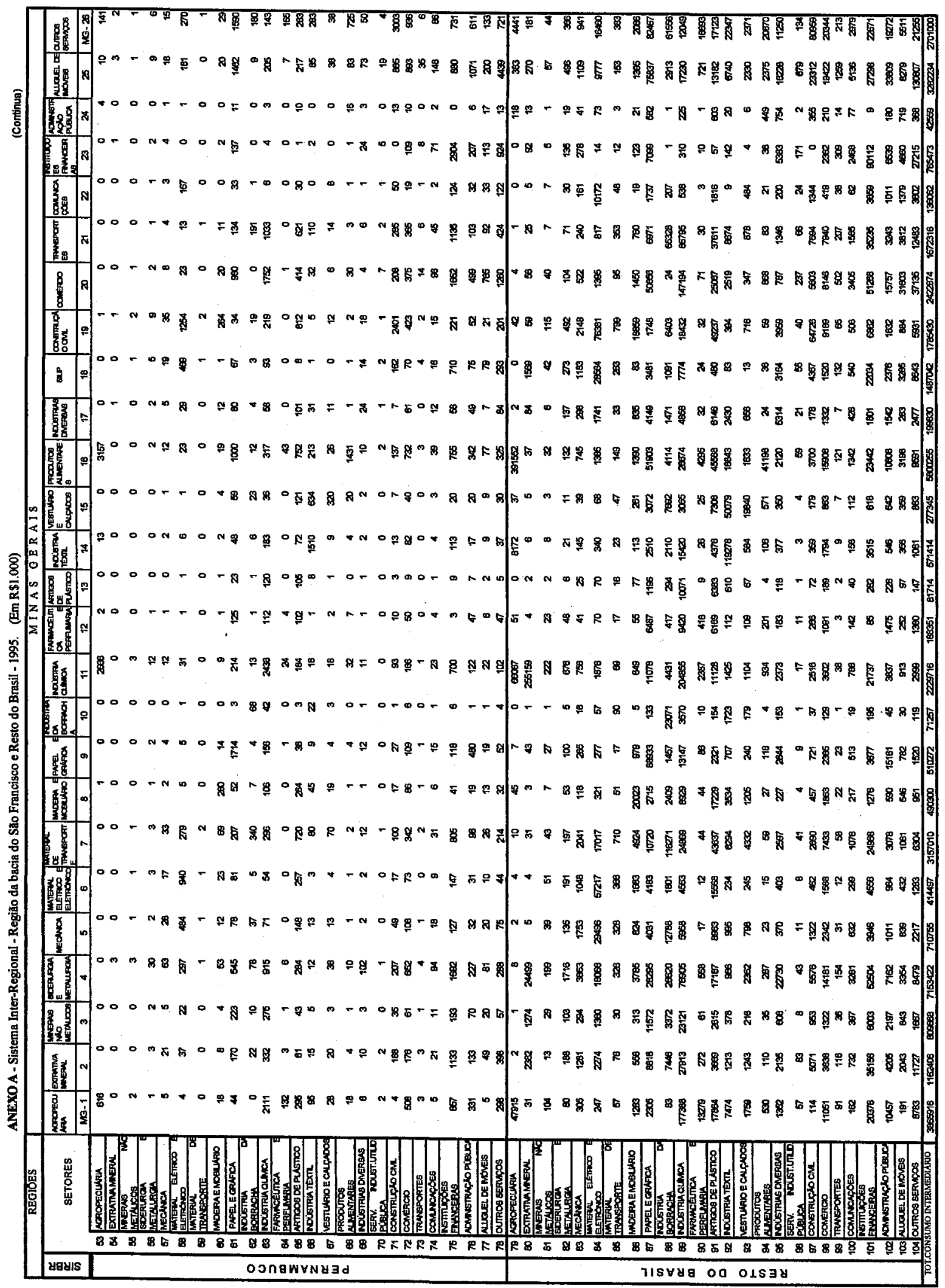




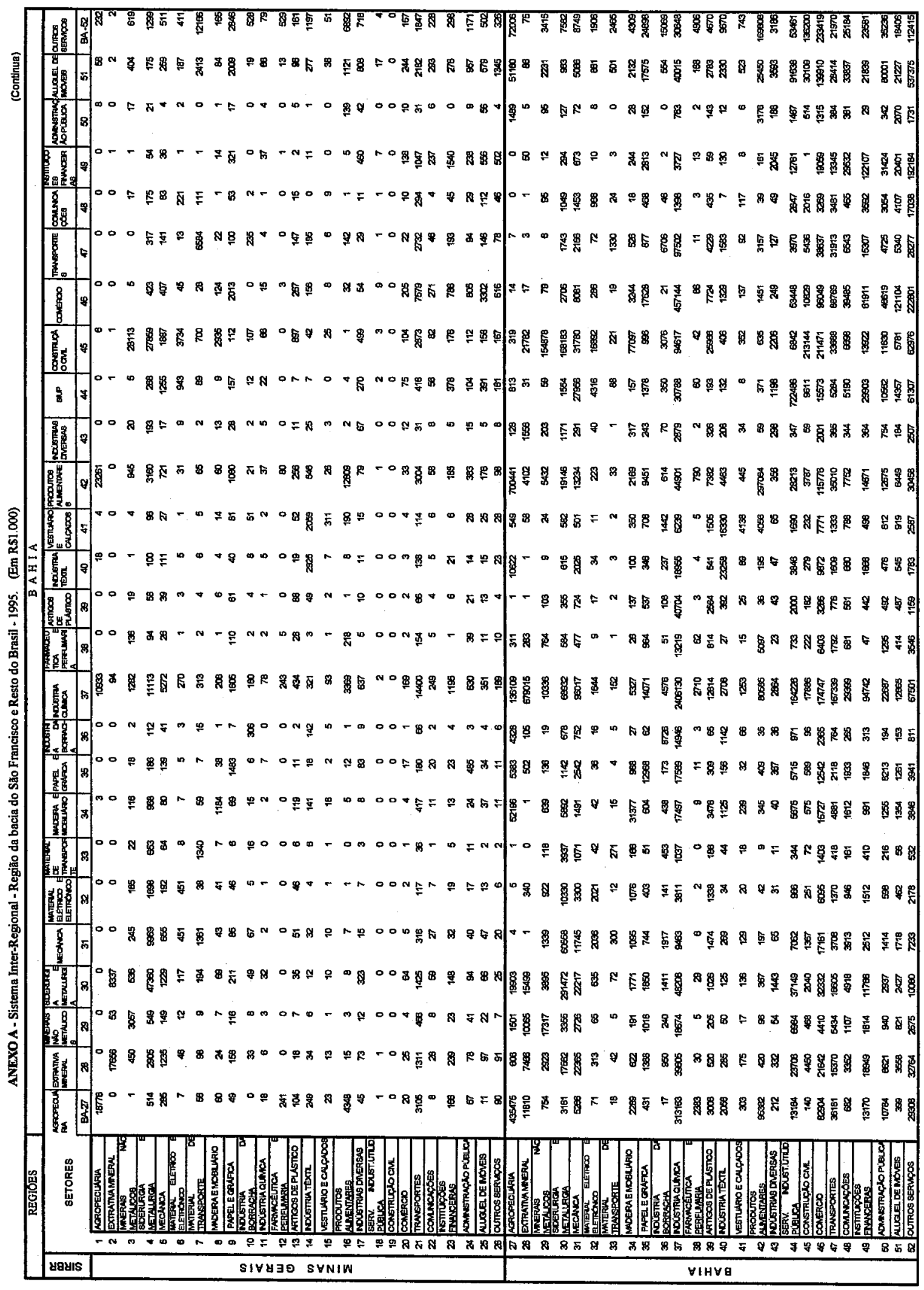




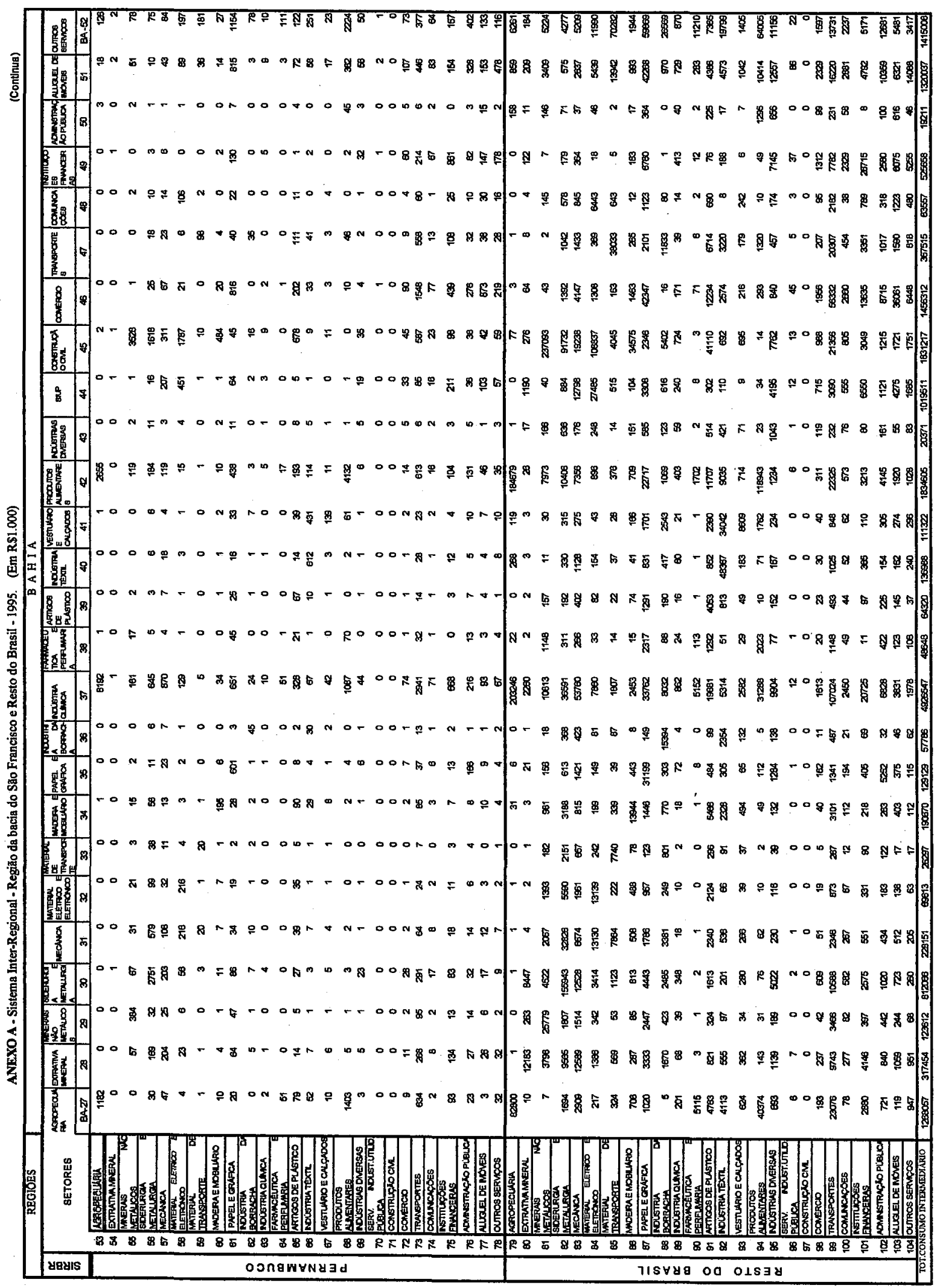




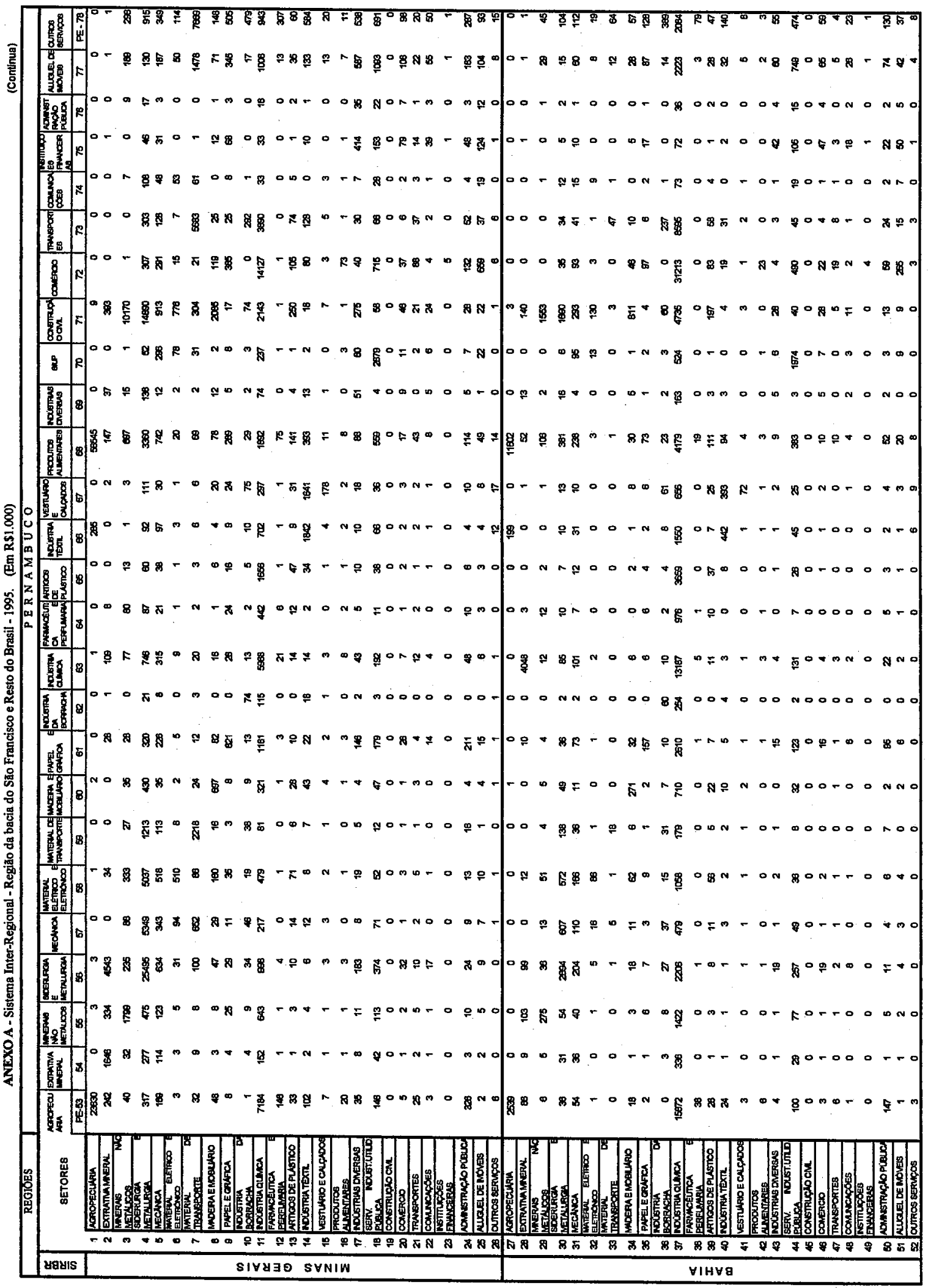




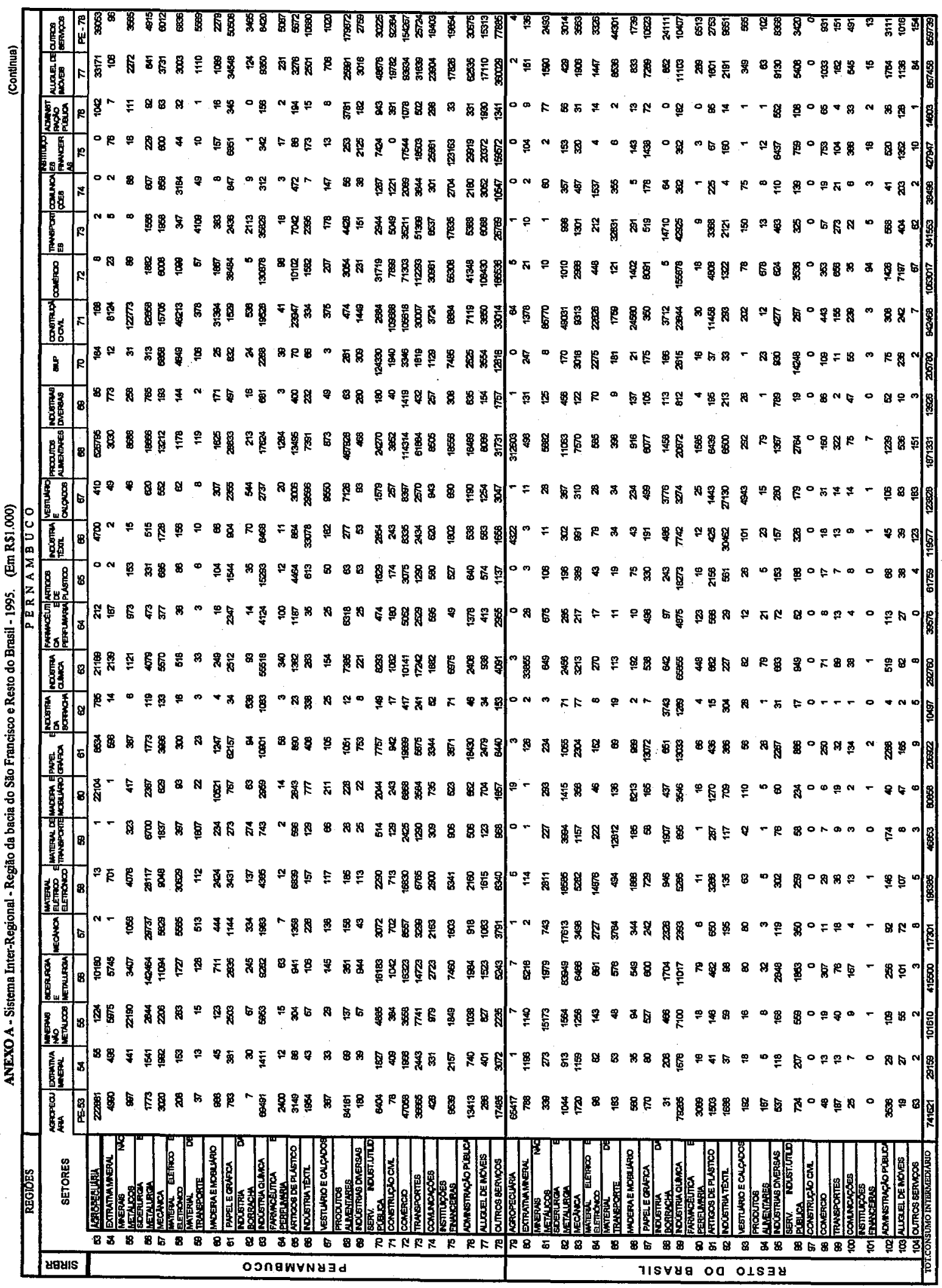




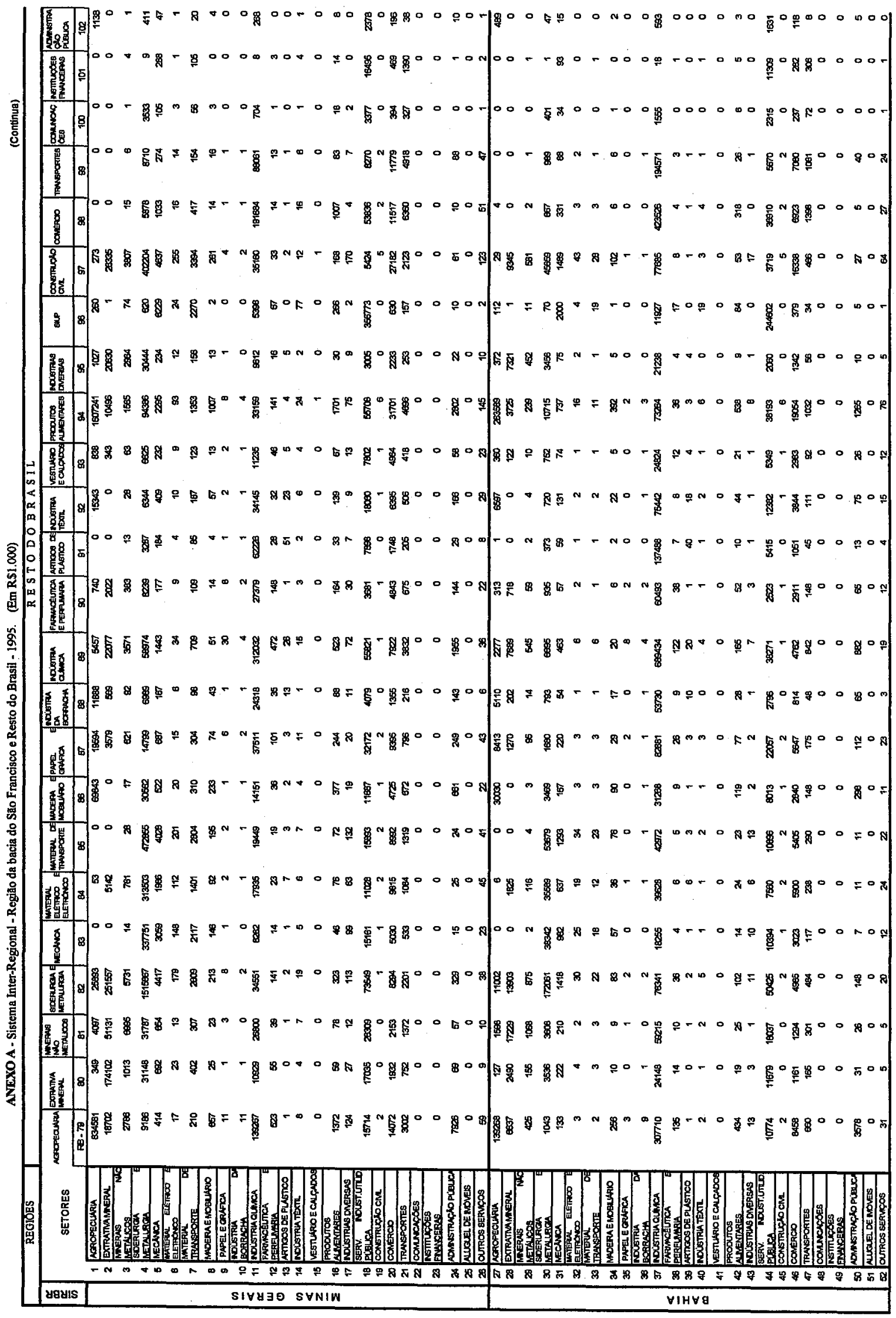




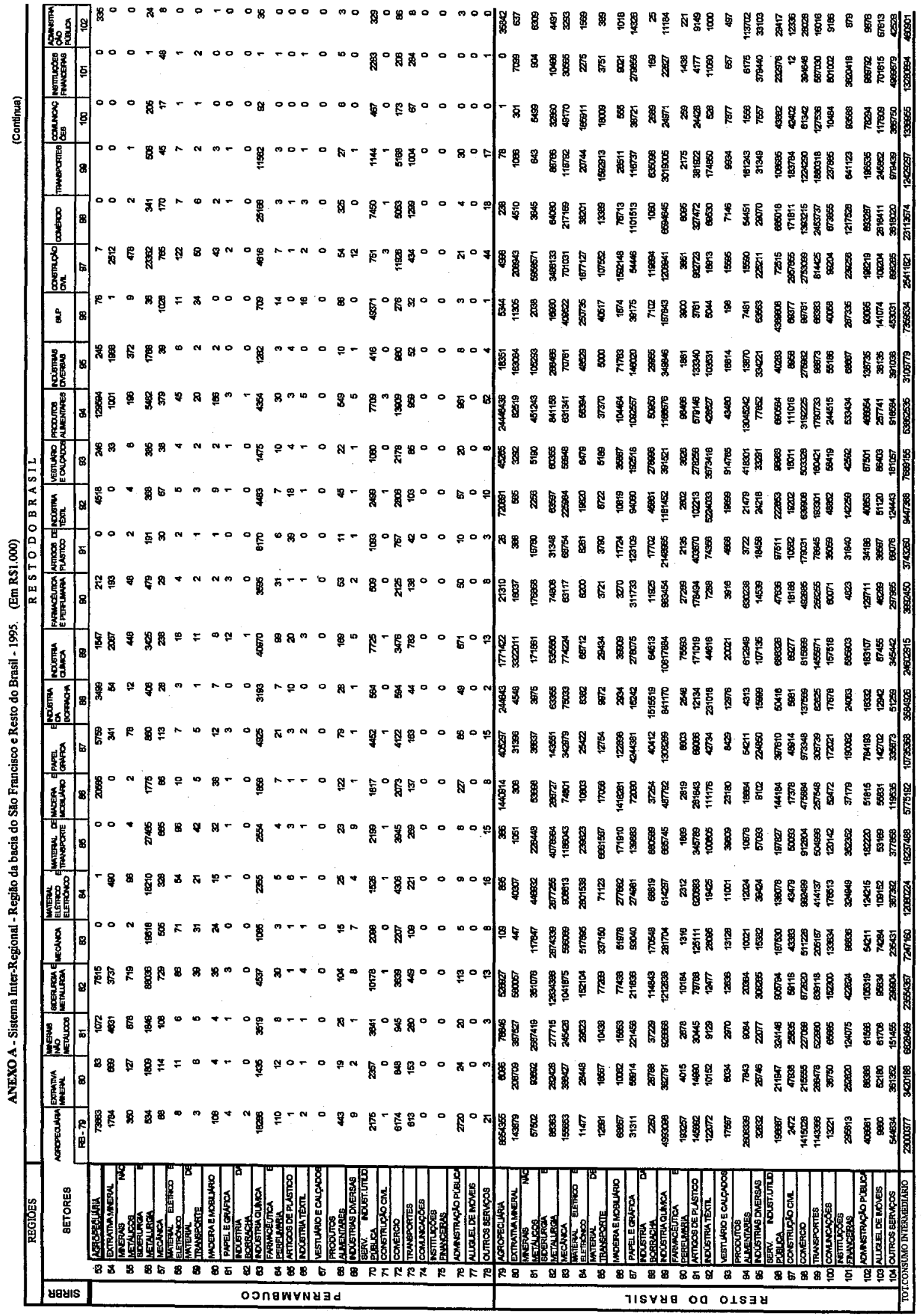




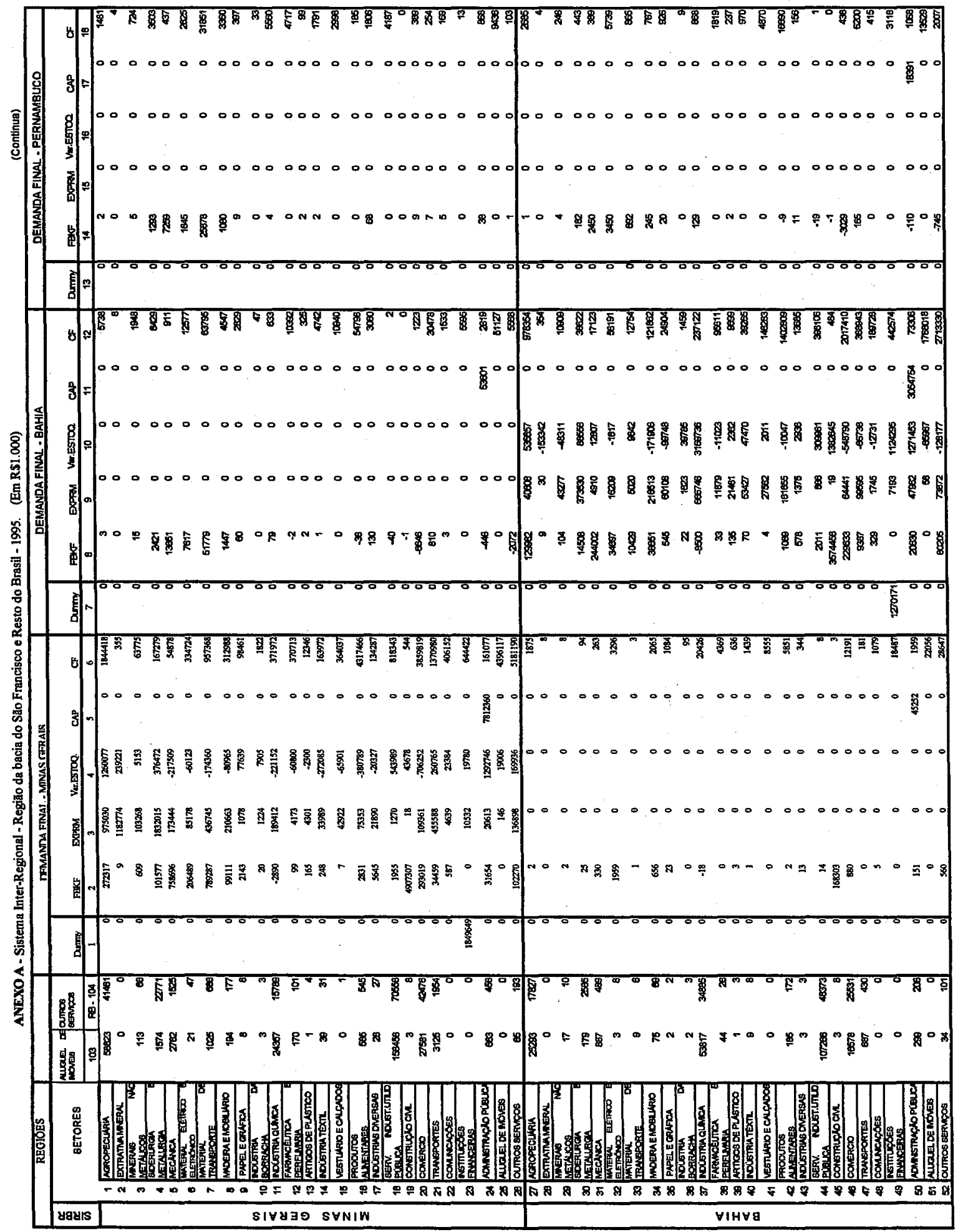




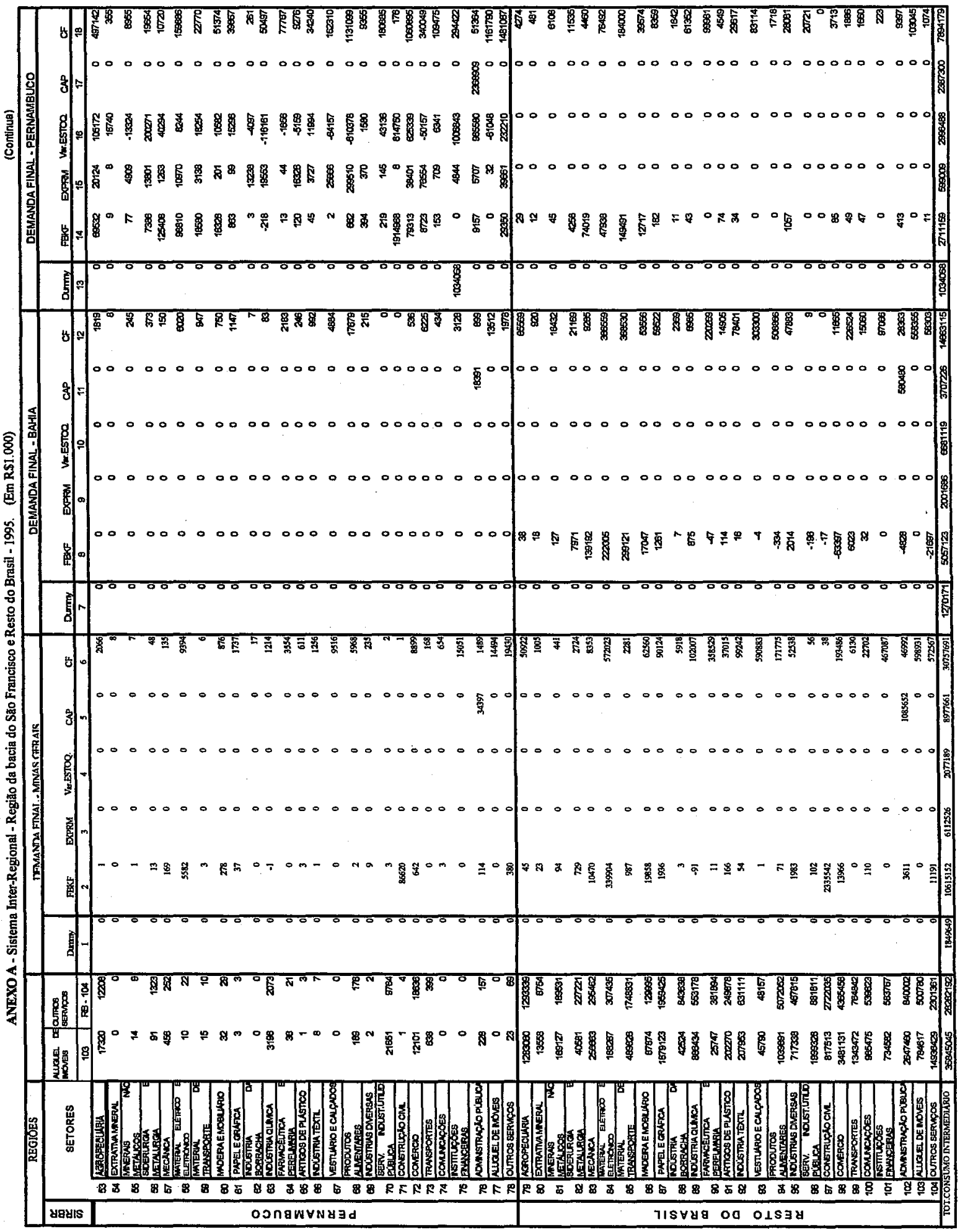




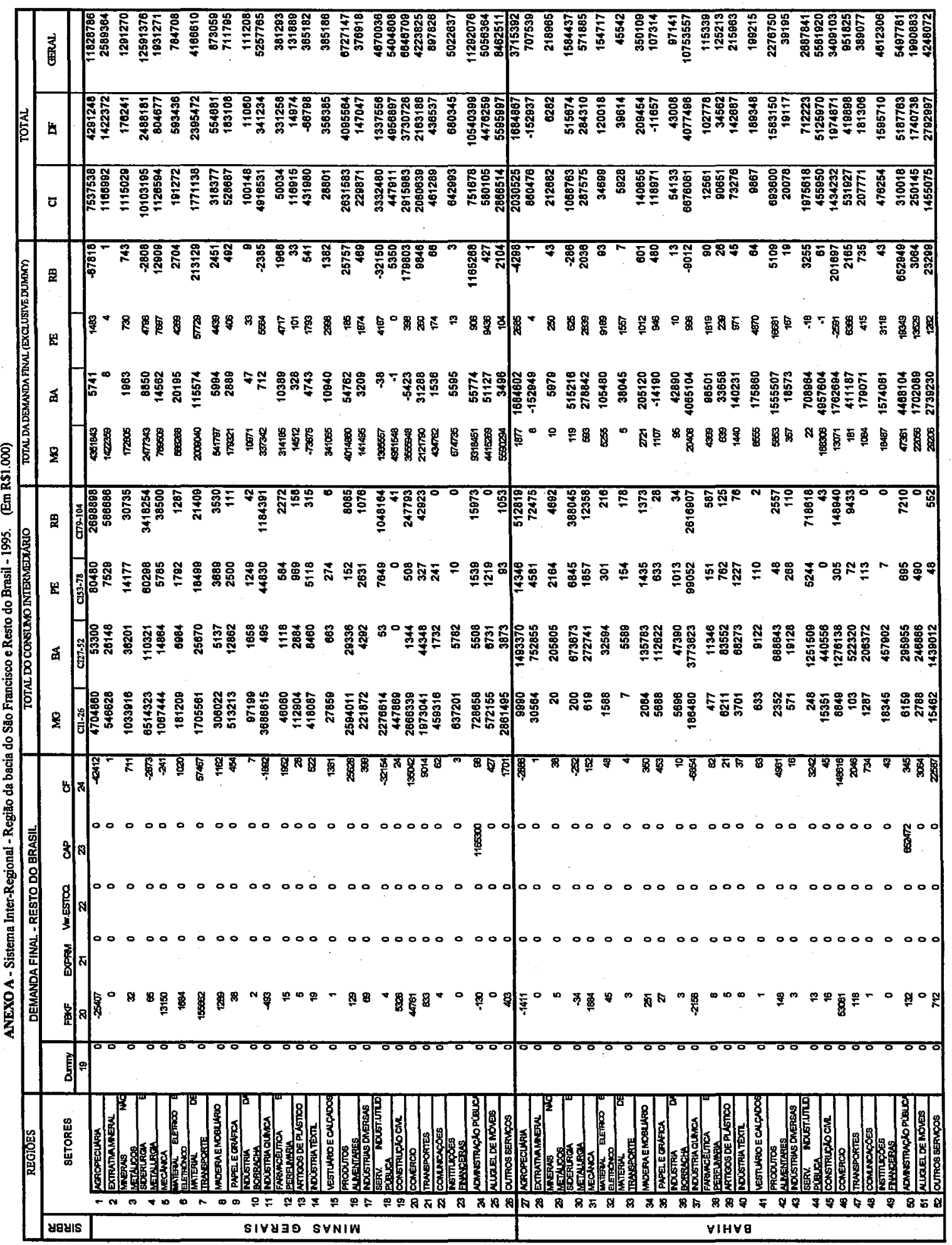




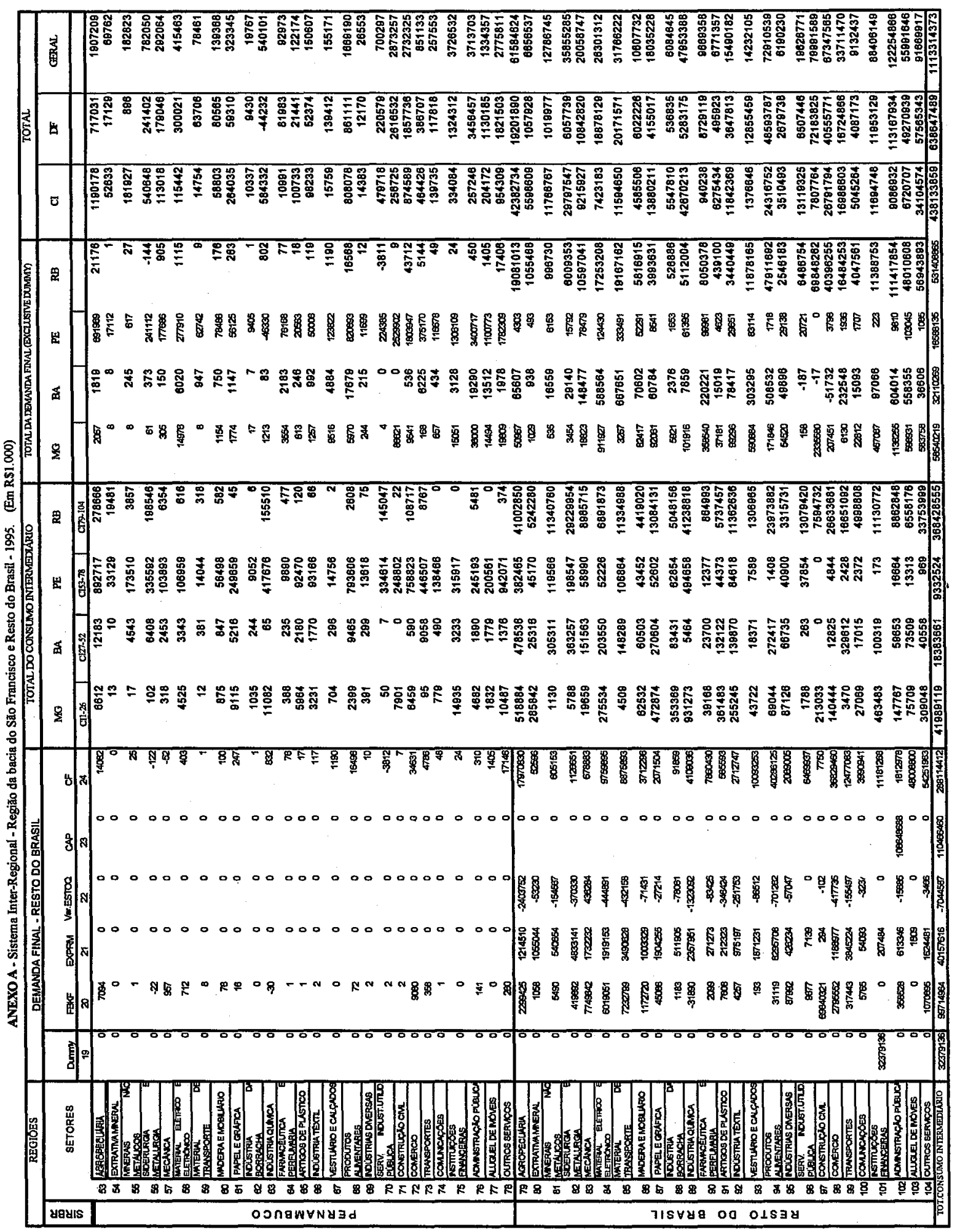



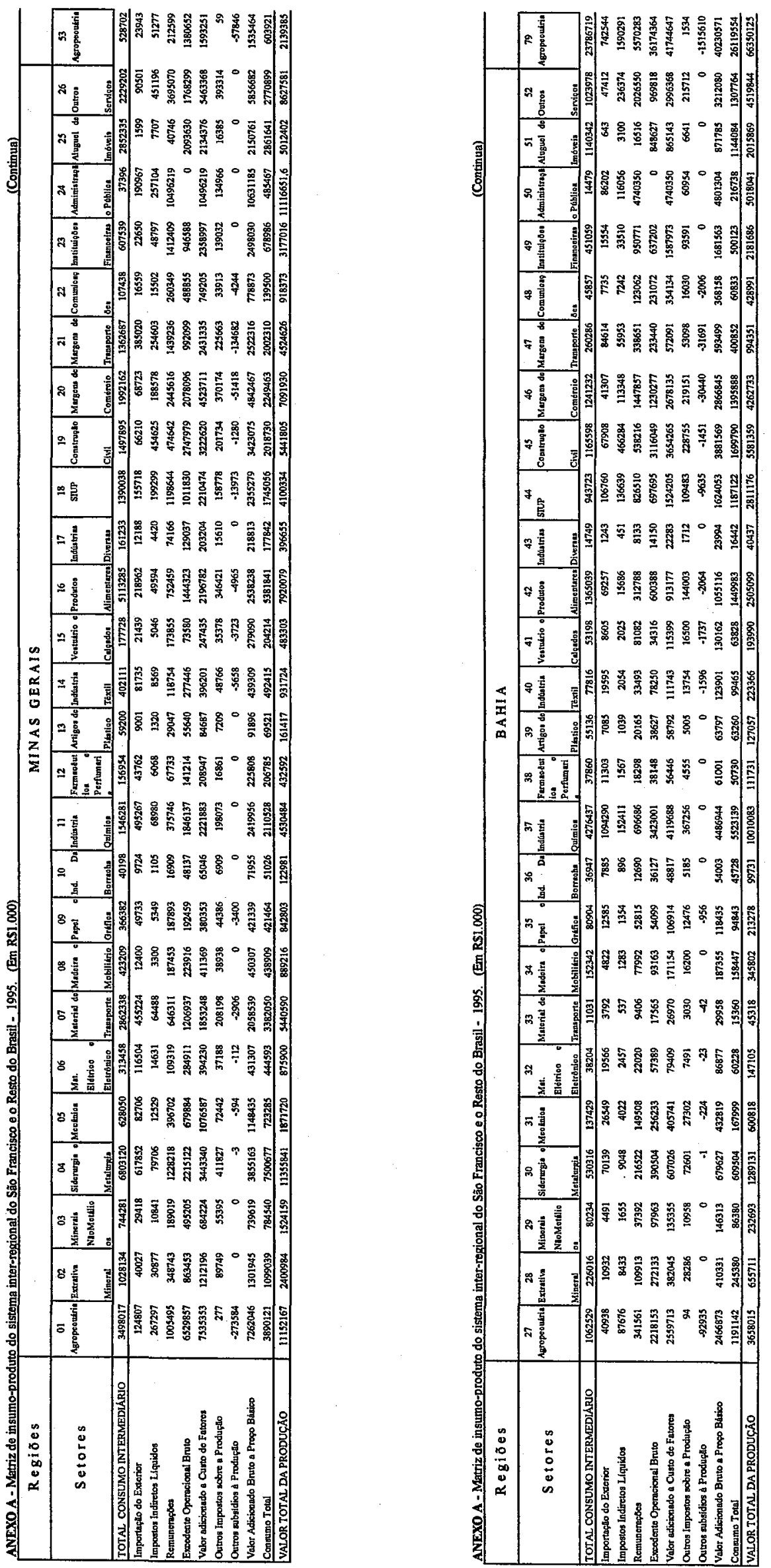

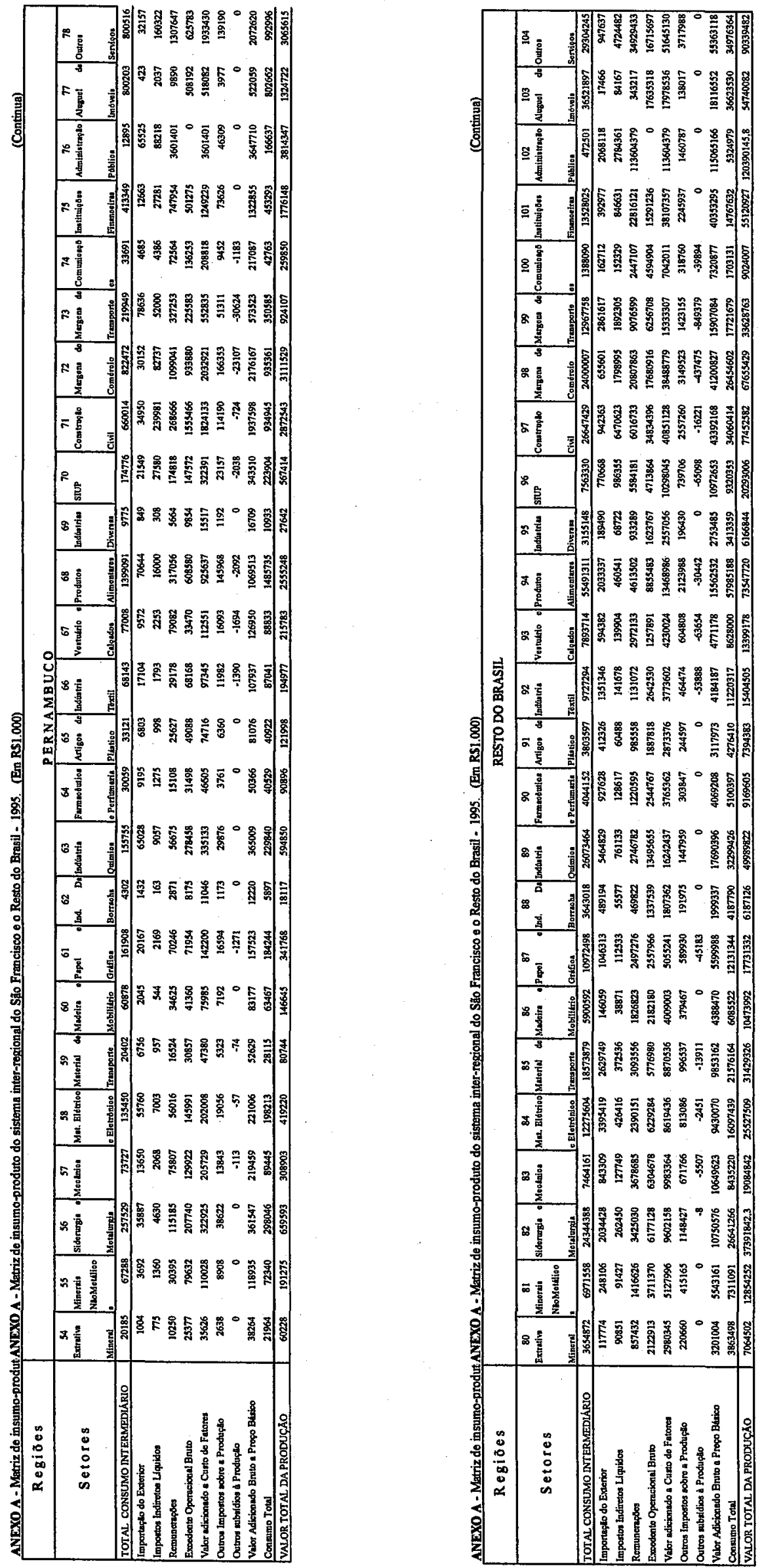

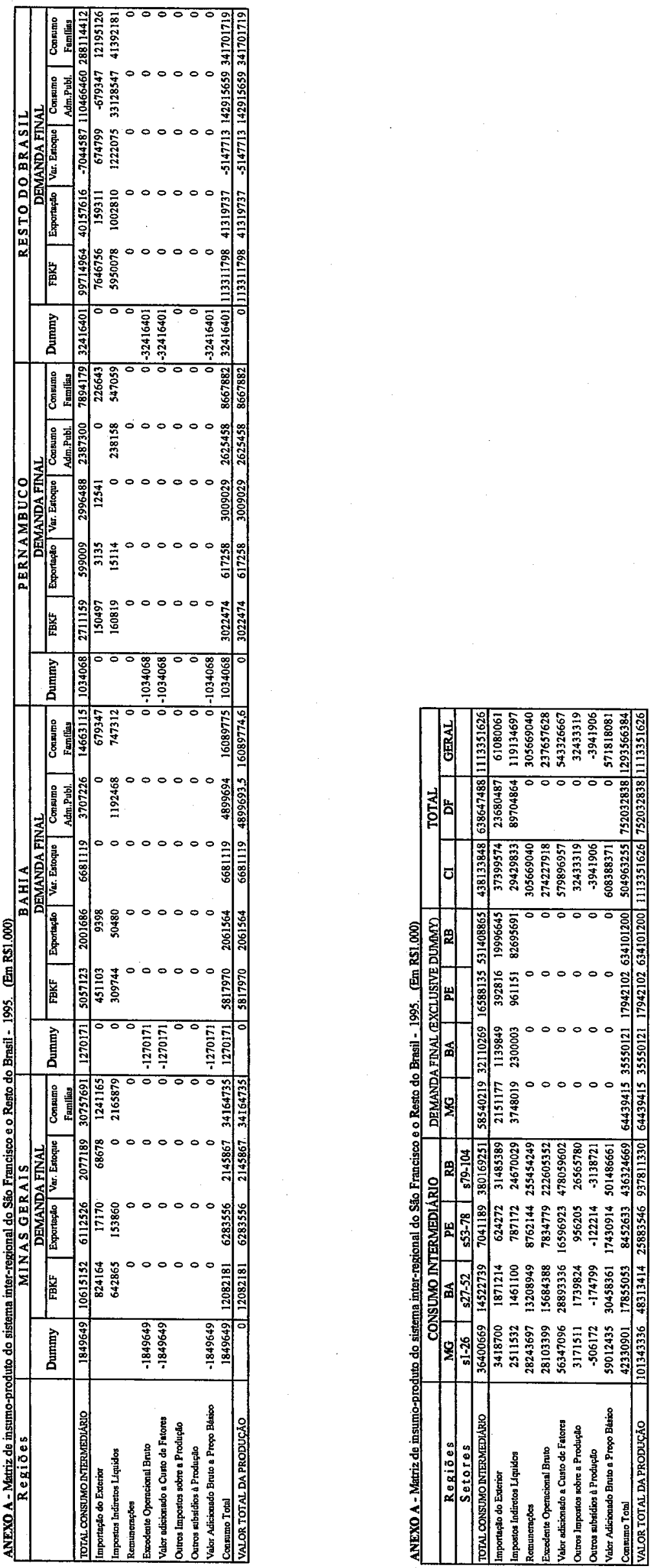
ANEXO B - Agregação dos produtos da matriz de insumo-produto.

\begin{tabular}{|c|c|c|c|}
\hline Ordem & $\begin{array}{l}\text { PRODUTOS } \\
\text { IBGE }\end{array}$ & Ordem & $\begin{array}{c}\text { SETORES } \\
\text { AGREGADOS }\end{array}$ \\
\hline 1 & Café em coco & \multirow{11}{*}{1} & \multirow{11}{*}{ Agropecuária } \\
\hline 2 & Cana-de-açúcar & & \\
\hline 3 & Arroz em casca & & \\
\hline 4 & Trigo em grão & & \\
\hline 5 & Algodão em caroço & & \\
\hline 6 & Soja em grão & & \\
\hline 7 & Milho em grão & & \\
\hline 8 & Bovinos e suínos & & \\
\hline 9 & Leite natural & & \\
\hline 10 & Aves vivas & & \\
\hline 11 & Outros produtos agropecuários & & \\
\hline 12 & Minério de ferro & \multirow{4}{*}{2} & \multirow{4}{*}{ Extrativa Mineral } \\
\hline 13 & Outros minerais & & \\
\hline 14 & Petróleo e gás & & \\
\hline 15 & Carvão e outros & & \\
\hline 16 & Produtos minerais não metálicos & 3 & Minerais não Metálicos \\
\hline 17 & Produtos siderúrgicos básicos & \multirow{4}{*}{4} & \multirow{4}{*}{ Siderurgia e Metalurgia } \\
\hline 18 & Laminados de aço & & \\
\hline 19 & Produtos metalúrgicos não ferrosos & & \\
\hline 20 & Outros produtos metalúrgicos & & \\
\hline 21 & Fab. e manut. de máq. e equipamentos & \multirow{2}{*}{5} & \multirow{2}{*}{ Mecânica } \\
\hline 22 & Tratores e máquinas terraplanagem & & \\
\hline 23 & Material elétrico & \multirow{2}{*}{6} & \multirow{2}{*}{ Material Elétrico e Eletrônico } \\
\hline 24 & Equipamentos eletrônicos & & \\
\hline 25 & Automóveis, caminhões e ônibus & \multirow{2}{*}{7} & \multirow{2}{*}{ Material de Transporte } \\
\hline 26 & Outros veículos e peças & & \\
\hline 27 & Madeira e mobiliário & 8 & Madeira e Mobiliário \\
\hline 28 & Papel, celulose, papelão e artefatos & 9 & Papel e Gráfica \\
\hline 29 & Produtos derivados da borracha & 10 & Indústria da Borracha \\
\hline 30 & Elementos químicos não petroquímicos & \multirow{11}{*}{11} & \multirow{11}{*}{ Indústria Química } \\
\hline 31 & Álcool de cana e de cereais & & \\
\hline 32 & Gasolina pura & & \\
\hline 33 & Óleos combustíveis & & \\
\hline 34 & Outros produtos do refino & & \\
\hline 35 & Produtos petroquímicos básicos & & \\
\hline 36 & Resinas & & \\
\hline 37 & Gasoalcool & & \\
\hline 38 & Adubos & & \\
\hline 39 & Tintas & & \\
\hline 40 & Outros produtos químicos & & \\
\hline 41 & Produtos farmacêuticos e de perfumaria & 12 & Farmacêutica e de Perfumaria \\
\hline
\end{tabular}


ANEXO B - Agregação dos produtos da matriz de insumo-produto

\begin{tabular}{|c|c|c|c|}
\hline 42 & Artigos de plástico & 13 & Artigos de Plástico \\
\hline 43 & Fios têxteis naturais & \multirow{5}{*}{14} & \multirow{5}{*}{ Indústria Têxtil } \\
\hline 44 & Tecidos naturais & & \\
\hline 45 & Fios têxteis artificiais & & \\
\hline 46 & Tecidos artificiais & & \\
\hline 47 & Outros produtos têxteis & & \\
\hline 48 & Artigos do vestuário & \multirow{2}{*}{15} & \multirow{2}{*}{ Vestuárịo e Calçados } \\
\hline 49 & Produtos de couro e calçados & & \\
\hline 50 & Produtos do café & \multirow{13}{*}{16} & \multirow{13}{*}{ Indústria de Produtos Alimentares } \\
\hline 51 & Arroz beneficiado & & \\
\hline 52 & Farinha de trigo & & \\
\hline 53 & Outros produtos vegetais beneficiados & & \\
\hline 54 & Carne bovina & & \\
\hline 55 & Carne de aves abatidas & & \\
\hline 56 & Leite beneficiado & & \\
\hline 57 & Outros laticínios & & \\
\hline 58 & Açúcar & & \\
\hline 59 & Óleos vegetais em bruto & & \\
\hline 60 & Óleos vegetais refinados & & \\
\hline 61 & Outros prod. alimentares inclusive rações & & \\
\hline 62 & Bebidas & & \\
\hline 63 & Produtos diversos & 17 & Indústrias Diversas \\
\hline 64 & Serviços industriais de utilidade pública & 18 & Serviços Industriais de Utilidade Pública \\
\hline 65 & Produtos da construção civil & 19 & Construção Civil \\
\hline 66 & Margem de comércio & 20 & Comércio \\
\hline 67 & Margem de transporte & 21 & Transportes \\
\hline 68 & Comunicações & 22 & Comunicações \\
\hline 69 & Seguros & \multirow{2}{*}{23} & \multirow{2}{*}{ Instituições Financeiras } \\
\hline 70 & Serviços financeiros & & \\
\hline 71 & Administração pública & \multirow{3}{*}{24} & \multirow{3}{*}{ Administração Pública } \\
\hline 72 & Saúde pública & & \\
\hline 73 & Educação pública & & \\
\hline 78 & Aluguel de imóveis & \multirow[b]{2}{*}{25} & \multirow[b]{2}{*}{ Aluguel de Imóveis } \\
\hline 79 & Aluguel imputado & & \\
\hline 74 & Alojamento e alimentação & \multirow{5}{*}{26} & \multirow{5}{*}{ Outros Serviços } \\
\hline 75 & Outros serviços & & \\
\hline 76 & Saúde e educação mercantis & & \\
\hline 77 & Servicos prestados às empresas & & \\
\hline 80 & Serviços privados não mercantis & & \\
\hline
\end{tabular}


ANEXO B - Agregação dos setores da matriz de insumo-produto.

\begin{tabular}{|c|c|c|c|}
\hline Ordem & $\begin{array}{l}\text { SETORES } \\
\text { IBGE }\end{array}$ & Ordem & $\begin{array}{l}\text { SETORES } \\
\text { AGREGADO }\end{array}$ \\
\hline 1 & Agropecuária & 1 & Agropecuária \\
\hline 2 & Extrativa Mineral & & \\
\hline 3 & Extração de Petróleo e Gás & 2 & Extratıva Mineral \\
\hline 4 & Minerais não Metálicos & 3 & Minerais não Metálicos \\
\hline 5 & Siderurgia & \multirow{3}{*}{4} & \multirow{3}{*}{ Siderurgia e Metalurgia } \\
\hline 6 & Metalurgia não Ferrosos & & \\
\hline 7 & Outros Metalúrgicos & & \\
\hline 8 & Máquinas Tratores & 5 & Mecânica \\
\hline 9 & Material Elétrico & \multirow{2}{*}{6} & \multirow{2}{*}{ Material Elétrico e Eletrônico } \\
\hline 10 & Equipamentos Eletrônicos & & \\
\hline 11 & Automóveis, Caminhões e Ônibus & \multirow{2}{*}{7} & \multirow{2}{*}{ Material de Transporte } \\
\hline 12 & Outros Veículos e Peças & & \\
\hline 13 & Madeira e Mobiliário & 8 & Madeira e Mobiliário \\
\hline 14 & \begin{tabular}{|l|} 
Papel e Gráfica \\
\end{tabular} & 9 & Papel e Gráfica \\
\hline 15 & Indústria da Borracha & 10 & Indústria da Borracha \\
\hline 16 & Elementos Químicos & \multirow{3}{*}{11} & \multirow{3}{*}{ Indústria Química } \\
\hline 17 & \begin{tabular}{|l|} 
Refino do Petróleo \\
\end{tabular} & & \\
\hline 18 & Químicos Diversos & & \\
\hline 19 & Farmacêutica e Perfumaria & 12 & Farmacêutica e de Perfumaria \\
\hline 20 & Artigos de Plástico & 13 & Artigos de Plástico \\
\hline 21 & Indústria Têxtil & 14 & Indústria Têxtil \\
\hline 22 & Artigos do Vestuário & \multirow{2}{*}{15} & \multirow{2}{*}{ Vestuário e Calçados } \\
\hline 23 & Fabricação de Calçados & & \\
\hline 24 & Indústria do Café & \multirow{7}{*}{16} & \multirow{7}{*}{ Indústria de Produtos Alimentares } \\
\hline 25 & Beneficiamento de Produtos Vegetais & & \\
\hline 26 & Abate de Animais & & \\
\hline 27 & Indústria de Laticínios & & \\
\hline 28 & Indústria de Açúcar & & \\
\hline 29 & Fabricação de Óleos Vegetais & & \\
\hline 30 & Outros Produtos Alimentares & & \\
\hline 31 & Indústrias Diversas & 17 & Indústrias Diversas \\
\hline 32 & Serviços Industriais de Utilidade Pública & 18 & Serviços Industriais de Utilidade Pública \\
\hline 33 & Construção Civil & 19 & \begin{tabular}{|l|} 
Construção Civil \\
\end{tabular} \\
\hline 34 & Comércio & 20 & Comércio \\
\hline 35 & Transportes & 21 & Transportes \\
\hline 36 & Comunicações & 22 & Comunicaç̃es \\
\hline 37 & \begin{tabular}{|l|} 
Instituicōes Financeiras \\
\end{tabular} & 23 & \begin{tabular}{|l} 
Instituicóes Financeiras \\
\end{tabular} \\
\hline 38 & Administração pública & 24 & Administração Pública \\
\hline 41 & Aluguel de Imóveis & 25 & \begin{tabular}{|l} 
Aluguel de Imóveis \\
\end{tabular} \\
\hline 39 & Serviços Prestados às Famílias & \multirow[b]{3}{*}{26} & \multirow{3}{*}{ Outros Serviços } \\
\hline 40 & Serviços Prestados às Empresas & & \\
\hline 42 & Serviços Privados não Mercantis & & \\
\hline 43 & Dummy Financeiro & & \\
\hline
\end{tabular}




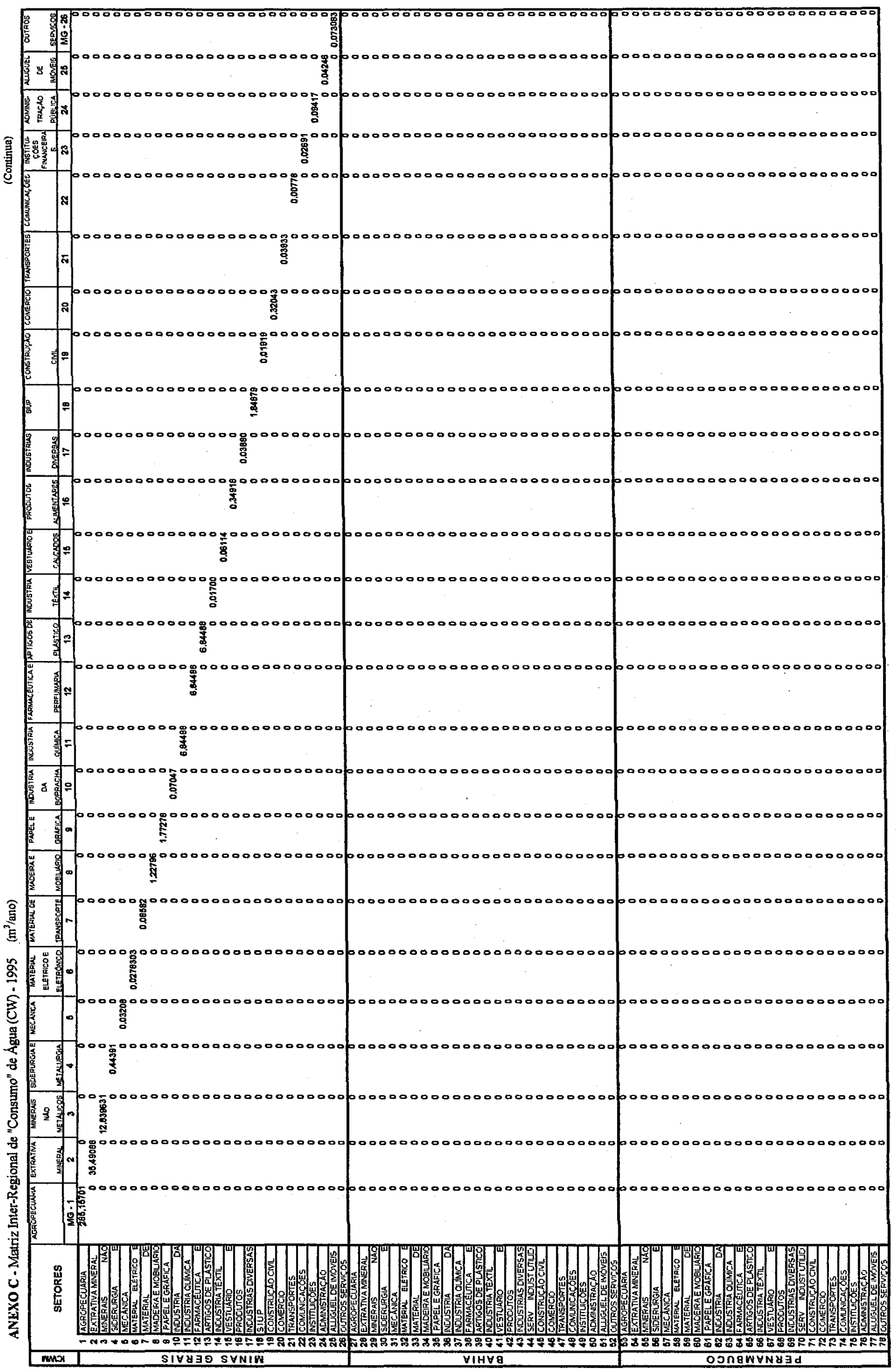




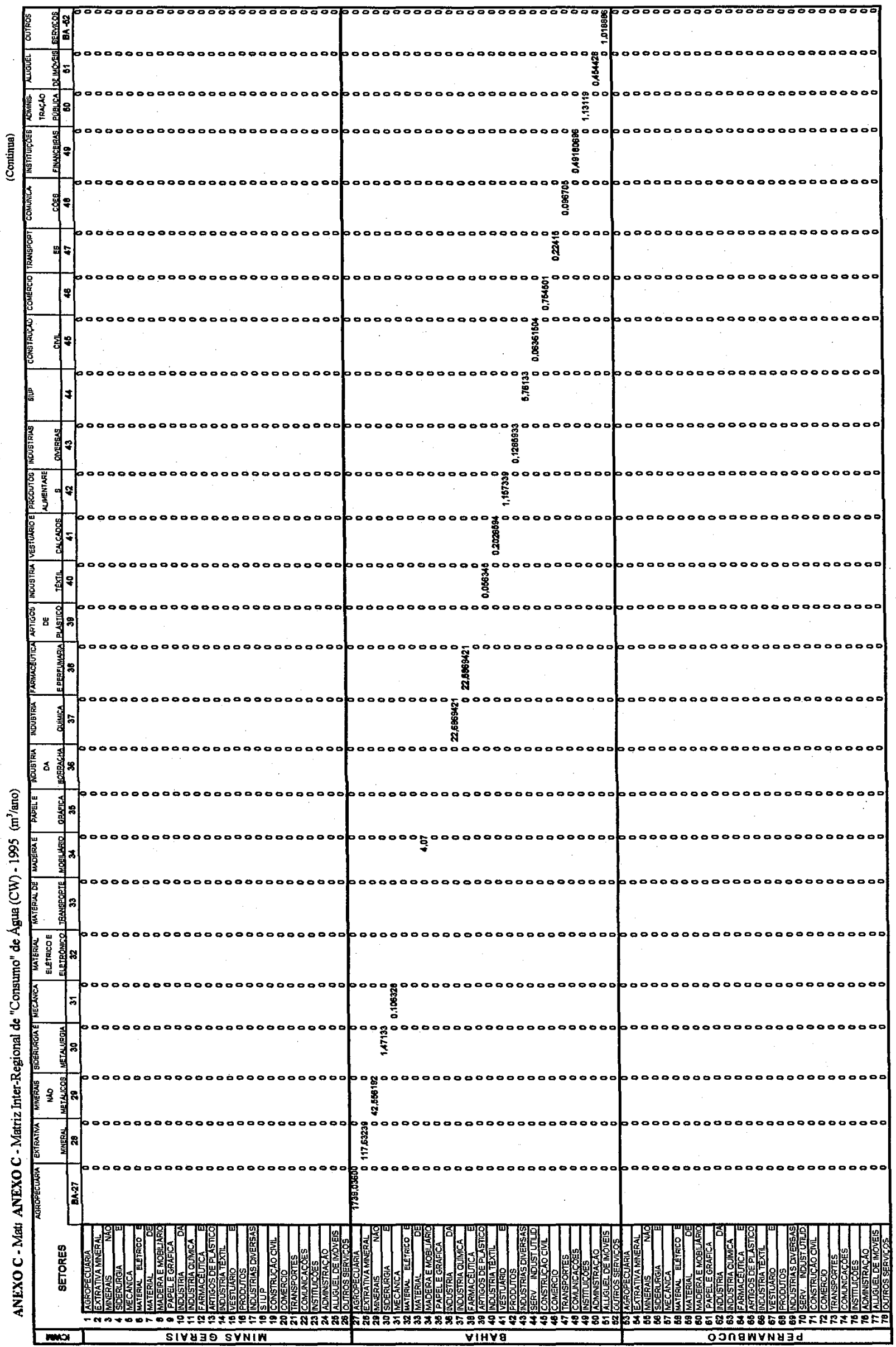




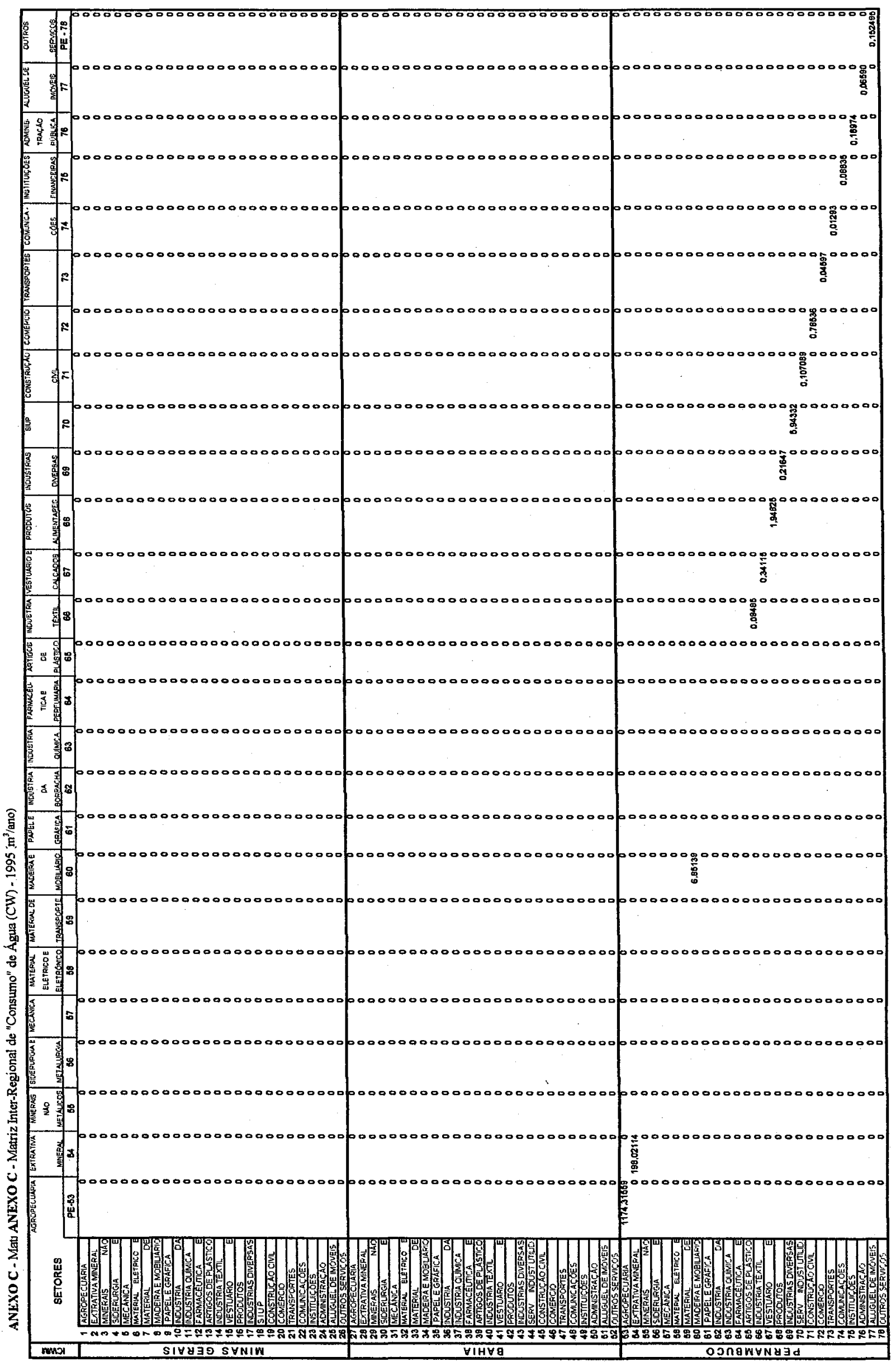




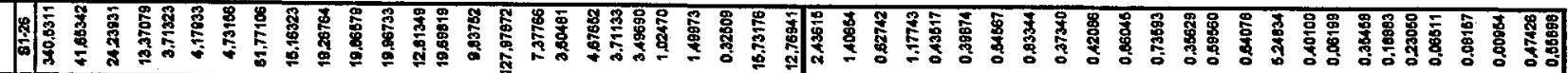

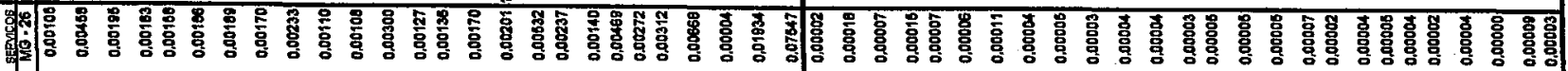

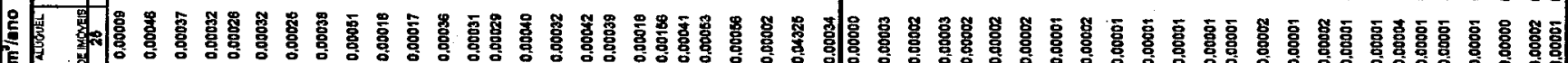

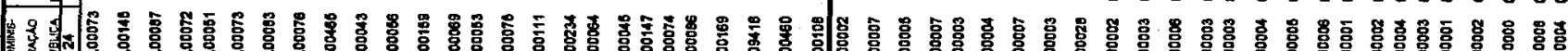

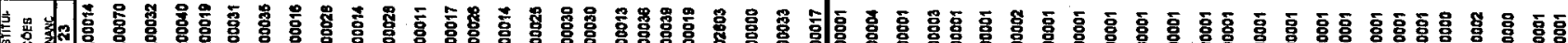

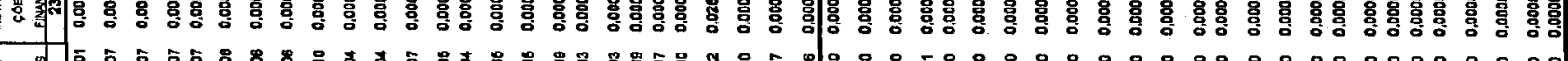

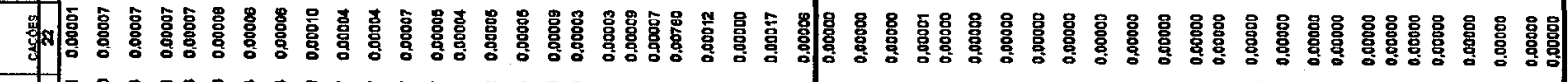

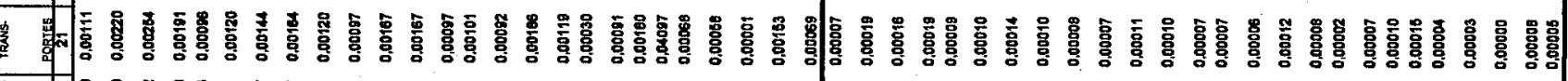

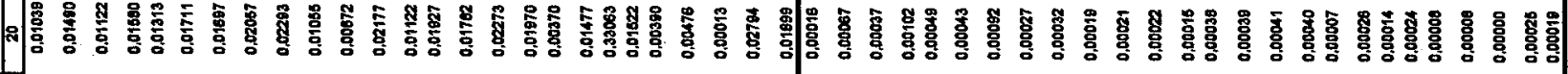

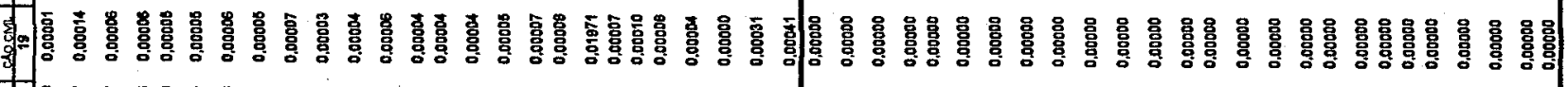

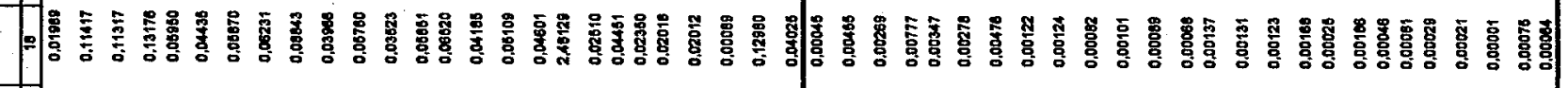

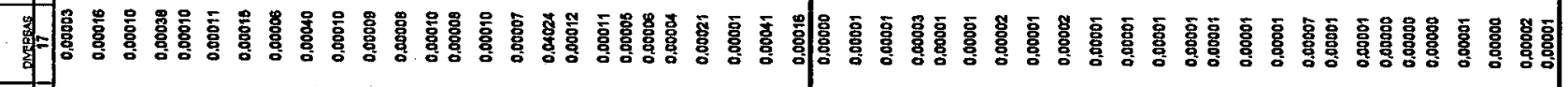

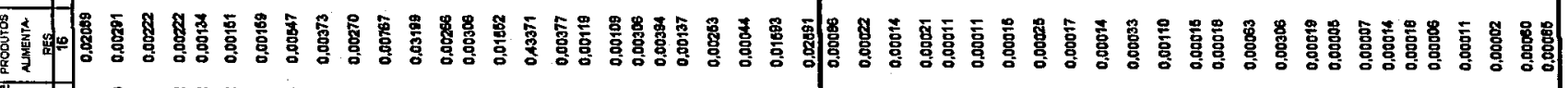

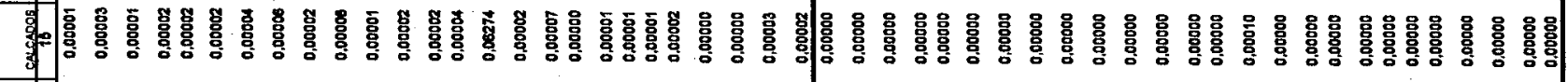

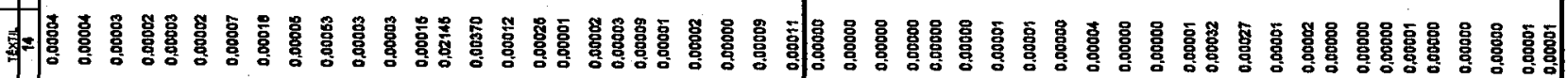

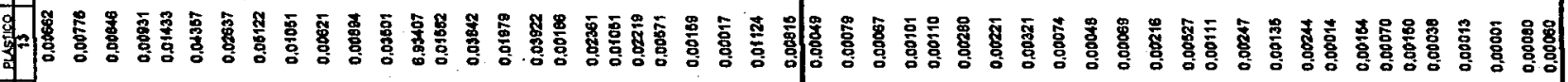

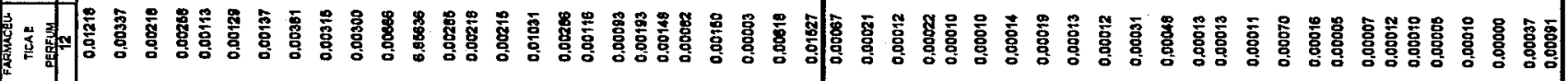

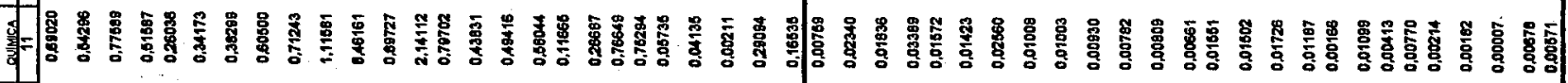

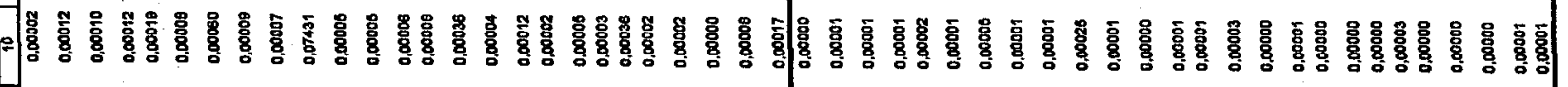

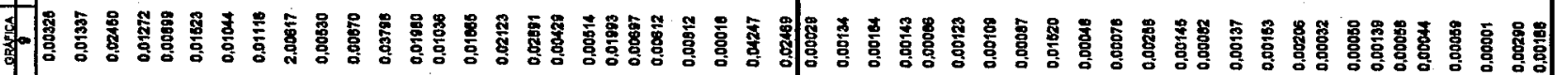

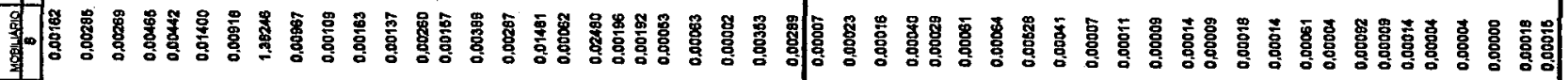

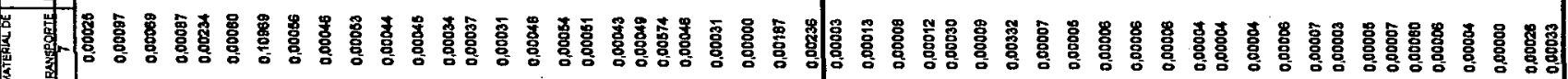

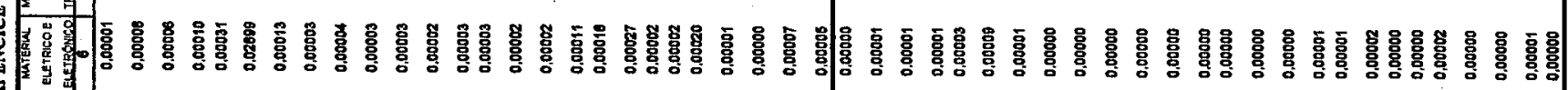

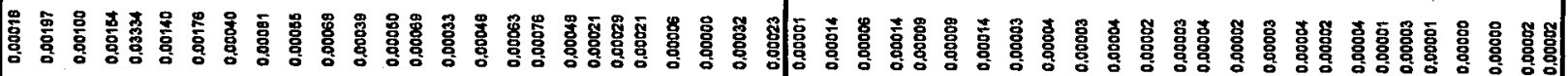

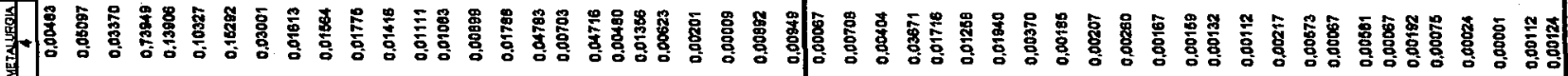

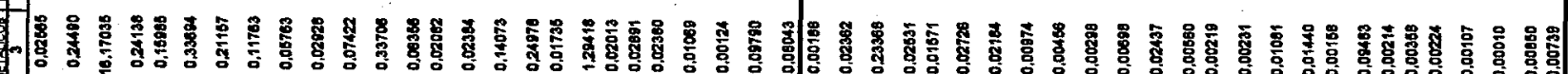

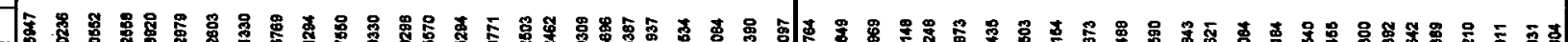

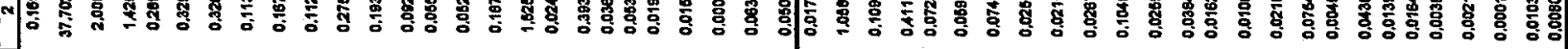

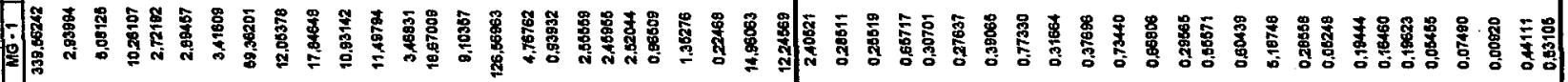

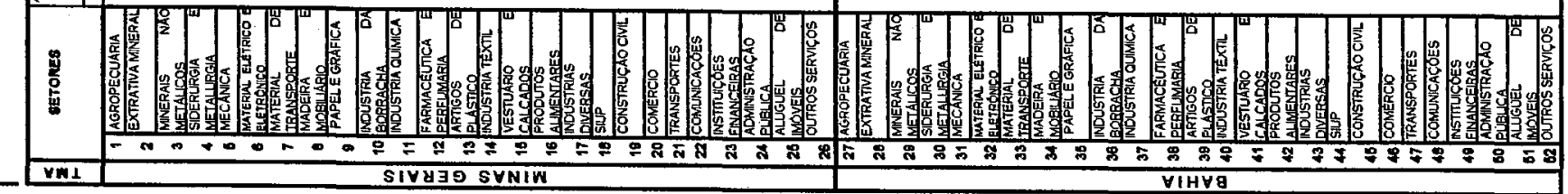




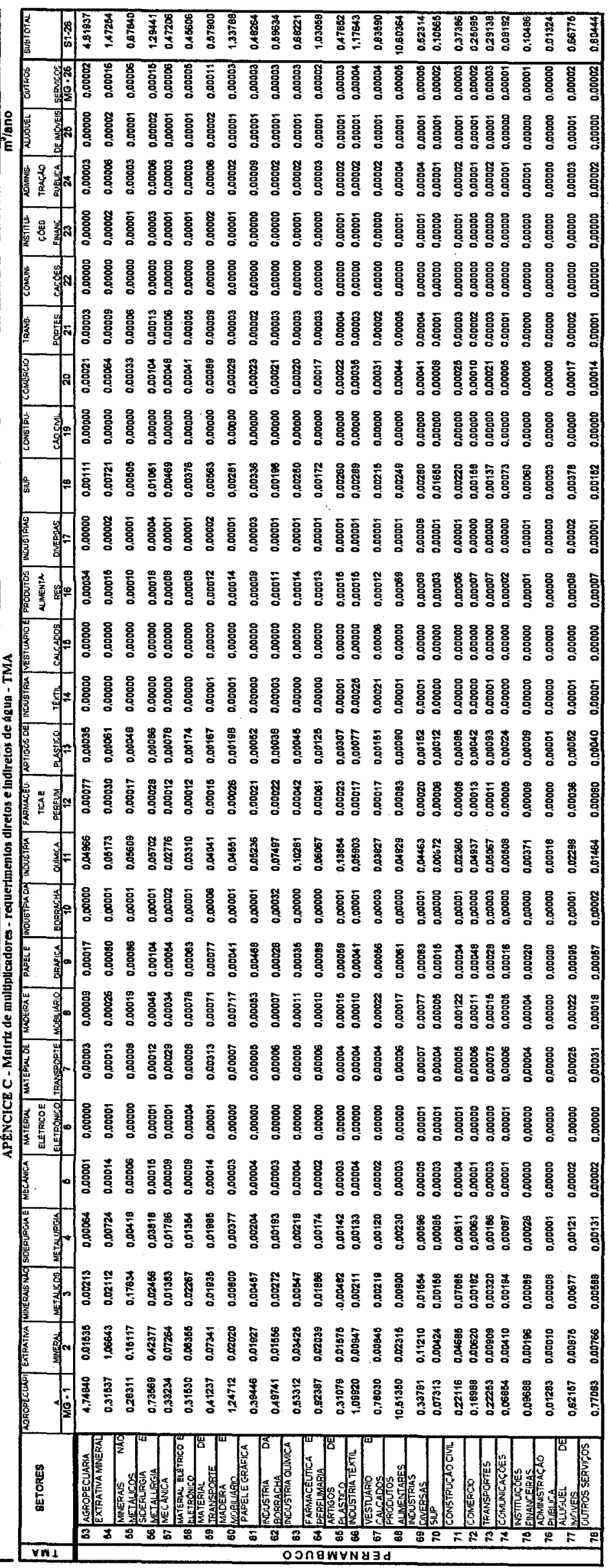




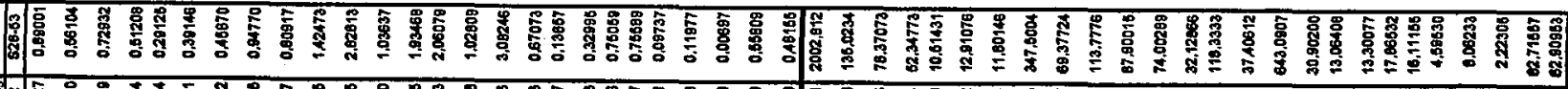

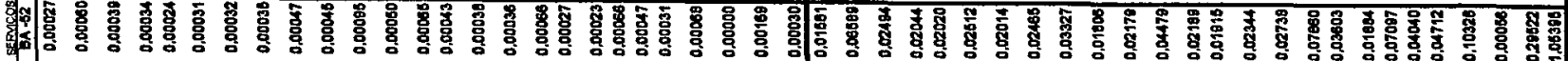

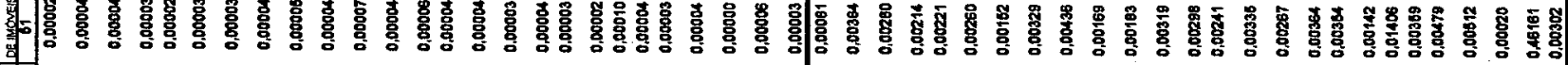

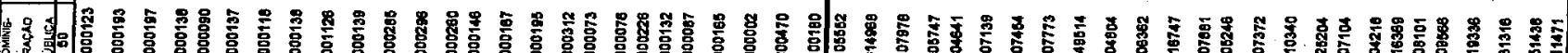

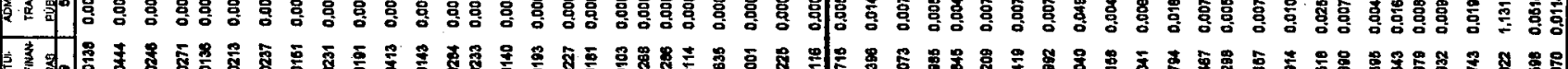

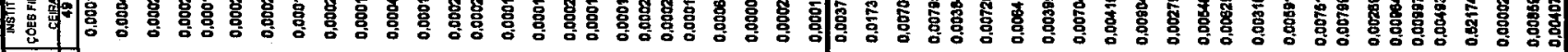

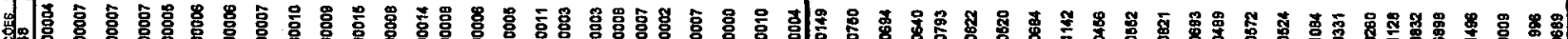

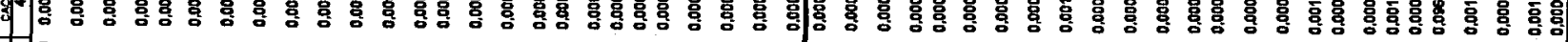

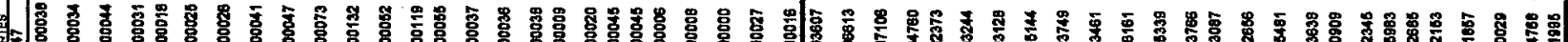
H (1)

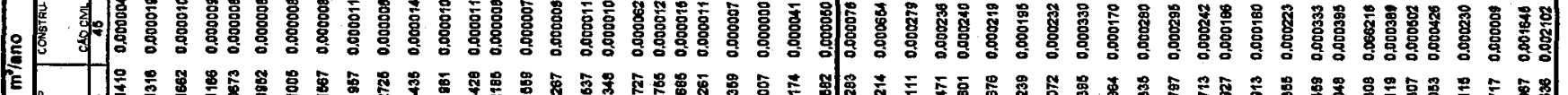
HO

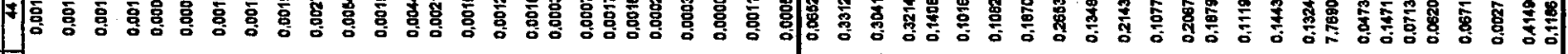

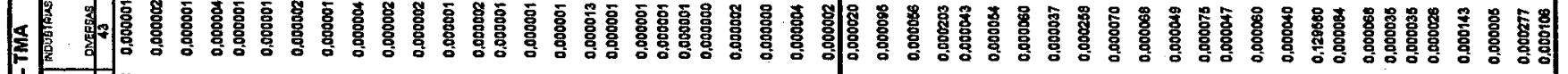

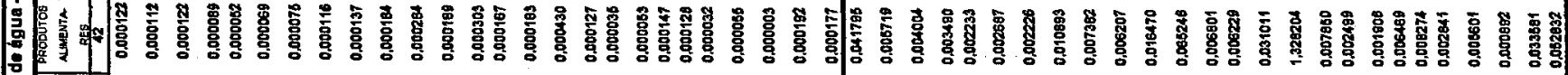

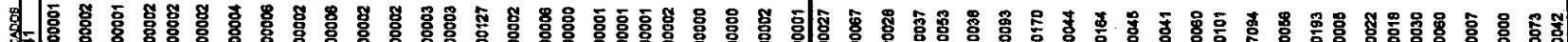

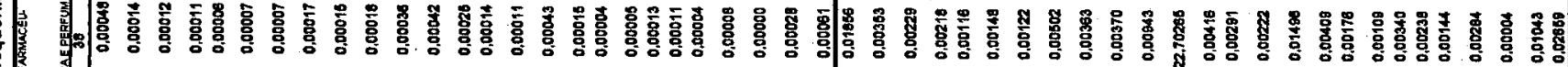

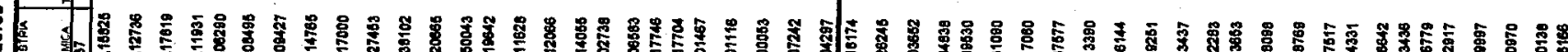
位

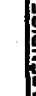

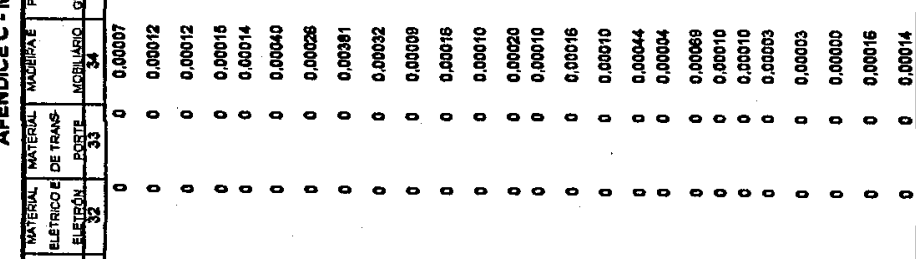

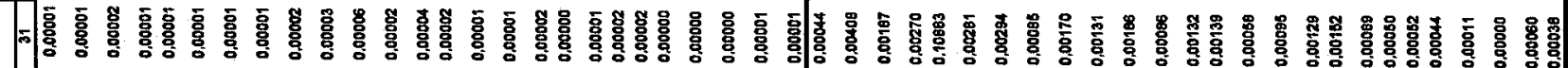

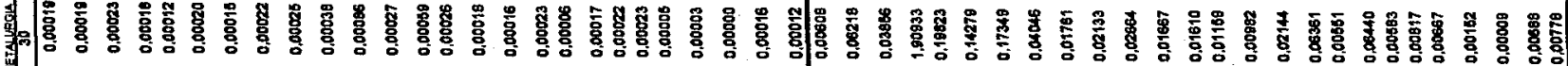

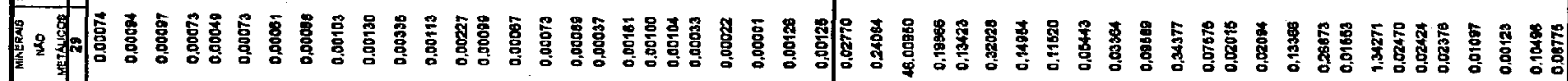

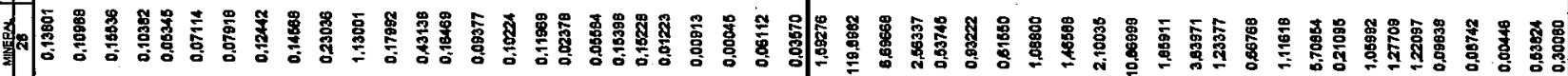

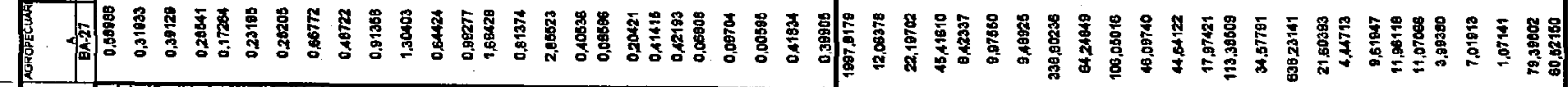

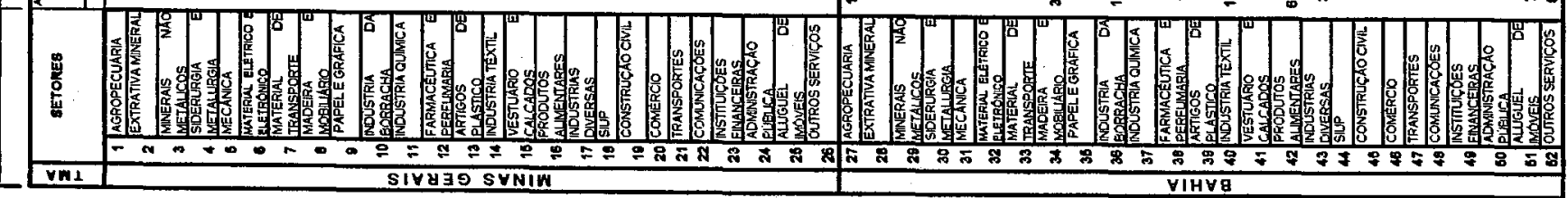




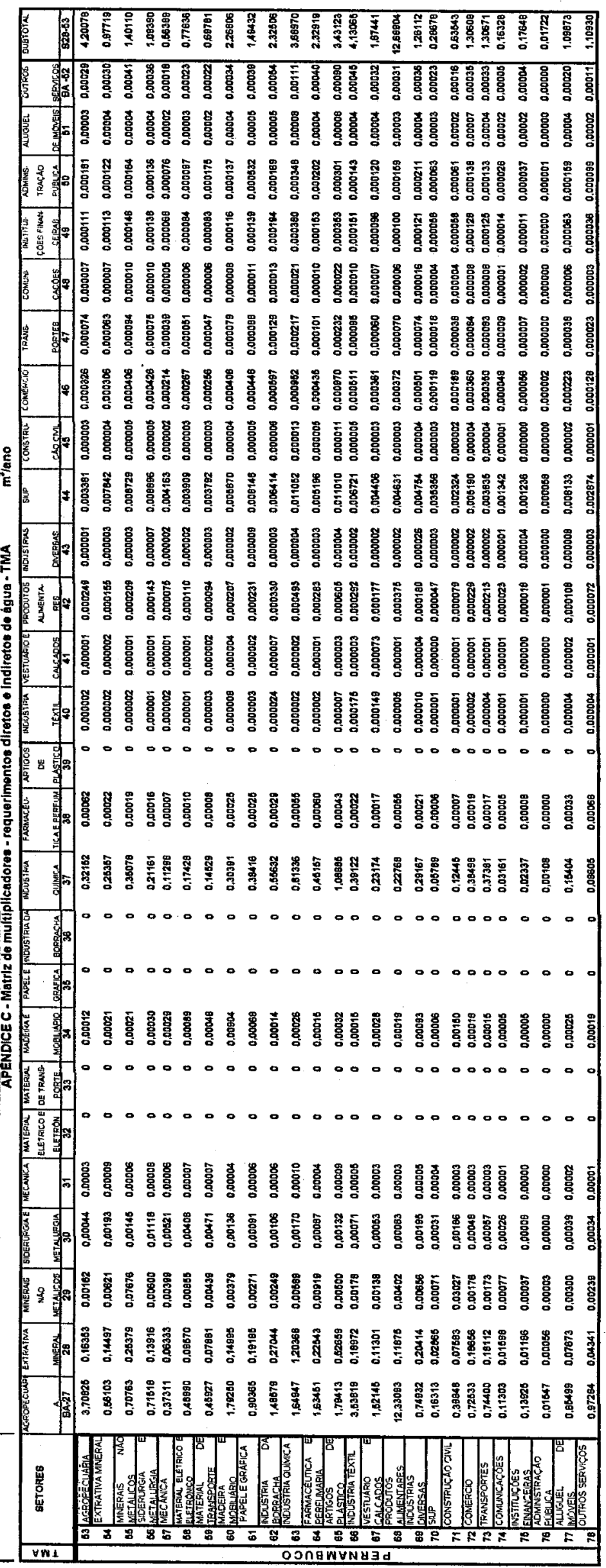


芫

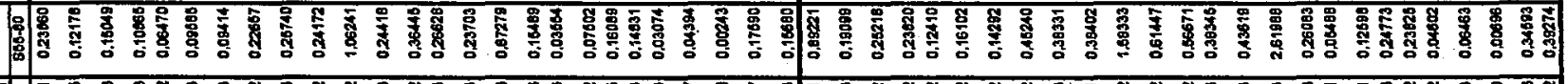

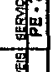
部

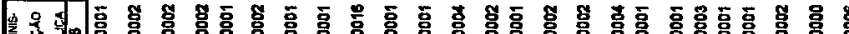


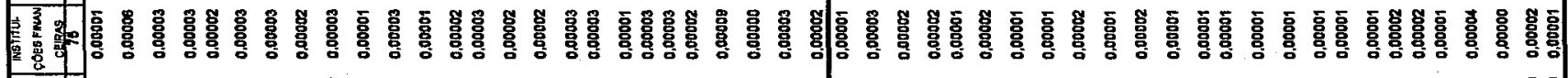

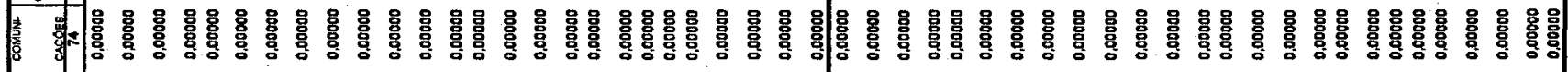
"

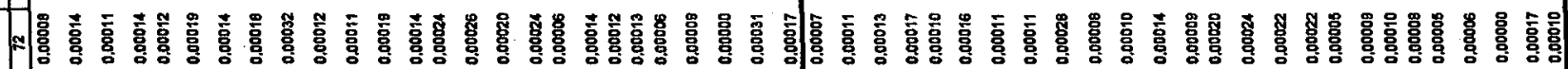

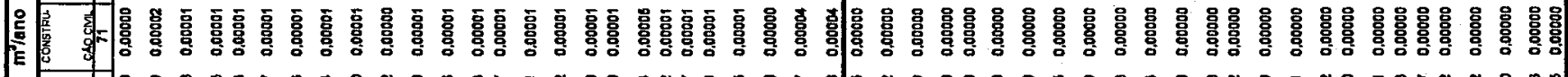

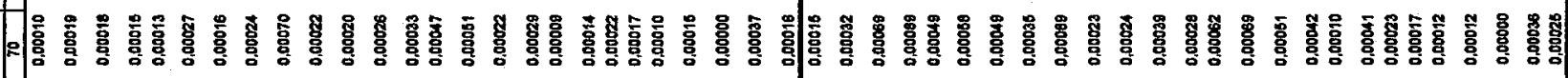

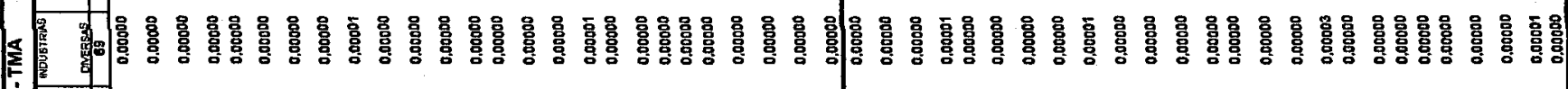

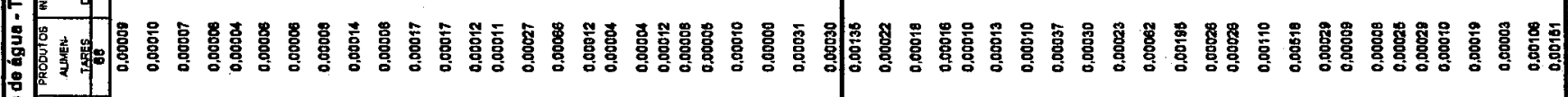

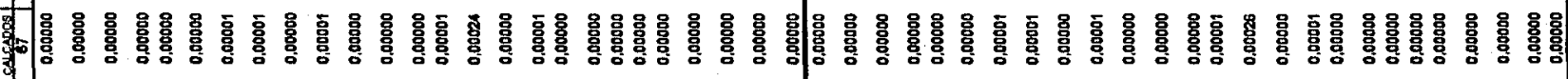

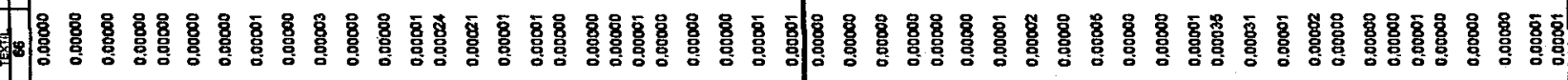

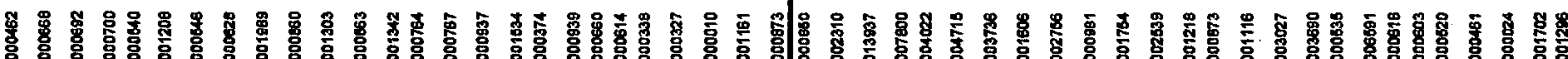

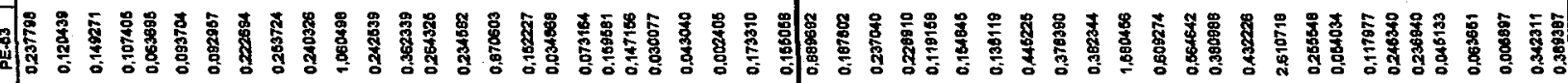

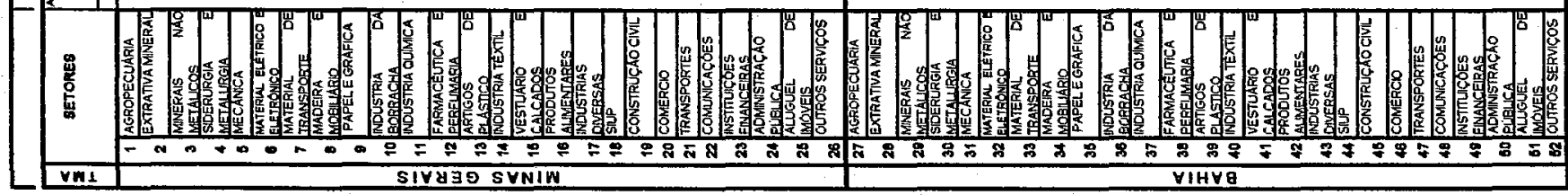




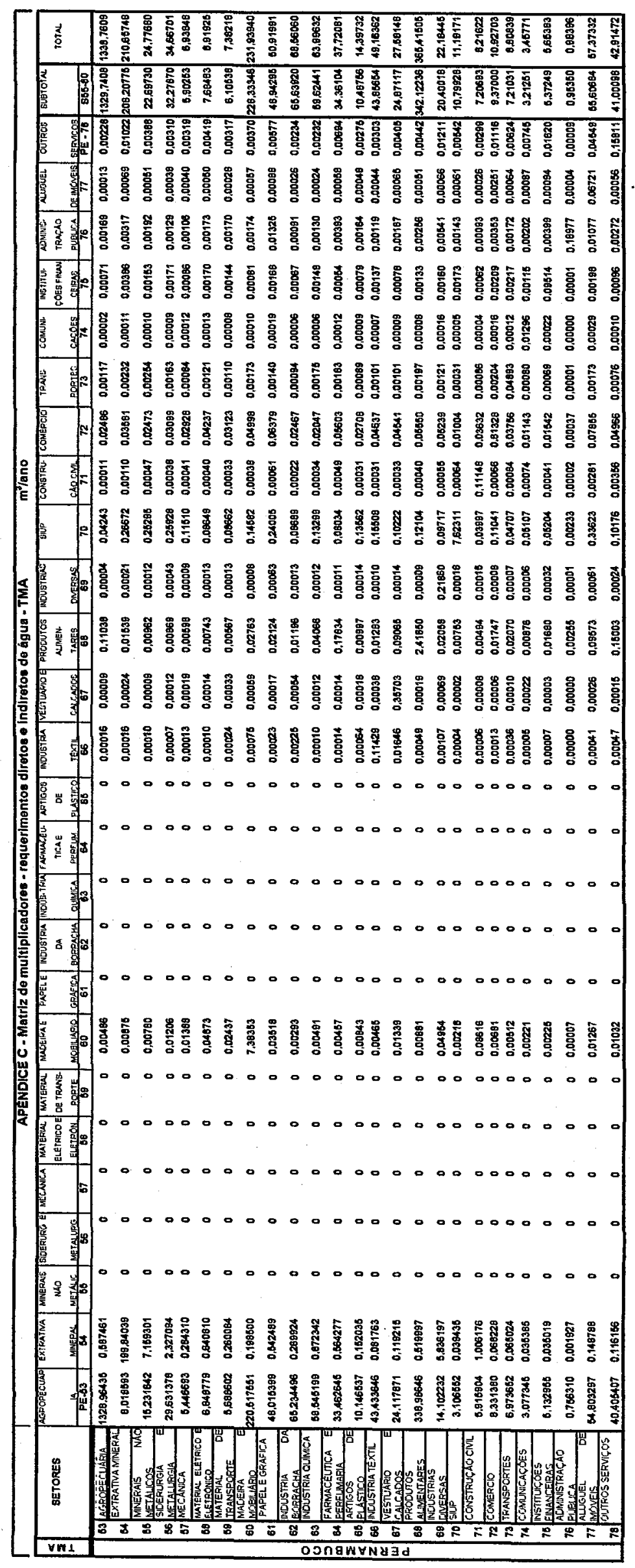




\section{REFERÊNCLAS BIBLIOGRÁFICAS}

ABDALLAH, Patrízia Raggi \& MONTOYA, Marco Antonio. Perspectivas da utilização

de modelos de insumo-produto na administração do meio ambiente. In.: MONTOYA, Marco Antonio (Org.) Relações intersetoriais do mercosul e da economia brasileira: uma abordagem de equilíbrio geral do tipo insumo-produto. Passo Fundo: Ediupf, 1998. p.345 366.

ABREU, Teresa Lúcia de Muricy de. Etude des facteurs determinants de la depletion des eaux du lac de Sobradinho et les effects au niveau des usagers. Chambery. 1990. 162p. (Tese doutorado).

ALVES, Francisco Ferreira; GOMES, Francisco de Assis L.; SILVA FILHO, Guerino E. da; ARY, José Carlos Azyz; VIANA, Manuel O. de Lima \& SOARES, Paulo Henrique. O setor industrial do Nordeste: diagnóstico, modernização e concentração espacial. Diretrizes para um plano de ação do BNB (1991-1995); Setor Secundário. Fortaleza, 1997. 7v., v.3. p.9-260. (BNB. Estudos Econômicos e Sociais, v.59).

AMARAL FILHO, Jair do. A endogeneização do desenvolvimento econômico regional. In.: Anais do XXVII Encontro Nacional de Economia, Belém, 1999. p.1281-1801.

ASSIRATI, Emílio Borsari. Uma avaliação das políticas de irrigação no Nordeste.

In.: Revista Econômica do Nordeste. Fortaleza, v.25, no 4, out./dez. 1994. p. 545-574.

AVELLAR, Maria Angélica Braga de. O DNOCS e a irrigação no Nordeste. Brasília: Ministério do Interior. 1976. 32p.

AZZONI, Carlos Roberto \& FERREIRA, Dirceu Alves. Competitividade regional e reconcentração industrial: o futuro das desigualdades regionais no Brasil. In.: Revista Econômica do Nordeste. Fortaleza. v. 28, nº especial, julho, 1997. p. 55-85.

BACHARACH, M. Biproportional matrices and input-output change. Cambridge: Cambridge University Press. 1970. 170p.

BAER, Werner. A economia brasileira. Tradução Edite Scuilli. São Paulo: Nobel, 1996. $416 \mathrm{p}$.

BDMG (Banco de Desenvolvimento de Minas Gerais). Economia mineira 1989: diagnósticos e perspectivas. Belo Horizonte, 1989a. 5 v. em 7. 
BDMG (Banco de Desenvolvimento de Minas Gerais). Economia mineira 1989:

diagnósticos e perspectivas. Belo Horizonte, 1989b. v.2: Indústria. t.1. Novos Desafios. $114 \mathrm{p}$.

BERNARDO, Salassier. Impacto ambiental da irrigação no Brasil. In.: SILVA, Demétrius David da \& PRUSKI, Fernando Falco(eds.). Recursos hídricos e desenvolvimento sustentável da agricultura. Brasília, DF: MMA; SRH; ABEAS; Viçosa, MG: UFV, Departamento de Engenharia Agrícola, 1997. p.79-88.

BNB (Banco do Nordeste do Brasil S/A). Diretrizes para um plano de ação do BNB (19911995); Infra-estrutura econômica e social do Nordeste. Fortaleza, 1997. 7v., v.6, t 2. p. 296. (BNB. Estudos Econômicos e Sociais, v.59).

BRASIL. Anuário Mineral Brasileiro - 1996: anobase1995.

http://www.dnpm.gov.br/dnpm_tr1.html.(13 out. 1998)

BULMER-THOMAS, V. Input-output analysis in developing countries. New York: John Wiley \& Sons Ltd. 1982. 297p.

CAO-PINNA, Vera. Problems of establishing and using regional input-output accounting. In.: Regional economic planning: techniques of analysis for less developed areas. Isard, Walter \& Cumberland, John H. (eds.). Paris: European Productivity agency of the Organization for European Economic Co-operation. 1961. p.305-338.

CANO, Wilson. Desequilíbrios regionais e concentração industrial no Brasil, 1930-1995. $2^{\mathrm{a}}$ ed. Campinas, SP: UNICAMP. IE, 1998. $421 \mathrm{p}$.

CARDOSO, Herbert E. A.; MANTOVANI, Everardo Chartuni \& COSTA, Luiz Cláudio. As águas da agricultura. In.: Agroanalysis - A Revista de economia da FGV. Instituto Brasileiro de economia. Centro de estudos agrícolas. v.19, $\mathrm{n}^{\mathbf{0}} 3$, março, 1998. p. 27 - 28.

CARTER, Anne P. \& PETRI, Peter A. Leontief's contribution to economics. In.: Journal of Policy Modeling. v.11, n⿳0 1, 1989. p. 7-30.

CARVALHO, Daniel Fonseca de. Otimização do uso da água no perímetro irrigado do Gorutuba. Viçosa, MG: UFV, 145p. Tese (Doutorado). 1998.

CAVALCANTI, José Euclides A. An Interregional input-output model for the northeast of Brazil. London. 1990. (Ph.D. Thesis). Queen Mary College. 182 p.

CNI - Confederação Nacional da Indústria. Economia brasileira: comparações regionais.

Confederação Nacional da Indústria, Departamento Econômico. Rio de Janeiro: CNI, DEC, $\mathrm{n}^{\circ}$ 2, 1996. 78p. 
COMPANHIA DE DESENVOLVIMENTO DO VALE DO SÃO FRANCISCO (CODEVASF). Projeto semi-árido: proposta de desenvolvimento sustentável da bacia do rio São Francisco e do semi-árido nordestino. Brasília: CODEVASF, 1996a. $60 \mathrm{p}$.

COMPANHIA DE DESENVOLVIMENTO DO VALE DO SÃO FRANCISCO (CODEVASF). Produção agrícola de 1997. Brasília: CODEVASF. Diretoria de Planejamento. Coordenadoria de Acompanhamento e Avaliação. 1998a. 71p.

COMPANHIA DE DESENVOLVIMENTO DO VALE DO SÃO FRANCISCO (CODEVASF). Relatório anual de monitoria. Diretoria de Planejamento. Brasília: CODEVASF. 1995; 1996b.

COMPANHIA DE DESENVOLVIMENTO DO VALE DO SÃO FRANCISCO (CODEVASF). http://www.codevasf.gov.br. O Vale do São Francisco. 1998b.

COMPANHIA DE SANEAMENTO DO ESTADO DE MINAS GERAIS (COPASA). Cadastro usuário e volume consumido na bacia do São Francisco. COPASA: Superintendência de Programação e controle de Empreendimentos. 1999 (disquete).

CONSIDERA, Cláudio. M.; MEDINA, Mérida. H. PIB por unidade da federação: valores corrente e constantes - 1985/96. Rio de Janeiro: IPEA, 1998. (Texto para discussão, 610). $32 \mathrm{p}$.

CONSIDERA, Cláudio. M.; RAMOS, R. L. O.; MAGALHÃES, K. M. M. et al. Matrizes de insumo-produto regionais 1985 e 1992: metodologia e resultados. Rio de Janeiro: IPEANEMESIS, 1997. 55p.

CROCOMO, Francisco Constantino. Análise das relaçóes inter-regionais e intersetoriais na economia brasileira em 1985: uma aplicação de insumo-produto. Piracicaba, 1998. Tese (Doutorado). Escola Superior de Agricultura Luiz de Queiroz/USP. 179 p.

CUMBERLAND, John H. A regional interindustry model for analysis of development objetives. Regional Science Association, 1966. p. 65-94.

DALY, H. E. On economic as a life science. In.: Journal of Polical Economy, v.76. (mai./jun.), 1968. p. 392-405.

DAVIS, H. Craig. Multirregional input-output techniques and western water resources development. Part V. Economic evaluation of water. Sanitary Engineering research Laboratory, College of Engineering e School of Public Health, University of California. Berkeley: Water Resources Center. 1968. 142p. (Contribution $n^{\circ} 125$ ). 
DABI, Daniel Davou \& ANDERSON, Willian P. Application of a commodity-by-industry economic-ecological model to water demand in a rural economy. (mimeo). University Hamilton. Ontario. 1998. 38 p.

DECALUWÉ, Bernard; PATRY, André; SAVARD, Luc. Quand l'eau n'est plus un don du ciel: un MEGC appliqué au Maroc. Colloque International sur la Modelisation en Equilibre General Calculable en economie du Developpement. Université Laval. 1997. 26p.

DIAS, José Maria A. M. A bacia do rio das Velhas. In.: Agroanalysis - A Revista de economia da FGV. Instituto Brasileiro de economia. Centro de estudos agrícolas. v.19, $\mathrm{n}^{\mathbf{o}}$ 3, março, 1998. p. 37-39.

DINIZ, Clélio Campolina. A dinâmica regional recente da economia brasileira e suas perspectivas. Instituto de Pesquisa Econômica Aplicada (IPEA), Rio de Janeiro (RJ), jun. 1995. 36 p. (Texto para Discussão n⿳0 375).

DINIZ, Clélio Campolina. A nova configuração urbano-industrial no Brasil. In.: Anais do XXVII Encontro Nacional de Economia. Belém, 1999. P.1341-1361. (ANPEC).

DIXON, Peter B.; PARMENTER, B. R.; POWELL, Alan A; WILCOXEN, Peter J. Notes and problems in applied general equilibrium economics. New York: Elsevier Science Publishing Company Inc., 1992. 391p.

DEPARTAMENTO NACIONAL DE ÁGUAS E ENERGLA ELÉTRICA (DNAEE).

Transposição das águas do São Francisco e Tocantins para o Semi-Árido Nordestino: versão preliminar. Ministério das Minas e Energia / Departamento Nacional de Águas e Energia Elétrica / divisão de Controle de Recursos Hídricos. nov. 1983. 72p.

ERNST \& YOUNG CONSULTORES. Doing business in Bahia. 178p.

FERNANDES, C. L. de L. A inserção de Minas Gerais na economia nacional: uma análise de insumo-produto inter-regional. Rio de Janeiro, 1997. Tese (Doutorado). Universidade Federal do Rio de Janeiro.

FREITAS, A. J. de. Direito de outorga de uso de água. In.: SILVA, Demétrius. D. da \& PRUSKI, Fernando Falco(eds.). Recursos hídricos e desenvolvimento sustentável da agricultura. Brasília, DF: MMA; SRH; ABEAS; Viçosa, MG: UFV, Departamento de Engenharia Agrícola, 1997. p15-36.

FUNDAÇÃO INSTITUTO BRASILEIRO DE GEOGRAFIA E ESTATÍSTICA. Anuário Estatístico do Brasil. Rio de Janeiro: IBGE, v. 56. 1996.

FUNDAÇÃO INSTITUTO BRASILEIRO DE GEOGRAFIA E ESTATÍSTICA. Matriz de Insumo-produto: Brasil - 1995. Rio de Janeiro: IBGE, 1997. 217p. 
FUNDAÇÃo INSTITUTO BRASILEIRO DE GEOGRAFIA E ESTATÍsTICA. Censo agropecuário 1995-1996: Brasil (compact disc). Rio de Janeiro: IBGE, 1998.

FUNDAÇÃo INSTITUTO BRASILEIRO DE GEOGRAFIA E ESTATísticA. Censo agropecuário 1995-1996: Minas Gerais (compact disc). Rio de Janeiro: IBGE, 1998.

FUNDAÇão INSTITUTO BRASILEIRO DE GEOGRAFIA E ESTAtísticA. Censo agropecuário 1995-1996: Bahia (compact disc). Rio de Janeiro: IBGE, 1998.

FUNDAÇÃO INSTITUTO BRASILEIRO DE GEOGRAFIA E ESTATÍSTICA.

Censo agropecuário 1995-1996: Pernambuco (compact disc). Rio de Janeiro: IBGE, 1998.

GALINDO, Osmil. Os distritos industriais e os grandes eixos de atividade econômica do Nordeste. In.: Diretrizes para um plano de ação do BNB (1991-1995); Infra-estrutura econômica e social do Nordeste. Fortaleza, 1997. 7v., v.6, t 2. p. 79-117. (BNB. Estudos Econômicos e Sociais, v.59).

GALVÃO, Olímpio J. de Arrouxelas. Globalização, novos paradgmas tecnológicos e processos de reestruturação produtiva no Brasil e no Nordeste. In.: Anais do XXVII Encontro Nacional de Economia. Belém, 1999. P.1319-1338. (ANPEC).

GARRIDO, R. Os novos preceitos. In.: Agroanalysis - A Revista de economia da FGV. Instituto Brasileiro de economia. Centro de estudos agrícolas. v.19, nº3, março, 1998. p. 27 - 28.

GOMES, Gustavo Maia \& VERGOLINO, José Raimundo. A macroeconomia do desenvolvimento nordestino: 1960/1994. Instituto de Pesquisa Econômica Aplicada (IPEA), Rio de Janeiro (RJ), mai. 1995. 109 p. (Texto para Discussão no 372).

GOVERNO FEDERAL / GOVERNO DO ESTADO DE MINAS GERAIS. Plano diretor de recursos hídricos das bacias de afluentes do rio São Francisco, em Minas Gerais. Tomo XI Inventário dos Recursos Hídricos Regionais. Levantamento de Usuários. Ruralminas / consórcio Ecoplan - Magna - Coba (Relatório Preliminar). Junho, 1999.

GOVERNO DO ESTADO DE MINAS GERAIS. Secretaria da Fazenda. Guia de informaçðes das operações e prestações interestaduais (GI/ICMS). (disquete).

GUILHOTO, J. J. M.; SONIS, M.; HEWINGS, G. J. D.; MARTINS, E. B. Índices de ligações e setores-chave na economia brasileira: 1959/80. Pesquisa e Planejamento Econômico, v.24, n.2, p.287-314, ago. 1994.

GUILHOTO, J. J. M.; SONIS, M.; HEWINGS, G. J. D. Linkages and multipliers in a multiregional framework: integration of alternative approaches. Urbana: University of Illinois. Regional Economics Applications Laboratory, 1996. 20p. (Discussion Paper, 96-T-8). 
GUILHOTO, J. J. M.; HEWINGS, G. J. D.; SONIS, M. Interdependence, linkeges and multipliers in Asia: an international input-output analysis. Urbana: University of Illinois. Regional Economics Applications Laboratory, 1997. 33p. (Discussion Paper, 97-T-2).

GUILHOTO, J. J. M.; HEWINGS, G. J. D.; SONIS, M. Synergetic interctions between 2 Brasilian regions: an application of input-output linkages. 45 North American Meetings of the RSAI. Santa Fe, New Mexico, 11-14 nov., 1998.

GUILHOTO, J. J. M. Decomposition \& synergy: a study of the interactions and dependence among the 5 brasilian macro regions. Dublin, Irland: 39 European Congress of the ERSA/RSAI, 1999. 23p.

GUILHOTO, J. J. M.; HEWINGS, G. J. D.; SONIS, M. Produtive relations in the northest and the rest of Barazil regions in 1992: decomposition \& synergy in input-output systems. In: ENCONTRO NACIONAL DE ECONOMIA, 27, Belém, 1999. Anais, v2. Rio de Janeiro: ANPEC, 1999. p.1437-1450.

GUIMARÃES NETO, Leonardo. Ciclos econômicos e desigualdades regionais no Brasil. In.: Anais do XXIV Encontro Nacional de Economia. ANPEC, 1996.

HADDAD, Paulo Roberto \& ANDRADE, Thompson A. Política fiscal e desequilíbrios regionais. Estudos econômicos, v.4, n. ${ }^{\circ} 1,1974$. p. 9-52.

HADDAD, Paulo Roberto. Contabilidade social e economia regional: análise de insumoproduto. Zahar Editores. 1976. 242p.

HADDAD, Paulo Roberto (org.). Economia regional teorias e métodos de análise. Fortaleza, BNB. ETENE, 1989.694p.

HAMILTON, Joel R.; ROBISON, M. Henry; WHITTLESEY, Norman K.; DELLIS, John. Interregional spillovers in regional impact assessment: New Mexico, Texas, and the Supreme Court. In.: Growth and Change. v.25. p. 75-89. 1994.

HANSEN, W.; TIEBOUT, C. An intersectorial flow analysis of the California economy. The Review of Economics and Statistics, v.45, n.4, p. 409-418, 1963.

HEWINGS, Geoffrey John Dennis. Introduction. In.: DEWHURST, John H. Ll.; HEWINGS, Geoffrey J. D. \& JENSEN, Rodney C. Regional input-output modelling: new developments and interpretations. England, Avebury Academic Publishing Group. 1991. p.1-13.

HEWINGS, Geoffrey John Dennis; FONSECA, Manuel; GUILHOTO, Joaquim J.

Martins \& SONIS, Michael. Key sectors and structural change in the brasilian economy: a comparison of alternative approaches and their policy implications. Journal of Policy Modeling, v.11, n. ${ }^{\circ} 1,1989$, p. $67-90$. 
HIRSCHMAN, A. O. The strategy of economic development. New Haven: Yale University Press, 1958. 217p.

ISARD, Walter. Interregional and regional input-output techniques. In.: ISARD, Walter. Methods of regional analysis. Cambridge: The MIT Press. 1960. p.309-374.

ISARD, Walter; AZIS, Iwan.. J.; DRENNAN, Matthew P.; MILLER, Ronald E.; SALTZMAN, Sidney \& THORBECKE, Erick. Methods of interregional and regional analysis. England: Ashgate, 1998. 490p.

LANNA, A. Eduardo. \& ROCHA, Virgílio. Análises econômica e financeira de projetos de irrigação. Associação Brasileira de Educação Superior (ABEAS), Brasília, módulo 12. 1988. 159p. (Curso de Engenharia de Irrigação).

LAVINAS, Lena; GARCIA, Eduardo Henrique \& AMARAL, Rubens Marcelo do. Desigualdades regionais e retomada do crescimento num quadro de integração econômica. Instituto de Pesquisa Econômica Aplicada (IPEA), Rio de Janeiro (RJ), mar. 1997. 37 p. (Texto para Discussão n. 466).

LEONTIEF, Wassily. Input-output economies. $2^{\mathrm{a}}$ ed. New York: Oxford University Press. 1986. p. 241-260.

LEONTIEF, Wassily. A economia do insumo-produto. São Paulo: Abril Cultural. 1983. 226 p.

LEONTIEF, Wassily \& STROUT, Alan. Multiregional input-output analysis. In.: BARNA, Tibor (ed.). Structural interdependence and economic development. New York: St. Martin's Press. 1967. p.119-150.

LIMA, João Policarpo R. O estado e a agroindústria canavieira no Nordeste: a acumulação administrada. In.: Anais do XV Encontro Nacional de Economia. Salvador, 1987. v. 2, p. 171- . (ANPEC).

LOCATELLI, Ronaldo Lamounier \& SILVA, José A. Beltrão. Complexos Industriais: Análise e Perspectivas. Estudos multissetoriais da economia mineira. Belo Horizonte (MG), 1991. (Relatório III). 26p.

LOCATELLI, Ronaldo Lamounier \& SILVA, José A. Beltrão. As relações intersetoriais e os setores-chave da economia nordestina. In.: BANCO DO NORDESTE DO BRASIL. Diretrizes para um plano de ação do BNB (1991-95): setor secundário. Fortaleza: ETENE, 1997. 7v. V.3. p. 261-321.

LOFTING, E. M. \& McGAUHEY, P. H. An interindustry analisys of the California water economy. Part III. Economic evaluation of water. Sanitary Engineering research Laboratory, College of Engineering e School of Public Health, University of California. Berkeley: Water Resources Center. 1963. 83p. (Contribution n. 67). 
MAYER, Wolfgang \& PLEETER, Saul. A theoretical justification for use of location quotients. In.: Regional Science and Urban Economics. 1975. n. ${ }^{\circ}$ 5, p. 343-355.

MEI, Xie; GUISHENG, Nie; XIANGLAN, Jin. Application of an input-output model to the Beijing urban water-use system. In.: POLENSKE, Karen R. \& XIKANG, Chen (eds.). Chinese economic planning and input-output analysis. Hong Kong/New York: Oxford University Press. 1991. p.239-253.

MELO, Ademir Alves de \& DUARTE, Renato Santos. A dinâmica da economia do Nordeste nas décadas de 1970 e 1980 e perspectivas para os anos 1990. In.: Diretrizes para um plano de ação do BNB (1991-1995); Infra-estrutura econômica e social do Nordeste. Fortaleza, 1997. 7v., v.6, t 2. p. 32-73. (BNB. Estudos Econômicos e Sociais, v.59).

McGILVRAY, J. Linkages, key sectors and development strategy. In: LEONTIF, W. (Ed.). Structure, system and econome policy. Cambridge: University Press, 1977. p.49-56.

MERRETT, Stephen. Introduction to the economies of water resources: na international perspective. London: UCL Press Limited. 1997. 211 p.

METZLER, L. A multiple-regiao theory of income and trade. Econometrica, v. 8, p.329-354, out. 1950.

MIERNYK, William H. Elementos de análise do insumo-produto. São Paulo: Editora Atlas. 1974. $158 \mathrm{p}$.

MILLER, Ronald E. \& BLAIR, Peter D. Input-output analysis: foundations and extensions. New Jersey: Prentice Hall, Inc. 1985. 463p.

MIRANDA, Cláudio da Rocha. Economia e meio ambiente: uma abordagem de insumoproduto. Pesquisa e Panejamento Econômico. V. 10, nº 2, 1980. P. 601-636.

MIYAZAWA, K. Input-output analysis and the structure of income distribution. Berlin: Springer-Verlag, 1976. 135p.

MIYAZAWA, K. Internal and external matrix multipliers in the input-output model. Hitotsubashi Journal of economics, n. 7, v. 1, p. 38-55, 1966.

MONTOYA RODRIGUEZ, Marco Antonio. A matriz insumo-produto internacional do Mercosul em 1990: a desigualdade regional e o impacto intersetorial do comércio interregional. Piracicaba, 1998. Tese (Doutorado). Escola Superior de Agricultura Luiz de Queiroz/USP. 217 p. 
MONTOYA RODRIGUEZ, Marco Antonio \& GUILHOTO, Joaquim J. Martins. O perfil das estruturas de transações internacionais e os setores-chave na economia do Mercosul: uma abordagem de insumo-produto. Universidade de Passo Fundo, Faculdade de Economia e Administração, Centro Regional de Economia e administração, Passo Fundo (RS), jun. 1998. 20p. (Texto para Discussão n. ${ }^{\circ}$ 01/98).

MOSES, L. The stability of interregional trading patterns and input-output analysis. The American Economic Review, n.45, p.803-832, 1955.

MYRDAL, Gunnar. Teoria econômica e regiões subdesenvolvidas. Tradução de Ewaldo C. Lima. 2. ed. Rio de Janeiro: Instituto Superior de Estudos Brasileiros. 1960. 210p.

PEREIRA Jr., José de Sena. Por que gerir os recursos hídricos? Agroanalysis - A Revista de economia da FGV. Instituto Brasileiro de economia. Centro de Estudos Agrícolas. v.19, n. 3, março, 1998. p. 16-19.

PEREIRA, Ricardo Antônio de C. Modelo multi-regional de insumo-produto nordeste/resto do país e a análise dos impactos econômicos da agricultura irrigada no Nordeste. Fortaleza. (Diss. mestrado), 1993. Universidade Federal do Ceará. 172p.

PERROUX, F. Conceito de pólos de crescimento (1955). In.: SCHWARTZMAN, J. Economia regional - Textos escolhidos. Belo horizonte: CEDEPLAR. 1977. p. 145-156.

POLENSKE, K. An empirical test of interregional input-output models: estimation of 1963 japonese production. American Economic Review, p. 76-82, May, 1970.

RASMUSSEN, P. Studies in intersectoral relations. Amsterdam, North Holland, 1956.

RICHARDSON, Harry W. Input-output and regional economics. Wiltshire: Redwood Press. Limited.1972. 294p.

SANTOS, J.R. M dos. Irrigar é preciso. In.: Agroanalysis - A Revista de economia da FGV. Instituto Brasileiro de economia. Centro de estudos agrícolas. Vol.19, n.3, março, 1998. p. 29 -34 .

SECRETARIA DE COMÉRCIO EXTERIOR / DEPARTAMENTO DE COMÉRCIO EXTERIOR (SECEX/DECEX). Exportações e importações. Brasil, Minas Gerais, pernambuco e Bahia, 1995. (disquete).

SETTI, Arnaldo Augusto. Legislação para uso dos recursos hídricos. Brasília, DF: ABEAS; Viçosa, MG: UFV; Departamento de Engenharia Agrícola, 1998. 227p.

SILVEIRA, Antônio Henrique P. A estrutura da indústria de transformação na Bahia 197884: um exercício de aplicação do modelo biproporcional insumo-produto. Rio de Janeiro. (Diss. mestrado), 1992. Universidade federal do Rio de Janeiro. 160p. 
SOLLEY, Wayne B.; PIERCE, Robert B. \& PERLMAN, Howard A. Estimated use of water in the United States in 1995. U. S. Geological Survey Circular 1200. United States Government Printing Office. 1998. 71p.

SONIS, Michael \& HEWINGS, Geoffrey J. D. Error and sensitivity input-output analysis: a new approach. In: MILLER, R. E.; POLENSKE, K. R.; ROSE, A. Z. (Ed.). Frontiers of InputOutput Analysis. New York: Oxford University Press, 1989.

SONIS, Michael \& HEWINGS, Geoffrey J. D. Fields of influence in input-output systems. Urbana: University of Illinois. Regional Economics Applications Laboratory, 1994. (mimeo)

SONIS, Michael \& HEWINGS, Geoffrey J. D. Multiplier product matrix analysis for multirregional input-output analysis. s.l. s.ed. /1999?/

SONIS, Michael; HEWINGS, Geoffey J. D \& GUO, Jie Min. Input-output multiplier product matrix. Urbana: University of Illinois. Regional Economics Applications Laboratory, 1997. (Discussion Paper, 94-T-12).

SONIS, Michael; HEWINGS, Geoffrey J. D. \& GUO, Jie Mei. Comparative analysis of China's metropolitan economies: an input-output perspective. s.n.t.

SONIS, Michael; HEWINGS, G. J. D. \& MIYAZAWA, K. Synergetic interetions within the pair-wise hirarchy of economic linkges sub-sistems. Hitotsubashi Journal of Economics, $n$. 38, p. 2-17, dez. 1997.

SONIS, Michael; HEWINGS, Geoffrey J. D. Economic landscapes: multiplier product matrix analysis for multirregional input-output systems. Hitotsubashi Journal of Economics, v.40, n.1, p.59-74, 1999.

SOUSA, Maria da C. S. de; OLIVEIRA, Augusto C. de; SOUZA, Hermínio R. de. Emprego e renda em modelos típicos de produção na agricultura irrigada. In.: Revista Econômica do Nordeste. Fortaleza, v.20, n.4, out./dez.1989. p. 409-430.

SOUSA, Maria da C. S. de e SOUZA, Hermínio R. de. Padrões regionais de emprego e renda na agricultura irrigada no Brasil. In.: Estudos Econômicos. São Paulo, v.19, n.3, 1989. p. 417441.

SOUZA, Nali de J. Metodologia de obtenção das matrizes de insumo-produto dos estados da região sul, 1985 e 1995. Porto Alegre: UFRGS, 1997. (Texto para discussão, 97/14). 15p.

SPERLING, Eduardo von. Qualidade da água. In.: SILVA, Demétrius. D. da \& PRUSKI, Fernando Falco(eds.). Recursos hídricos e desenvolvimento sustentável da agricultura. Brasília, DF: MMA; SRH; ABEAS; Viçosa, MG: UFV, Departamento de Engenharia Agrícola, 1997. p.89-113. 
TATE, Donald M. \& SCHARF, David N. Water use in canadian industry, 1986. Social Science Series n. ${ }^{\circ} 24$. Ecosystem Sciences and Evaluation Directorate - Economics and Conservation Branch. Otawa, Canada, 1992. 19p.

VERGOLINO, Tercina B. \& VERGOLINO, José R. Reforma do Estado: efeitos sobre a renda e o emprego na região do submédio São Francisco (Petrolina/Juazeiro). In.: Revista Econômica do Nordeste. Fortaleza, v.28, n. especial, julho 1997. p.447-459.

VICTOR, Peter A. Pollution: economy and environment. London: George Allen \& Unwin Ltd. 1972. 